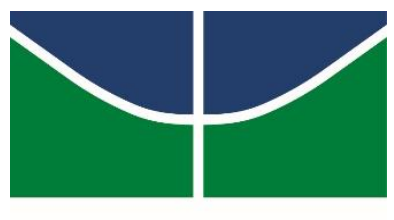

\title{
UnB
}

Universidade de Brasília

Instituto de Química

Programa de Pós-Graduação em Química

Laboratório de Pesquisa em Polímeros e Nanomateriais

\section{Síntese e caracterização de polímeros obtidos a partir do óleo de mamona (Ricinus communis L.)}

\author{
DISSERTAÇÃO DE MESTRADO \\ Jessica Delavechia Oliveira Rodrigues
}

Brasília, DF

2016 
Universidade de Brasília Instituto de Química

Programa de Pós-Graduação em Química

Laboratório de Pesquisa em Polímeros e Nanomateriais

\title{
Síntese e caracterização de polímeros obtidos a partir do óleo de mamona (Ricinus communis L.)
}

\author{
DISSERTAÇÃO DE MESTRADO \\ Jessica Delavechia Oliveira Rodrigues
}

Orientadora: Prof. Dra. Maria José Araújo Sales

Co-orientador: Prof. Dr. Carlos Kleber Zago de Andrade

Brasília, DF

2016 


\section{FOLHA DE APROVAÇÃO}

Comunicamos a aprovação da Defesa de Dissertação de Mestrado do (a) aluno (a) Jéssica Delavechia Oliveira Rodrigues, matrícula no 15/0104006, intitulada "Síntese e caracterização de polímeros a partir do óleo de mamona (Ricinus communis L.)", apresentada no (a) Auditório Lauro Morhy do Instituto de Química (IQ) da Universidade de Brasília (UnB) em 7 de dezembro de 2016.

Prof.a Dra. Maria José Araújo Sales

Presidente de Banca (IO/UnB)

Prof. a Dra. Roseany de Vasconcelos Vieira Lopes

Membro Titular (FGA / UnB)

Prof. Dr. Ângelo Henrique de Lira Machado Membro Titular (IO/UnB)

Dra. Ana Paula Pinho Rodrigues Leal

Membro Suplente (PNUD)

Em 7 de dezembro de 2016. 
Dedico esta dissertação aos meus pais Marcia Helena e Claudio Barboza, à minha irmã Stelamaris e à minha Vó Jorgete, por todo apoio e incentivo. 


\section{Agradecimentos}

Agradeço a Deus por ter me guiado em todos os momentos, por ter sido minha luz nos momentos de dúvidas, por ter colocado em meu caminho as maravilhosas pessoas que me ajudaram em meu trabalho, em todos os momentos.

Agradeço aos meus pais, Marcia Helena e Claudio Barboza, por terem me dado a vida e por estarem ao meu lado sendo minha motivação, inspiração e apoio ao longo de todos esses anos.

Agradeço às minhas irmãs Stelamaris e Karine, pelas palavras de incentivo e por todo o carinho.

Agradeço à minha Vó Jorgete, por ser meu exemplo de força e determinação.

Agradeço aos meus familiares que sempre torceram por mim e me desejaram o melhor.

Agradeço à minha amiga e orientadora Maria José Sales, por acreditar em mim nos momentos que até mesmo eu duvidei. Por me ensinar, me guiar e me capacitar. Pela paciência durante todos esses anos. Por ser o meu exemplo de mulher na ciência.

Agradeço o meu co-orientador Carlos Kleber Zago de Andrade, por toda a contribuição, durante a minha formação, e pela contribuição cientifica no trabalho.

Agradeço aos professores doutores Leonardo Giordano Paterno, José Alves Dias, Ângelo Henrique de Lira Machado, Roseanny Vasconcelos Vieira Lopes, Rafael Oliveira Rocha e Aline Lima de Oliveira por todo o auxilio com reagentes, vidrarias e por toda contribuição cientifica. Em especial ao professor Dr. Sanclayton Geraldo Carneiro Moreira, pela realização das análises de DSC.

Agradeço ao meu namorado Nilton Claudio, por ser meu companheiro e me apoiar e acredita em mim em todos os momentos, pelas palavras de incentivo, e por todas as discussões cientificas.

Agradeço às minhas amigas Wanessa Felix, Beatriz Lemes e Michele Ávila, pela amizade e apoio e por terem dividido os momentos de alegria e tristeza ao longo do mestrado.

Agradeço aos meus amigos do LabPolN, que sempre são solícitos ao ajudar nos experimentos e por todas as discussões cientificas. Um agradecimento à Raquel pela sua contribuição na realização das análises por TG. Sei que sem a ajuda de cada um no dia a dia seria mais difícil à conclusão da pesquisa.

Agradeço aos meus amigos da química, por toda a motivação e pela fé depositada em mim. 
Aos amigos de vários laboratórios do IQ, que cederam vidrarias, reagentes e tudo mais que foi necessário, para realização dessa pesquisa.

Agradeço aos alunos da pós-graduação Anderson Mateus Mendonça e Silva Medeiros, Alan Thyago Jensen e João Victor de Moraes Silva pela ajuda nas análises de GPC, e pela interpretação dos dados. Resultado de extrema importância para a conclusão do trabalho.

Aos técnicos de outros laboratórios, em especial ao Faustino dos Santos, por serem solícitos, e gentis em todos os momentos.

À Coordenação do Programa de Pós-Graduação em Química.

Ao Instituto de Química da Universidade de Brasília.

Ao CNPq pelo apoio à pesquisa e incentivo financeiro.

Agradeço a todos que de alguma forma ajudaram na realização desse trabalho. 
ÍNDICE

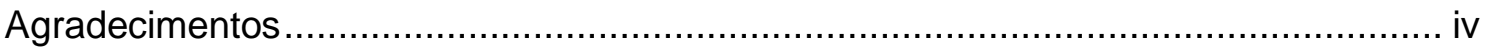

LISTA DE ABREVIATURAS E ACRÔNIMOS ....................................................

LISTA DAS DENOMINAÇÕES DOS MATERIAIS OBTIDOS ...................................xii

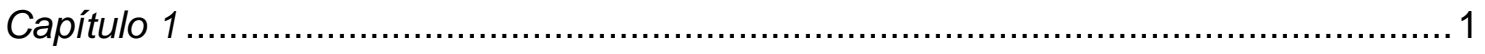

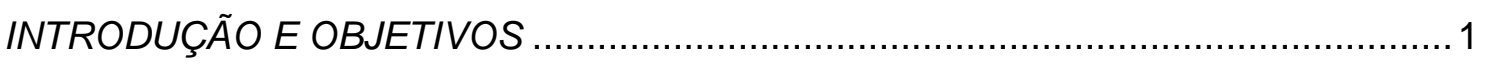

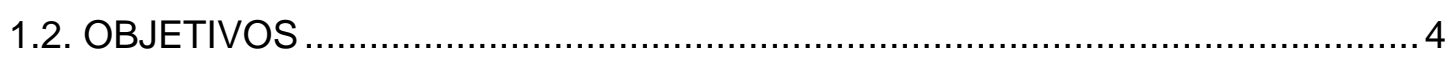

1.2.1. Objetivo Geral ........................................................................... 4

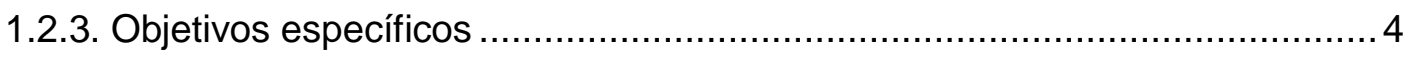

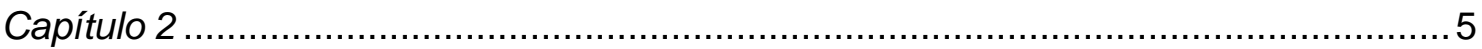

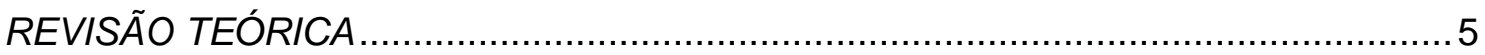

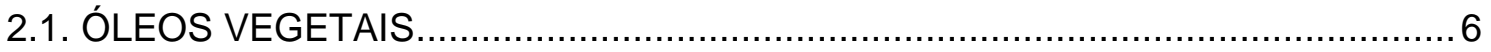

2.1.1. Óleo de Mamona .................................................................................... 7

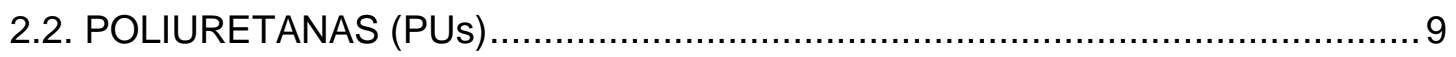

2.2.1. Poliuretanas livres de isocianato (NIPU) ..................................................... 12

2.3. CATÁLISE NA SÍNTESE DE POLIURETANAS (PUs) E POLIURETANAS

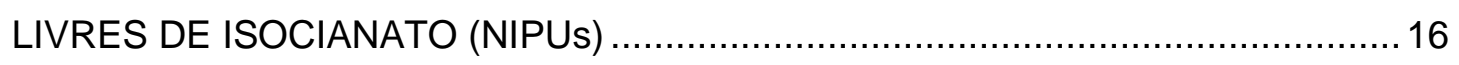

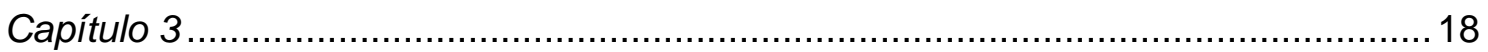

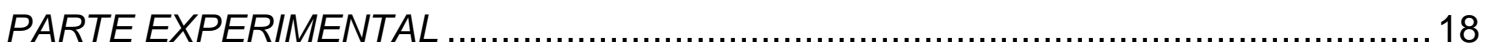

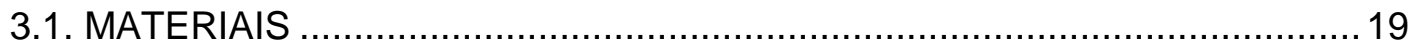

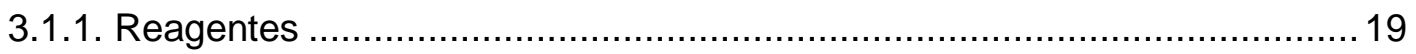

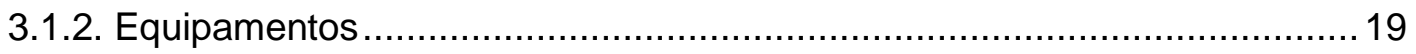

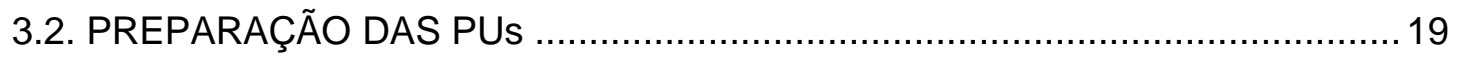

3.2.1. Síntese com Utilização de Solvente ...................................................... 19

3.2.2. Síntese sem Utilização de Solvente ................................................... 22

3.3. CARACTERIZAÇÃO DOS MATERIAIS ................................................ 26

3.3.1. Espectroscopia na Região do Infravermelho com Transformada de Fourier

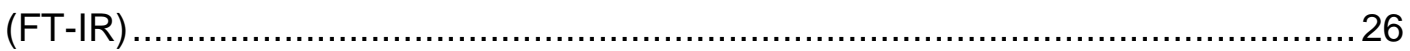

3.3.2. Ressonância Magnética Nuclear de Hidrogênio $\left(\mathrm{RMN}^{1} \mathrm{H}\right)$.........................26

3.3.3. Ressonância Magnética Nuclear de Carbono $\left(\mathrm{RMN}{ }^{13} \mathrm{C}\right)$........................... 27

3.3.4. RMN ${ }^{13} \mathrm{C}$ no Estado Sólido......................................................... 27

3.3.5. Termogravimetria (TG)/Termogravimetria Derivada (DTG) .....................27

3.3.6. Calorimetria Exploratória Diferencial (DSC) …....................................... 28

3.3.8. Cromatografia de Exclusão por Tamanho ou Cromatografia de Permeação

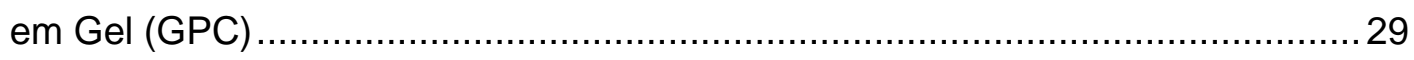

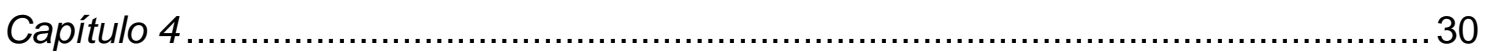


RESULTADOS E DISCUSSÕES. 30

4.1. CARACTERIZAÇÃO DO ÓLEO DE MAMONA E DA UREIA .

4.2. SÍNTESE COM A UTILIZAÇÃO DE SOLVENTE ........................................... 36

4.3. SÍNTESE SEM A UTILIZAÇÃO DE SOLVENTE …..................................... 45

4.4. PROPOSTA PRELIMINAR DO MECANISMO DE REAÇÃO COM CATÁLISE. 77

4.5. CONTRA PROVAS DA PROPOSTA PRELIMINAR DO MECANISMO DE

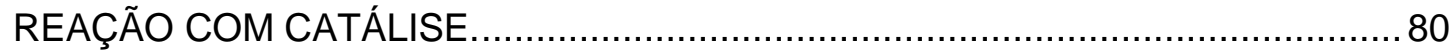

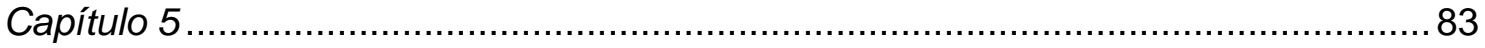

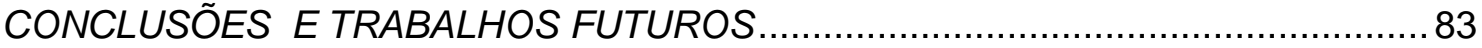

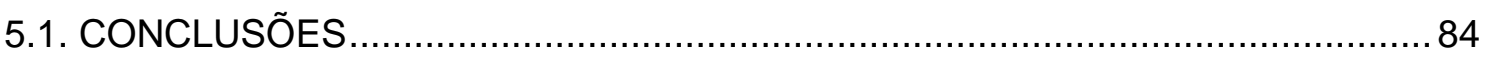

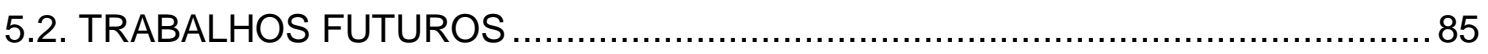




\section{ÍNDICE DE FIGURAS}

Figura 1. Representação do percentual de aplicações de PUs no mercado mundial. ...2

Figura 2. Representação gráfica da evolução anual da demanda de PU. ..................... 2

Figura 3. Representação dos pontos de reatividade de um triglicerídeo. ....................... 7

Figura 4. Representação dos pontos de reatividade do acido ricinoleico. ..................... 7

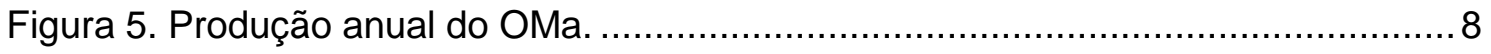

Figura 6. Representação geral da síntese de PUs................................................ 10

Figura 7. Representação das ligações cruzadas (cross-link). ................................ 10

Figura 8. Representação de micela franjada de um polímero semi-cristalino..............11

Figura 9. Representação do efeito da temperatura na formação de ligações cruzadas.

Figura 10. Representação geral da síntese de NIPUs. ......................................... 13

Figura 11. Representação geral da síntese de poli(hidroxi)uretanas........................... 13

Figura 12. Representação geral da síntese de NIPU: 1) poliadição de carbonato cíclico com diamina; 2) policondensação de etileno carbonato com diamina e diois; 3) polimerização com abertura de anel catiônica de uretana cíclica; 4) co-polimerização de aziridinas substituídas com dióxido de carbono. ..................................................... 14 Figura 13. Representação geral da síntese da poli(hidroxi)uretana a partir do óleo de soja carbonato e diamina............................................................................. 14

Figura 14. Representação geral da síntese de policondensação de diaminas com diuretanodiois (transuretano).

Figura 15. Imagem digital do sistema montado para a reação com a utilização de solvente. . . .

Figura 16. Fluxograma representativo das sínteses com a utilização de solvente. .....21

Figura 17. Imagem digital do sistema montado para a reação sem utilização de solvente.

Figura 18. Fluxograma representativo das sínteses sem a utilização de solvente, usando dois diferentes catalisadores.

Figura 19. Fluxograma representativo das sínteses sem a utilização de solvente, usando o $\mathrm{BF}_{3}\left(\mathrm{Et}_{2} \mathrm{O}\right)$ e variando a proporção óleo:ureia e o tempo de cura. ................24

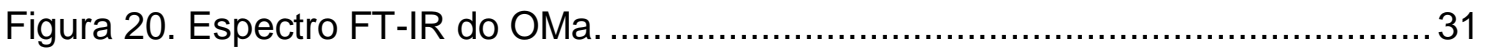

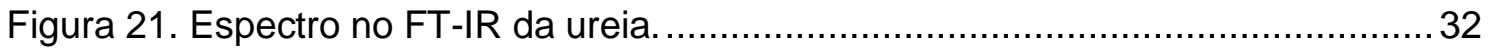

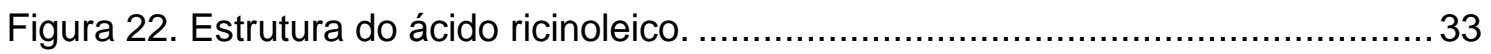

Figura 23. Espectro de $\mathrm{RMN}{ }^{1} \mathrm{H}$ do $\mathrm{OMa}$ com identificação dos seus sinais. ............... 33

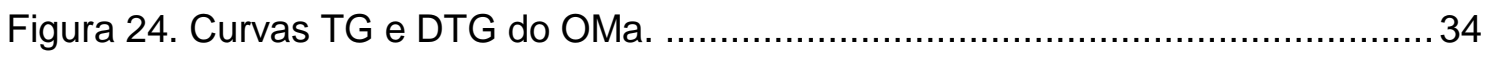

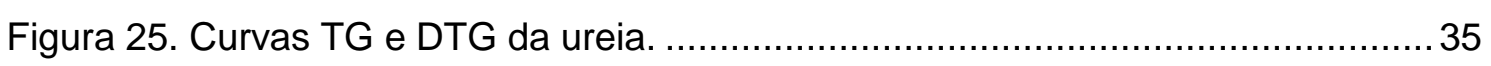

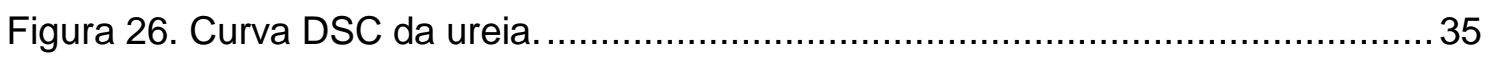


Figura 27. Espectros no FT-IR da amostra MatOMa(1:4)/Zn/Et/8h/24h, fases liquida e sólida.

Figura 28. Espectro no FT-IR da parte sólida das amostras MatOMa(1:4)/Zn/Et/8h/24h e MatOMa(1:4)/Sn/Et/8h/24h.

Figura 29. Espectros no FT-IR da parte sólida das amostras MatOMa(1:4)/BF $3 / \mathrm{Et} / 8 \mathrm{~h} / 24 \mathrm{~h}$ e MatOMa(1:8)/BF $3 / \mathrm{Et} / 8 \mathrm{~h} / 24 \mathrm{~h}$. 38

Figura 30. Espectro de $\mathrm{RMN}{ }^{1} \mathrm{H}$ da parte liquida da amostra $\mathrm{MatOMa}(1: 4) / \mathrm{BF}_{3} / \mathrm{Et} / 8 \mathrm{~h} / 24 \mathrm{~h}$.

Figura 31. Espectro de CP/MAS $\mathrm{RMN}{ }^{13} \mathrm{C}$, no estado sólido, da amostra $\operatorname{MatOMa}(1: 4) / Z n / E t / 8 h / 24 h$. 40

Figura 32. Espectro de CP/MAS $\mathrm{RMN}{ }^{13} \mathrm{C}$, no estado sólido, da amostra $\operatorname{MatOMa(1:4)/Sn/Et/8h/24h.~}$

Figura 33. Curvas (a) TG e (b) DTG da parte sólida das amostras $\operatorname{MatOMa}(1: 4) / \mathrm{Zn} / \mathrm{Et} / 8 \mathrm{~h} / 24 \mathrm{~h}$ e MatOMa(1:4)/Sn/Et/8h/24h.

Figura 34. Curvas (a) TG e (b) DTG da parte sólida das amostras MatOMa(1:4)/BF $/$ Et/8h/24h e MatOMa(1:8)/BF $/ \mathrm{Et} / 8 \mathrm{~h} / 24 \mathrm{~h}$. 42

Figura 35. Comparação da $T_{\text {onset }}$ do OMa, ureia e dos materiais obtidos na síntese com etanol. 43

Figura 36. Curva DSC da amostra MatOMa(1:4)/Zn/Et/8h/24h. 44

Figura 37. Curva DSC da amostra MatOMa(1:4)/Sn/Et/8h/24h. 44

Figura 38. Espectros no FT-IR da amostra PUOMa(1:2)/Zn/1h/24h, fases líquida e sólida. 46

Figura 39. Espectros no FT-IR da amostra PUOMa(1:2)/Zn/4h/24h, fases líquida e sólida. 46

Figura 40. Espectros no FT-IR dos materiais com a proporção OMa:ureia de 1:2, mudando apenas o tempo de cura.

Figura 41. Espectros no FT-IR dos materiais com a proporção OMa:ureia de 1:3, mudando apenas o tempo de cura. 48

Figura 42. Espectros no FT-IR dos materiais com a proporção OMa:ureia de 1:4, mudando apenas o tempo de cura. 49

Figura 43. Espectro no FT-IR da amostra PUOMa(1:8)/BF $/ 5 \mathrm{~min} / 24 \mathrm{~h}$ .50

Figura 44. (a) Espectros no FT-IR dos materiais com $24 \mathrm{~h}$ de cura, nas proporções OMa:ureia de 1:2, 1:3 e 1:4; (b) ampliação da absorção da carbonila de carbamato (c) ampliação da absorção de carbonila de amidas secundárias. 52

Figura 45. (a) Espectros no FT-IR dos materiais com $48 \mathrm{~h}$ de cura, nas proporções OMa:ureia de 1:2, 1:3 e 1:4; (b) ampliação da absorção da carbonila de carbamato (c) ampliação da absorção de carbonila de amidas secundárias. .53 
Figura 46. (a) Espectros no FT-IR dos materiais com $72 \mathrm{~h}$ de cura, nas proporções OMa:ureia de 1:2, $1: 3$ e 1:4; (b) ampliação da absorção da carbonila de carbamato (c) ampliação da absorção de carbonilas de amidas secundárias. .54

Figura 47. Espectro de $\mathrm{RMN}{ }^{13} \mathrm{C}$, no estado sólido, da amostra $\mathrm{PUOMa}(1: 2) / \mathrm{BF}_{3} / 5 \mathrm{~min} / 24 \mathrm{~h}$. .55

Figura 48. Estrutura do mero da poli(acil-uretana) com os sinais assinalados referentes ao espectro de $\mathrm{RMN}{ }^{1} \mathrm{H}$. .56

Figura 49. Espectro de $\mathrm{RMN}{ }^{1} \mathrm{H}$ da amostra PUOMa(1:2)/BF $/ 5 \mathrm{~min} / 72 \mathrm{~h}$. .56

Figura 50. Estrutura do mero da poli(acil-uretana) com os sinais assinalados referentes ao espectro de $\mathrm{RMN}{ }^{13} \mathrm{C}$. .57

Figura 51. Espectro de $\mathrm{RMN}{ }^{13} \mathrm{C}$ da amostra $\mathrm{PUOMa}(1: 2) / \mathrm{BF}_{3} / 5 \mathrm{~min} / 72 \mathrm{~h} . \ldots \ldots \ldots \ldots \ldots . . . . . . . .57$

Figura 52. Curvas TG e DTG da amostra PUOMa(1:2)/Zn/4h/24h.......................... 58

Figura 53. Curvas TG e DTG dos materiais: (a) $\operatorname{PUOMa}(1: 2) / \mathrm{BF}_{3} / 5 \mathrm{~min} / 24 \mathrm{~h}$, (b)

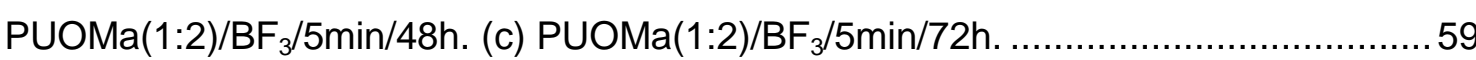

Figura 54. Curvas TG e DTG dos materiais: (a) PUOMa(1:3)/BF $/ 5 \mathrm{~min} / 24 \mathrm{~h}$, (b)

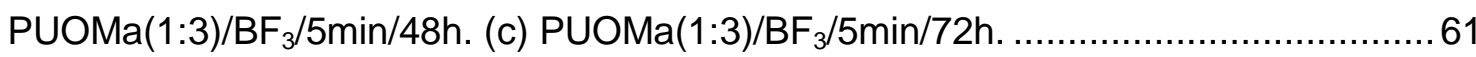

Figura 55. Curvas TG e DTG dos materiais: (a) PUOMa(1:4)/BF $/ 5 \mathrm{~min} / 24 \mathrm{~h}$, (b)

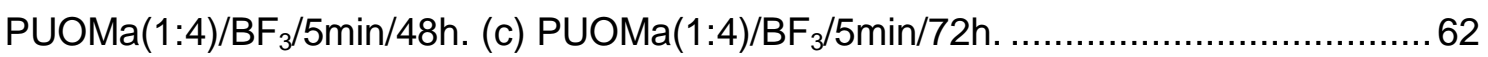

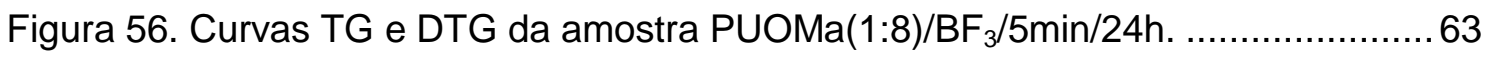
Figura 57. Comparação dos valores de $\mathrm{T}_{\text {onset }}$ do $\mathrm{OMa}$, da ureia e de todos os materiais obtidos usando o catalisador $\mathrm{BF}_{3}\left(\mathrm{Et}_{2} \mathrm{O}\right)$ nas sínteses sem solvente. 64

Figura 58. Curvas TG dos materiais em diferentes tempos de cura e proporção OMa:ureia: (a) 1:2; (b) 1:3 e (c) 1:4.

Figura 59. Curvas DSC dos materiais obtidos na proporção OMa:ureia de 1:2, nos diferentes tempos de cura, com o catalisador $\mathrm{BF}_{3}\left(\mathrm{Et}_{2} \mathrm{O}\right)$ 66 Figura 60. Curvas de absorção de umidade em função do tempo para os materiais obtidos na proporção OMa:ureia de 1:2, nos diferentes tempos de cura, com o catalisador $\mathrm{BF}_{3}\left(\mathrm{Et}_{2} \mathrm{O}\right)$.

Figura 61. Linearização dos dados de absorção de água para os materiais obtidos na proporção OMa:ureia de 1:2, nos diferentes tempos de cura, com o catalisador $\mathrm{BF}_{3}\left(\mathrm{Et}_{2} \mathrm{O}\right)$.

Figura 62. Curvas de cinética de sorção para os materiais obtidos na proporção OMa:ureia de 1:2, nos diferentes tempos de cura, com o catalisador $\mathrm{BF}_{3}\left(\mathrm{Et}_{2} \mathrm{O}\right)$ .70 Figura 63. Curvas GPC para PUOMa(1:2)/BF $/ 5 \mathrm{~min} / 24 \mathrm{~h}, \mathrm{PUOMa}(1: 2) / \mathrm{BF}_{3} / 5 \mathrm{~min} / 48 \mathrm{~h}$ e

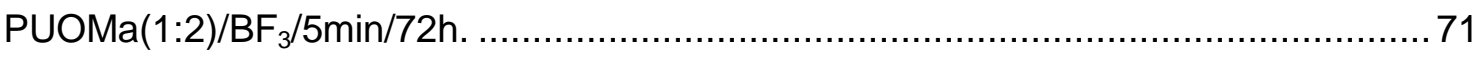

Figura 64. Imagens digitais da poli(acil-uretana) PUOMa(1:2)/BF $/ 5 \mathrm{~m} / 24 \mathrm{~h} \ldots \ldots \ldots \ldots \ldots . . . . .73$

Figura 65. Imagens digitais da poli(acil-uretana) PUOMa(1:2)/BF $/ 5 \mathrm{~m} / 48 \mathrm{~h} \ldots \ldots \ldots \ldots \ldots . . . . .74$ 
Figura 66. Imagens digitais da poli(acil-uretana) PUOMa(1:2)/BF $/ 5 \mathrm{~m} / 72 \mathrm{~h}$. 75

Figura 67. Imagens digitais das poli(acil-uretanas): (a) PUOMa(1:2)/BF $/ 5 \mathrm{~m} / 24 \mathrm{~h}$, (b)

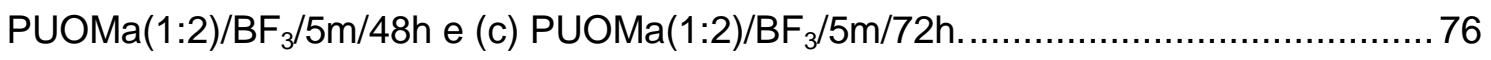

Figura 68. Representação das cargas parciais do composto $\mathrm{BF}_{3}\left(\mathrm{Et}_{2} \mathrm{O}\right)$. ................... 77

Figura 69. Espectro no FT-IR da amostra MatOmaracujá(1:2)/BF $/ 5 \mathrm{~m} / 24 \mathrm{~h}$. ............... 81

Figura 70 . Espectros de $\mathrm{RMN}^{1} \mathrm{H}$ do $\mathrm{OM}$ e do material MatOmaracujá(1:2)/BF $3 / 5 \mathrm{~m} / 24 \mathrm{~h}$. 82

Figura 71. Estrutura representando o OM. .82 


\section{ÍNDICE DE TABELAS}

Tabela 1. Estrutura, nomenclatura e ponto de fusão de alguns ácidos graxos. 6

Tabela 2. Composição do óleo de mamona...

Tabela 3. Denominações dadas aos materiais obtidos, com a utilização do etanol, e suas descrições.

Tabela 4. Denominações dadas aos materiais obtidos, sem a utilização do etanol, e suas descrições.

Tabela 5. Principais bandas de absorção no FTIR para o OMa, com suas respectivas atribuições.

Tabela 6. Deslocamentos químicos de $\mathrm{RMN}{ }^{1} \mathrm{H}$ característicos de um espectro de óleo vegetal.

Tabela 7. Dados de $T_{d}$ e perda de massa dos materiais obtidos com diferentes catalisadores.

Tabela 8. Principais bandas de absorção no FT-IR dos espectros apresentados nas Figuras 35 a 40, com suas respectivas atribuições.

Tabela 9. Deslocamentos químicos de $\mathrm{RMN}{ }^{1} \mathrm{H}$ característicos do espectro da Poli(aciluretana) .56

Tabela 10. Deslocamentos químicos de $\mathrm{RMN}{ }^{13} \mathrm{C}$ característicos do espectro da poli(acil-uretana).

Tabela 11. Dados dos valores de $T_{d}$ e perda de massa dos materiais obtidos com diferentes proporções OMa:ureia e tempos de cura, usando o catalisador $\mathrm{BF}_{3}\left(\mathrm{Et}_{2} \mathrm{O}\right) .64$ Tabela 12. Valores do expoente de difusão para os materiais obtidos na proporção OMa:ureia de 1:2, nos diferentes tempos de cura, com o catalisador $\mathrm{BF}_{3}\left(\mathrm{Et}_{2} \mathrm{O}\right)$

Tabela 13. Valores do coeficiente de difusão para os materiais obtidos na proporção OMa:ureia de 1:2, nos diferentes tempos de cura, com o catalisador $\mathrm{BF}_{3}\left(\mathrm{Et}_{2} \mathrm{O}\right) \ldots \ldots \ldots . .70$ Tabela 14. Massas molares médias e polidispersividade, obtidas por GPC, dos materiais na proporção OMa:ureia de 1:2, nos diferentes tempos de cura, com o

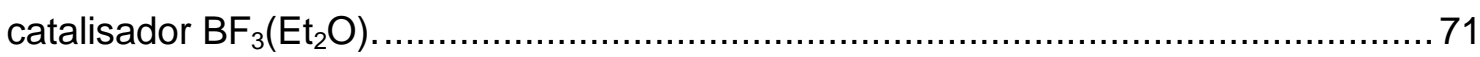

Tabela 15. Composição percentual (\%) dos principais ácidos graxos do OM .............80 


\section{ÍNDICE DE ESQUEMAS}

Esquema 1. Proposta preliminar do mecanismo de reação para a síntese da poli(aciluretana) livre de isocianato. .79 


\section{LISTA DE ABREVIATURAS E ACRÔNIMOS}

ATR - atenuador de reflexão total

BDMAEE - 2,2-bis(dimetilaminoetileter)

DABCO - 1,4-diazabiciclo [2,2,2]octano

DBTDL - dilaurato de dibutilestanho

DBU - 1,8-diazabiciclo[5,4,0]undec-7-eno

DMA - análise dinâmico-mecânica

DSC - calorimetria exploratória diferencial

FTIR - espectroscopia no infravermelho por transformada de Fourier

MET - microscopia eletrônica de transmissão

MEV - microscopia eletrônica de varredura

MM - massa molar média

$\overline{M_{n}}$ - massa molar numérica média

$\overline{M_{w}}$ - massa molar ponderal média

NIPU - non-isocianate polyurethane

$\mathrm{PU}$ - poliuretana

PUU - poliuretana poliureia

RMN ${ }^{1} \mathrm{H}$ - ressonância magnética nuclear, com núcleo de hidrogênio

$\mathrm{RMN}{ }^{13} \mathrm{C}$ - ressonância magnética nuclear, com núcleo de carbono

$\mathrm{RMN}{ }^{13} \mathrm{C}$ sólido - ressonância magnética nuclear de sólido, com núcleo de carbono

$\mathrm{T}_{\mathrm{d}}$ - temperatura de decomposição

TPU - poliuretanas termoplásticas

TG - termogravimétria

$\mathrm{T}_{\mathrm{g}}$ - temperatura de transição vítrea

THF - tetrahidrofurano 


\section{RESUMO}

O objetivo desta pesquisa foi estudar diferentes condições reacionais para sintetizar polímeros utilizando o óleo de mamona (Ricinus communis L.), na tentativa de obter materiais poliméricos com aplicações diversificadas e, principalmente, ecologicamente viáveis ao meio ambiente. A intenção era obter materiais biodegradáveis, considerando a origem e as características dos seus precursores. A viabilidade das sínteses foi estudada, usando duas metodologias, com e sem o uso de solvente, e três catalisadores diferentes, acetato de zinco $\left[\left(\mathrm{CH}_{3} \mathrm{COO}\right)_{2} \mathrm{Zn} .2 \mathrm{H}_{2} \mathrm{O}\right]$, cloreto de estanho $\left(\mathrm{SnCl}_{2} 2 \mathrm{H}_{2} \mathrm{O}\right)$ e trifluoreto de boro eterato $\left[\mathrm{BF}_{3}\left(\mathrm{Et}_{2} \mathrm{O}\right)\right]$. Na metodologia com solvente, foi usado o etanol, agitação magnética por $8 \mathrm{~h}$, modificando-se alguns parâmetros da reação, como temperatura, tempo de cura e os catalisadores. Na metodologia das sínteses sem solvente, as reações foram feitas sob agitação mecânica, com os catalisadores $\left(\mathrm{CH}_{3} \mathrm{COO}\right)_{2} \mathrm{Zn} .2 \mathrm{H}_{2} \mathrm{O}$ e $\mathrm{BF}_{3}\left(\mathrm{Et}_{2} \mathrm{O}\right)$ e diferentes tempos de cura. $\mathrm{A}$ caracterização dos materiais de partida foi realizada por ressonância magnética nuclear dos núcleos de ${ }^{1} \mathrm{H}\left(\mathrm{RMN}{ }^{1} \mathrm{H}\right)$, espectroscopia no infravermelho com transformada de Fourier (FT-IR), termogravimetria (TG) e calorimetria exploratória diferencial (DSC). Os materiais obtidos foram analisados por $\mathrm{RMN}{ }^{1} \mathrm{H}$ e $\mathrm{RMN}{ }^{13} \mathrm{C}$, em estado sólido, FT-IR, DSC, cromatografia de permeação em gel (GPC) e testes de absorção de umidade. Os resultados das análises evidenciaram a viabilidade das sínteses, a eficiência dos catalisadores, algumas propriedades físico-químicas.

Palavras-chave: Polímeros, óleo de mamona, ácidos de Lewis. 


\begin{abstract}
The aim of this research is to study different reaction conditions to synthesize polymers using castor oil (Ricinus communis L.) in an attempt to obtain a polymeric material with diversified applications and especially environmentally friend. The intention was to get biodegradable materials, considering the origin and characteristics of their precursors. The viability of the syntheses was studied using two methods, with and without solvent, and three different catalysts, zinc acetate $\left[\left(\mathrm{CH}_{3} \mathrm{COO}\right)_{2} \mathrm{Zn}_{2} 2 \mathrm{H}_{2} \mathrm{O}\right]$, tin chloride $\left(\mathrm{SnCl}_{2} .2 \mathrm{H}_{2} \mathrm{O}\right)$, and boron trifluoride etherate $\left[\mathrm{BF}_{3}\left(\mathrm{Et}_{2} \mathrm{O}\right)\right]$. In the methodology with solvent, ethanol was used with magnetic stir during $8 \mathrm{~h}$, modifying some reaction parameters such as temperature, cure time and catalysts. In the methodology without solvent, the reactions were performed under mechanical stiring, with the catalysts $\left(\mathrm{CH}_{3} \mathrm{COO}\right)_{2} \mathrm{Zn} .2 \mathrm{H}_{2} \mathrm{O}$ and $\mathrm{BF}_{3}\left(\mathrm{Et}_{2} \mathrm{O}\right)$ and different curing times. The characterization of the precursor materials was made by nuclear magnetic resonance of ${ }^{1} \mathrm{H}\left({ }^{1} \mathrm{H} N M R\right)$ infrared spectroscopy with Fourier transform (FT-IR), thermogravimetry (TG) and differential scanning calorimetry (DSC). The materials obtained were analyzed by ${ }^{1} \mathrm{H}$ RMN and ${ }^{13} \mathrm{C}$ RMN in solid state, FT-IR, DSC, gel permeation chromatography (GPC) and water absorption test. The results of the analyses showed the viability of the synthesis, the efficiency of the catalysts and some physico-chemical properties.
\end{abstract}

Keywords: Polymers, castor oil, urea, Lewis acid. 


\section{LISTA DAS DENOMINAÇÕES DOS MATERIAIS OBTIDOS}

MatOMa(1:4)/Zn/Et/8h/24h - Material sintetizado com óleo de mamona e ureia, proporção molar de $1 \mathrm{~mol}$ de óleo para 4 mols de ureia, catalisador $\left(\mathrm{CH}_{3} \mathrm{COO}\right)_{2} \mathrm{Zn} .2 \mathrm{H}_{2} \mathrm{O}$, solvente etanol, $8 \mathrm{~h}$ de agitação e $24 \mathrm{~h}$ de cura.

MatOMa(1:4)/Sn/Et/8h/24h - Material sintetizado com óleo de mamona e ureia, proporção molar de $1 \mathrm{~mol}$ de óleo para 4 mols de ureia, catalisador $\mathrm{SnCl}_{2} 2 \mathrm{H}_{2} \mathrm{O}$, solvente etanol, $8 \mathrm{~h}$ de agitação e $24 \mathrm{~h}$ de cura.

MatOMa(1:4)/BF $/ \mathrm{Bt}_{3} / \mathbf{8 h} / \mathbf{2 4 h}$ - Material sintetizado com óleo de mamona e ureia, proporção molar de $1 \mathrm{~mol}$ de óleo para 4 mols de ureia, catalisador $\mathrm{BF}_{3}\left(\mathrm{Et}_{2} \mathrm{O}\right)$, solvente etanol, $8 \mathrm{~h}$ de agitação e $24 \mathrm{~h}$ de cura.

MatOMa(1:8)/BF $/ \mathrm{Et}_{3} / \mathbf{8 h} / \mathbf{2 4 h}$. - Material sintetizado com óleo de mamona e ureia, proporção molar de $1 \mathrm{~mol}$ de óleo para 4 mols de ureia, catalisador $\mathrm{BF}_{3}\left(\mathrm{Et}_{2} \mathrm{O}\right)$, solvente etanol, $8 \mathrm{~h}$ de agitação e $24 \mathrm{~h}$ de cura.

MatOmaracujá(1:2)/BF $3 / 5 \mathrm{~m} / 24 \mathrm{~h}$. - Material sintetizado com óleo de maracujá e ureia, proporção molar de 1 mol de óleo para 2 mols de ureia, catalisador $\mathrm{BF}_{3}\left(\mathrm{Et}_{2} \mathrm{O}\right)$, sem solvente $1 \mathrm{~h}$ de agitação e $24 \mathrm{~h}$ de cura.

PUOMa(1:2)/BF $/ 3$ min/24h - Poli(acil-uretana) de óleo de mamona e ureia, proporção de $1 \mathrm{~mol}$ de óleo para 2 mols de ureia, catalisador $\mathrm{BF}_{3}\left(\mathrm{Et}_{2} \mathrm{O}\right)$, sem solvente, 5 min de agitação e 24 h de cura.

PUOMa(1:3)/BF $/ 5$ min/24h - Poli(acil-uretana) de óleo de mamona e ureia, proporção de 1 mol de óleo para 3 mols de ureia, catalisador $\mathrm{BF}_{3}\left(\mathrm{Et}_{2} \mathrm{O}\right)$, sem solvente, 5 min de agitação e 24 h de cura.

PUOMa(1:4)/BF $/ 5$ min/24h - Poli(acil-uretana) de óleo de mamona e ureia, proporção de $1 \mathrm{~mol}$ de óleo para 4 mols de ureia, catalisador $\mathrm{BF}_{3}\left(\mathrm{Et}_{2} \mathrm{O}\right)$, sem solvente, 5 min de agitação e 24 h de cura.

PUOMa(1:8)/BF $3 / 5$ min/24h - Poli(acil-uretana) de óleo de mamona e ureia, proporção de $1 \mathrm{~mol}$ de óleo para 8 mols de ureia, catalisador $\mathrm{BF}_{3}\left(\mathrm{Et}_{2} \mathrm{O}\right)$, sem solvente, 5 min de agitação e 24 h de cura.

PUOMa(1:2)/BF $/ 3$ min/48h - Poli(acil-uretana) de óleo de mamona e ureia, proporção de $1 \mathrm{~mol}$ de óleo para 2 mols de ureia, catalisador $\mathrm{BF}_{3}\left(\mathrm{Et}_{2} \mathrm{O}\right)$, sem solvente, $5 \mathrm{~min}$ de agitação e $48 \mathrm{~h}$ de cura.

PUOMa(1:3)/BF $/ 3$ min/48h - Poli(acil-uretana) de óleo de mamona e ureia, proporção de $1 \mathrm{~mol}$ de óleo para 3 mols de ureia, catalisador $\mathrm{BF}_{3}\left(\mathrm{Et}_{2} \mathrm{O}\right)$, sem solvente, 5 min de agitação e 48 h de cura. 
PUOMa(1:4)/BF $3 / 5$ min/48h - Poli(acil-uretana) de óleo de mamona e ureia, proporção de $1 \mathrm{~mol}$ de óleo para 4 mols de ureia, catalisador $\mathrm{BF}_{3}\left(\mathrm{Et}_{2} \mathrm{O}\right)$, sem solvente, 5 min de agitação e $48 \mathrm{~h}$ de cura.

PUOMa(1:2)/BF $/ 5$ min/72h - Poli(acil-uretana) de óleo de mamona e ureia, proporção de $1 \mathrm{~mol}$ de óleo para 2 mols de ureia, catalisador $\mathrm{BF}_{3}\left(\mathrm{Et}_{2} \mathrm{O}\right)$, sem solvente, 5 min de agitação e 72 h de cura.

PUOMa(1:3)/BF $/ 5$ min/72h - Poli(acil-uretana) de óleo de mamona e ureia, proporção de 1 mol de óleo para 3 mols de ureia, catalisador $\mathrm{BF}_{3}\left(\mathrm{Et}_{2} \mathrm{O}\right)$, sem solvente, $5 \mathrm{~min}$ de agitação e 72 h de cura.

PUOMa(1:4)/BF $/ 3$ min/72h - Poli(acil-uretana) de óleo de mamona e ureia, proporção de $1 \mathrm{~mol}$ de óleo para 4 mols de ureia, catalisador $\mathrm{BF}_{3}\left(\mathrm{Et}_{2} \mathrm{O}\right)$, sem solvente, 5 min de agitação e 72 h de cura.

PUOMa(1:2)/Zn/1h/24h - Poli(acil-uretana) de óleo de mamona e ureia, proporção de 1 mol de óleo para 2 mols de ureia, catalisador $\left(\mathrm{CH}_{3} \mathrm{COO}\right)_{2} \mathrm{Zn} .2 \mathrm{H}_{2} \mathrm{O}$, sem solvente, $1 \mathrm{~h}$ de agitação e $24 \mathrm{~h}$ de cura.

PUOMa(1:2)/Zn/4h/24h - Poli(acil-uretana) de óleo de mamona e ureia, proporção de 1 mol de óleo para 2 mols de ureia, catalisador $\left(\mathrm{CH}_{3} \mathrm{COO}\right)_{2} \mathrm{Zn} .2 \mathrm{H}_{2} \mathrm{O}$, sem solvente, $4 \mathrm{~h}$ de agitação e $24 \mathrm{~h}$ de cura. 
Capítulo 1

INTRODUÇÃO E OBJETIVOS 


\subsection{INTRODUÇÃO}

As poliuretanas (PUs) são materiais com expressivo crescimento de produção e consumo no mercado mundial de polímeros. ${ }^{1}$ Sua utilização ocorre nas várias indústrias que englobam a automotiva, construção, eletrodomésticos, eletroeletrônico, calçados, entre outras (Figura 1). ${ }^{1}$ Seu consumo pode ser justificado, por sua grande versatilidade, visto que, este pode ser encontrado como espumas rígidas, flexíveis, tintas, elastômeros, adesivos e resinas (Figura 1). ${ }^{1}$

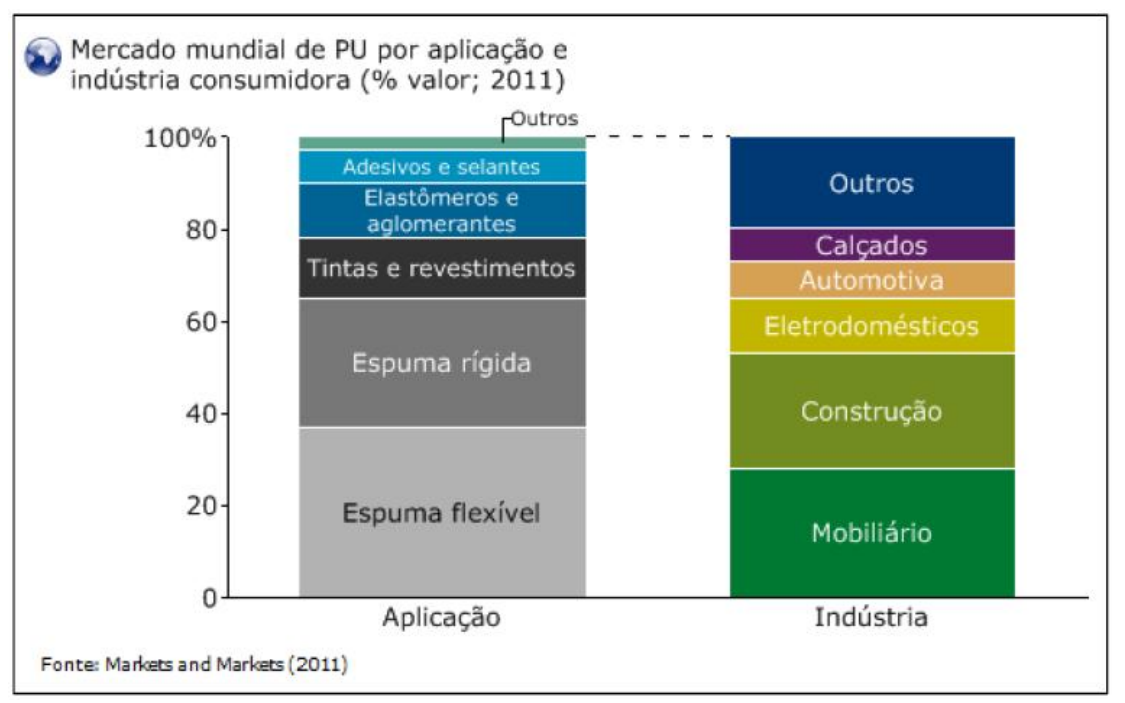

Figura 1. Representação do percentual de aplicações de PUs no mercado mundial. ${ }^{1}$

A produção de PU no ano de 2011 foi em torno de 14 milhões de toneladas. E a perspectiva, até o final de 2016, é que a produção continue a crescer (Figura 2). ${ }^{1}$

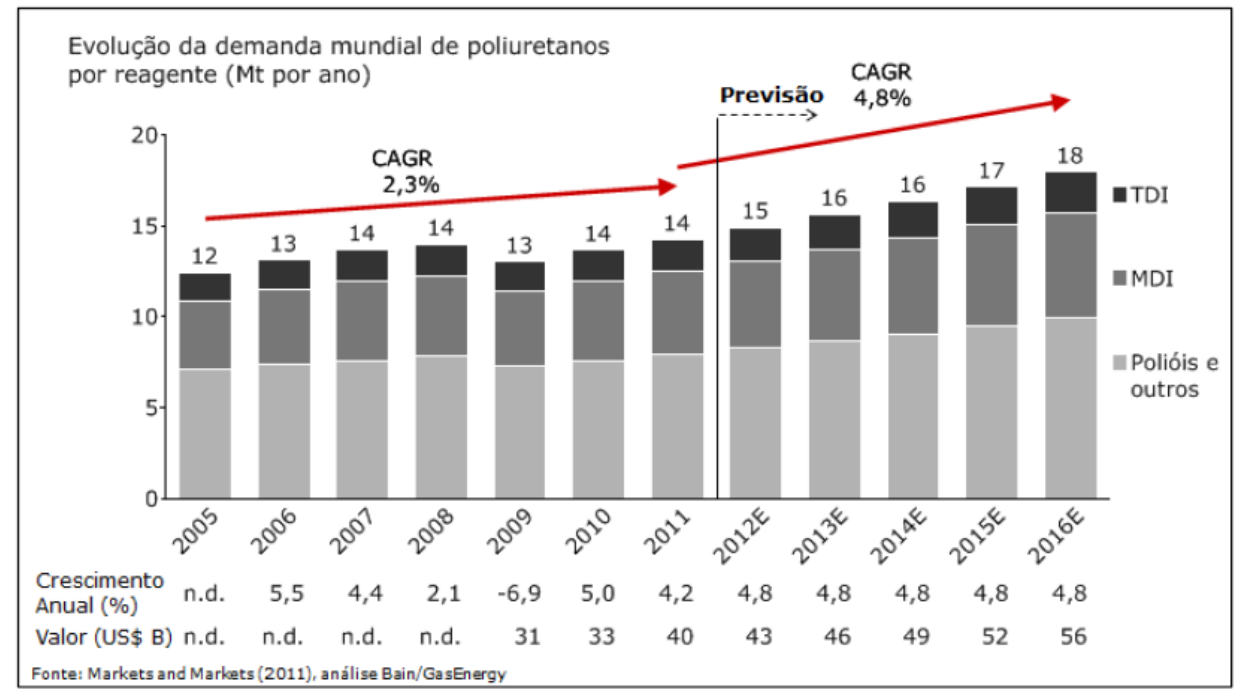

Figura 2. Representação gráfica da evolução anual da demanda de PU. ${ }^{1}$ 
Em grande parte da produção de PUs são utilizados isocianatos alifáticos ou aromáticos como precursores, que são reagentes extremamente tóxicos e produzem materiais com baixa taxa de degradação. ${ }^{2}$

Existe um crescente interesse de pesquisadores e da indústria que sejam desenvolvidas metodologias de sínteses de PUs, com precursores de fontes renováveis, sendo livres de isocianato e sem produção de resíduos. ${ }^{3-12}$ Estes materiais são considerados verdes. A expectativa é que ocorra uma melhoria nas propriedades químicas e físicas desses novos materiais poliméricos e que eles possam ser biodegradáveis e biocompativeis, características que ampliariam anda mais a faixa de aplicação das PUs. ${ }^{5}$

Sendo uma fonte renovável, muitas são as metodologias que propõem os óleos vegetais como possíveis fontes de diois para a reação de formação de PUs. Isso agrega valor a essa fonte renovável de vasta abundância no Brasil.3,4,10

Em especial, há o óleo de mamona (Ricinus communis L.) (OMa), que é bastante conhecido como um precursor na síntese de PUs, pelo fato da sua estrutura possuir grupos hidroxilas, que reagem espontaneamente e exotermicamente com o isocianato, formando as PUs. ${ }^{13-19}$

Além da utilização de óleos vegetais para obtenção de PUs, sem o uso de matérias-primas de origem petroquímica, novas metodologias propõem as denominadas PUs livres de isocianatos (NIPU). Em sua grande maioria, elas são sintetizadas a partir da reação de carbamatos, com diaminas, na presença de catalisadores. Esta reação ocorre pelo mecanismo de abertura de anel, em que há o ataque nucleofílico dos pares de elétrons livres do nitrogênio da amina, no carbono da carboxila do carbonato. ${ }^{7-10}$

Ao considerar a toxicidade da utilização dos isocianatos na produção industrial e nas PUs comercializadas é que surge o interesse nas pesquisas das NIPUs, que geram uma nova possibilidade de materiais com uma síntese favorável ao meio ambiente, além de um polímero com boas perspectivas de baixa toxicidade e alta taxa de degradação. ${ }^{7-10}$

Outra possibilidade de síntese de PUs, conhecida como polímeros supramoleculares, é onde a síntese ocorre sem a utilização de solvente, com a produção mínima de resíduos, por agitação mecânica. ${ }^{12,20,21}$ Neste caso, existe um ponto negativo, tendo em vista que boa parte das novas metodologias obtém as PUs como oligômeros e não como polímeros. Ou seja, com massa molar muito baixo e com propriedades físicas que não podem ser comparadas às dos polímeros convencionais, o que descarta a maioria das possibilidades de utilização dessas PUs. ${ }^{4-12}$ 
Muitos são os aspectos que podem ser melhorados na síntese das NIPUs, visando à obtenção de novos materiais poliméricos. Daí, a motivação deste trabalho de pesquisa, que é a busca de produzir PUs livres de isocianatos, com propriedades compatíveis com as existentes no mercado e, de preferência, que sejam biodegradáveis.

\subsection{OBJETIVOS}

\subsubsection{Objetivo Geral}

O objetivo geral do trabalho é propor uma metodologia de reação entre o OMa e a ureia, na presença de catalisadores do tipo ácidos de Lewis, para obter PUs livres de isocianatos (NIPUs).

\subsubsection{Objetivos específicos}

- Caracterizar os materiais de partida.

- Verificar a síntese das poli(acil-uretanas) com o uso de um solvente (etanol).

- Observar a influência da mudança nos parâmetros da reação com etanol, no material obtido.

- Realizar a síntese poli(acil-uretanas) sem uso de solvente.

- Observar a influência da mudança nos parâmetros da reação sem solvente, no material obtido.

- Caracterização química, físico-química e morfológica dos materiais obtidos.

- Propor um mecanismo para a reação de obtenção do polímero obtido, verificando a influência dos catalisadores na síntese. 


\section{Capítulo 2}

REVISÃO TEÓRICA 


\section{1. ÓLEOS VEGETAIS}

Os óleos vegetais são fontes renováveis, de baixo custo, com propriedades químicas bastante atrativas para a indústria polimérica, e podem ser obtidos das polpas, frutos, nozes e sementes, a depender do tipo de óleo vegetal. ${ }^{3}$

De modo geral, eles sãos constituídos dos componentes principais, os triacilglicerideos e de componentes menores que são os esteróis, hidrocarbonetos, alcoóis graxos, tocofenois, carotenos, entre outros. ${ }^{3,22}$

Os triacilglicerideos são lipídeos formados por três cadeias de ácidos graxos ligadas, podendo ter diferentes estruturas. ${ }^{3,22}$ De acordo com o tipo de óleo vegetal, as composições dos ácidos graxos existentes e as suas proporções são variadas. ${ }^{3}$

Em um mesmo óleo, as proporções dos ácidos graxos podem variar, conforme as condições de plantio, clima, tipo de solo, maturidade da planta, forma de colheita e forma de extração do óleo.,22

A classificação dos ácidos graxos é de acordo com a quantidade de instaurações e pelo tamanho da cadeia carbônica. ${ }^{3,22}$ As estruturas, nomes e pontos de fusão dos principais ácidos graxos estão apresentados na Tabela 1.

Tabela 1. Estrutura, nomenclatura e ponto de fusão de alguns ácidos graxos. ${ }^{3,23}$

Símbolo ${ }^{\text {(a) }}$

\footnotetext{
${ }^{(a)}$ Número de átomos de carbono:número de ligações duplas
} 
Os componentes primários dos óleos são os triglicerídeos (Figura 3) e são eles que despertam a atenção, por possuírem diversos pontos de reatividade, que podem ser modificados, portanto, passíveis de serem utilizados em diversas sínteses, incluindo a de polímeros. ${ }^{3,5}$

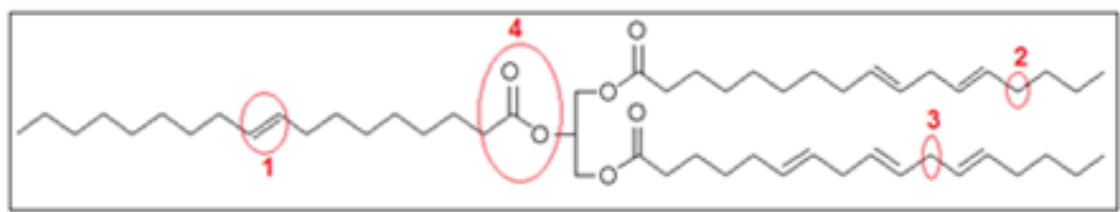

1. Dupla ligação

2- Posição monoalílica

3- Posição bisalílica

4- Grupo Éster

Figura 3. Representação dos pontos de reatividade de um triglicerídeo.

\subsection{1. Óleo de Mamona}

Dentre os diversos óleos usados na indústria, o OMa é bem conhecido e utilizado em sínteses poliméricas. ${ }^{13,17}$ Esse óleo possui majoritariamente em sua composição o ácido ricinoleico, cerca de $90 \%$ (Tabela 2), ${ }^{13,17}$ e como diferencial dos outros triglicerídeos é conhecido por possuir naturalmente grupos hidroxilas em sua cadeia carbônica (Figura 4). ${ }^{13,17}$ Isso amplia a possibilidade de reações poliméricas, justificando a sua vasta utilização na indústria.

Tabela 2. Composição do óleo de mamona. ${ }^{17}$

\begin{tabular}{ccc}
\hline Ácido graxo & Fórmula molecular & Percentual (\%) \\
\hline Palmítico & $\mathrm{C}_{16} \mathrm{H}_{32} \mathrm{O}_{2}$ & $0,8-1,1$ \\
Esteárico & $\mathrm{C}_{18} \mathrm{H}_{36} \mathrm{O}_{2}$ & $0,7-1,0$ \\
Oleico & $\mathrm{C}_{18} \mathrm{H}_{34} \mathrm{O}_{2}$ & $2,2-3,3$ \\
Linoleico & $\mathrm{C}_{18} \mathrm{H}_{32} \mathrm{O}_{2}$ & $4,1-4,7$ \\
Linolênico & $\mathrm{C}_{18} \mathrm{H}_{30} \mathrm{O}_{2}$ & $0,5-0,7$ \\
Ricinoleico & $\mathrm{C}_{18} \mathrm{H}_{34} \mathrm{O}_{3}$ & $87,7-90,4$ \\
\hline
\end{tabular}

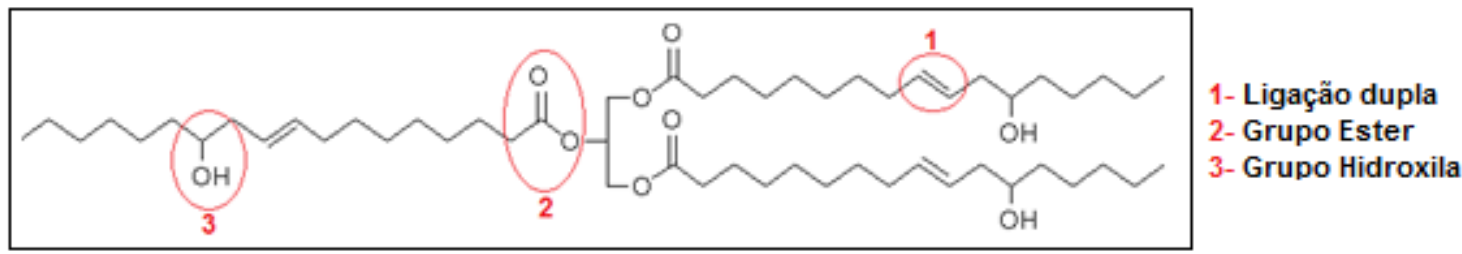

Figura 4. Representação dos pontos de reatividade do acido ricinoleico.

O acido ricinoleico possui os seguintes pontos de reatividade: as duplas ligações, o grupo éster e as hidroxilas (Figura 4). Com a dupla ligação é possível a realização de reações como oxidação, polimerização, hidrogenação, epoxidação, halogenação, 
adição e sulfonação. Com o grupo éster pode ocorrer hidrólise, esterificação, alcoólise, saponificação, redução, amidação, e halogenação. Enquanto na hidroxila, é possível desidratação, hidrólise, pirólise, alcoxilação, esterificação, halogenação, formação de uretana e sulfonação. ${ }^{17}$

Com tantos pontos de reatividade no OMa, há uma vasta possibilidade de modificação da sua estrutura, por reações orgânicas bem conhecidas, sendo esse óleo muito atrativo, tanto para pesquisadores quanto para a indústria polimérica. Por isso que há anos o OMa tem sido usado como precursor nas sínteses de PUs. ${ }^{15-18}$

Para se tiver uma ideia da importância do OMa como um interessante precursor no mercado brasileiro, atualmente o Brasil ocupa o terceiro lugar de maior produtor deste óleo no mundo, atrás apenas da China e da Índia. ${ }^{17}$ Vale ressaltar, que essa produção se mantém há muitos anos (Figura 5$).{ }^{17}$

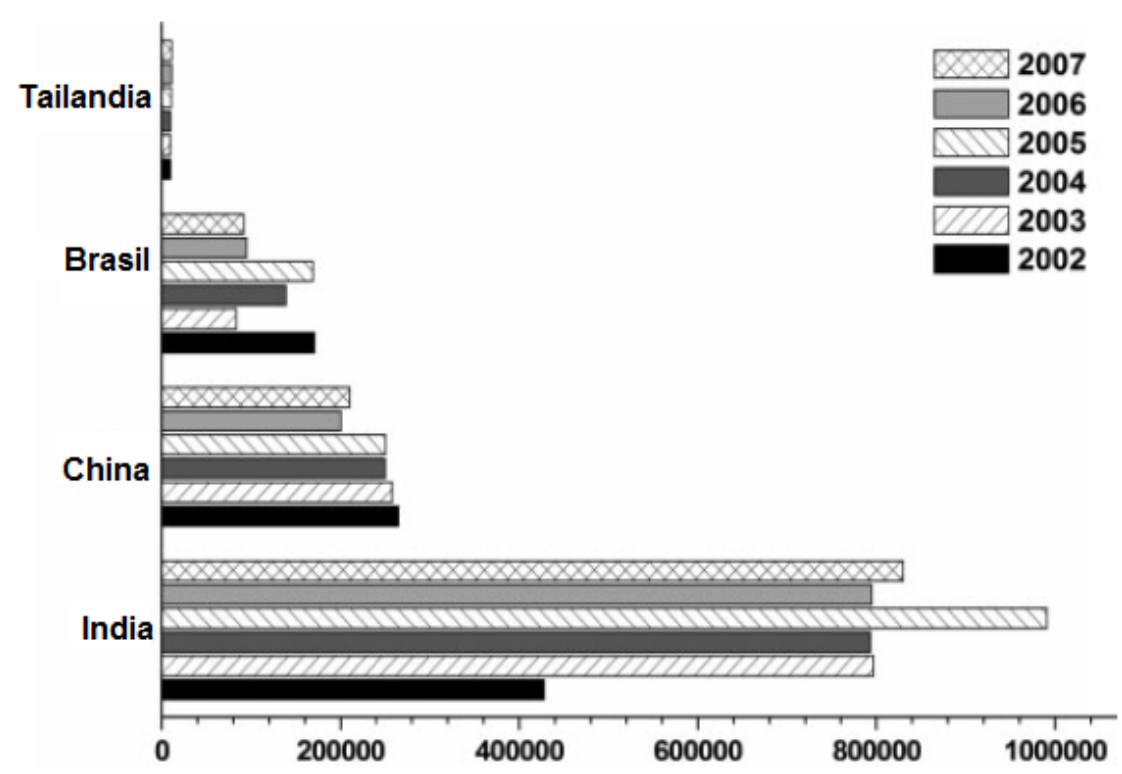

Figura 5. Produção anual do OMa. ${ }^{17}$

Com tal produção, é que se torna viável a utilização desse material em outros fins, o que amplia a sua aplicação, agregando valor à fonte renovável e ampliando seu uso na indústria nacional.

O OMa é proveniente da mamoeira, planta pertencente à família Euforbiácea e típica da Ásia e da África. O óleo é obtido da semente, por combinação de processos de extração por pressão e extração por solvente. ${ }^{17} \mathrm{O}$ seu rendimento varia de acordo com a metodologia utilizada, mas de modo geral fica em torno de 60 a $70 \% .^{13,16,17}$ 
Além do uso do OMa na pesquisa e indústria, ele é bem conhecido por ser usado medicinalmente, com resultados positivos em problemas respiratórios, digestivos, cardiovasculares, de articulações, infecções, entre outros. ${ }^{16}$

\subsection{POLIURETANAS (PUS)}

Uma das classes de polímeros mais importante na atualidade são as PUs, por serem materiais versáteis e, portanto, com ampla faixa de aplicação. ${ }^{3,23,29}$ Inicialmente conhecidas apenas como espumas rígidas, atualmente as PUs podem ser obtidas como espumas rígidas e flexíveis, empregadas como elastômeros, adesivos, resinas e tintas. $^{3}$

As diversas metodologias de síntese de PUs existentes são originadas de um conhecimento prévio bem fundamentado e desenvolvido para a obtenção deste material. ${ }^{24}$ Afinal, com a variabilidade de características físicas e químicas, é de se esperar que seja um material extremamente visado por pesquisadores e pela indústria polimérica.

Desde a primeira produção industrial realizada por Otto Bayer, em 1947, ${ }^{26,27}$ muitas foram as modificações e melhorias propostas para a otimização do processo e obtenção de diferentes PUs, tendo em vista que as espumas não possuíam propriedades tão desejáveis do ponto de vista ambiental. Essas propriedades indesejadas dependem da rota sintética, pois é utilizado um precursor tóxico, o isocianato, além dos produtos obtidos serem de difícil reutilização e degradabilidade.

Mesmo com esses aspectos negativos, o material foi incorporado à indústria por apresentar interessantes propriedades físicas, como rigidez, absorção ao impacto, isolamento térmico e acústico, ${ }^{1}$ podendo, portanto, serem aplicadas em diversos eletrodomésticos, eletroeletrônicos, automóveis e para revestimento de estúdios e casas noturnas. ${ }^{1}$

As PUs são originalmente sintetizadas pela reação exotérmica entre isocianatos, aromáticos ou alifáticos, e um grupo diol, em uma reação de policondensação (Figura 6). ${ }^{27}$ A princípio, qualquer grupo que possui a hidroxila em sua constituição poderá reagir espontaneamente com 0 isocianato. ${ }^{3,27} \mathrm{~A}$ escolha do tipo de isocianato e 0 grupo diol para tal reação, é que define as propriedades finais do material polimérico obtido. ${ }^{2,28}$ 


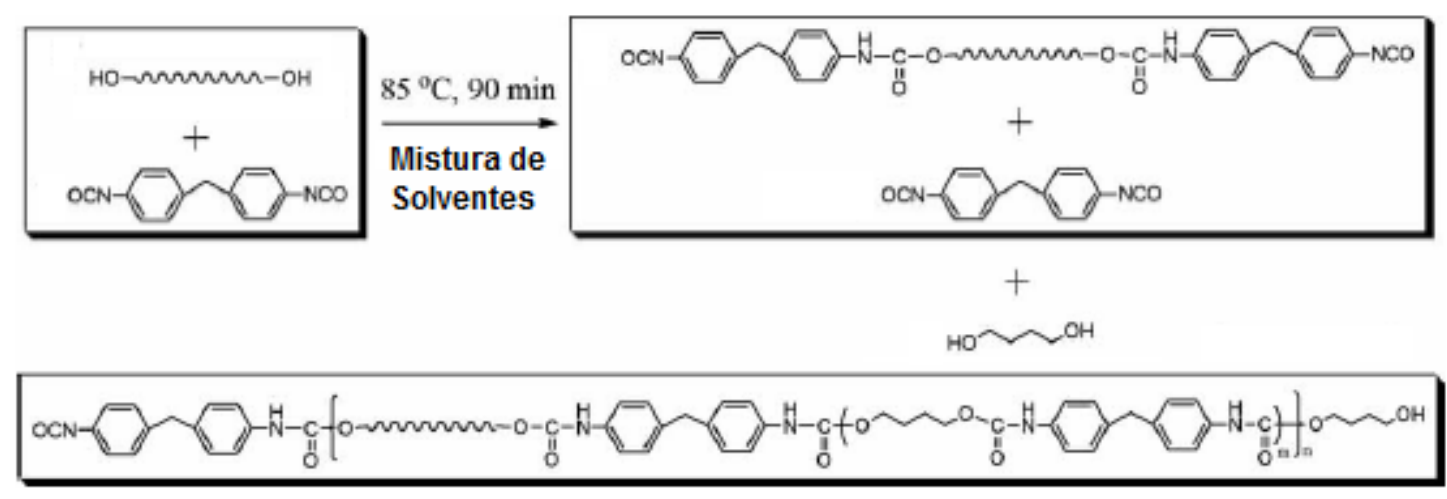

Figura 6. Representação geral da síntese de PUs. ${ }^{28}$

De acordo com as novas metodologias encontradas na literatura, as PUs são subdivididas em PUs termorrígidas (PU) e PUs termoplásticas (TPU). ${ }^{29,30}$ Essa classificação corresponde às PUs rígidas, que não podem ser remoldadas, e não apresentam ponto de fusão. Em contrapartida, as TPUs são flexíveis, com ponto de fusão e possibilidade de serem remoldadas diversas vezes. ${ }^{29,30}$

Em espumas termorrígidas, opta-se pela síntese com isocianatos aromáticos, do tipo 4,4-difenil diisocianato (MDI), tolueno diisocianato (TDI), naftaleno diisocianato (NDI) e grupos diois., ${ }^{3,6,7}$ Já, as TPUs, de modo geral são polímeros em que se utiliza um isocianato de cadeia alifática como hexametileno diisocianato (HDI). ${ }^{3,6,7}$

As primeiras PUs obtidas pela reação de grupos diois e isocianato com catálise eram espumas rígidas e classificadas, essencialmente, como materiais termorrígidos ou termofixos. ${ }^{30,31}$

Materiais termorrígidos são classificados por não poderem ser moldados, após resfriados. Durante a síntese, quando submetidos a elevadas temperaturas, favorecem a formação de ligações cruzadas (Figura 7). ${ }^{3}$ Depois de formados, esses materiais se decompõem, quando aquecidos, dificultando assim sua reciclagem. ${ }^{30,31}$ As PUs obtidas a partir de óleos vegetais com isocianatos aromáticos, em sua grande maioria, são espumas rígidas. ${ }^{28,29}$

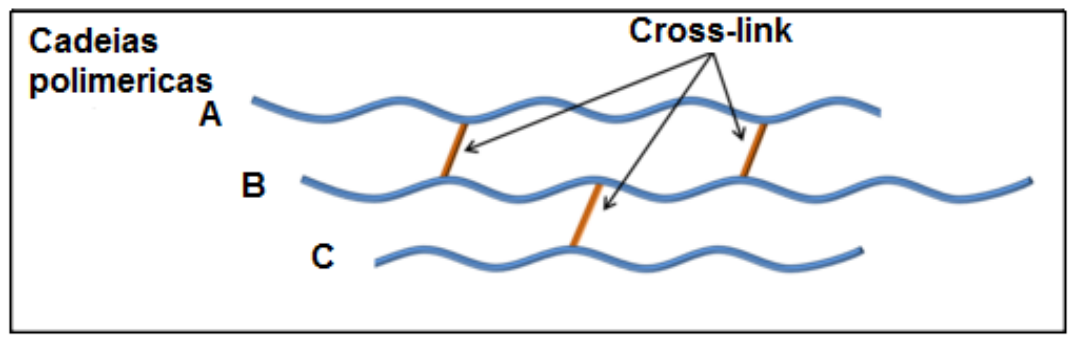

Figura 7. Representação das ligações cruzadas (cross-link). ${ }^{32}$ 
Esses materiais não possuem ponto de fusão, logo possuem estrutura, essencialmente, amorfa (Figura 8), com cadeias altamente entrelaçadas pelas ligações cruzadas formadas durante a cura do material (Figura 9).

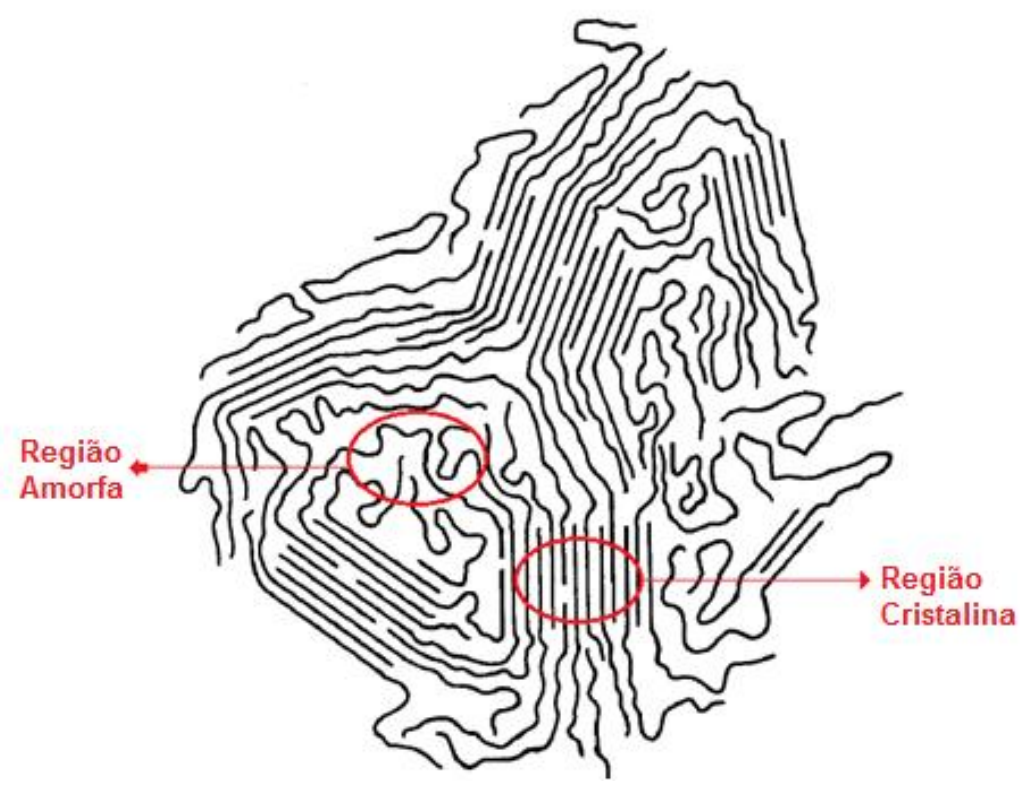

Figura 8. Representação de micela franjada de um polímero semi-cristalino. ${ }^{30}$

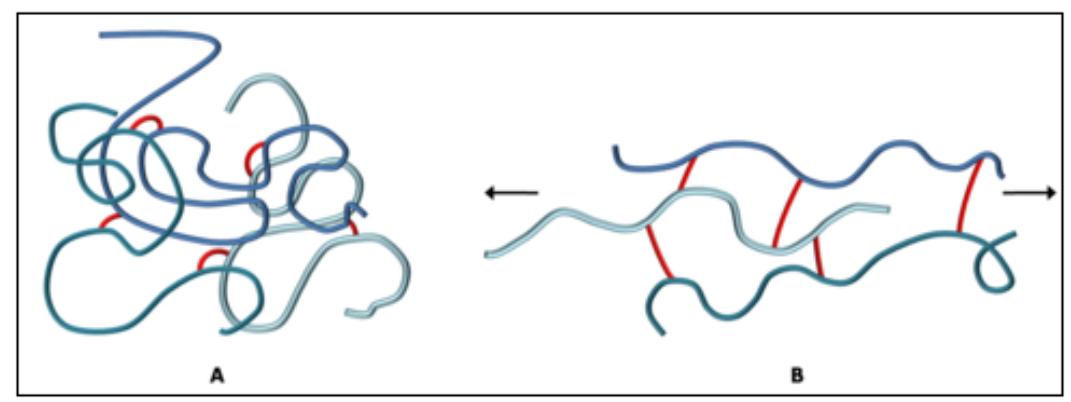

Figura 9. Representação do efeito da temperatura na formação de ligações cruzadas. ${ }^{32}$

Entretanto, as TPUs possuem estrutura, majoritariamente, cristalina (Figura 8) e, portanto, ponto de fusão, característica vantajosa no seu possível processamento. Exemplos de TPUs são os adesivos e as espumas aplicadas na indústria automobilística. ${ }^{30,31}$ As TPUs podem ser obtidas pela reação com isocianatos alifáticos e pelas novas metodologias de abertura de anel, desde que a estrutura final do material seja constituído de cadeias alifáticas. ${ }^{30,31}$

De forma geral, não é possível se obter um material completamente amorfo, ou completamente cristalino. A sua classificação é de acordo com a predominância da 
sua constituição. A maioria dos materiais poliméricos é classificada como semicristalinos, com parte amorfa e parte cristalina (Figura 8). ${ }^{30}$

São as características físicas que indicam o teor de cristalinidade do polímero, pois quanto maior a sua cristalinidade, melhores são a rigidez, a densidade, a resistência química, resistência à abrasão, a temperatura de fusão $\left(T_{m}\right)$ e temperatura de transição vítrea $\left(\mathrm{T}_{\mathrm{g}}\right)$. Porém há uma diminuição de outras propriedades como resistência ao impacto, elongação na ruptura e claridade óptica. ${ }^{30}$

Atualmente, preocupa-se com a síntese de matérias sustentáveis, com precursores originados de fontes renováveis, com baixa toxicidade, baixo custo e evitando-se o uso de solvente, para que a própria rota sintética se torne mais viável, produzindo menos resíduos. ${ }^{2,6,10,25,33,34}$

A utilização de óleos vegetais como fontes de diois faz parte das primeiras metodologias propostas que buscam a síntese de materiais verdes. Destaque é dado ao OMa, por possuir majoritariamente em sua constituição triglicerídica o ácido ricinoleico, com o grupo hidroxila. ${ }^{6,7,13}$

As PUs originadas de óleos vegetais não se restringem às obtidas pelo OMa. Com os vários sítios ativos dos triglicerídeos que compõem os óleos vegetais, muitas são as pesquisas que utilizam outras fontes oleaginosas, realizando a hidroxilação das cadeias, $^{5,35-38}$ tornando possível a reação com o isocianato. Dessa forma, são sintetizados uma grande variedade de materiais, usando óleos de linhaça, pequi, maracujá, macaúba, babaçu, entre outros. ${ }^{2,3,5,35-37}$

Os isocianatos ainda são muito utilizados nas metodologias propostas, mesmo em trabalhos que se autodenominam verdes. Porém, este é o grande responsável pelos riscos das rotas sintéticas, além da toxicidade dos produtos obtidos. ${ }^{18}$

\subsubsection{Poliuretanas livres de isocianato (NIPU)}

Nos últimos 5 anos, foram iniciadas diversas pesquisas que buscam a eliminação dos isocianatos nas sínteses das $\mathrm{PUs},{ }^{6-8}$ surgindo uma nova classe de PUs, denominadas PUs livres de isocianatos, abreviadas por NIPU - non isocyanate polyurethane. $^{6-8}$

Muitas são as metodologias propostas atualmente para a síntese das NIPUs, porém o mecanismo geral é de abertura do anel de um carbonato cíclico, podendo ocorrer por um grupo diamida, diamina, ou aminoálcool (Figura 10). ${ }^{7-10,39}$ 


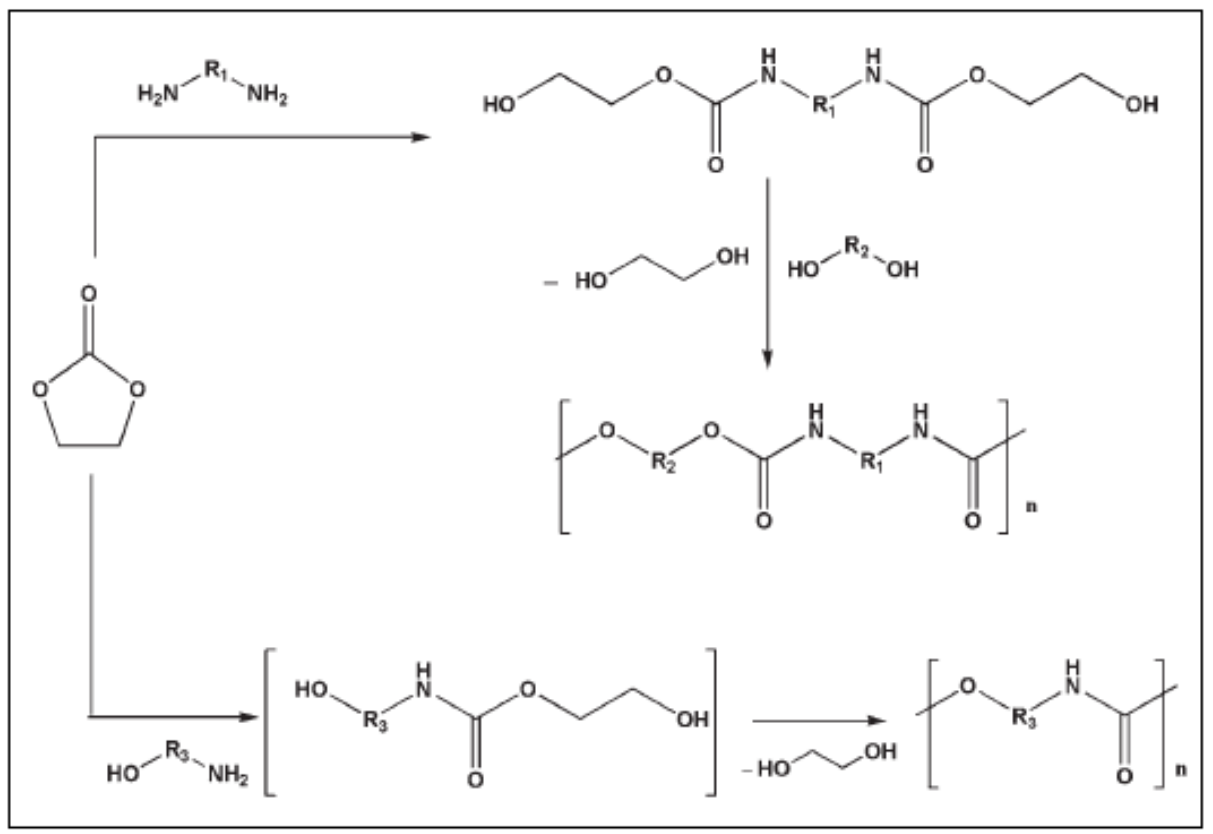

Figura 10. Representação geral da síntese de NIPUs. ${ }^{36}$

Rokicki et al. ${ }^{24}$ propuseram a síntese das NIPUs com a reação entre um oligômero do tipo carbonato cíclico com uma diamina, na presença de catalisadores, assim como diversos outros autores. ${ }^{6,9,25,34,40,41}$ Para que a PU seja formada, o oligômero deve possuir em sua estrutura carbônica um anel de cinco membros que irá se abrir pelo ataque da diamina. ${ }^{41-46} \mathrm{O}$ produto formado possui uma hidroxila beta $(\beta)$ ao grupo uretano, sendo portanto denominado poli(hidroxi)uretana (Figura 11). ${ }^{47}$

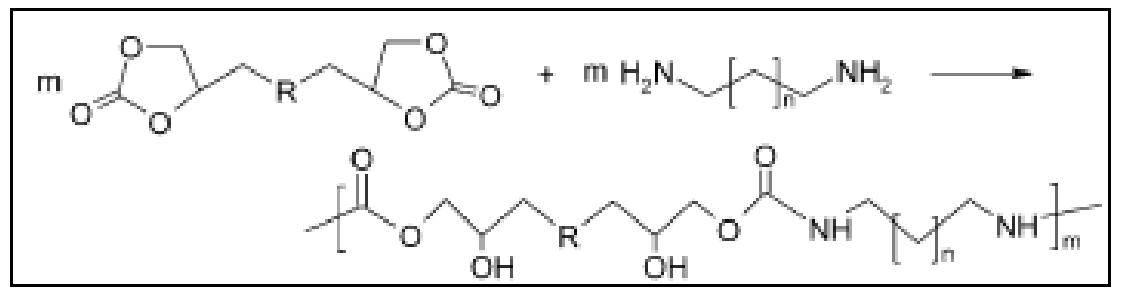

Figura 11. Representação geral da síntese de poli(hidroxi)uretanas. ${ }^{47}$

Outra forma comum de obtenção de NIPUs, proposta entre as novas metodologias, ocorre pela abertura de anel de uma uretana cíclica, pelo ataque de uma diamina ou diois. $^{47}$

Dentre as metodologias encontradas na literatura, as consideradas mais verdes seriam a abertura de anel de poliadição de carbonato cíclico por uma diamina, a policondensação de etileno carbonato com diamina e diois, a polimerização com 
abertura de anel catiônica de uretana cíclica e a co-polimerização de aziridinas substituídas com dióxido de carbono (Figura 12). ${ }^{48}$

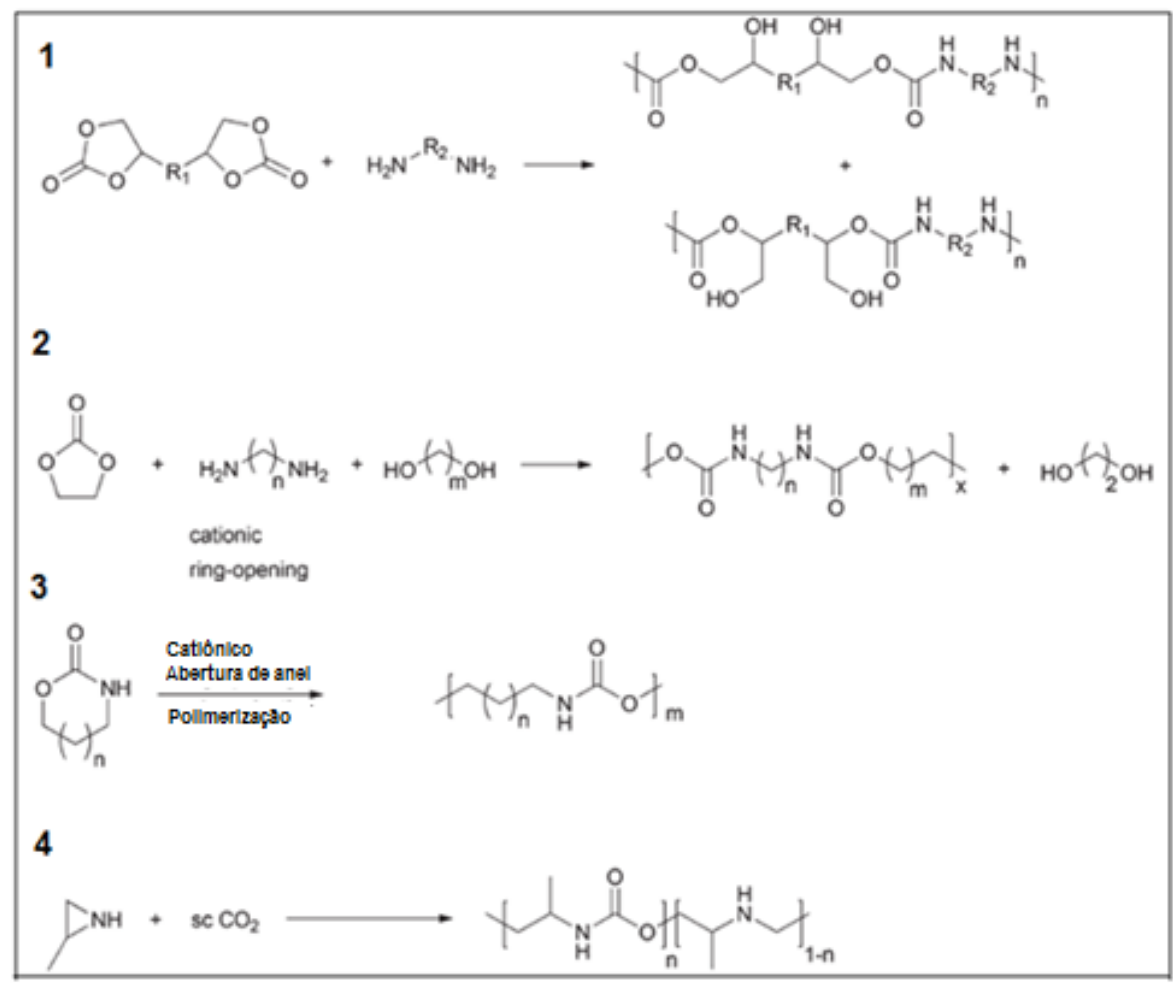

Figura 12. Representação geral da síntese de NIPU: 1) poliadição de carbonato cíclico com diamina; 2) policondensação de etileno carbonato com diamina e diois; 3) polimerização com abertura de anel catiônica de uretana cíclica; 4) co-polimerização de aziridinas substituídas com dióxido de carbono. ${ }^{48}$

Dentre as metodologias que utilizam óleos vegetais como precursores, Javni et al. ${ }^{10}$ estudaram a reação do óleo de soja carbonato com uma diamina (Figura 13), obtendo-se um material denominado poli(hidroxi)uretana. ${ }^{10}$

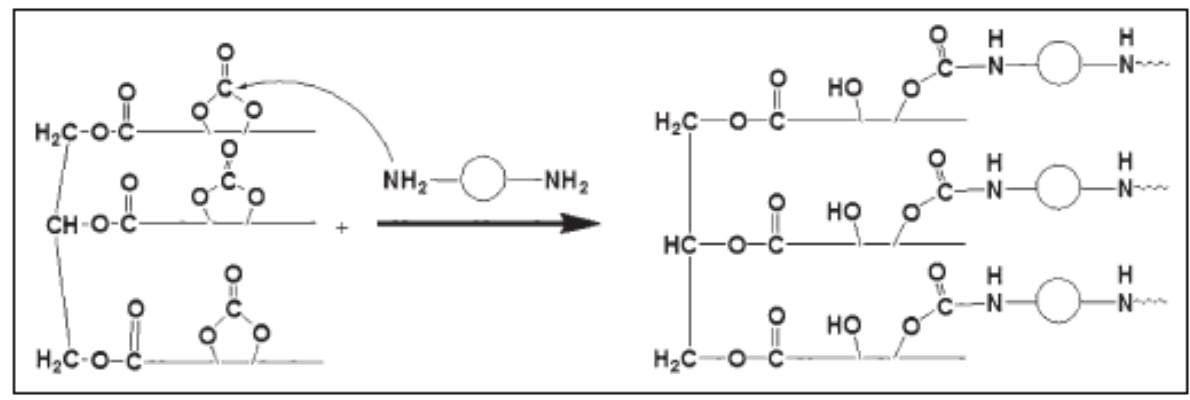

Figura 13. Representação geral da síntese da poli(hidroxi)uretana a partir do óleo de soja carbonato e diamina. ${ }^{10}$ 
Todos os materiais até então citados possuem baixa massa molar, muitas vezes considerados oligômeros e não polímeros, ${ }^{6-12,32,35}$ o que justifica a síntese de um prépolímero em muitos estudos aqui reportados, ${ }^{6-12,32,35}$ seguida de uma reação adicional com um material extensor de cadeias, que favorece os chamados crosslinks. ${ }^{6-12,40,43}$

Alternativamente, a literatura sugere a possibilidade de realização das sínteses, dispensando a utilização de solventes, considerando as dificuldades encontradas nas solubilizações dos precursores e produtos com alto grau de ligações intercruzadas. ${ }^{34}$ Um exemplo é a chamada reação transuretana proposta por Li et al., ${ }^{34}$ que ocorre pela policondensação de diaminas e diuretanodiois com catálise, favorecendo a síntese de um polímero constituído de poliuretana e poliureia, denominado poliuretana poliureia (PUU) (Figura 14).

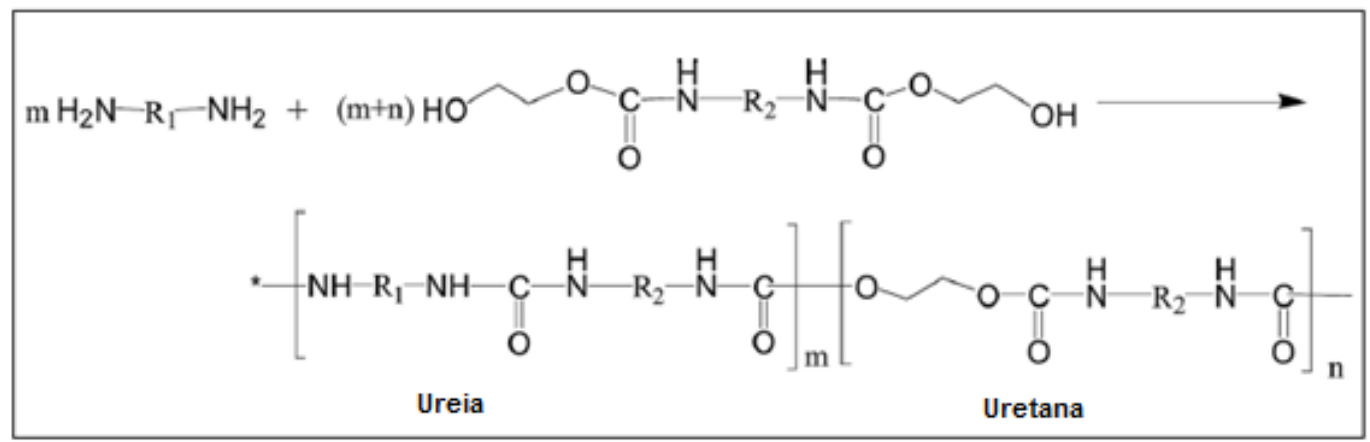

Figura 14. Representação geral da síntese de policondensação de diaminas com diuretanodiois (transuretano). ${ }^{45}$

Os denominados polímeros supramoleculares são sintetizados sem a adição de solvente na metodologia sintética, onde são utilizados apenas os precursores e agitação mecânica (conhecida como síntese orgânica mecano-química). ${ }^{43}$

A síntese dos polímeros supramoleculares faz parte de uma metodologia que tem despertado bastante interesse nos últimos 10 anos, ${ }^{43}$ pois, dessa forma, elimina-se a etapa da procura por um solvente que solubilize os precursores e os produtos formados. Geralmente, na síntese de polímeros, conforme ocorre a formação do produto, esse sai de fase, por não ser mais solúvel no solvente inicial, o que prejudica o rendimento da reação, por interferir no seu equilíbrio. ${ }^{12}$

A proposta da síntese de polímeros supramoleculares possibilita uma rota sintética com a mínima produção de resíduo, característica esperada e positiva para as propostas atuais.

Os materiais obtidos, assim como nas sínteses com utilização de solventes, são polímeros com baixa massa molar, ${ }^{12,43}$ sendo ainda necessária a formação de um prépolímero e uma segunda reação com os chamados extensores de cadeias, que gerarão as ligações intercruzadas. 


\subsection{CATÁLISE NA SÍNTESE DE POLIURETANAS (PUs) E POLIURETANAS LIVRES DE ISOCIANATO (NIPUS)}

A primeira síntese de PU realizada por Bayer, em 1947, foi uma reação com adição de poliois em poliisocianatos, na presença de catalisador. ${ }^{26,27}$

Os organometálicos e as aminas terciárias são os catalisadores mais utilizados em metodologias de sínteses que envolvem reações dos grupos diois com isocianato, ${ }^{47}$ porque são fortes nucleófilos que formam ligações entre os carbonos, após o ataque à carboxila.

O organometálico mais utilizado como catalisador na indústria polimérica é o dilaurato de dibutilestanho (DBTDL). O seu uso não é recomendado, devido à sua toxicidade e parte dele ficar na estrutura final do material polimérico sintetizado, além de gerar um grande volume de resíduo. Para o produto final, a presença deste metal na matriz polimérica dificulta o seu envelhecimento, logo a sua degradabilidade diminui. ${ }^{49}$

Com o crescente interesse por propostas metodológicas mais sustentáveis, que gerem menos resíduos, o metal dos catalisadores tem sido substituído por grupos orgânicos, como carbenos, tioureias e guanidinas. ${ }^{47}$ Esses catalisadores mostraram ser eficientes para as reações de polimerização, permitindo uma boa seletividade e rendimento. ${ }^{49,50}$

Comparativamente com o DBTDL, quando aminas terciárias são utilizadas para a catálise de PUs, como 1,4-diazabiciclo [2,2,2]octano (DABCO), 2,2bis(dimetilaminoetileter) (BDMAEE), ou outras aminas como 1,8diazabiciclo[5,4,0]undec-7-eno (DBU), ${ }^{49,51}$ não são obtidos bons rendimentos e alta seletividade. ${ }^{47-49,51}$

Industrialmente, com uma catálise lenta e não efetiva, é obtida uma mistura de monômeros, fazendo com que a reação não ocorra completamente, o que diminui o rendimento. $^{30}$

Em novas propostas metodológicas, a exemplo das sínteses das NIPUs e das que utilizam óleos vegetais como precursores, os conhecidos ácidos de Lewis são o tipo de catalisador escolhido. Eles agem como iniciadores da reação, ao realizar a ativação e orientação para o ataque à carboxila dos triglicerídeos. ${ }^{6,8,9,30}$ Com essa catálise a polimerização é do tipo catiônica, onde os ácidos que são eletrofilos fortes formam uma ligação covalente com os pares de elétrons livres, no caso em questão os do oxigênio da carboxila, ocorrendo uma reorganização de cargas que favorece o seu ataque. $^{30}$ 
Os haletos metálicos amplamente utilizados nesse mecanismo são cloreto de alumínio $\left(\mathrm{AlCl}_{3}\right)$, fluoreto de boro $\left(\mathrm{BF}_{3}\right)$, cloreto de estanho $\left(\mathrm{SnCl}_{4}\right)$, cloreto de antimônio $\left(\mathrm{SbCl}_{5}\right)$, cloreto de zinco $\left(\mathrm{ZnCl}_{2}\right)$, cloreto de titânio $\left(\mathrm{TiCl}_{4}\right)$ e também os ácidos de Lewis $\mathrm{RAICl}_{2}, \mathrm{R}_{2} \mathrm{AICl}$ e $\mathrm{R}_{3} \mathrm{Al}$ (em que $\mathrm{R}=$ grupo orgânico). ${ }^{6,8,9,30}$

A escolha do melhor ácido de Lewis para a síntese depende de dados empíricos. Porém, existem regras genéricas que preveem a força dos ácidos. Em geral, comparando-se diferentes metais, a força aumenta com o aumento do número atômico, pois há o aumento de número de orbitais, ou de níveis de energia, favorecendo uma sobreposição e uma interação mais efetiva entre o nucleófilo e o ácido de Lewis. ${ }^{30,31}$

O ácido de Lewis mais forte para a síntese polimérica é o fluoreto de antimônio $\left(\mathrm{SbF}_{5}\right)$, que não é amplamente utilizado industrialmente, por gerar uma polimerização quase que incontrolável, portanto produtos heterogêneos. ${ }^{28}$

Mesmo com a busca de sínteses que gerem menos resíduos, os catalisadores ainda continuam sendo para a indústria polimérica um desafio, pois poucas metodologias são desenvolvidas para a purificação desses materiais. ${ }^{6-12}$

No caso das PUs, que são insolúveis em muitos dos solventes comuns utilizados industrialmente, o que impede processos de efetiva purificação por extração, os catalisadores acabam ficando presos em sua matriz polimérica. ${ }^{43}$ 
Capítulo 3

PARTE EXPERIMENTAL 


\subsection{MATERIAIS}

\subsubsection{Reagentes}

O óleo de mamona (Ricinus communis L.) foi adquirido do Mundo dos óleos, ACQ \& GBM Comércio e Desenvolvimento Ltda. A ureia $\left(\mathrm{NH}_{2} \mathrm{CONH}_{2}\right) \mathrm{PA}, \mathrm{SnCl}_{2} 2 \mathrm{H}_{2} \mathrm{O} \mathrm{PA}$ e álcool etílico $\left(\mathrm{C}_{2} \mathrm{H}_{5} \mathrm{OH}\right) \quad 95 \%$ da Vetec Química fina Ltda. Acetato de zinco $\left[\left(\mathrm{CH}_{3} \mathrm{COO}\right)_{2} \mathrm{Zn} .2 \mathrm{H}_{2} \mathrm{O}\right] \mathrm{PA}$ e o cloreto de estanho $\left(\mathrm{SnCl}_{2} 2 \mathrm{H}_{2} \mathrm{O}\right)$ PA foram adquiridos da Quimex S. A. e o trifluoreto de boro $\left[\mathrm{BF}_{3}\left(\mathrm{Et}_{2} \mathrm{O}\right)\right]$ da Fluka.

\subsubsection{Equipamentos}

Para a preparação e caracterização dos materiais foram utilizados, além das vidrarias usuais de laboratório, os equipamentos listados a seguir.

- Agitador mecânico Caframo;

- Balança analítica Marte, modelo AY220;

- Bomba de vácuo Boekel, com pressão de 635 mmHg;

- Estufa Lab-line ${ }^{\circledR}$ Duo-Vac Oven, Lab-line Instruments, Inc.

- Analisador termogravimétrico Shimadzu, modelo DTG-60H;

- Calorímetro exploratório diferencial Shimadzu, modelo DSC-60;

- Calorímetro exploratório diferencial Shimadzu, modelo DSC-60A Plus;

- Espectrofotômetro de absorção na região do infravermelho com transformada de Fourier (FT-IR) Vertex 70 da Bruker Corporation;

- Espectrômetro de ressonância magnética nuclear (RMN) Varian 300 MHz, modelo Mercury Plus.

- Espectrômetro de ressonância magnética nuclear (RMN) Brucker 600 MHz, modelo Advance 3D.

\subsection{PREPARAÇÃO DAS PUS}

\subsubsection{Síntese com Utilização de Solvente}

As quatro primeiras sínteses foram realizadas com a utilização de solvente, etílico $\left(\mathrm{C}_{2} \mathrm{H}_{5} \mathrm{OH}\right)$, com o uso de um balão de duas bocas e condensador reto, agitação magnética e aquecimento em banho de óleo. O sistema foi montado de acordo com a Figura 15. 


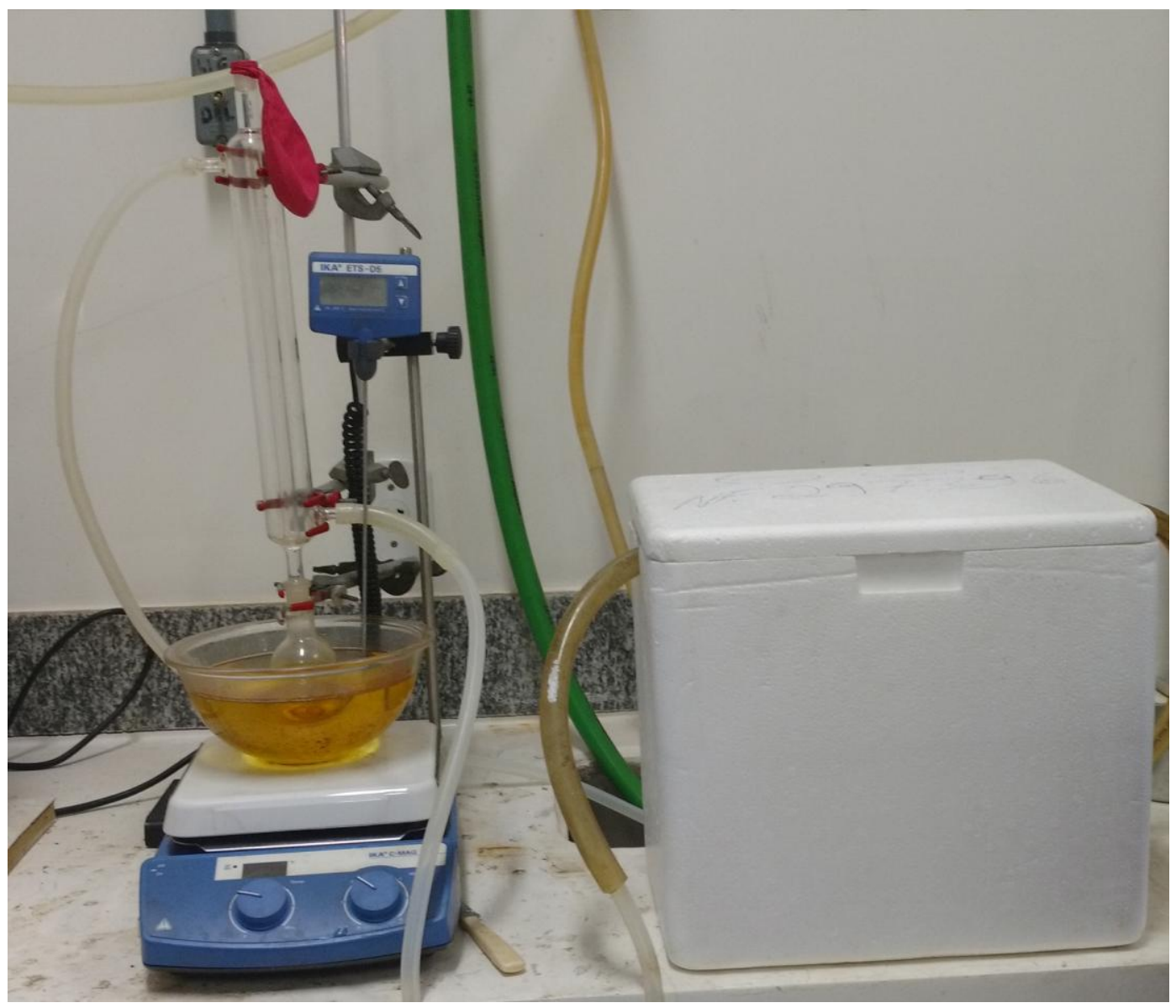

Figura 15. Imagem digital do sistema montado para a reação com a utilização de solvente.

Vários parâmetros foram testados, a fim de se obter a melhor condição da síntese do material polimérico. Os parâmetros estudados foram: tempo de reação, catalisador e a proporção utilizada de óleoureia, de acordo com a Figura 16. 


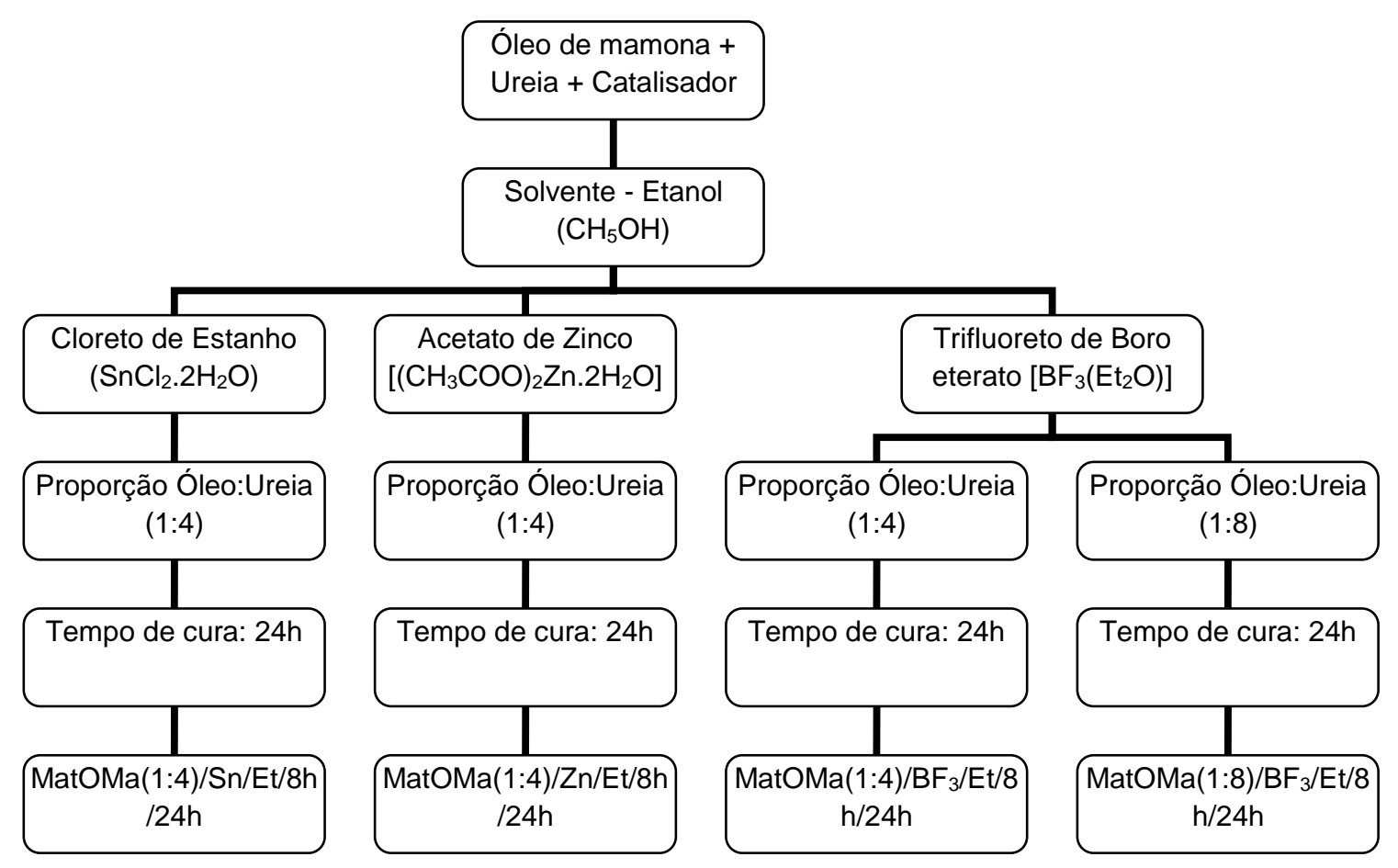

Figura 16. Fluxograma representativo das sínteses com a utilização de solvente.

A agitação magnética, utilizada na síntese dos materiais, foi realizada a uma temperatura de $120^{\circ} \mathrm{C}$ e a cura do material polimérico a $100 \stackrel{\circ}{ } \mathrm{C}$, por $24 \mathrm{~h}$.

A Tabela 3 apresenta as denominações dadas aos materiais obtidos com a utilização do etanol como solvente, nas sínteses, e suas descrições.

Tabela 3. Denominações dadas aos materiais obtidos, com a utilização do etanol, e suas descrições.

\section{Denominações}

MatOMa(1:4)/Zn/Et/8h/24h

$\operatorname{MatOMa}(1: 4) / \mathrm{Sn} / \mathrm{Et} / 8 \mathrm{~h} / 24 \mathrm{~h}$

$\operatorname{MatOMa}(1: 4) / \mathrm{BF}_{3} / \mathrm{Et} / 8 \mathrm{~h} / 24 \mathrm{~h}$

$\operatorname{MatOMa}(1: 8) / \mathrm{BF}_{3} / \mathrm{Et} / 8 \mathrm{~h} / 24 \mathrm{~h}$

\section{Descrição}

Material sintetizado com óleo de mamona e ureia, proporção molar de $1 \mathrm{~mol}$ de óleo para 4 mols de ureia, catalisador $\left(\mathrm{CH}_{3} \mathrm{COO}\right)_{2} \mathrm{Zn} .2 \mathrm{H}_{2} \mathrm{O}$, solvente etanol, $1 \mathrm{~h}$ de agitação e $24 \mathrm{~h}$ de cura.

Material sintetizado com óleo de mamona e ureia, proporção molar de $1 \mathrm{~mol}$ de óleo para 4 mols de ureia, catalisador $\mathrm{SnCl}_{2} .2 \mathrm{H}_{2} \mathrm{O}$, solvente etanol, $8 \mathrm{~h}$ de agitação e $24 \mathrm{~h}$ de cura.

Material sintetizado com óleo de mamona e ureia, proporção molar de $1 \mathrm{~mol}$ de óleo para 4 mols de ureia, catalisador $\mathrm{BF}_{3}\left(\mathrm{Et}_{2} \mathrm{O}\right)$, solvente etanol, $8 \mathrm{~h}$ de agitação e $24 \mathrm{~h}$ de cura.

Material sintetizado com óleo de mamona e ureia, proporção molar de $1 \mathrm{~mol}$ de óleo para 8 mols de ureia, catalisador $\mathrm{BF}_{3}\left(\mathrm{Et}_{2} \mathrm{O}\right)$, solvente etanol, $8 \mathrm{~h}$ de agitação e $24 \mathrm{~h}$ de cura. 
Para os materiais MatOMa(1:4)/Sn/Et/8h/24h e MatOMa(1:4)/Zn/Et/8h/24h sintetizados com $\mathrm{SnCl}_{2} 2 \mathrm{H}_{2} \mathrm{O}$ e $\left(\mathrm{CH}_{3} \mathrm{COO}\right)_{2} \mathrm{Zn} .2 \mathrm{H}_{2} \mathrm{O}$, respectivamente, foi utilizada a proporção de $10 \%(\mathrm{~m} / \mathrm{m})$ dos catalisadores, em relação à massa do óleo.

Nos materiais $\operatorname{MatOMa}(1: 4) / \mathrm{BF}_{3} / \mathrm{Et} / 8 \mathrm{~h} / 24 \mathrm{~h}, \quad \operatorname{MatOMa}(1: 8) / \mathrm{BF}_{3} / \mathrm{Et} / 8 \mathrm{~h} / 24 \mathrm{~h}$, catalisados com $\mathrm{BF}_{3}\left(\mathrm{Et}_{2} \mathrm{O}\right)$, foram utilizados $10 \%(\mathrm{~m} / \mathrm{v})$ do catalisador, em relação à massa de óleo.

Todos os materiais obtidos possuíam duas fases, uma sólida e uma líquida bastante viscosa, sendo a parte sólida formada por grânulos compactados e similares. As duas fases foram caracterizadas por FT-IR, enquanto a fase liquida foi caracterizada por $\mathrm{RMN}{ }^{1} \mathrm{H}$ e a fase sólida por $\mathrm{RMN}{ }^{13} \mathrm{C}$ em estado sólido.

\subsubsection{Síntese sem Utilização de Solvente}

As primeiras sínteses sem utilização de solvente foram realizadas em béquer de $25 \mathrm{~mL}$, com agitação mecânica (rotação de $2.000 \mathrm{rpm}$ ) e aquecimento em banho de óleo $\left(\mathrm{T}=70^{\circ} \mathrm{C}\right)$, conforme aparato apresentado na Figura 17.

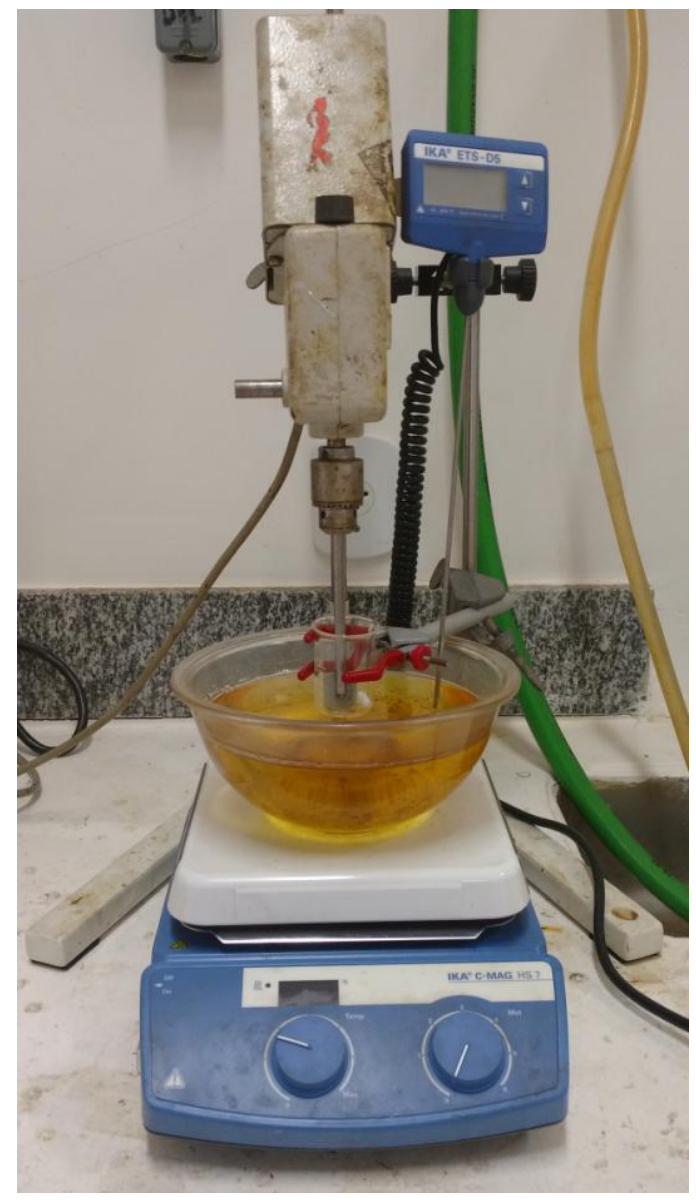

Figura 17. Imagem digital do sistema montado para a reação sem utilização de solvente. 
As sínteses seguintes foram realizadas de acordo com o observado nas primeiras, que indicaram a viabilidade da eliminação do solvente, com êxito na reação e formação do produto esperado.

Os parâmetros tempo de reação, catalisador e a proporção óleo:ureia foram testados, a fim de se obter a melhor condição para a síntese do material polimérico (Figuras 18 e 19).

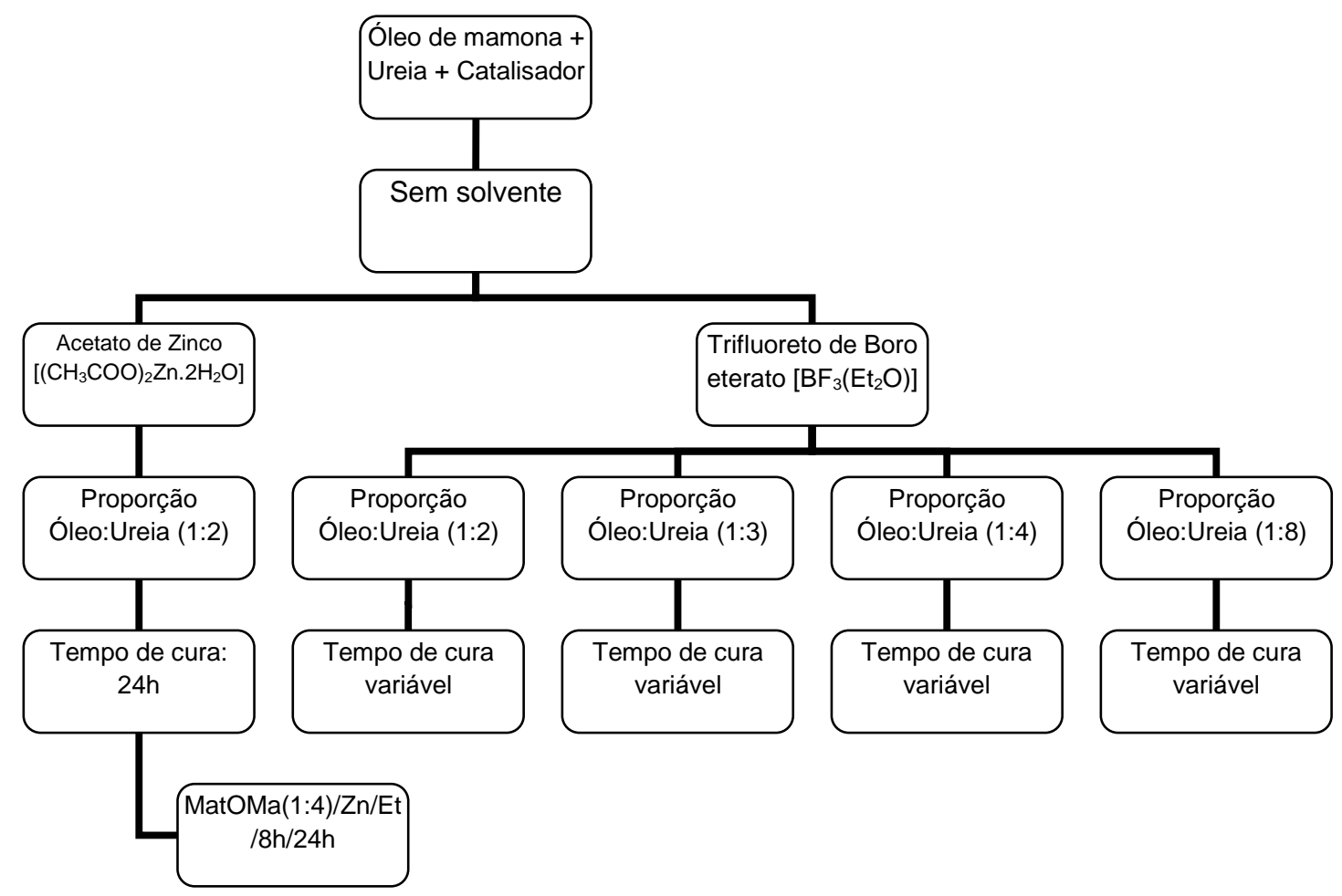

Figura 18. Fluxograma representativo das sínteses sem a utilização de solvente, usando dois diferentes catalisadores. 


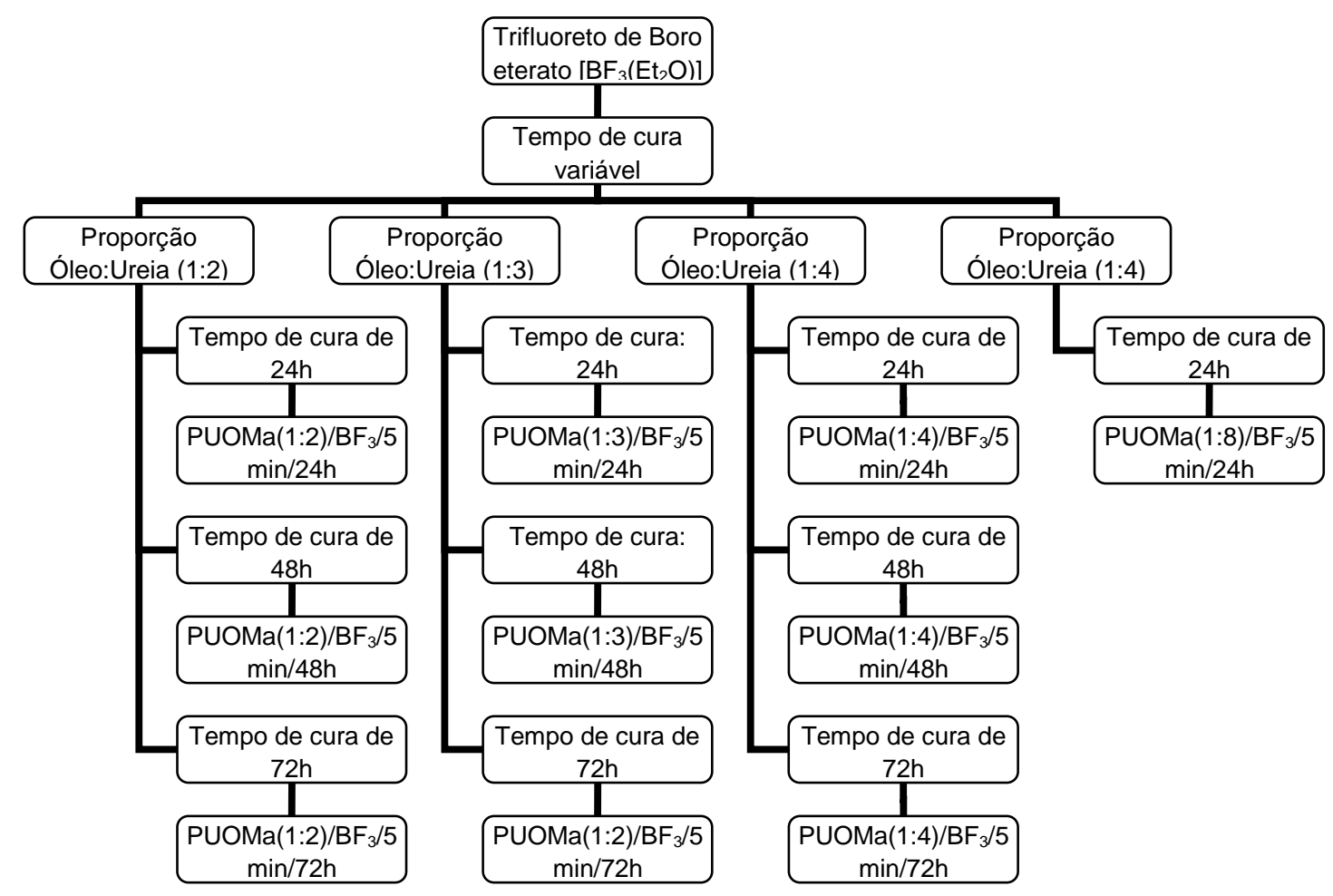

Figura 19. Fluxograma representativo das sínteses sem a utilização de solvente, usando o $\mathrm{BF}_{3}\left(\mathrm{Et}_{2} \mathrm{O}\right)$ e variando a proporção óleo:ureia e o tempo de cura.

As denominações dadas aos materiais obtidos sem a utilização do etanol, nas sínteses, e suas descrições estão listadas na Tabela 4. 
Tabela 4. Denominações dadas aos materiais obtidos, sem a utilização do etanol, e suas descrições.

\begin{tabular}{|c|c|}
\hline Denominações & Descrição \\
\hline $\mathrm{PUOMa}(1: 2) / \mathrm{BF}_{3} / 5 \mathrm{~min} / 24 \mathrm{~h}$ & $\begin{array}{l}\text { Poli(acil-uretana) de óleo de mamona e ureia, proporção de } 1 \mathrm{~mol} \text { de } \\
\text { óleo para } 2 \text { mols de ureia, catalisador } \mathrm{BF}_{3}\left(\mathrm{Et}_{2} \mathrm{O}\right) \text {, sem solvente, } 5 \mathrm{~min} \\
\text { de agitação e } 24 \mathrm{~h} \text { de cura. }\end{array}$ \\
\hline $\mathrm{PUOMa}(1: 3) / \mathrm{BF}_{3} / 5 \mathrm{~min} / 24 \mathrm{~h}$ & $\begin{array}{l}\text { Poli(acil-uretana) de óleo de mamona e ureia, proporção de } 1 \mathrm{~mol} \text { de } \\
\text { óleo para } 3 \text { mols de ureia, catalisador } \mathrm{BF}_{3}\left(\mathrm{Et}_{2} \mathrm{O}\right) \text {, sem solvente, } 5 \mathrm{~min} \\
\text { de agitação e } 24 \mathrm{~h} \text { de cura. }\end{array}$ \\
\hline $\mathrm{PUOMa}(1: 4) / \mathrm{BF}_{3} / 5 \mathrm{~min} / 24 \mathrm{~h}$ & $\begin{array}{l}\text { Poli(acil-uretana) de óleo de mamona e ureia, proporção de } 1 \mathrm{~mol} \text { de } \\
\text { óleo para } 4 \text { mols de ureia, catalisador } \mathrm{BF}_{3}\left(\mathrm{Et}_{2} \mathrm{O}\right) \text {, sem solvente, } 5 \mathrm{~min} \\
\text { de agitação e } 24 \mathrm{~h} \text { de cura. }\end{array}$ \\
\hline $\mathrm{PUOMa}(1: 8) / \mathrm{BF}_{3} / 5 \mathrm{~min} / 24 \mathrm{~h}$ & $\begin{array}{l}\text { Poli(acil-uretana) de óleo de mamona e ureia, proporção de } 1 \mathrm{~mol} \text { de } \\
\text { óleo para } 8 \text { mols de ureia, catalisador } \mathrm{BF}_{3}\left(\mathrm{Et}_{2} \mathrm{O}\right) \text {, sem solvente, } 5 \mathrm{~min} \\
\text { de agitação e } 24 \text { h de cura. }\end{array}$ \\
\hline PUOMa(1:2)/BF $/ 5 \mathrm{~min} / 48 \mathrm{~h}$ & $\begin{array}{l}\text { Poli(acil-uretana) de óleo de mamona e ureia, proporção de } 1 \text { mol de } \\
\text { óleo para } 2 \text { mols de ureia, catalisador } \mathrm{BF}_{3}\left(\mathrm{Et}_{2} \mathrm{O}\right) \text {, sem solvente, } 5 \mathrm{~min} \\
\text { de agitação e } 48 \mathrm{~h} \text { de cura. }\end{array}$ \\
\hline $\mathrm{PUOMa}(1: 3) / \mathrm{BF}_{3} / 5 \mathrm{~min} / 48 \mathrm{~h}$ & $\begin{array}{l}\text { Poli(acil-uretana) de óleo de mamona e ureia, proporção de } 1 \mathrm{~mol} \text { de } \\
\text { óleo para } 3 \text { mols de ureia, catalisador } \mathrm{BF}_{3}\left(\mathrm{Et}_{2} \mathrm{O}\right) \text {, sem solvente, } 5 \mathrm{~min} \\
\text { de agitação e } 48 \mathrm{~h} \text { de cura. }\end{array}$ \\
\hline $\mathrm{PUOMa}(1: 4) / \mathrm{BF}_{3} / 5 \mathrm{~min} / 48 \mathrm{~h}$ & $\begin{array}{l}\text { Poli(acil-uretana) de óleo de mamona e ureia, proporção de } 1 \mathrm{~mol} \text { de } \\
\text { óleo para } 4 \text { mols de ureia, catalisador } \mathrm{BF}_{3}\left(\mathrm{Et}_{2} \mathrm{O}\right) \text {, sem solvente, } 5 \mathrm{~min} \\
\text { de agitação e } 48 \mathrm{~h} \text { de cura. }\end{array}$ \\
\hline $\mathrm{PUOMa}(1: 2) / \mathrm{BF}_{3} / 5 \mathrm{~min} / 72 \mathrm{~h}$ & $\begin{array}{l}\text { Poli(acil-uretana) de óleo de mamona e ureia, proporção de } 1 \text { mol de } \\
\text { óleo para } 2 \text { mols de ureia, catalisador } \mathrm{BF}_{3}\left(\mathrm{Et}_{2} \mathrm{O}\right) \text {, sem solvente, } 5 \mathrm{~min} \\
\text { de agitação e } 72 \mathrm{~h} \text { de cura. }\end{array}$ \\
\hline $\mathrm{PUOMa}(1: 3) / \mathrm{BF}_{3} / 5 \mathrm{~min} / 72 \mathrm{~h}$ & $\begin{array}{l}\text { Poli(acil-uretana) de óleo de mamona e ureia, proporção de } 1 \mathrm{~mol} \text { de } \\
\text { óleo para } 3 \text { mols de ureia, catalisador } \mathrm{BF}_{3}\left(\mathrm{Et}_{2} \mathrm{O}\right) \text {, sem solvente, } 5 \mathrm{~min} \\
\text { de agitação e } 72 \mathrm{~h} \text { de cura. }\end{array}$ \\
\hline $\mathrm{PUOMa}(1: 4) / \mathrm{BF}_{3} / 5 \mathrm{~min} / 72 \mathrm{~h}$ & $\begin{array}{l}\text { Poli(acil-uretana) de óleo de mamona e ureia, proporção de } 1 \mathrm{~mol} \text { de } \\
\text { óleo para } 4 \text { mols de ureia, catalisador } \mathrm{BF}_{3}\left(\mathrm{Et}_{2} \mathrm{O}\right) \text {, sem solvente, } 5 \mathrm{~min} \\
\text { de agitação e } 72 \mathrm{~h} \text { de cura. }\end{array}$ \\
\hline PUOMa(1:2)/Zn/1h/24h & $\begin{array}{l}\text { Poli(acil-uretana) de óleo de mamona e ureia, proporção de } 1 \text { mol de } \\
\text { óleo para } 2 \text { mols de ureia, catalisador }\left(\mathrm{CH}_{3} \mathrm{COO}\right)_{2} \mathrm{Zn} .2 \mathrm{H}_{2} \mathrm{O} \text {, sem } \\
\text { solvente, } 1 \mathrm{~h} \text { de agitação e } 24 \mathrm{~h} \text { de cura. }\end{array}$ \\
\hline PUOMa(1:2)/Zn/4h/24h & $\begin{array}{l}\text { Poli(acil-uretana) de óleo de mamona e ureia, proporção de } 1 \text { mol de } \\
\text { óleo para } 2 \text { mols de ureia, catalisador }\left(\mathrm{CH}_{3} \mathrm{COO}\right)_{2} \mathrm{Zn} .2 \mathrm{H}_{2} \mathrm{O} \text {, sem } \\
\text { solvente, } 4 \text { h de agitação e } 24 \mathrm{~h} \text { de cura. }\end{array}$ \\
\hline
\end{tabular}

Em todas as reações foi usada agitação mecânica (rotação de 2.000 rpm), com aquecimento a $70{ }^{\circ} \mathrm{C}$, durante $5 \mathrm{~min}$, e temperatura de cura de $100^{\circ} \mathrm{C}$, em diferentes 
tempos. Para a reação de cura, o material polimérico foi colocado em uma placa de Teflon $^{\circledR}$.

Nos materiais PUOMa(1:2)/BF $/ 5 \mathrm{~min} / 24 \mathrm{~h}, \quad \mathrm{PUOMa}(1: 2) / \mathrm{BF}_{3} / 5 \mathrm{~min} / 48 \mathrm{~h}$, $\mathrm{PUOMa}(1: 2) / \mathrm{BF}_{3} / 5 \mathrm{~min} / 72 \mathrm{~h}, \mathrm{PUOMa}(1: 3) / \mathrm{BF}_{3} / 5 \mathrm{~min} / 24 \mathrm{~h}, \mathrm{PUOMa}(1: 3) / \mathrm{BF}_{3} / 5 \mathrm{~min} / 48 \mathrm{~h}, \mathrm{PU}$ $\mathrm{OMa}(1: 3) / \mathrm{BF}_{3} / 5 \mathrm{~min} / 72 \mathrm{~h}, \mathrm{PUOMa}(1: 4) / \mathrm{BF}_{3} / 5 \mathrm{~min} / 24 \mathrm{~h}, \mathrm{PUOMa}(1: 4) / \mathrm{BF}_{3} / 5 \mathrm{~min} / 48 \mathrm{~h}$, PUOMa(1:4)/BF $/ 5 \min / 72 \mathrm{~h}$, para cada proporção (1:2, 1:3 e 1:4) foram utilizados três tempos distintos de cura (24, 48 e 72 h), para observar a cinética das reações em estudo.

Os materiais obtidos apresentaram uma coloração amarelada e foram caracterizados por FT-IR, termogravimetria (TG), calorimetria exploratória diferencial (DSC) e $R M N ~{ }^{13} \mathrm{C}$, no estado sólido, embora somente alguns materiais tenham sido analisados por DSC e RMN ${ }^{13} \mathrm{C}$, no estado sólido. Todos os materiais foram mantidos a vácuo, para minimizar mudanças nas suas propriedades físico-químicas.

Além desses materiais obtidos a partir do OMa, sem a utilização do etanol, na síntese, foi feita uma reação usando óleo de maracujá e ureia, na proporção molar de 1 mol de óleo para 2 mols de ureia, sem uso de solvente, com o catalisador $\mathrm{BF}_{3}\left(\mathrm{Et}_{2} \mathrm{O}\right)$, $1 \mathrm{~h}$ de agitação e $24 \mathrm{~h}$ de cura e foi denominado MatOmaracujá(1:2)/BF $/ 1 \mathrm{~h} / 24 \mathrm{~h}$ e caracterizado por FT-IR e RMN ${ }^{1} \mathrm{H}$. Esse material foi preparado apenas para confirmar o mecanismo proposto, neste trabalho, da reação a partir do OMa com a ureia.

\subsection{CARACTERIZAÇÃO DOS MATERIAIS}

As técnicas utilizadas para caracterização do OMa, da ureia, dos catalisadores e dos materiais poliméricos obtidos estão listadas a seguir.

\subsubsection{Espectroscopia na Região do Infravermelho com Transformada de Fourier} (FT-IR)

Os espectros FT-IR foram obtidos por ATR (Attenuated Total Reflectance), no espectrômetro Vertex 70 da Bruker Corporation (região $4000-400 \mathrm{~cm}^{-1}$ ), no Laboratório de Espectroscopia Óptica do Instituto de Física da UnB.

\subsubsection{Ressonância Magnética Nuclear de Hidrogênio ( $\left.R M N^{1} H\right)$}

O espectro RMN ${ }^{1} \mathrm{H}$ do OMa foi adquirido em um espectrômetro Varian $300 \mathrm{MHz}$, modelo Mercury Plus, na Central Analítica do Instituto de Química da UnB. Para a análise, a amostra foi solubilizada em clorofórmio deuterado $\left(\mathrm{CDCl}_{3}\right)$ e foi utilizado trimetilsilano $(\delta T M S=0,0)$ como padrão interno. $O$ espectro foi obtido com frequência de ressonância de $300 \mathrm{MHz}$, intervalo entre os pulsos de $1 \mathrm{~s}$ e 16 varreduras. Os 
sinais FID (free induction decay) foram processados no software ACD/NMR Processor Academic Edition.

\subsubsection{Ressonância Magnética Nuclear de Carbono (RMN ${ }^{13} \mathrm{C}$ )}

O espectro RMN ${ }^{13} \mathrm{C}$ do OMa foi adquirido em um espectrômetro Varian $300 \mathrm{MHz}$, modelo Mercury Plus, na Central Analítica do Instituto de Química da UnB. Para a análise, a amostra foi solubilizada em clorofórmio deuterado $\left(\mathrm{CDCl}_{3}\right)$ e foi utilizado trimetilsilano $(\delta T M S=0,0)$ como padrão interno.

$\mathrm{O}$ espectro de $\mathrm{RMN}{ }^{13} \mathrm{C}$ do polímero $\mathrm{PUOMa}(1: 2) / \mathrm{BF}_{3} / 5 \mathrm{~min} / 72 \mathrm{~h}$ foi obtido pelo espectrômetro RMN da Bruker $600 \mathrm{MHz}$, modelo Advance 3D na Central Analítica do Instituto de Química da UnB. A amostra foi solubilizada pelo solvente tetrahidrofurano deuterado (THF-d8) $\left(\delta_{\text {TMS }}=25,0\right)$ O espectro foi obtido com frequência de ressonância de $150 \mathrm{MHz}$, intervalo entre os pulsos de $1 \mathrm{~s}$ e 64 varreduras.

Os sinais FID (free induction decay) foram processados no software ACD/NMR Processor Academic Edition.

\subsubsection{RMN ${ }^{13} \mathrm{C}$ no Estado Sólido}

Os materiais MatOMa(1:4)/Zn/Et/8h/24h, MatOMa(1:4)/Sn/Et/8h/24h e PUOMa(1:2)/BF $/ 5 \mathrm{~min} / 24 \mathrm{~h}$ foram analisados por $\mathrm{RMN}{ }^{13} \mathrm{C}$, no estado sólido, com polarização cruzada (CP) e rotação no ângulo mágico (MAS). O experimento foi conduzido em um espectrômetro RMN da Bruker $600 \mathrm{MHz}$, modelo Advanced 3D, equipado com um rotor de zircônio de $5 \mathrm{~mm}$ de diâmetro, com frequências de ressonância igual a $600 \mathrm{MHz}$ para $0{ }^{13} \mathrm{C}$, hexametilbenzeno $(\mathrm{HMB})$ foi utilizado como padrão interno. O espectro foi adquirido com tempo de contato de $4 \mathrm{~ms}$; tempo relaxação de $1 \mathrm{~s}$; tempo de aquisição de $0,05 \mathrm{~s}$ e velocidade de $10 \mathrm{kHz}$. Para o processamento dos dados foi utilizado o programa ACD Labs (1D NMR processor).

\subsubsection{Termogravimetria (TG)/Termogravimetria Derivada (DTG)}

As curvas TG e DTG dos materiais analisados para investigação da estabilidade térmica foram adquiridas em um analisador termogravimétrico Shimadzu, Modelo DTG-60H, no Laboratório Multiusuários II do IQ-UnB. Cerca de $6 \mathrm{mg}$ de cada amostra foram pesados em cela de platina e os ensaios foram realizados em atmosfera de nitrogênio $\left(30 \mathrm{~mL} \mathrm{~min}^{-1}\right)$, com taxa de aquecimento de $10{ }^{\circ} \mathrm{C} \mathrm{min}^{-1}$, da temperatura ambiente até $750{ }^{\circ} \mathrm{C}$. As temperaturas em que a velocidade de decomposição da amostra é máxima $\left(T_{d}\right)$ foram obtidas pelas curvas de termogravimetria derivada (DTG). As propriedades térmicas foram calculadas com a ajuda do software TA-60 (Shimadzu). 


\subsubsection{Calorimetria Exploratória Diferencial (DSC)}

As análises calorimétricas da ureia e dos materiais MatOMa(1:4)/Zn/Et/8h/24h e

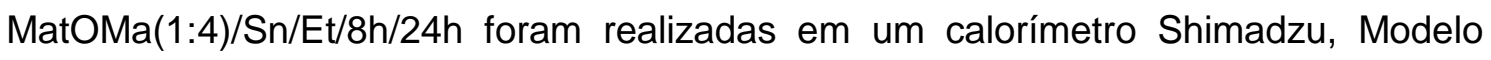
DSC-60, no Laboratório Multiusuários II do IQ-UnB. Cerca de $6 \mathrm{mg}$ de cada amostra foram acondicionados em celas de alumínio fechadas. As amostras foram resfriadas com nitrogênio líquido a $-100^{\circ} \mathrm{C}$ e, em seguida, aquecidas até $150{ }^{\circ} \mathrm{C}$, a $10^{\circ} \mathrm{C} \mathrm{min}^{-1}$, em atmosfera de hélio $\left(50 \mathrm{~mL} \mathrm{~min}^{-1}\right)$. Das duas varreduras feitas para cada amostra, foi considerada a segunda para obtenção das transições termodinâmicas. As transições termodinâmicas foram obtidas usando o software TA-60 (Shimadzu).

As medidas calorimétricas dos materiais $\mathrm{PUOMa}(1: 2) / \mathrm{BF}_{3} / 5 \mathrm{~min} / 24 \mathrm{~h}$, PUOMa(1:2)/BF $/ 5 \mathrm{~min} / 48 \mathrm{~h}$ e PUOMa(1:2)/BF $/ 5 \mathrm{~min} / 72 \mathrm{~h}$ foram feitas em um calorímetro Shimadzu, modelo DSC-60A Plus, no Laboratório de Cromatografia do Instituto de Geociências da Universidade Federal do Pará (UFPA). As amostras (aproximadamente, $3 \mathrm{mg}$ ), em cadinho de alumínio, foram analisadas, utilizando uma faixa de temperatura de -140 a $200 \stackrel{\circ}{\circ}$, com taxa de aquecimento de $10 \stackrel{\circ}{\circ} \min ^{-1} \mathrm{e}$ fluxo de nitrogênio de $100 \mathrm{~mL} \mathrm{~min}{ }^{-1}$. A aquisição dos dados e seu tratamento foram realizados no software TA60, versão 2.21 , também da Shimadzu.

\subsubsection{Absorção de Água}

Amostras de $1 \mathrm{~cm}^{2}$ dos materiais poliméricos foram mantidas a vácuo, até massa constante. As amostras foram, em seguida, condicionadas em dessecador de vidro com solução aquosa saturada de $\mathrm{Mg}\left(\mathrm{NO}_{3}\right)_{2} \cdot 6 \mathrm{H}_{2} \mathrm{O}$ (53\% de umidade relativa), de acordo com a norma ASTM E 10478. A massa das amostras foi pesada em sucessivos intervalos de tempo até atingir o equilíbrio. A quantidade de água absorvida foi calculada pela Equação 1:

$$
\% A=\left(\frac{M_{t}-M_{0}}{M_{0}}\right) \times 100
$$

Onde, $M_{t}$ e $M_{0}$ são as massas da amostra após um tempo "t" de exposição a um ambiente com umidade relativa controlada e antes da exposição ao referido ambiente, respectivamente.

Além disso, o coeficiente de difusão da água foi determinado de acordo com a Equação 2:

$$
\left(\frac{M_{t}-M_{0}}{M_{\infty}}\right)=\frac{2}{L}\left(\frac{D}{\pi}\right)^{1 / 2} t^{1 / 2}
$$


Onde, $M_{\infty}$ é a massa de água absorvida no equilíbrio, $L$ é a espessura do filme polimérico e D é o coeficiente de difusão.

\subsubsection{Cromatografia de Exclusão por Tamanho ou Cromatografia de Permeação em Gel (GPC)}

A cromatografia de permeação em gel (GPC) se baseia na separação de moléculas de acordo com os diferentes tamanhos das suas cadeias. É uma análise amplamente utilizada para análise de macromoléculas, por fornecer a informação da distribuição de massas molares (DMM).

A DMM (Equação 3) é dada pela razão entre a massa molar ponderal média $\left(\overline{M_{w}}\right)$ e a massa molar numérica média $\left(\overline{M_{n}}\right)$, ambas determinadas por GPC..$^{3,51,52}$

$$
D M M=\frac{\overline{M_{w}}}{\overline{M_{n}}}
$$

O GPC foi utilizado para analisar as curvas da distribuição de massas molares das poli(acil-uretanas), onde os valores de $\overline{M_{w}}$ e $\overline{M_{n}}$ foram determinados, utilizando um um cromatógrafo Shimadzu LC-20A equipado com um detector de índice de refração (RID-10A) utilizando o solvente tetrahidrofurano como fase móvel. As análises foram realizadas à temperatura de $40{ }^{\circ} \mathrm{C}$ e com fluxo de solvente de $1 \mathrm{~mL} \mathrm{~min}^{-1}$. Para a análise foi injetado, por meio do injetor automático, $100 \mu \mathrm{L}$ de uma solução obtida a partir das poli(acil-uretanas) a $1 \%(\mathrm{~m} / \mathrm{m})$ diluído com o mesmo solvente da fase móvel. A fase estacionária utilizada era constituída por três colunas (300 mm x $8 \mathrm{~mm}$ ) em série (GPC-803, GPC-804 e GPC-805). O poliestireno, com uma faixa de massa molar entre 2.500 e $1.355 .000 \mathrm{~g} \mathrm{~mol}^{-1}$, foi utilizado como padrão para realizar os cálculos das massas molares médias e da massa molar das amostras. 
Capítulo 4

RESULTADOS E DISCUSSÕES 


\subsection{CARACTERIZAÇÃO DO ÓLEO DE MAMONA E DA UREIA}

Para a caracterização estrutural, dos materiais de partida, foi utilizada inicialmente a espectroscopia no FT-IR. Na Figura 20, que apresenta o espectro FT-IR do OMa, é possível observar bandas características de absorção de óleos vegetais. Em 3400 $\mathrm{cm}^{-1}$, o estiramento característico de ligação $\mathrm{O}-\mathrm{H}$ dos grupos hidroxilas; próximo a $3013 \mathrm{~cm}^{-1}$, o estiramento de ligação entre carbono $\mathrm{sp}^{2}$ e hidrogênio $(=\mathrm{C}-\mathrm{H})$; em 2930 $\mathrm{cm}^{-1}$ e $2860 \mathrm{~cm}^{-1}$, o estiramento de ligação do carbono $\mathrm{sp}^{3}$ com hidrogênio $(\mathrm{C}-\mathrm{H})$; além do estiramento em $1740 \mathrm{~cm}^{-1}$ característico de carboxila de éster. Essas e outras atribuições das bandas do espectro FT-IR do OMa estão descritas na Tabela 5.

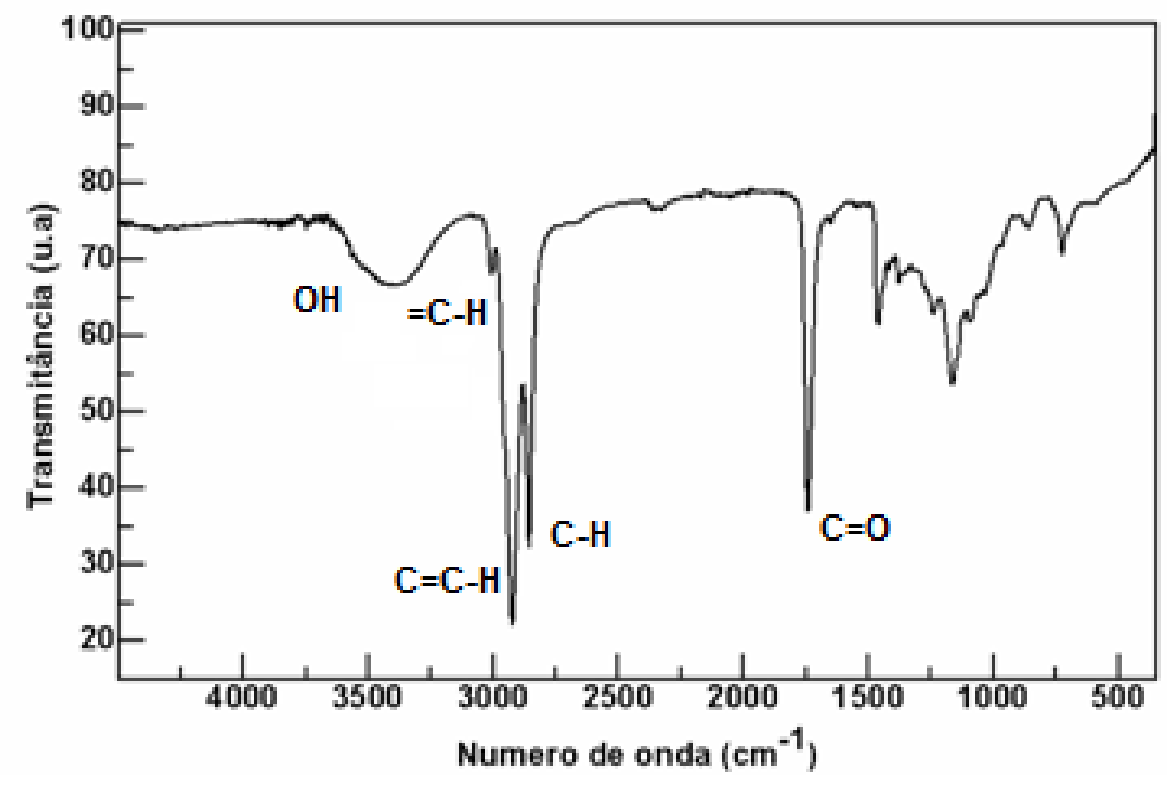

Figura 20. Espectro FT-IR do OMa.

Tabela 5. Principais bandas de absorção no FTIR para o OMa, com suas respectivas atribuições. $^{54,55}$

\begin{tabular}{cc}
\hline Número de onda $\left.\mathbf{( c m}^{1}\right)$ & Atribuições \\
\hline 3400 & Estiramento simétrico $\mathrm{OH}$ \\
3009 & Estiramento $\mathrm{C}-\mathrm{H}$ da ligação dupla $($ cis $)=\mathrm{C}-\mathrm{H}$ \\
2955 & Estiramento assimétrico $\mathrm{CH}_{3}$ \\
2924 & Estiramento assimétrico $\mathrm{CH}_{2}$ \\
2854 & Estiramento simétrico $\mathrm{CH}_{2}$ \\
1746 & Estiramento do grupo $\mathrm{C}=\mathrm{O}$ de éster \\
1651 & Estiramento $\mathrm{C}=\mathrm{C}($ cis $)$ \\
1463 & Deformação de $\mathrm{CH}_{2}$ e $\mathrm{CH}_{3}$ alifáticos \\
1377 & Deformação simétrica de $\mathrm{CH}_{3}$ \\
1230 & Deformação de $\mathrm{CH}_{2}$ \\
1163 & Deformação assimétrica C-O \\
721 & Deformação de $\mathrm{CH}_{2}$
\end{tabular}


O espectro FT-IR da ureia é mostrado na Figura 21, onde são observados dois estiramentos que a caracterizam, próximos a $3436 \mathrm{~cm}^{-1}$ e $3340 \mathrm{~cm}^{-1}$, relacionados à ligação C-NH característica de amidas primárias, e a deformação de N-H, em 1590 $\mathrm{cm}^{-1}$, além de carboxila de ureia com estiramento em $1670 \mathrm{~cm}^{-1}$.

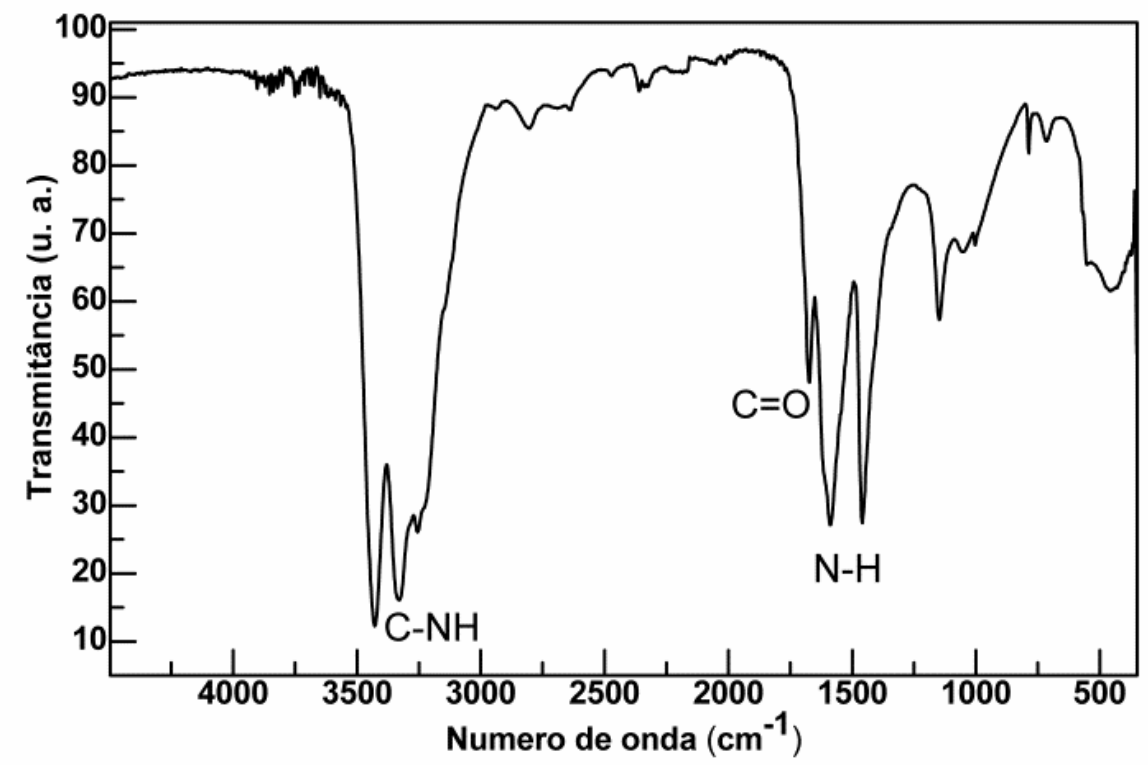

Figura 21. Espectro no FT-IR da ureia.

A espectroscopia de RMN é uma técnica de extrema importância para a elucidação estrutural dos materiais de partida, ampliando a confiabilidade dos materiais obtidos pelas reações posteriores.

$\mathrm{Na}$ Tabela 6, estão listados os sinais dos prótons característicos dos óleos vegetais que serão elucidados nas Figuras 22 e 23.

Tabela 6. Deslocamentos químicos de $\mathrm{RMN}{ }^{1} \mathrm{H}$ característicos de um espectro de óleo vegetal. ${ }^{54}$

\begin{tabular}{ccc}
\hline $\begin{array}{c}\text { Descolamento } \\
\text { químico (ppm) }\end{array}$ & Próton & $\begin{array}{c}\text { Referência estrutural } \\
\text { das Figuras } \mathbf{1 9} \text { e 20 }\end{array}$ \\
\hline 0,97 & $\mathrm{CH}_{3} \mathrm{CH}_{2} \mathrm{CH}=\mathrm{CH}$ & $\mathrm{I}$ \\
$1,20-1,30$ & $\mathrm{CH}_{2}$ & $\mathrm{H}$ \\
1,60 & $\mathrm{CH}_{2} \mathrm{CH}_{2} \mathrm{C}=\mathrm{O}$ & $\mathrm{G}$ \\
2,00 & $\mathrm{CH}_{2} \mathrm{CH}=\mathrm{CH}$ & $\mathrm{E}$ \\
2,30 & $\mathrm{CH}_{2} \mathrm{C}=\mathrm{O}$ & $\mathrm{D}$ \\
2,80 & $\mathrm{CH}=\mathrm{CHCH} \mathrm{CH}_{2} \mathrm{OH}$ & $\mathrm{J}$ \\
3,5 & $\mathrm{CH}-\mathrm{OH}$ & $\mathrm{C}$ \\
$4,10-4,30$ & $\mathrm{~B}$ \\
5,25 & $\mathrm{CH}_{2} \mathrm{OCOR}_{(\text {metilênicos do glicerol })}$ & $\mathrm{A}$ \\
$5,30-5,40$ & $\mathrm{CH}_{2} \mathrm{CHCH}_{2}($ metínico do glicerol $)$ &
\end{tabular}




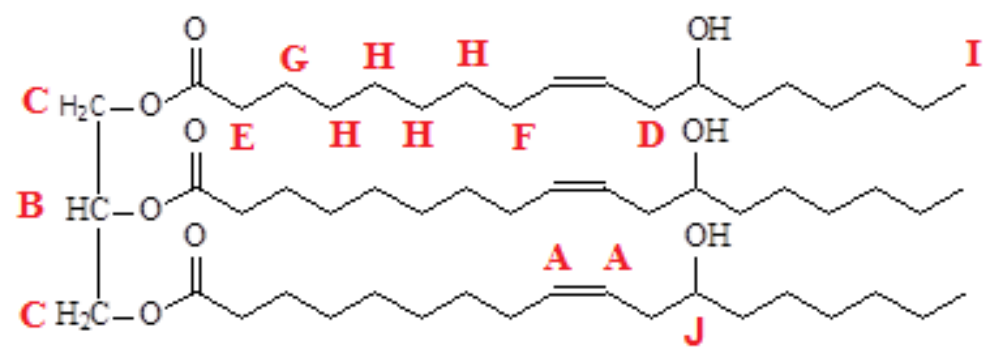

Figura 22. Estrutura do ácido ricinoleico.

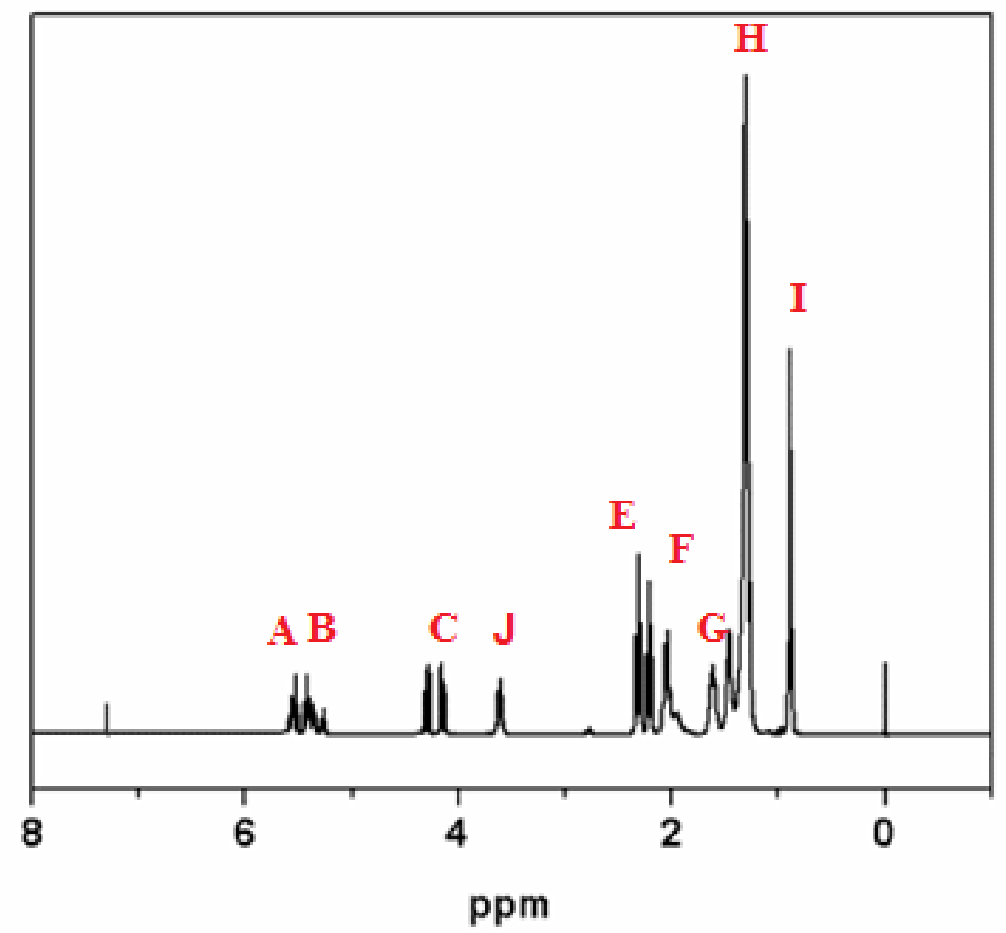

Figura 23. Espectro de RMN ${ }^{1} \mathrm{H}$ do OMa com identificação dos seus sinais.

De acordo com os dados apresentados nas Figuras 20, 21, 22 e 23, a estrutura do OMa, um dos materiais iniciais da síntese, está confirmada.

O OMa e a ureia também foram caracterizados por TG e DTG. Nas curvas TG e DTG do OMa (Figura 21), observa-se que ele apresenta apenas uma etapa de decomposição térmica e uma boa estabilidade térmica, tendo em vista que sua $T_{\text {onset }}$ é próxima de $348{ }^{\circ} \mathrm{C}$. A curva DTG do OMa mostra que reações se sobrepõem nesta única etapa de decomposição. Estas reações que se sobrepõem são relacionadas à decomposição dos ácidos graxos insaturados, dos ácidos graxos saturados e das cadeias carbônicas. ${ }^{3,55} \mathrm{O}$ valor da $\mathrm{T}_{\mathrm{d}}$ da reação é próximo a $390{ }^{\circ} \mathrm{C}$ e a decomposição total gerou uma perda de massa de $95 \%$. Então, os dados mostram que o OMa tem 
uma boa estabilidade térmica e essa estabilidade está relacionada à sua estrutura triglicerídea.

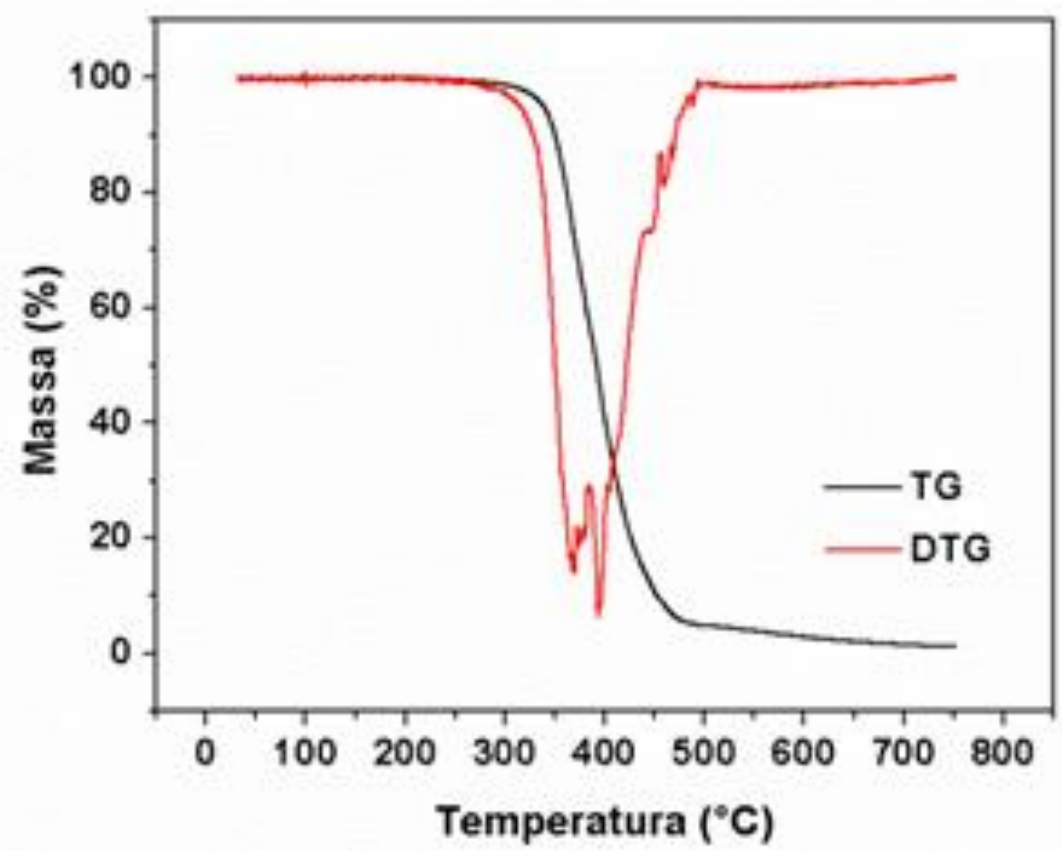

Figura 24. Curvas TG e DTG do OMa.

A decomposição térmica da ureia é mostrada nas curvas TG e DTG da Figura 25, onde é possível observar três etapas. Na primeira, a $T_{d}$ está próxima de $225^{\circ} \mathrm{C}$ e é seguida por uma pequena decomposição, que pode estar associada a uma decomposição secundária dessa primeira etapa. A terceira ocorre com $T_{d}$ em $335^{\circ} \mathrm{C}$. A primeira etapa é a mais expressiva e é relacionada à perda de $\mathrm{NH}_{3}$, enquanto a terceira etapa representa a decomposição do material restante, visto que a curva TG foi realizada com a ureia a seco, não existindo água presente para a formação de algum subproduto diferente. ${ }^{57,58} \mathrm{Na}$ curva DTG da ureia (em vermelho) (Figura 25), as três etapas são vistas com mais evidência. 


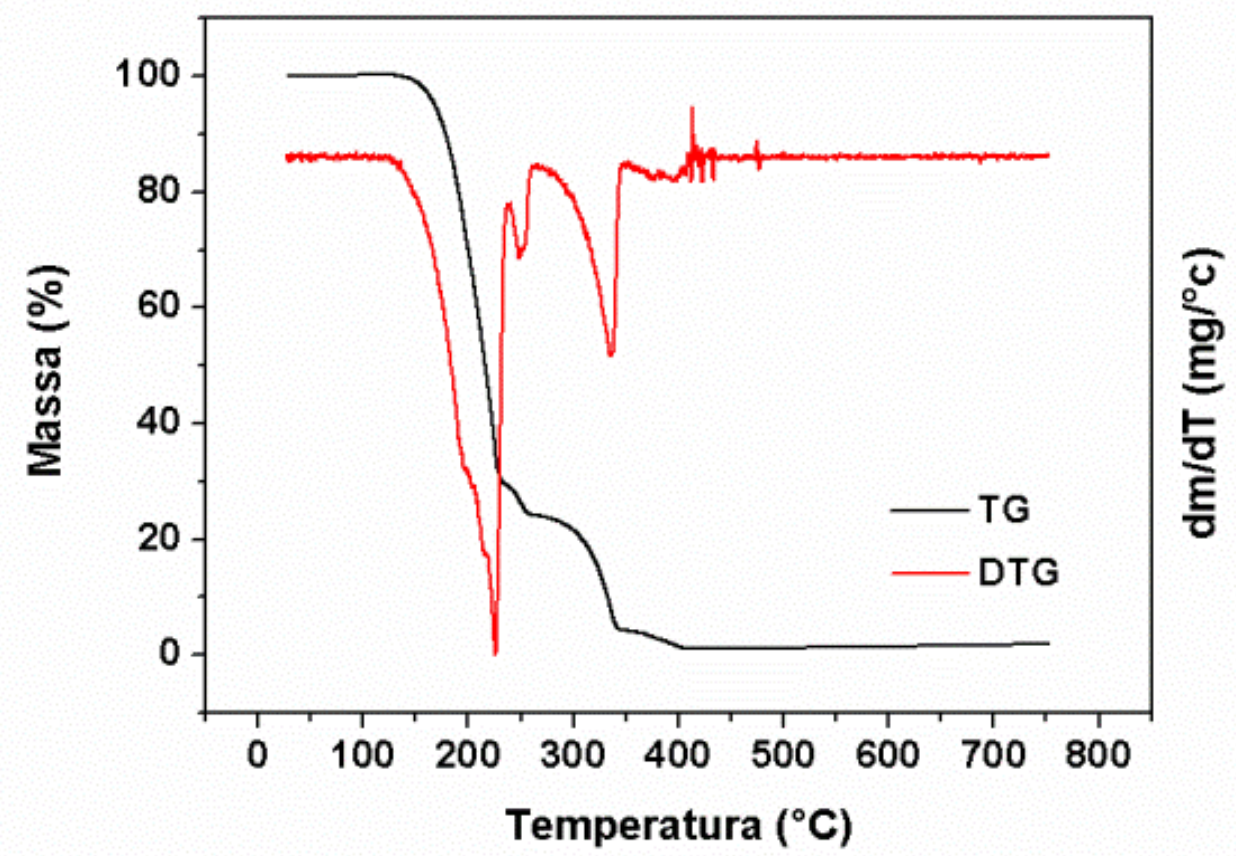

Figura 25. Curvas TG e DTG da ureia.

A ureia foi analisada por DSC e sua curva (Figura 26) apresenta uma transição termodinâmica endotérmica, entre $109^{\circ} \mathrm{C}$ e $136{ }^{\circ} \mathrm{C}$, característica da sua fusão. ${ }^{56} \mathrm{~A} \mathrm{~T}_{\mathrm{m}}$ da ureia nessa curva tem um valor de $130^{\circ} \mathrm{C}$ e corresponde com o valor descrito na literatura. ${ }^{59}$

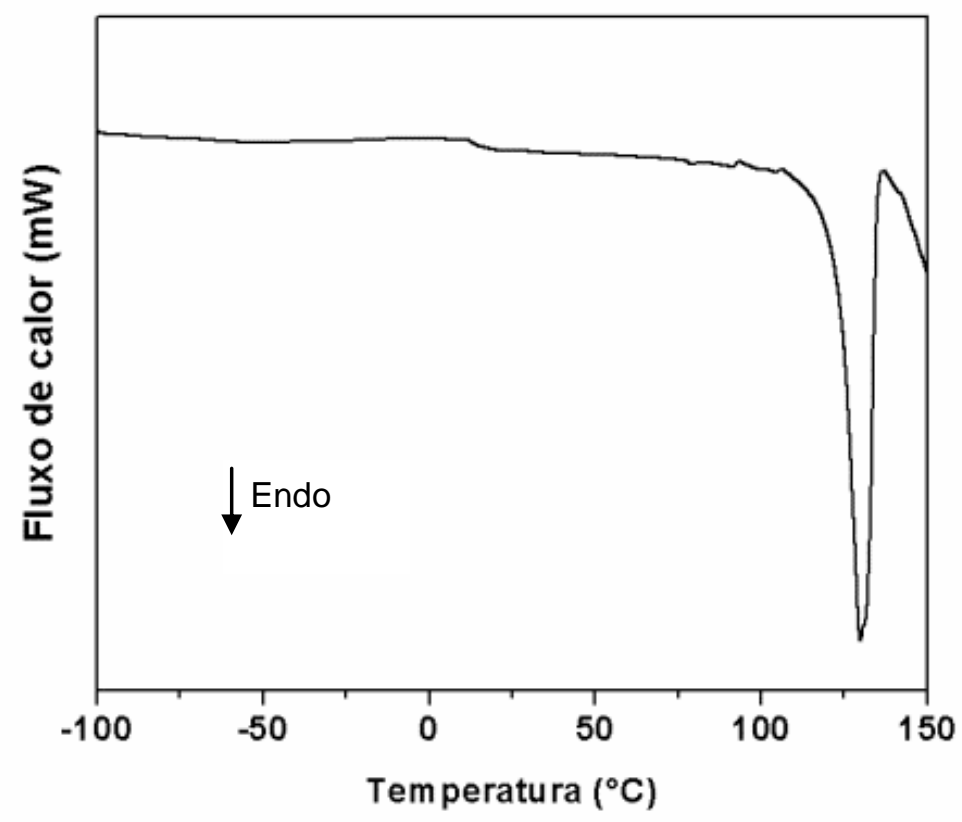

Figura 26. Curva DSC da ureia. 


\subsection{SÍNTESE COM A UTILIZAÇÃO DE SOLVENTE}

Conforme dito no item 3.2.1, todos os materiais obtidos com a utilização do etanol, na síntese, possuíam duas fases, uma sólida e uma líquida bastante viscosa, sendo a parte sólida formada por grânulos compactados e similares.

A Figura 27 apresenta os espectros FT-IR da parte líquida e sólida da reação de obtenção do material MatOMa(1:4)/Zn/Et/8h/24h. É possível observar no espetro FTIR da parte líquida bastante similaridade dos picos de absorção com os do OMa (Figura 20), o que sugere que a parte líquida resultante da reação corresponde ao OMa que não reagiu.

No entanto, é observado grande mudança nos picos de absorção no espectro do material MatOMa(1:4)/Zn/Et/8h/24h. Há a presença do estiramento de ligação de C$\mathrm{NH}$ característico de amida primária em $3400 \mathrm{~cm}^{-1}$, que se sobrepõe aos picos de carbono $\mathrm{sp}^{3}$ em $2920 \mathrm{~cm}^{-1}$ e $2860 \mathrm{~cm}^{-1}$, ocorre o aparecimento do estiramento em $2200 \mathrm{~cm}^{-1}$, referente à formação de estiramento $\mathrm{N}=\mathrm{C}=\mathrm{O}$, a deformação em $1590 \mathrm{~cm}^{-1}$ característico da ligação $(\mathrm{N}-\mathrm{H})$ de amida primária, além do deslocamento da carbonila, que no liquido é em $1740 \mathrm{~cm}^{-1}$, característico de carboxila de éster, e no solido pode ser observada em $1650 \mathrm{~cm}^{-1}$, característico de amida.

$\mathrm{O}$ aparecimento do estiramento $\mathrm{N}=\mathrm{C}=\mathrm{O}$ pode indicar que ocorreu uma modificação na estrutura da ureia, resultado da reação com o acido ricínoleico. Com isso pode-se inferir que ocorre uma reação, porém incompleta, tendo em vista a quantidade de OMa residual, indicando que alguns dos seus parâmetros deve ser modificado. 


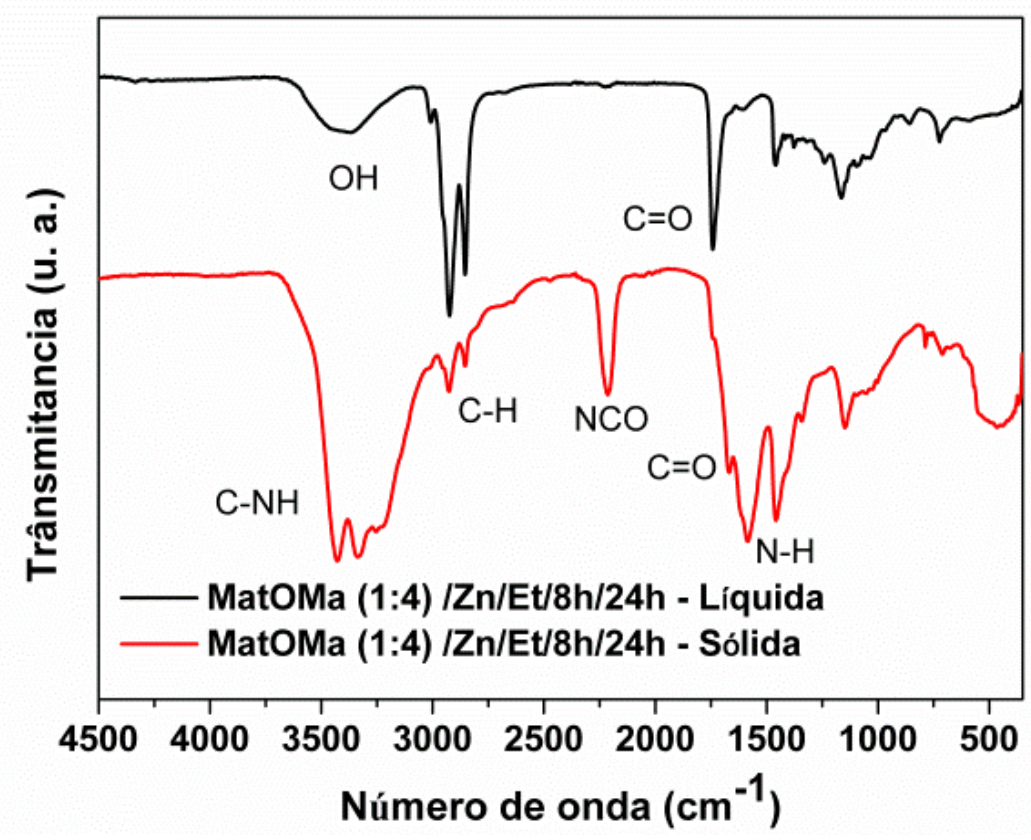

Figura 27. Espectros no FT-IR da amostra MatOMa(1:4)/Zn/Et/8h/24h, fases liquida e sólida.

Foi então substituído o catalisador $\left(\mathrm{CH}_{3} \mathrm{COO}\right)_{2} \mathrm{Zn} .2 \mathrm{H}_{2} \mathrm{O}$ por $\mathrm{SnCl}_{2} 2 \mathrm{H}_{2} \mathrm{O}$ com o intuito de observar a sua influencia no sucesso da síntese. Na Figura 28, apresentamse os espectros dos dois materiais obtidos com os dois catalisadores. Pode-se perceber que os dois materiais apresentam espectros similares, exceto pela ausência da absorção em $2200 \mathrm{~cm}^{-1}$, referente à formação estiramento característico estiramento $\mathrm{N}=\mathrm{C}=\mathrm{O}$, no espectro $\mathrm{FT}-\mathrm{IR}$ do produto obtido usando o $\mathrm{SnCl}_{2} 2 \mathrm{H}_{2} \mathrm{O}$, sugerindo que o catalisador influencia na síntese dos materiais.

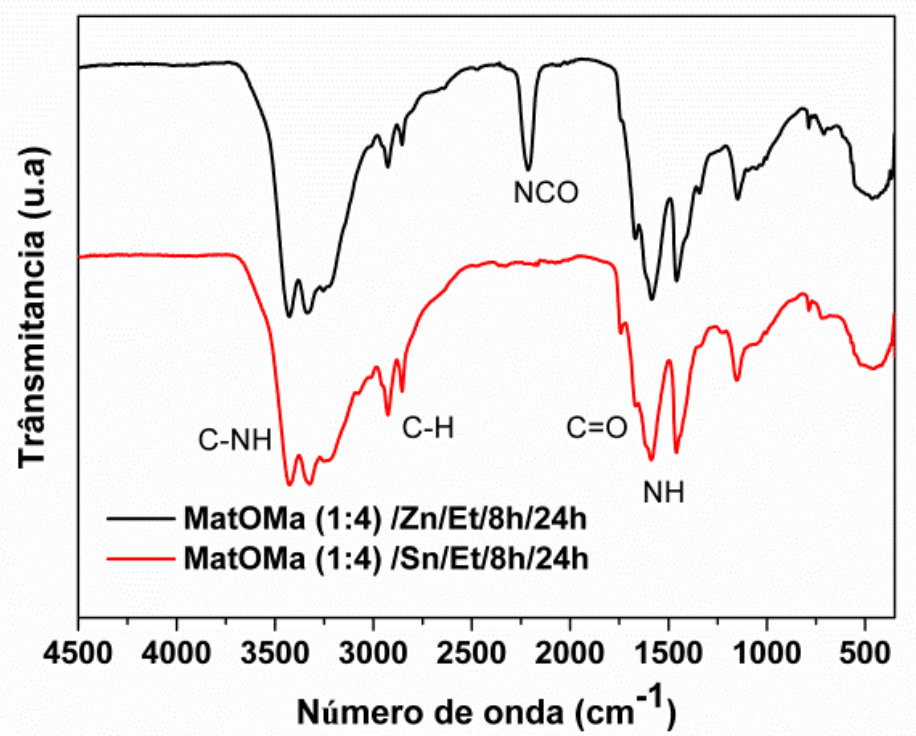

Figura 28. Espectro no FT-IR da parte sólida das amostras MatOMa(1:4)/Zn/Et/8h/24h e $\operatorname{MatOMa}(1: 4) / \mathrm{Sn} / \mathrm{Et} / 8 \mathrm{~h} / 24 \mathrm{~h}$. 
Ainda sob a perspectiva de investigar a influência do catalisador na síntese, optouse pela utilização do $\mathrm{BF}_{3}\left(\mathrm{Et}_{2} \mathrm{O}\right)$, considerando ser esse um ácido de Lewis mais forte que os demais. Na primeira síntese com esse catalisador, foram usadas as mesmas condições das reações anteriores, resultando no material MatOMa(1:4)/BF $3 / \mathrm{Et} / 8 \mathrm{~h} / 24 \mathrm{~h}$ e feito o seu espectro FT-IR (Figura 29), onde foram observadas mudanças nas bandas de absorção, em relação aos materiais obtidos com os catalisadores $\left(\mathrm{CH}_{3} \mathrm{COO}\right)_{2} \mathrm{Zn} .2 \mathrm{H}_{2} \mathrm{O}$ e $\mathrm{SnCl}_{2} 2 \mathrm{H}_{2} \mathrm{O}$. Em função disso, foi realizada uma nova síntese aumentando a quantidade de ureia, com o intuito de favorecer a reação, obtendo-se o material MatOMa(1:8)/BF $/ \mathrm{BF}_{3} / 8 \mathrm{~h} / 24 \mathrm{~h}$. Na Figura 29, estão apresentados os dois espectros FT-IR dos materiais obtidos com o catalisador $\mathrm{BF}_{3}\left(\mathrm{Et}_{2} \mathrm{O}\right)$, nas proporções OMa:ureia de 1:4 e 1:8, respectivamente.

Foram observadas nítidas mudanças nas bandas de absorção no FT-IR, em relação aos espectros da Figura 28, quais sejam: estiramento em $3300 \mathrm{~cm}^{-1}$, característico de ligação $\mathrm{C}-\mathrm{NH}$ de amida secundária; estiramento da carbonila de amida em $1650 \mathrm{~cm}^{-1}$ e deformação $\mathrm{N}-\mathrm{H}$ em $1612 \mathrm{~cm}^{-1}$. Também, percebe-se que uma quantidade maior de ureia gera absorções mais definidas, sugerindo que a ureia interfere na ação do $\mathrm{BF}_{3}\left(\mathrm{Et}_{2} \mathrm{O}\right)$.

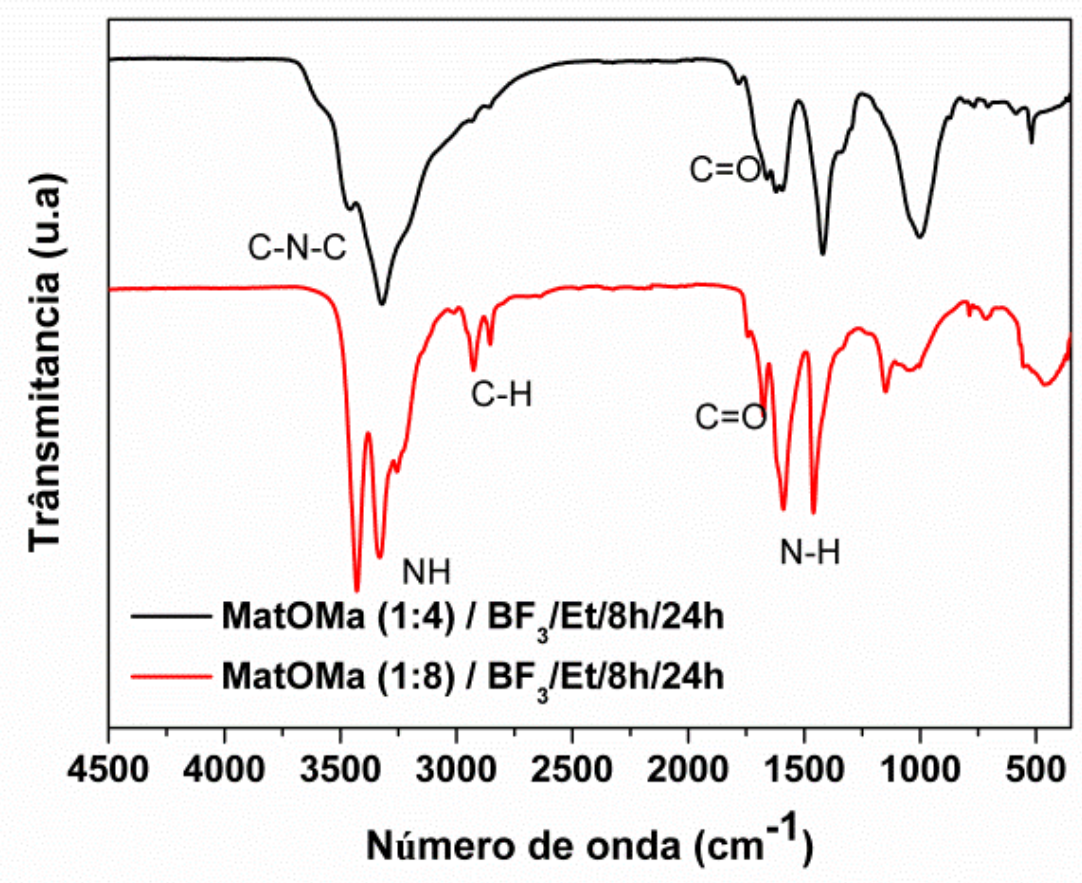

Figura 29. Espectros no FT-IR da parte sólida das amostras MatOMa(1:4)/BF $3 / \mathrm{Et}^{2} / 8 \mathrm{~h} / 24 \mathrm{~h}$ e $\mathrm{MatOMa}(1: 8) / \mathrm{BF}_{3} / \mathrm{Et} / 8 \mathrm{~h} / 24 \mathrm{~h}$.

A parte líquida do produto da reação, usando $\mathrm{BF}_{3}\left(\mathrm{Et}_{2} \mathrm{O}\right)$, foi analisada por $\mathrm{RMN}{ }^{1} \mathrm{H}$ e, comparando-se o seu espectro (Figura 30) com o do OMa (Figura 23), percebe-se 
uma similaridade nos sinais o que permite deduzir que o líquido remanescente da síntese do $\mathrm{MatOMa}(1: 4) / \mathrm{BF}_{3} / \mathrm{Et} / 8 \mathrm{~h} / 24 \mathrm{~h}$ não reagiu, existindo, portanto, uma quantidade considerável de óleo residual.

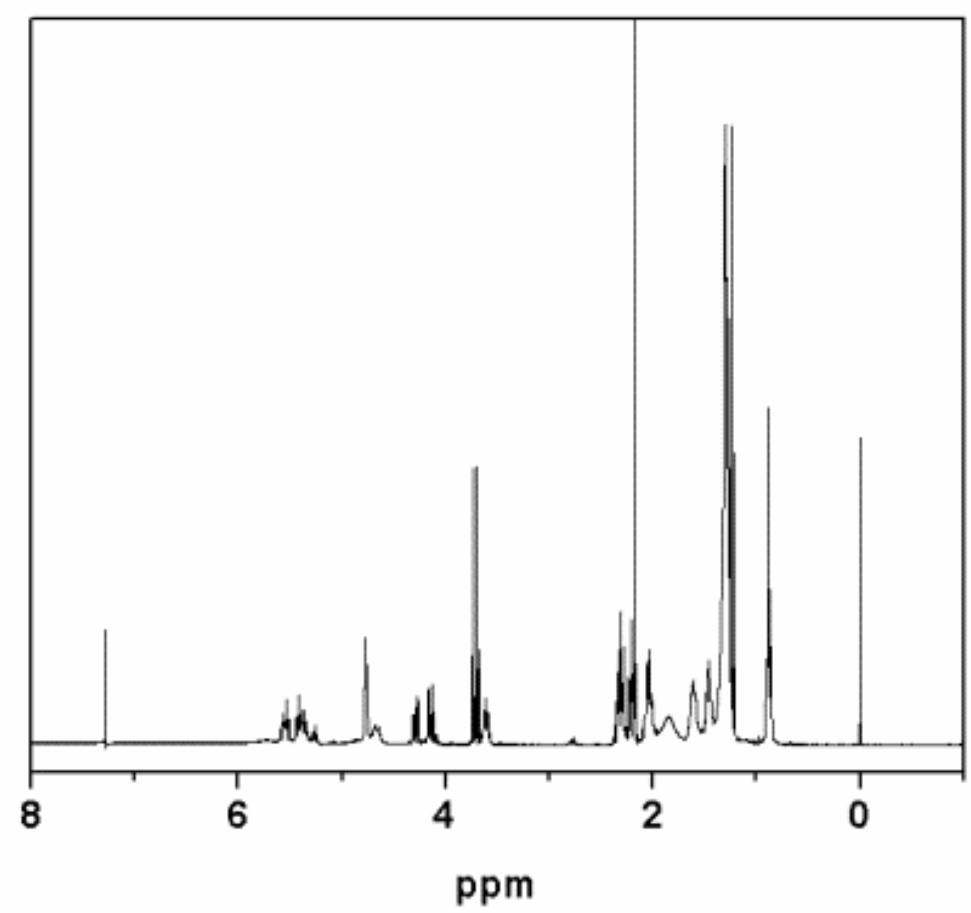

Figura 30. Espectro de $\mathrm{RMN}^{1} \mathrm{H}$ da parte liquida da amostra MatOMa(1:4)/BF $/ \mathrm{Et} / 8 \mathrm{~h} / 24 \mathrm{~h}$.

A técnica de $\mathrm{RMN}{ }^{13} \mathrm{C}$, no estado sólido, foi utilizada para analisar as amostras $\mathrm{MatOMa}(1: 4) / \mathrm{Zn} / \mathrm{Et} / 8 \mathrm{~h} / 24 \mathrm{~h}$ e MatOMa(1:4)/Sn/Et/8h/24h (Figuras 31 e 32). Verifica-se, no espectro da Figura 31, dois picos próximos a 157 ppm e 163 ppm, característicos do grupo carbamato e ureia, respectivamente, além de picos sobrepostos na região entre 16 e 39 ppm, característicos dos carbonos $\mathrm{sp}^{3}$ da cadeia do óleo, de acordo com a literatura. ${ }^{54,55}$

$\mathrm{O}$ espectro RMN ${ }^{13} \mathrm{C}$, no estado sólido, de MatOMa(1:4)/Sn/Et/8h/24h (Figura 32) apresenta apenas um pico próximo de 163 ppm, região típica de carbonila de amida da ureia. Então, é possível afirmar que a reação entre o óleo e a ureia, utilizando o catalisador $\mathrm{SnCl}_{2} 2 \mathrm{H}_{2} \mathrm{O}$, ocorreu em pouca extensão e que o sólido analisado possuía ainda grande quantidade de ureia em sua composição. Portanto, a catálise do $\left(\mathrm{CH}_{3} \mathrm{COO}\right)_{2} \mathrm{Zn} .2 \mathrm{H}_{2} \mathrm{O}$ se mostrou mais viável, comparada à do $\mathrm{SnCl}_{2} .2 \mathrm{H}_{2} \mathrm{O}$. 


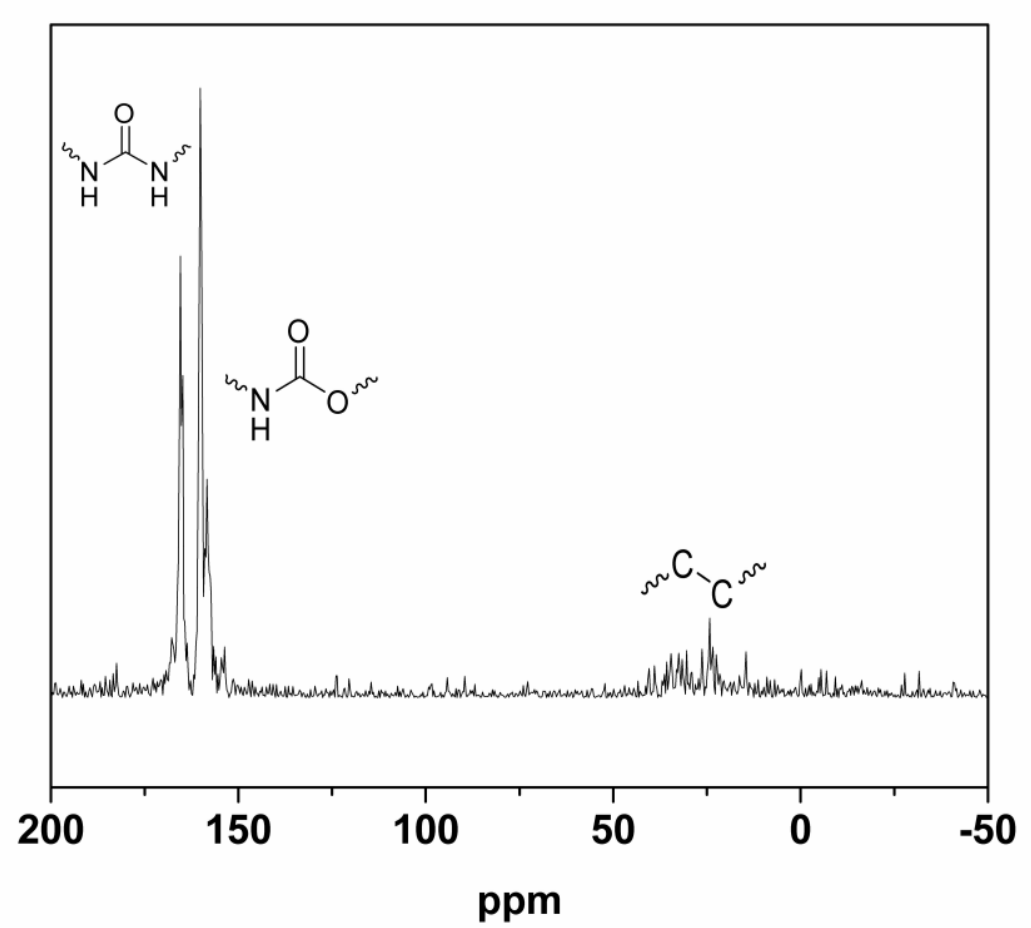

Figura 31. Espectro de CP/MAS RMN ${ }^{13} \mathrm{C}$, no estado sólido, da amostra $\mathrm{MatOMa}(1: 4) / \mathrm{Zn} / \mathrm{Et} / 8 \mathrm{~h} / 24 \mathrm{~h}$.

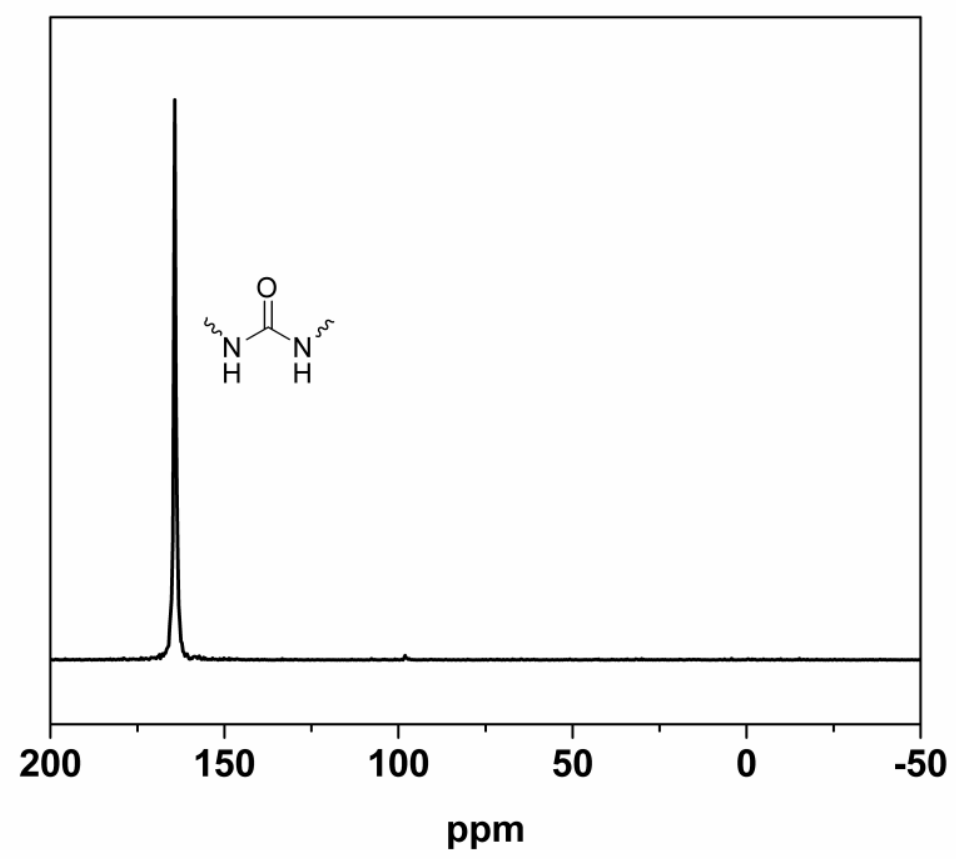

Figura 32. Espectro de CP/MAS RMN ${ }^{13} \mathrm{C}$, no estado sólido, da amostra $\mathrm{MatOMa}(1: 4) / \mathrm{Sn} / \mathrm{Et} / 8 \mathrm{~h} / 24 \mathrm{~h}$.

Para a caracterização das propriedades térmicas, foram realizadas as análises de TG e DTG das amostras MatOMa(1:4)/Zn/Et/8h/24h, MatOMa(1:4)/Sn/Et/8h/24h, 
MatOMa(1:4)/BF $/ \mathrm{Et} / 8 \mathrm{~h} / 24 \mathrm{~h}$ e MatOMa(1:8)/BF $/ \mathrm{Et}_{3} / 8 \mathrm{~h} / 24 \mathrm{~h}$, e suas curvas TG e DTG estão exibidas nas Figuras 33 e 34. Percebe-se que todas as curvas TG dos materiais apresentam duas etapas principais de decomposição térmica e na Tabela 7 estão reportados os valores das $T_{d} s$ das duas etapas e das suas respectivas perdas de massa. Os valores próximos das $T_{d} S$ dos diferentes materiais sugerem que eles possuem uma estabilidade térmica similar.
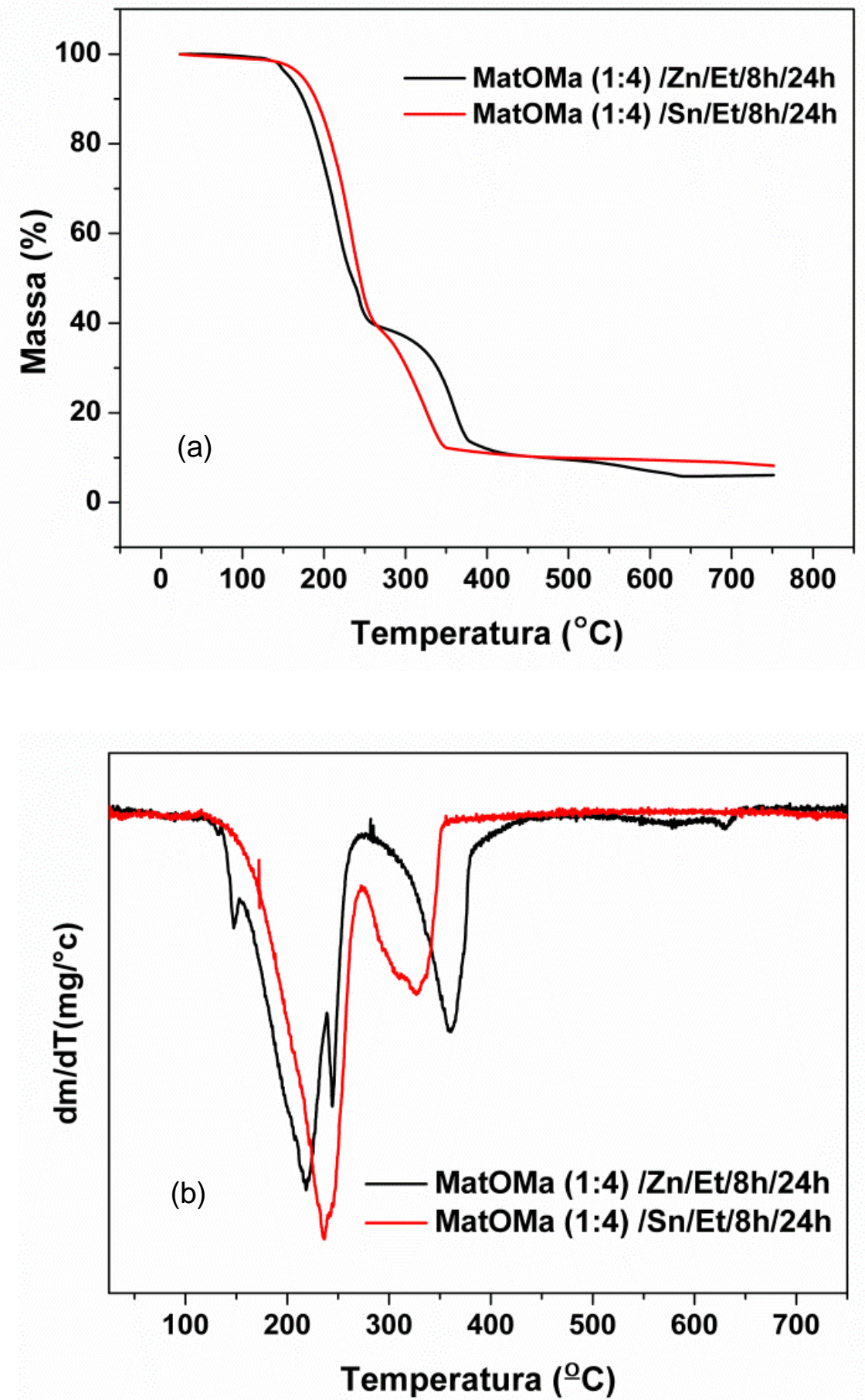

Figura 33. Curvas (a) TG e (b) DTG da parte sólida das amostras MatOMa(1:4)/Zn/Et/8h/24h e $\mathrm{MatOMa}(1: 4) / \mathrm{Sn} / \mathrm{Et} / 8 \mathrm{~h} / 24 \mathrm{~h}$. 

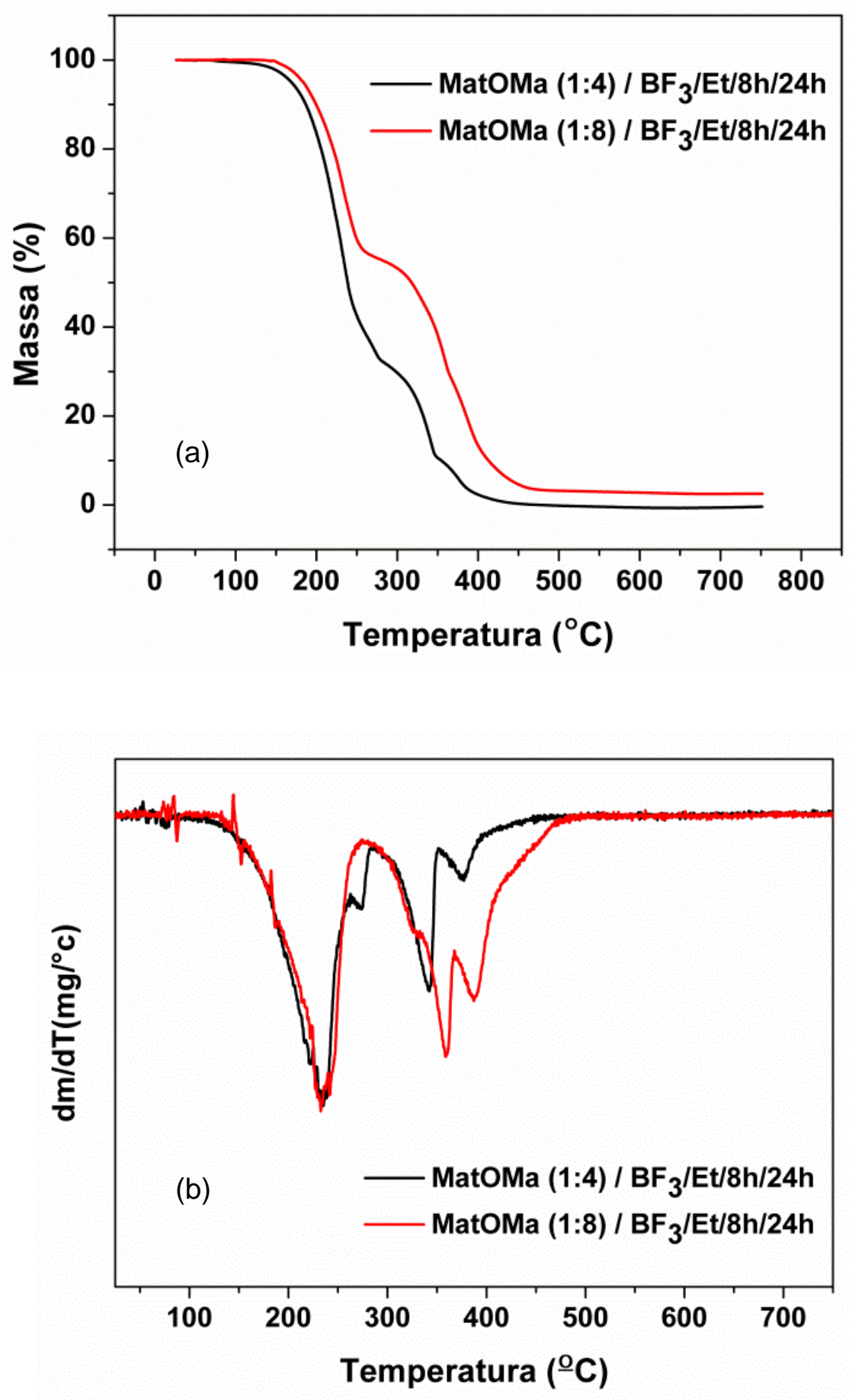

Figura 34. Curvas (a) TG e (b) DTG da parte sólida das amostras MatOMa(1:4)/BF $/ \mathrm{Et}^{\mathrm{t}} / 8 \mathrm{~h} / 24 \mathrm{~h}$ e MatOMa(1:8)/BF $/ \mathrm{Et} / 8 \mathrm{~h} / 24 \mathrm{~h}$.

Realizando uma análise do $T_{\text {onset }}$ dos materiais até então obtidos (Figura 35), percebe-se que sua estabilidade térmica é próxima à estabilidade térmica da ureia, sugerindo que o OMa reage até uma certa quantidade não tem influência na estabilidade térmica dos produtos formados. Além disso, a mudança do catalisador gera um incremento de $50{ }^{\circ} \mathrm{C}$, aproximadamente, na estabilidade térmica dos materiais sintetizados usando $\mathrm{BF}_{3}\left(\mathrm{Et}_{2} \mathrm{O}\right)$. 
A Tabela 7 apresenta os valores das $T_{d} s$ e perda de massa e observa-se que 0 catalisador $\left(\mathrm{CH}_{3} \mathrm{COO}\right)_{2} \mathrm{Zn} .2 \mathrm{H}_{2} \mathrm{O}$ favorece à formação de materiais com menor estabilidade térmica e com similaridade nos valores das $T_{d} S$.

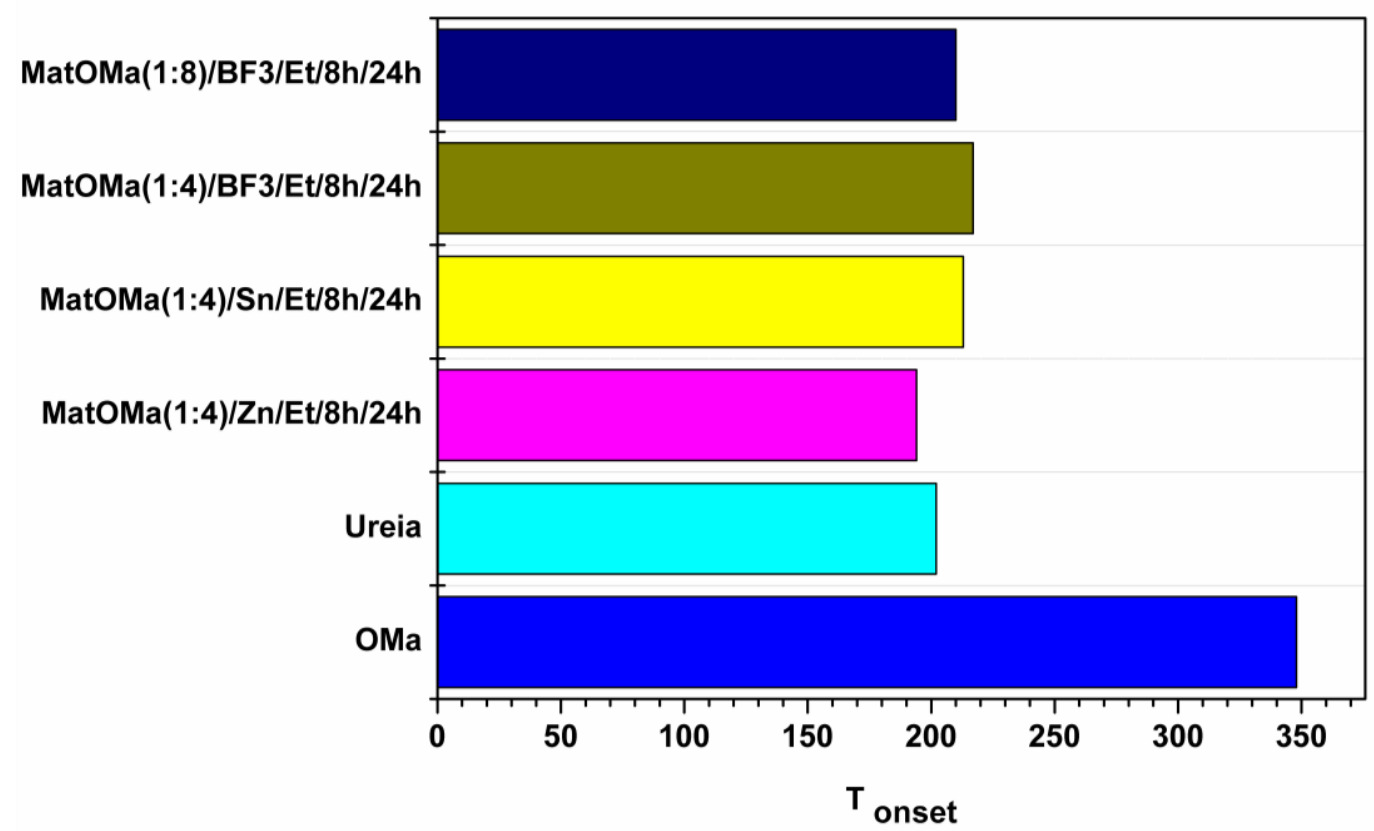

Figura 35. Comparação da $\mathrm{T}_{\text {onset }}$ do OMa, ureia e dos materiais obtidos na síntese com etanol.

Tabela 7. Dados de $T_{d}$ e perda de massa dos materiais obtidos com diferentes catalisadores.

\begin{tabular}{lcccc}
\hline \multicolumn{1}{c}{ Amostra } & $\mathbf{T}_{\mathbf{d}} \mathbf{1}\left({ }^{\circ} \mathbf{C}\right)$ & $\mathbf{T}_{\mathbf{d}} \mathbf{2}\left({ }^{\circ} \mathbf{C}\right)$ & $\begin{array}{c}\text { Perda de } \\
\text { massa 1 (\%) }\end{array}$ & $\begin{array}{c}\text { Perda de } \\
\text { massa 2 (\%) }\end{array}$ \\
\hline OMa & 390 & - & 95,0 & - \\
Ureia & 225 & 335 & 72,5 & 24,8 \\
MatOMa(1:4)/Zn/Et/8h/24h & 218 & 276 & 58,2 & 26,8 \\
MatOMa(1:4)/Sn/Et/8h/24h & 236 & 326 & 60,8 & 27,9 \\
MatOMa(1:4)/BF $/ \mathrm{Et} / 8 \mathrm{~h} / 24 \mathrm{~h}$ & 235 & 342 & 63,8 & 29,7 \\
MatOMa(1:8)/BF $/ \mathrm{Et} / 8 \mathrm{~h} / 24 \mathrm{~h}$ & 232 & 359 & 43,4 & 51,5 \\
\hline
\end{tabular}

A Figura 36 apresenta a curva DSC da amostra MatOMa(1:4)/Zn/Et/8h/24h, onde se observa uma possível transição termodinâmica de segunda ordem, próxima a 90 ${ }^{\circ} \mathrm{C}$, que pode estar relacionada à $\mathrm{T}_{\mathrm{g}}$ do material, e um pico endotérmico próximo a 125 ${ }^{\circ} \mathrm{C}$, associado, provavelmente, à fusão de ureia que não reagiu, tendo em vista que sua fusão ocorre em $130{ }^{\circ} \mathrm{C}$. No entanto, a curva DSC da amostra MatOMa(1:4)/Sn/Et/8h/24h (Figura 37) mostra um perfil bastante diferente da curva DSC do material obtido catalisado com $\left(\mathrm{CH}_{3} \mathrm{COO}\right)_{2} \mathrm{Zn} .2 \mathrm{H}_{2} \mathrm{O}$, pois apresenta apenas 
uma $\mathrm{T}_{\mathrm{g}}$ próxima a $45^{\circ} \mathrm{C}$. Isso sugere que só existem domínios amorfos no material obtido, catalisado com $\mathrm{SnCl}_{2} 2 \mathrm{H}_{2} \mathrm{O}$. Então, é possível que a utilização de diferentes catalisadores proporcione a formação de produtos com diferentes empacotamentos, que a reação de formação do $\mathrm{MatOMa(1:4)/Zn/Et/8h/24h} \mathrm{não} \mathrm{foi} \mathrm{completa,} \mathrm{tendo} \mathrm{em}$ vista o aparecimento do pico de fusão da ureia, e que o MatOMa(1:4)/Sn/Et/8h/24h é amorfo.

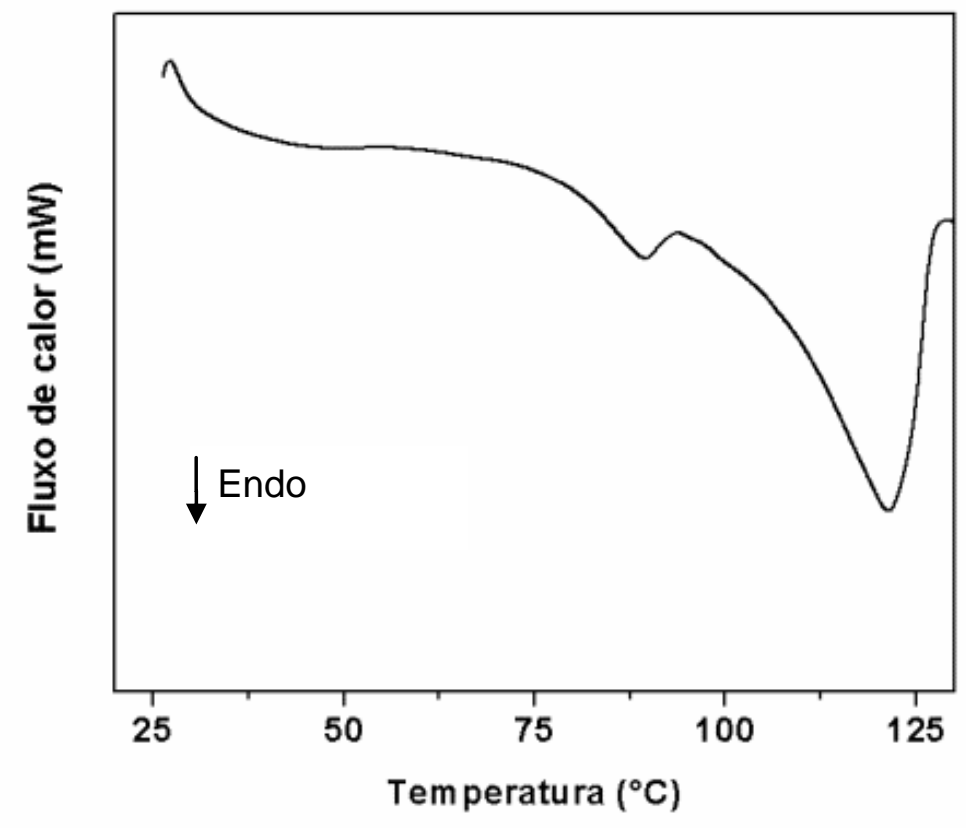

Figura 36. Curva DSC da amostra MatOMa(1:4)/Zn/Et/8h/24h.

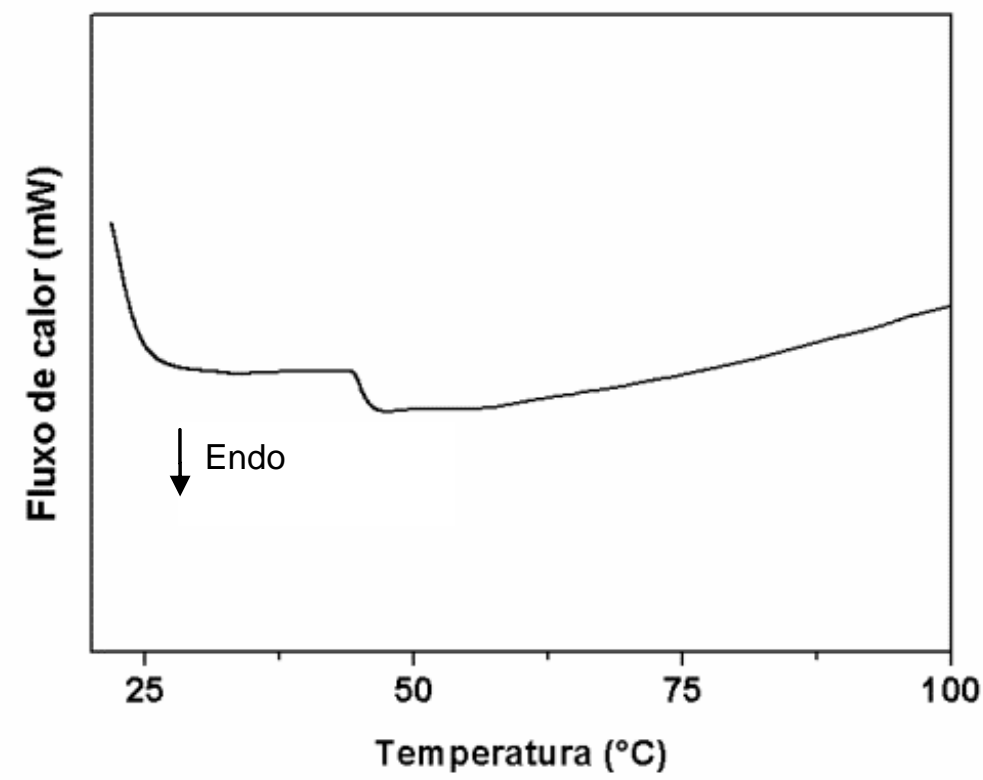

Figura 37. Curva DSC da amostra MatOMa(1:4)/Sn/Et/8h/24h. 
Os materiais sintetizados com a utilização do etanol como solvente não apresentaram as características físicas esperadas da síntese. Porém, pode-se inferir que, nas reações entre o OMa e a ureia com os catalisadores utilizados e usando etanol como solvente, foi possível observar a formação de ligações uretanas, mesmo com pequenos rendimentos, formando talvez oligômeros. Esses resultados indicam a necessidade de mudanças em alguns parâmetros da reação, para obtenção dos materiais esperados.

Fazendo uma análise do aspecto dos materiais obtidos, foi observado que os catalisadores $\left(\mathrm{CH}_{3} \mathrm{COO}\right)_{2} \mathrm{Zn} .2 \mathrm{H}_{2} \mathrm{O}$ e $\mathrm{BF}_{3}\left(\mathrm{Et}_{2} \mathrm{O}\right)$ proporcionaram a formação de sólidos mais compactados. E, uma vez que o OMa e a ureia ficavam em diferentes fases, durante quase toda a síntese, a possibilidade de uma interferência do solvente foi suscitada. E, de acordo com a literatura, polímeros com alto teor de ureia são mais susceptíveis à precipitação antecipada durante uma reação, sendo então necessários altas temperaturas e solventes muitos polares, para a estabilização da reação. ${ }^{42}$ Deste modo, foi sugerido que o etanol como solvente poderia ser um impedimento para que a reação ocorresse com melhor rendimento.

\subsection{SÍNTESE SEM A UTILIZAÇÃO DE SOLVENTE}

Para analisar os materiais obtidos na metodologia sem a utilização de solvente, a técnica usada, inicialmente, foi espectroscopia no FT-IR. Vale lembrar que, nessa metodologia, foram usados apenas dois catalisadores: $\left(\mathrm{CH}_{3} \mathrm{COO}\right)_{2} \mathrm{Zn} .2 \mathrm{H}_{2} \mathrm{O}$ e $\mathrm{BF}_{3}\left(\mathrm{Et}_{2} \mathrm{O}\right)$, conforme Figuras 18 e 19 da Parte Experimental. Essa escolha foi baseada nos resultados da primeira metodologia e, apesar do $\left(\mathrm{CH}_{3} \mathrm{COO}\right)_{2} \mathrm{Zn} .2 \mathrm{H}_{2} \mathrm{O}$ ser um ácido de Lewis mais fraco que $\mathrm{BF}_{3}\left(\mathrm{Et}_{2} \mathrm{O}\right)$, foram feitas as reações com este catalisador, na tentativa de obter materiais mais ambientalmente favoráveis.

$\mathrm{Na}$ metodologia sem solvente, usando o $\left(\mathrm{CH}_{3} \mathrm{COO}\right)_{2} \mathrm{Zn} .2 \mathrm{H}_{2} \mathrm{O}$ como catalisador, o único parâmetro que mudou foi tempo de agitação da reação (1 e 4 h). Os materiais obtidos PUOMa(1:2)/Zn/1h/24h e PUOMa(1:2)/Zn/4h/24h apresentaram duas fases, uma líquida e uma sólida bem compactada, ao final da reação. As duas fases foram analisadas por FT-IR (Figuras 38 e 39 ). 


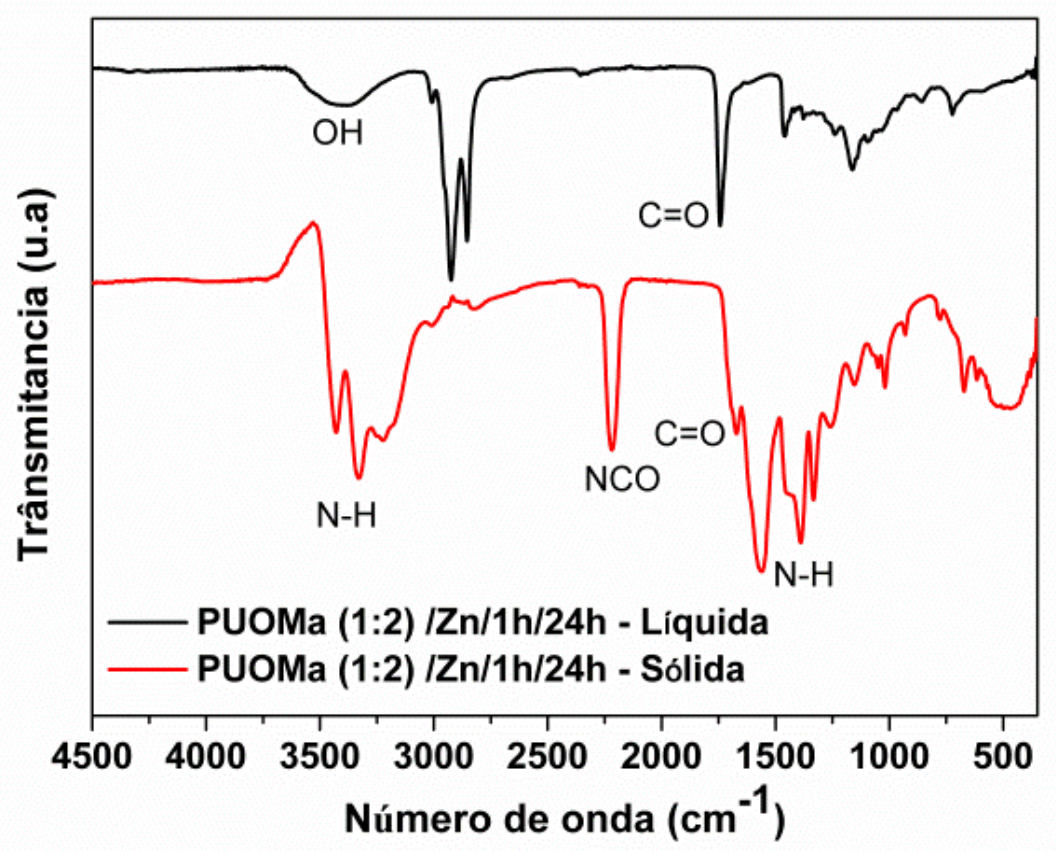

Figura 38. Espectros no FT-IR da amostra PUOMa(1:2)/Zn/1h/24h, fases líquida e sólida.

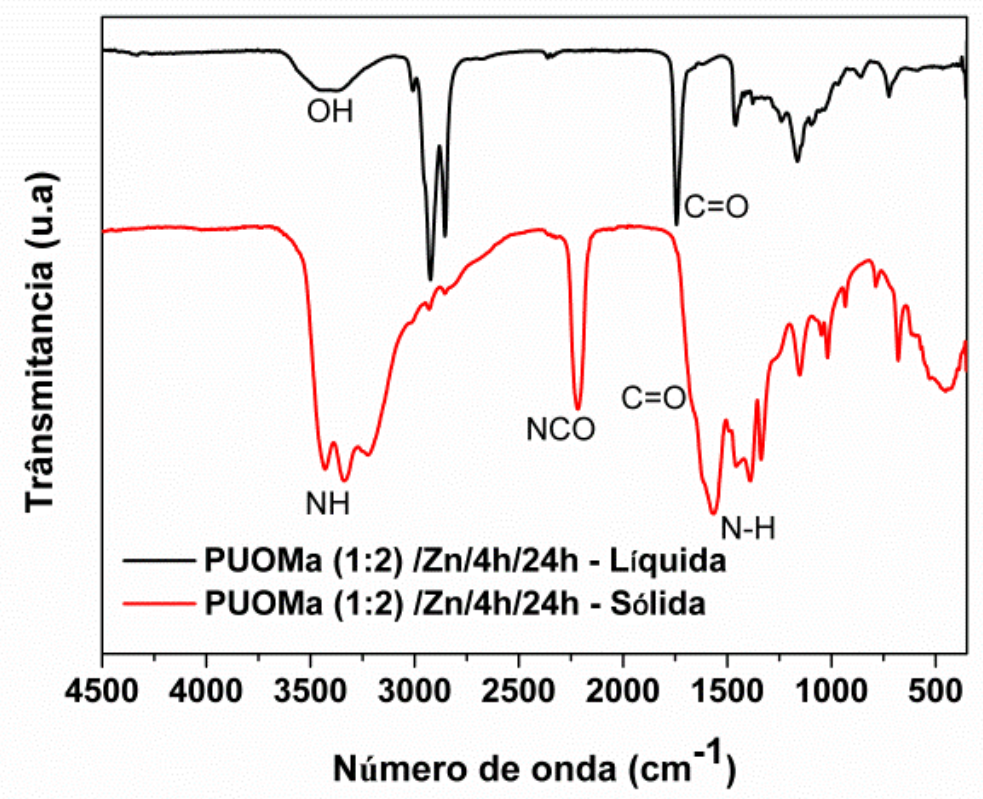

Figura 39. Espectros no FT-IR da amostra PUOMa(1:2)/Zn/4h/24h, fases líquida e sólida.

Nos espectros FT-IR da fase líquida das amostras (Figuras 40 e 41) é possível observar uma grande similaridade com o do OMa (Figuras 20), significando que a parte líquida do material seria OMa que não reagiu. Enquanto na porção sólida dos materiais, observa-se, nos seus espectros FT-IR (Figuras 40 e 41), a formação de uma banda característica de estiramento $\mathrm{N}=\mathrm{C}=\mathrm{O}$, próxima a $2200 \mathrm{~cm}^{-1}$, o que confirma a 
hipótese de que o catalisador não atua com eficiência, para favorecer a reação entre o óleo e a ureia. Isso sugere uma investigação maior com o outro catalisador em estudo.

Por conseguinte, foi realizado um estudo mais detalhado usando o catalisador $\mathrm{BF}_{3}\left(\mathrm{Et}_{2} \mathrm{O}\right)$ que, na metodologia com solvente, já tinha se mostrado mais eficiente. Então, de acordo com o fluxograma apresentado na Figura 19 da Parte Experimental, serão apresentados os espectros no FT-IR e os demais resultados dos materiais obtidos. Vale salientar que, para as proporções 1:2, 1:3 e 1:4 de OMa:ureia foram usados três tempos diferentes (24, 48 e 72 h) na cura do material, enquanto, para a proporção 1:8 de OMa:ureia a cura do material foi feita somente com $24 \mathrm{~h}$ e o tempo de agitação foi o mesmo em todas as proporções. Deve-se destacar também que, usando $\circ \mathrm{BF}_{3}\left(\mathrm{Et}_{2} \mathrm{O}\right)$ como catalisador nesta metodologia, foi formado apenas um material sólido, sem qualquer fase líquida.

Os espectros no FT-IR dos materiais com a proporção OMa:ureia de 1:2, mudando apenas o tempo de cura, estão apresentados na Figura 40. É observada a formação de duas bandas de estiramento em $3380 \mathrm{~cm}^{-1}$ e $3328 \mathrm{~cm}^{-1}$, referentes ao estiramento de amida primária $\left(\mathrm{C}-\mathrm{NH}_{2}\right)$, que estão sobrepostas ao estiramento do grupo $\mathrm{OH}$. O pico próximo a $3500 \mathrm{~cm}^{-1}$ é relacionado ao overtone da carboxila do grupo -CONCO-, indicando a formação da ligação uretana, com a formação de um grupo acil.

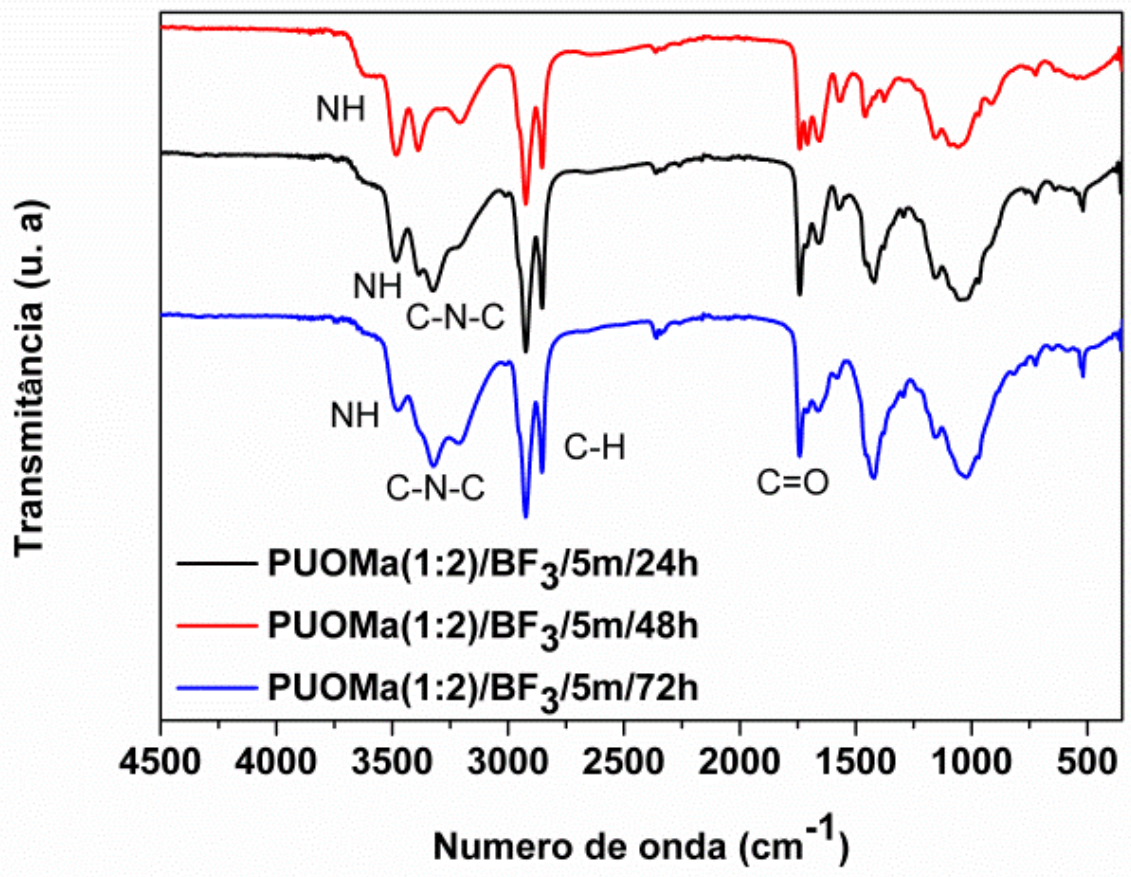

Figura 40. Espectros no FT-IR dos materiais com a proporção OMa:ureia de 1:2, mudando apenas o tempo de cura. 
A Figura 41 mostra os espectros no FT-IR dos materiais com a proporção OMa:ureia de 1:3, mudando apenas o tempo de cura, e percebe-se que eles apresentam picos similares aos espectros FT-IR dos materiais com proporção 1:2 de OMa:ureia (Figura 40)

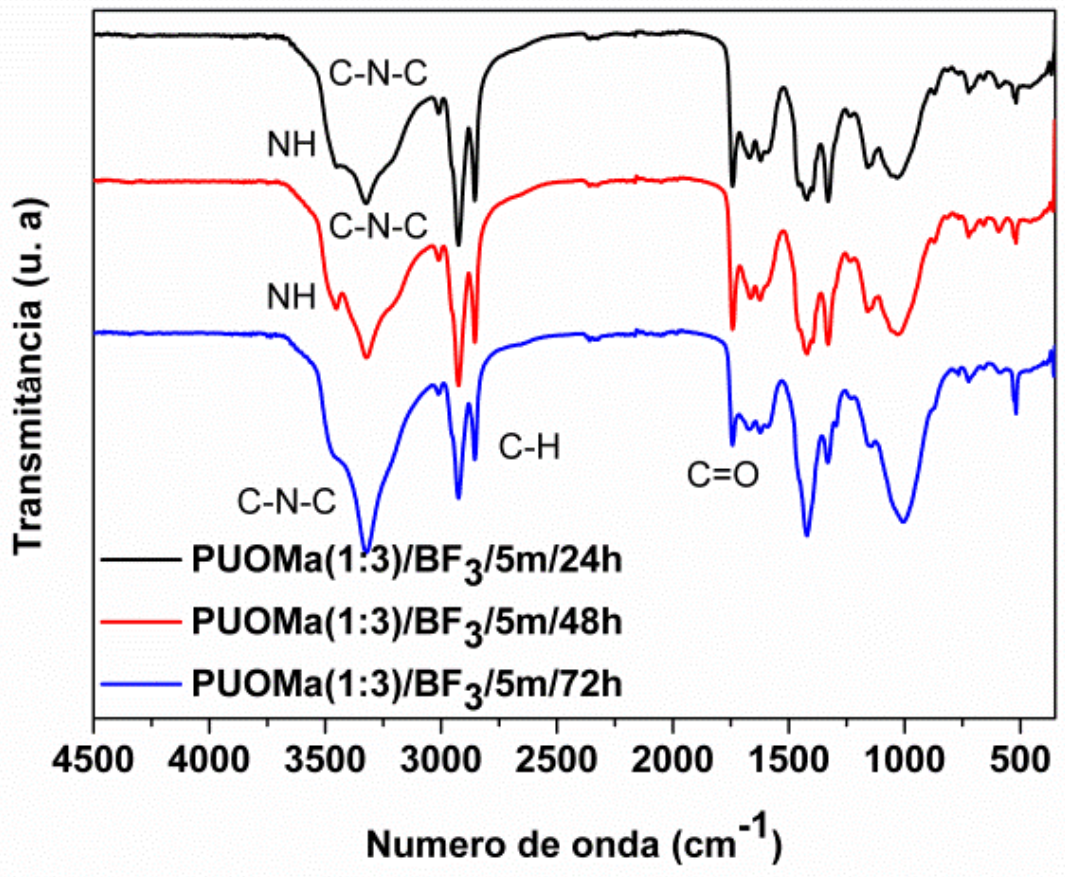

Figura 41. Espectros no FT-IR dos materiais com a proporção OMa:ureia de 1:3, mudando apenas o tempo de cura.

Aumentando mais um pouco a quantidade de ureia na reação, foram obtidos os materiais $\quad \mathrm{PUOMa}(1: 4) / \mathrm{BF}_{3} / 5 \mathrm{~min} / 24 \mathrm{~h}, \quad \mathrm{PUOMa}(1: 4) / \mathrm{BF}_{3} / 5 \mathrm{~min} / 48 \mathrm{~h} \quad \mathrm{e}$ PUOMa(1:4)/BF $/ 5 \mathrm{~min} / 72 \mathrm{~h}$ e seus espectros no FT-IR são reportados na Figura 42. Nos espectros FT-IR desses materiais, foi observada uma única banda referente ao estiramento $\mathrm{N}-\mathrm{H}$ de amida secundária $(\mathrm{C}-\mathrm{NH}-\mathrm{C})$, próxima a $3330 \mathrm{~cm}^{-1}$, sobreposta ao estiramento de O-H. O estiramento da carbonila de carbamato aparece próximo a $1750 \mathrm{~cm}^{-1}$, onde é provável que ele se apresente sobreposto à outra possível carbonila. Com esses deslocamentos é possível confirmar a formação de um material polimérico similar à PU. 


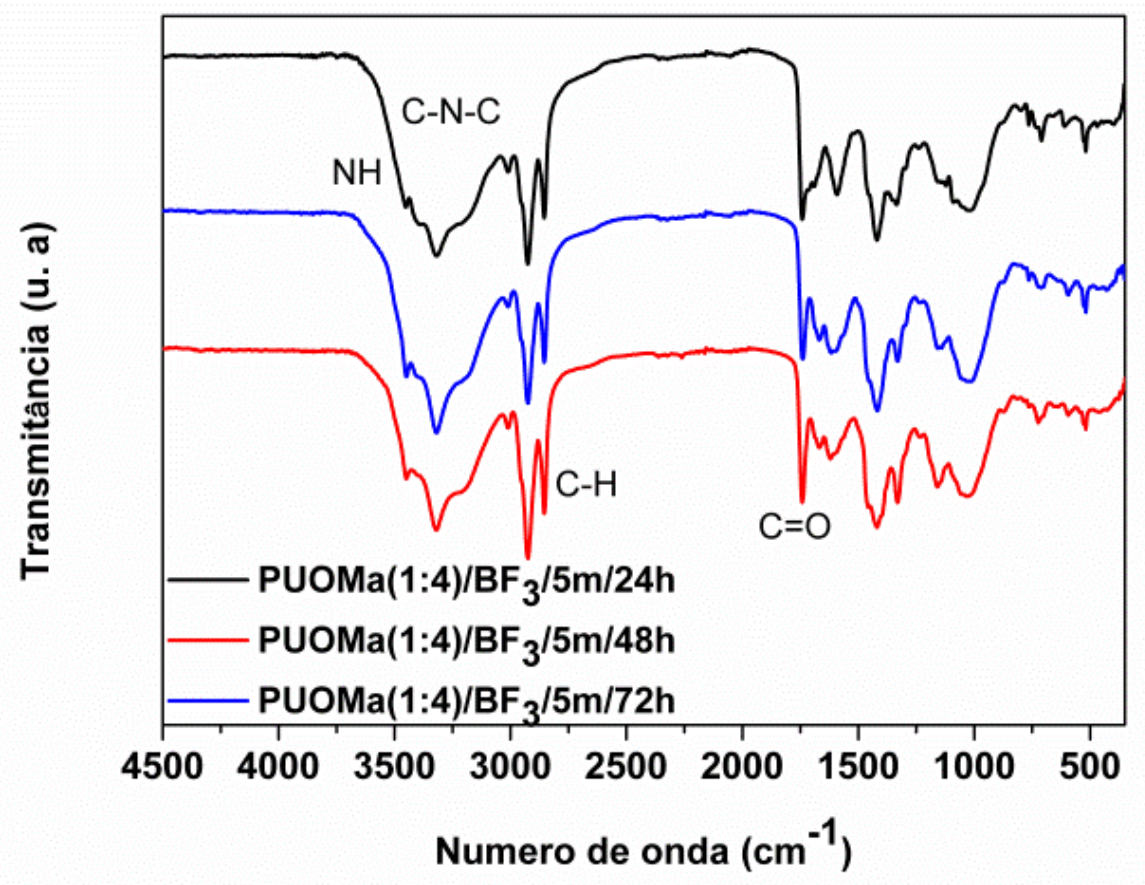

Figura 42. Espectros no FT-IR dos materiais com a proporção OMa:ureia de 1:4, mudando apenas o tempo de cura.

Depois desses resultados, verificou-se o comportamento da reação, usando o dobro da quantidade de ureia da proporção 1:4 de OMa:ureia, ou seja, 1:8 de OMa:ureia. No espectro FT-IR (Figura 43) do material resultante da reação, PUOMa(1:8)/BF $/ 5 \mathrm{~min} / 24 \mathrm{~h}$, são observadas duas bandas relacionadas ao estiramento de amida primária $\left(\mathrm{C}-\mathrm{NH}_{2}\right)$, próximas a $3450 \mathrm{~cm}^{-1}$ e $3350 \mathrm{~cm}^{-1}$ sobrepostas à banda de estiramento $\mathrm{O}-\mathrm{H}$, junto à uma deformação $\mathrm{N}-\mathrm{H}$ em $1613 \mathrm{~cm}^{-1}$, também característica de amina primária. Ainda, podem ser percebidos picos característicos de estiramento de carbonila em $1720 \mathrm{~cm}^{-1}$, de estiramento de éster em $1740 \mathrm{~cm}^{-1}$, de estiramento C-N em $1340 \mathrm{~cm}^{-1}$ e de deformação de carbonila de amida em $1630 \mathrm{~cm}^{-1}$. 


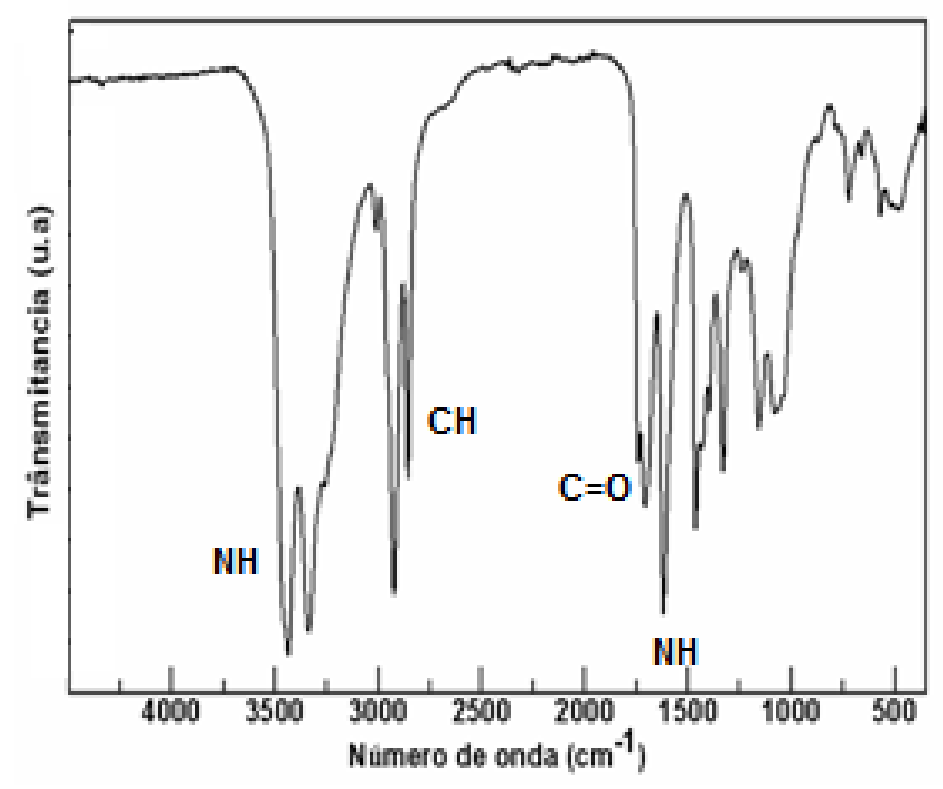

Figura 43. Espectro no FT-IR da amostra PUOMa(1:8)/BF $/ 5 \mathrm{~min} / 24 \mathrm{~h}$.

Com os dados obtido por FT-IR, é possivel inferir que, usando as três primeras proporções (1:2, 1:3 e 1:4) de OMa:ureia, obtém-se o polímero desejado, tendo em vista que as bandas caracteristicas de carbamatos e de amidas primárias e secundárias aparecem nos espectros dos materiais sintetizados. Portanto, é preferível que se utilize a sintese com menor proporção OMa:ureia, considerando fatores econômicos e ambientais.

Os valores dos números de onda apresentados nas discussões para todos os materiais estão relacionados na Tabela $8 \mathrm{com}$ suas respectivas atribuições. Essas bandas de absorção no FT-IR confirmam a formação de um polímero livre de isocianato, quando se utiliza como catalisador o $\mathrm{BF}_{3}\left(\mathrm{Et}_{2} \mathrm{O}\right)$, sem a utilização de etanol. 
Tabela 8. Principais bandas de absorção no FT-IR dos espectros apresentados nas Figuras 35 a 40 , com suas respectivas atribuições. ${ }^{54}$

\begin{tabular}{cc}
\hline Número de onda (cm- $\left.{ }^{-1}\right)$ & Atribuições \\
\hline $1680-1630$ & Estiramento C-O de amida. \\
$3350-3180$ & Estiramento, com duas bandas, $\mathrm{N}-\mathrm{H}$ em amidas \\
& primárias $\left(-\mathrm{NH}_{2}\right)$. \\
$1640-1550$ & Deformação $\mathrm{N}-\mathrm{H}$ de amidas primárias e \\
$1750-1735$ & secundárias. \\
$3400-3300$ & Estiramento C=O de éster alifático. \\
$1440-1220$ & Estiramento O-H com ligação de hidrogênio. \\
$1260-1000$ & Deformação C-O-H. \\
1009 & Estiramento C-O de álcool. \\
3400 & Estiramento C-O referente a alcoóis secundários. \\
3009 & Overtone de $\mathrm{C}=\mathrm{O}$ de ésteres \\
2955 & Estiramento C-H da ligação dupla (cis) $=\mathrm{C}-\mathrm{H}$ \\
2924 & Estiramento assimétrico $\mathrm{CH}_{3}$ \\
2854 & Estiramento assimétrico $\mathrm{CH}_{2}$ \\
1746 & Estiramento simétrico $\mathrm{CH}_{2}$ \\
1651 & Estiramento do grupo $\mathrm{C}=\mathrm{O}$ de éster \\
1463 & Estiramento $\mathrm{C}=\mathrm{C}($ cis $)$ \\
1377 & Deformação de $\mathrm{CH}_{2}$ e $\mathrm{CH}_{3}$ alifáticos \\
1230 & Deformação simétrica de $\mathrm{CH}_{3}$ \\
1163 & Deformação de $\mathrm{CH}_{2}$ \\
721 & Deformação assimétrica $\mathrm{C}-\mathrm{O}$ \\
& Deformação de $\mathrm{CH}_{2}$ \\
\hline
\end{tabular}

Para uma análise da influência da proporção de ureia utilizada, foram comparados, em um mesmo gráfico, os espectros de FT-IR dos materiais obtidos com o mesmo tempo de cura, mas variando a proporção OMa:ureia, nas Figuras 44, 45 e 46. São observados os mesmos picos relacionados à formação da carbonila de carbamato e de aminas secundárias, com absorções similares. Sendo assim, pode-se dizer que, pelos espectros de FT-IR, as proporções OMa:ureia usadas, nessas reações, têm pouca influência e que de fato o que muda a estrutura do material é o tempo de cura. 

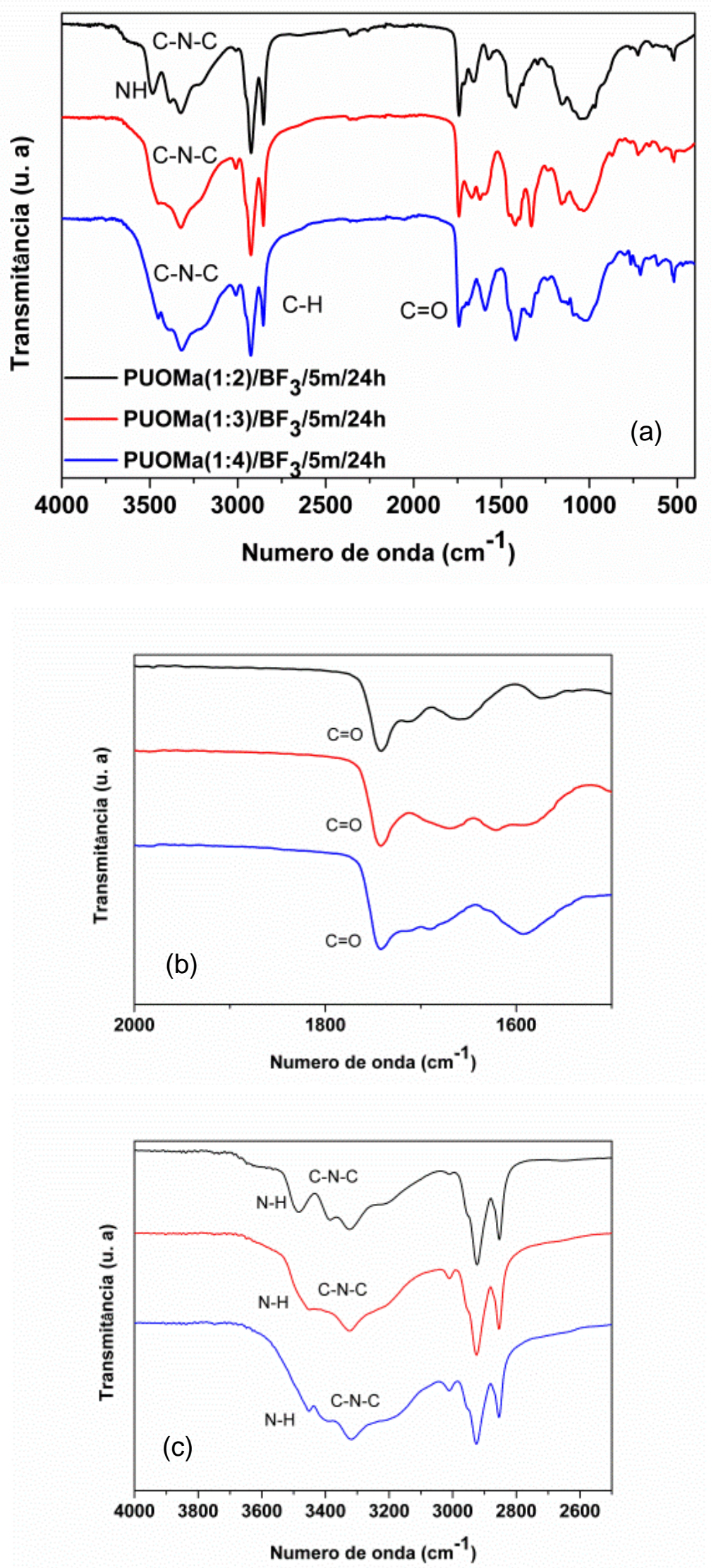

Figura 44. (a) Espectros no FT-IR dos materiais com $24 \mathrm{~h}$ de cura, nas proporções OMa:ureia de 1:2, 1:3 e 1:4; (b) ampliação da absorção da carbonila de carbamato (c) ampliação da absorção de carbonila de amidas secundárias. 

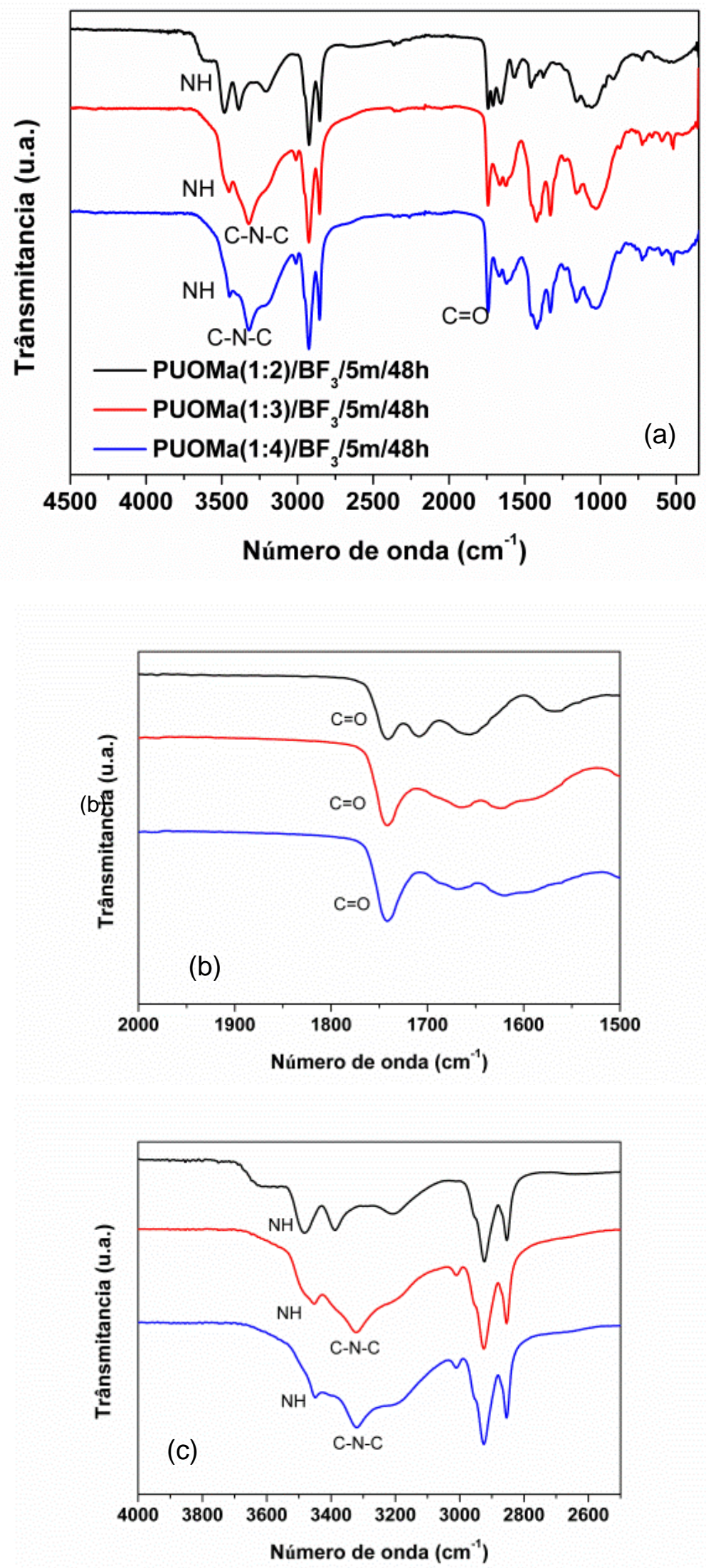

Figura 45. (a) Espectros no FT-IR dos materiais com $48 \mathrm{~h}$ de cura, nas proporções OMa:ureia de 1:2, 1:3 e 1:4; (b) ampliação da absorção da carbonila de carbamato (c) ampliação da absorção de carbonila de amidas secundárias. 

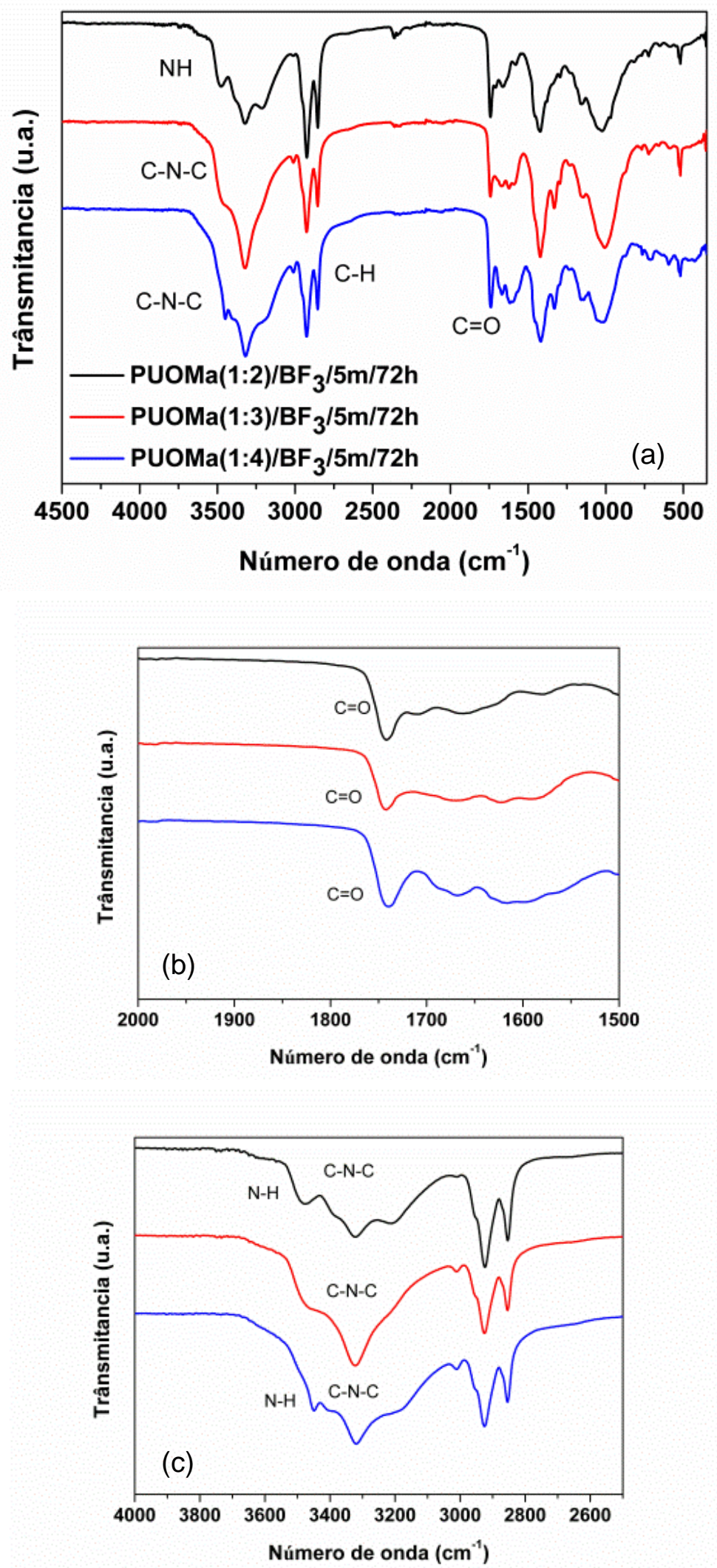

Figura 46. (a) Espectros no FT-IR dos materiais com $72 \mathrm{~h}$ de cura, nas proporções OMa:ureia de 1:2, 1:3 e 1:4; (b) ampliação da absorção da carbonila de carbamato (c) ampliação da absorção de carbonilas de amidas secundárias. 
Para corroborar os dados obtidos no FT-IR, foi feito o espectro de RMN ${ }^{13} \mathrm{C}$, no estado sólido, da amostra PUOMa(1:2)/BF $3 / 5 \mathrm{~min} / 24 \mathrm{~h}$ (Figura 47).

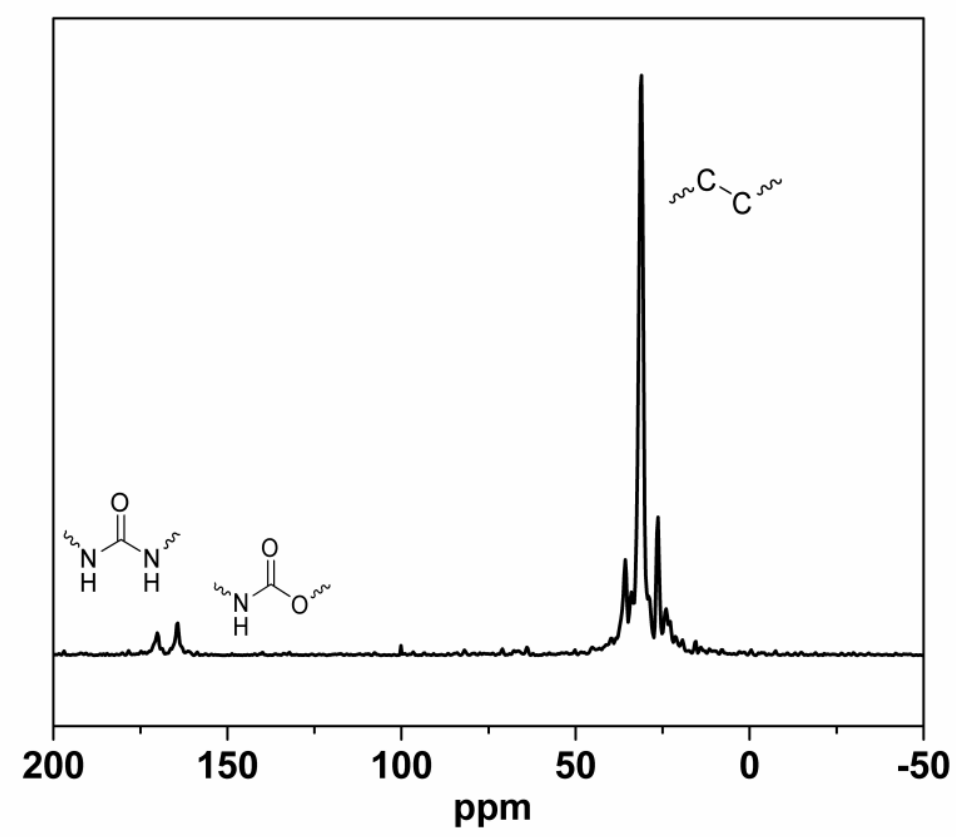

Figura 47. Espectro de $\mathrm{RMN}^{13} \mathrm{C}$, no estado sólido, da amostra PUOMa(1:2)/BF $/ 5 \mathrm{~min} / 24 \mathrm{~h}$.

Foi observado que o espectro de $\mathrm{RMN}{ }^{13} \mathrm{C}$, no estado sólido, apresenta deslocamentos em 170 ppm e 165 ppm, referentes à carbonila de amida e carbonila de carbamato, respectivamente, além dos sinais entre 38 ppm e 22 ppm, relacionados aos carbonos $\mathrm{sp}^{3}$ da cadeia do OMa. Esse espectro apresenta sinais de baixa intensidade de carbonila de amida e carbonila de carbamato, por diversos fatores: baixa proporção de carbonilas, comparada aos carbonos $\mathrm{sp}^{3}$, além do efeito anisotrópico que dificulta a orientação ao campo magnético das carbonilas. Esse efeito é menor nas cadeias de carbono $\mathrm{sp}^{3}$, que possuem movimentação livre..$^{29,60}$

Os resultados de $\mathrm{RMN}{ }^{13} \mathrm{C}$, no estado sólido, para a amostra PUOMa(1:2)/BF $/ 5 \mathrm{~min} / 24 \mathrm{~h}$, além de corroborarem os dados obtidos por espectroscopia no FT-IR, previamente apresentados, sugerem a formação de uma poli(acil-uretana), na metodologia sem solvente e usando o catalisador $\mathrm{BF}_{3}\left(\mathrm{Et}_{2} \mathrm{O}\right)$.

Com o intuito de confirmar a estrutura química do produto final, foi realizada a análise de $\mathrm{RMN}{ }^{1} \mathrm{H}$ e $\mathrm{RMN}{ }^{13} \mathrm{C}$ para o material $\mathrm{PUOMa}(1: 2) / \mathrm{BF}_{3} / 5 \mathrm{~min} / 72 \mathrm{~h}$. É importante salientar que, a solubilidade do material em questão foi parcial em tetrahidrofurano (THF), sendo assim, a caracterização pela técnica ocorreu apenas com as suas cadeias solúveis. 
$\mathrm{Na}$ Tabela 9, estão listados os sinais dos prótons característicos da poli(aciluretana) que serão elucidados nas Figuras 48 e 49.

Tabela 9. Deslocamentos químicos de RMN ${ }^{1} \mathrm{H}$ característicos do espectro da Poli(acil-uretana)

\begin{tabular}{ccc}
\hline $\begin{array}{c}\text { Descolamento } \\
\text { químico (ppm) }\end{array}$ & Próton & $\begin{array}{c}\text { Referência estrutural } \\
\text { da Figura 48 e 49. }\end{array}$ \\
\hline $1,3-1,6$ & $\mathrm{CH}_{2} \mathrm{CH}_{2} \mathrm{CH}_{2}$ & 5 \\
2,2 & $\mathrm{CH}_{2} \mathrm{CH}=\mathrm{CH}$ & 4 \\
2,80 & $\mathrm{CH}_{2} \mathrm{CH}_{2} \mathrm{CH}_{3}$ & 6 \\
3,7 & $\mathrm{CHOCOR}$ & 3 \\
4,0 & $\mathrm{CH}-\mathrm{OH}$ & 2 \\
5,4 & $\mathrm{CH}=\mathrm{CH}$ & 1 \\
& &
\end{tabular}

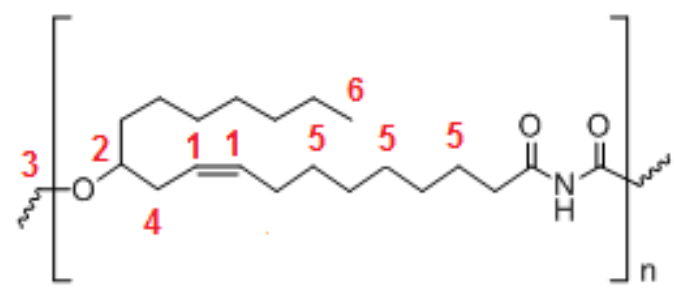

Figura 48. Estrutura do mero da poli(acil-uretana) com os sinais assinalados referentes ao espectro de $\mathrm{RMN}{ }^{1} \mathrm{H}$.

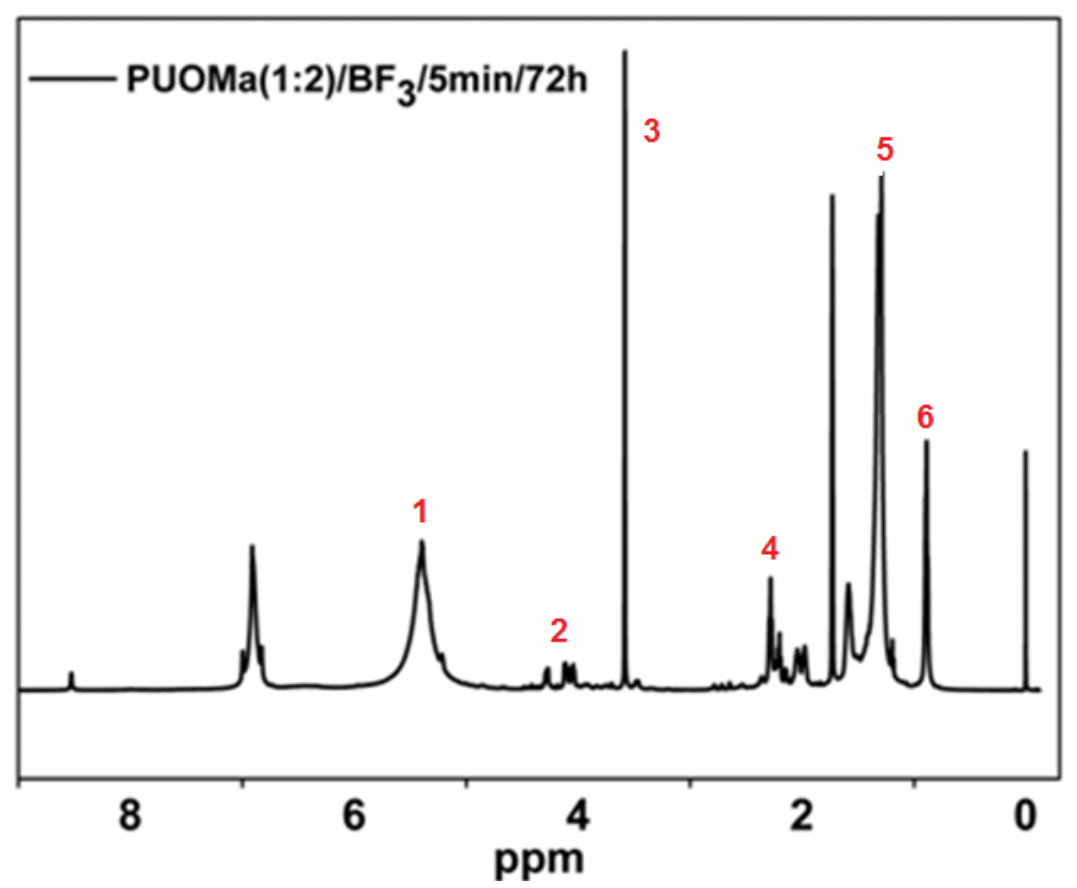

Figura 49. Espectro de $\mathrm{RMN}^{1} \mathrm{H}$ da amostra PUOMa(1:2)/BF $/ 5 \mathrm{~min} / 72 \mathrm{~h}$. 
Já, na Tabela 10, estão listados os sinais dos carbonos característicos das poli(acil-uretanas) que serão elucidados nas Figuras 50 e 51.

Tabela 10. Deslocamentos químicos de $\mathrm{RMN}{ }^{13} \mathrm{C}$ característicos do espectro da poli(aciluretana).

\begin{tabular}{ccc}
\hline $\begin{array}{c}\text { Descolamento } \\
\text { químico (ppm) }\end{array}$ & Carbono & $\begin{array}{c}\text { Referência estrutural } \\
\text { da Figura 50 e 51. }\end{array}$ \\
\hline 14,4 & $\mathrm{CH}_{3} \mathrm{CH}_{2}$ & 8 \\
$25,9-29,7$ & $\mathrm{CH}_{2} \mathrm{CH}_{2} \mathrm{CH}_{2}$ & 5 \\
$27,7-32,2$ & $\mathrm{HC}=\mathrm{CH}_{-} \mathrm{CH}_{2}$ & 6 \\
35,9 & $\mathrm{RCH} \mathrm{CONR}_{2}$ & 7 \\
72,3 & $\mathrm{CHOH}$ & 4 \\
$127-133$ & $\mathrm{HC}=\mathrm{CH}$ & 3 \\
162,2 & $\mathrm{ROCONR}$ & 2 \\
173,1 & $\mathrm{RCONR}$ & 1 \\
\hline
\end{tabular}

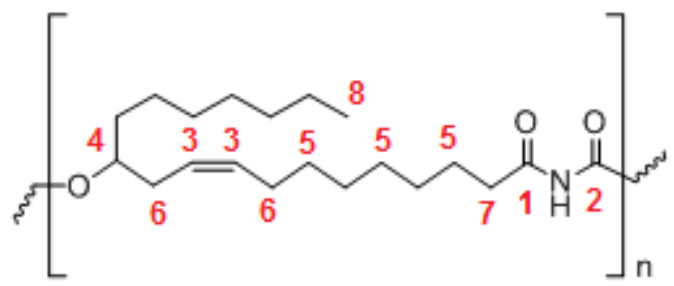

Figura 50. Estrutura do mero da poli(acil-uretana) com os sinais assinalados referentes ao espectro de RMN ${ }^{13} \mathrm{C}$.

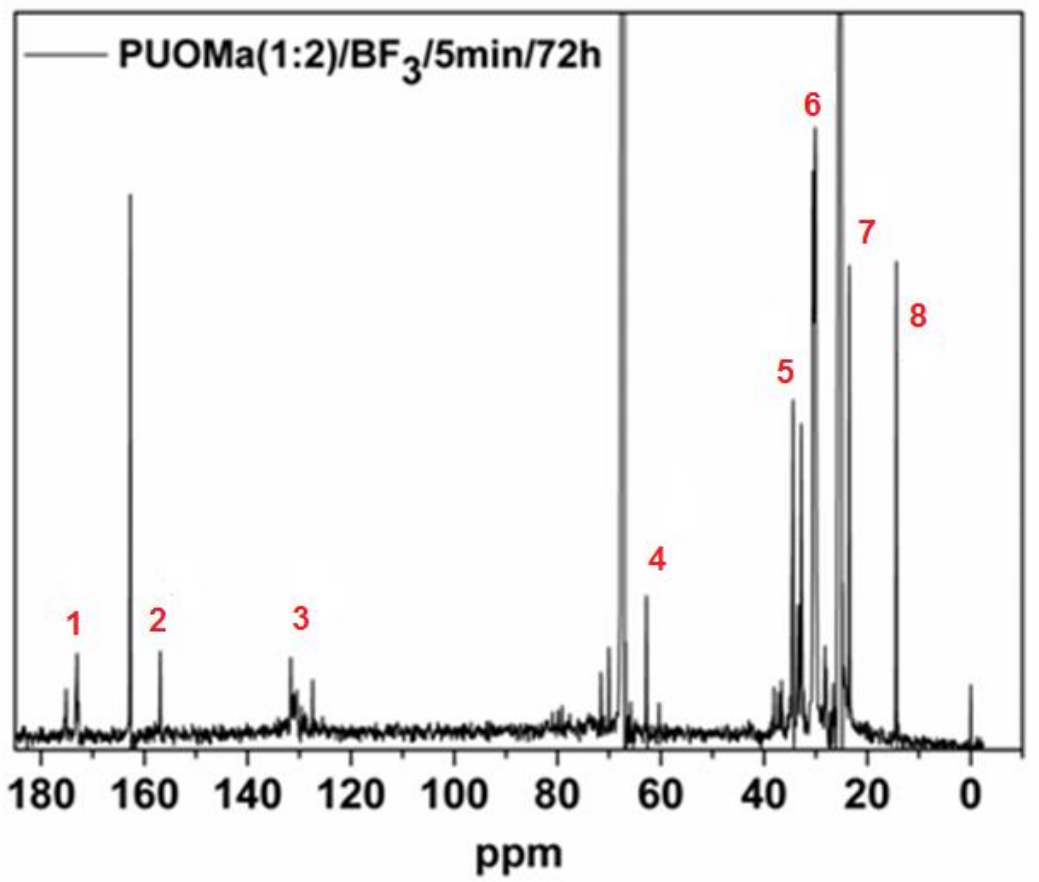

Figura 51. Espectro de $\mathrm{RMN}{ }^{13} \mathrm{C}$ da amostra $\mathrm{PUOMa}(1: 2) / \mathrm{BF}_{3} / 5 \mathrm{~min} / 72 \mathrm{~h}$. 
Com as análises de $\mathrm{RMN}{ }^{1} \mathrm{H}$ e $\mathrm{RMN}{ }^{13} \mathrm{C}$ foi possível confirmar pelos deslocamentos químicos mostrados nas Figuras 48 a 51, a formação da N-acilamida e, portanto, a síntese de poli(acil-uretanas).

Adicionalmente às análises espectroscópicas, foram realizadas análises por TG da maioria dos materiais obtidos na metodologia sem solvente.

Das reações feitas usando $\left(\mathrm{CH}_{3} \mathrm{COO}\right)_{2} \mathrm{Zn} .2 \mathrm{H}_{2} \mathrm{O}$ como catalisador, foi possível obter as curvas TG e DTG apenas do material com $4 \mathrm{~h}$ de agitação, apresentadas na Figura 52, porque a quantidade de material sólido obtido na reação com $1 \mathrm{~h}$ de agitação só foi suficiente para realizar a análise por FT-IR.

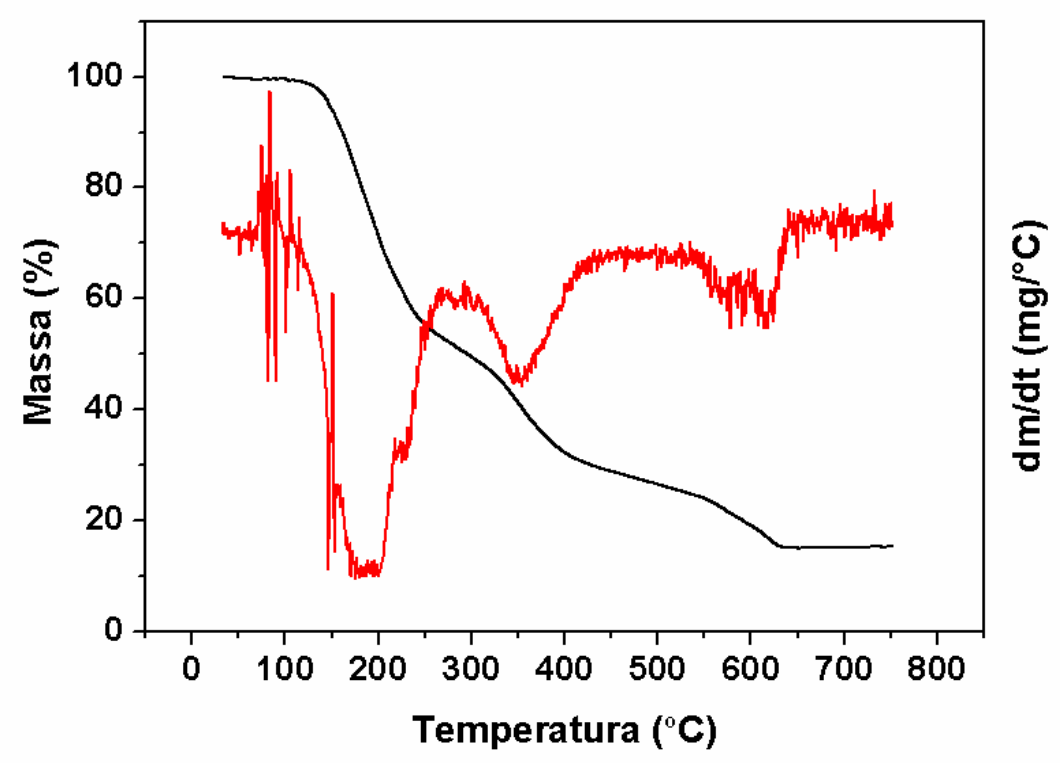

Figura 52. Curvas TG e DTG da amostra PUOMa(1:2)/Zn/4h/24h.

A Figura 52, referente às curvas TG e DTG da amostra PUOMa(1:2)/Zn/4h/24h, possui três etapas de decomposição térmica, com $\mathrm{T}_{d} 1$ em $170{ }^{\circ} \mathrm{C}, \mathrm{T}_{d} 2$ em $354^{\circ} \mathrm{C}$ e $\mathrm{T}_{\mathrm{d}} 3$ em $618^{\circ} \mathrm{C}$. Na primeira etapa de decomposição há uma perda de massa de $44 \%$, na segunda $23 \%$ e na terceira $17 \%$. A amostra possui uma baixa estabilidade térmica e as três etapas de decomposição mostram que o material é uma mistura de várias estruturas químicas e, consequentemente, de difícil análise das etapas de decomposição.

No que se refere às reações da metodologia sem solvente, usando o catalisador $\mathrm{BF}_{3}\left(\mathrm{Et}_{2} \mathrm{O}\right)$, foram realizadas análises por $\mathrm{TG}$ de todos os materiais obtidos.

As curvas TG e DTG dos materiais na proporção 1:2, nos diferentes tempos de cura, estão apresentadas na Figura 53. Percebe-se que elas apresentaram três etapas principais de decomposição, em que a primeira está na faixa de $300{ }^{\circ} \mathrm{C}$ a $314{ }^{\circ} \mathrm{C}$, a segunda de $376{ }^{\circ} \mathrm{C}$ a $400 \stackrel{\circ}{\circ}$ e a terceira entre $450 \stackrel{\circ}{\circ}$ a $613^{\circ} \mathrm{C}$. 

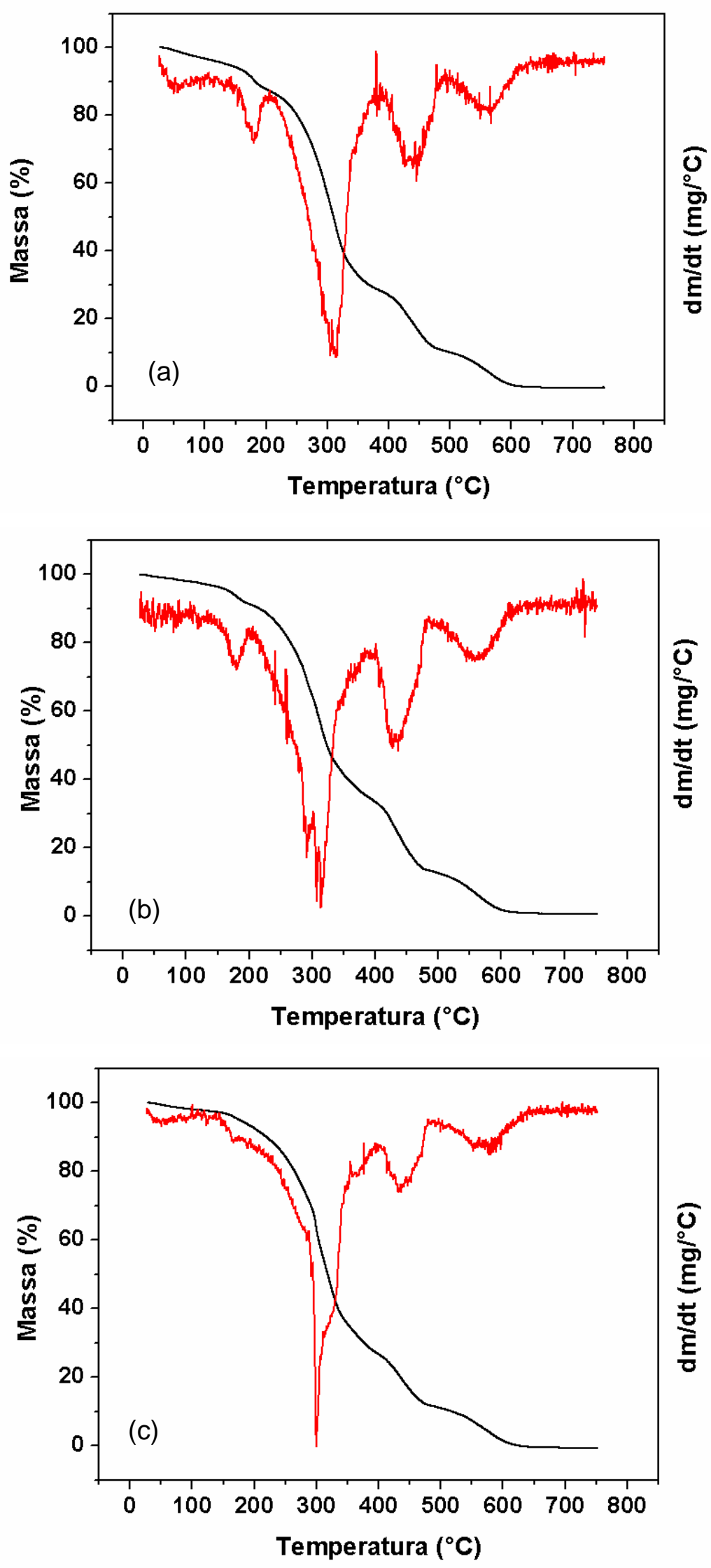

Figura 53. Curvas TG e DTG dos materiais: (a) $\operatorname{PUOMa}(1: 2) / \mathrm{BF}_{3} / 5 \mathrm{~min} / 24 \mathrm{~h}, \quad$ (b) $\mathrm{PUOMa}(1: 2) / \mathrm{BF}_{3} / 5 \mathrm{~min} / 48 \mathrm{~h}$. (c) $\mathrm{PUOMa}(1: 2) / \mathrm{BF}_{3} / 5 \mathrm{~min} / 72 \mathrm{~h}$. 
Os materiais na proporção 1:3 foram analisados por TG e suas curvas TG e DTG, nos três tempos de cura usados, são apresentadas na Figura 54. Com a mudança na proporção OMa:ureia de 1:2 para 1:3, percebe-se também algumas modificações no comportamento das curvas TG e DTG dos materiais com a proporção 1:3. A primeira delas é a redução do número de etapas de decomposição. Eles apresentam, praticamente, uma etapa de decomposição com algumas reações secundárias. Os picos das curvas DTG indicam que a primeira etapa pode ser relacionada à decomposição de ureia remanescente, enquanto a segunda e principal etapa de decomposição térmica pode ser relacionada à decomposição das ligações uretanas, acil-uretanas e cadeias carbônicas.

As curvas TG e DTG dos materiais na proporção 1:4 e nos três tempos de cura usados estão apresentadas na Figura 55. Observa-se também que o aumento da quantidade de ureia na reação modifica o perfil das curvas TG e DTG, em relação às proporções 1:2 e 1:3, assemelhando-se mais às curvas TG e DTG da proporção 1:3, onde a primeira etapa pode ser relacionada à decomposição de ureia remanescente, a segunda e principal etapa de decomposição térmica pode estar associada com as decomposições sobrepostas das ligações uretanas, acil-uretanas e cadeias carbônicas. 

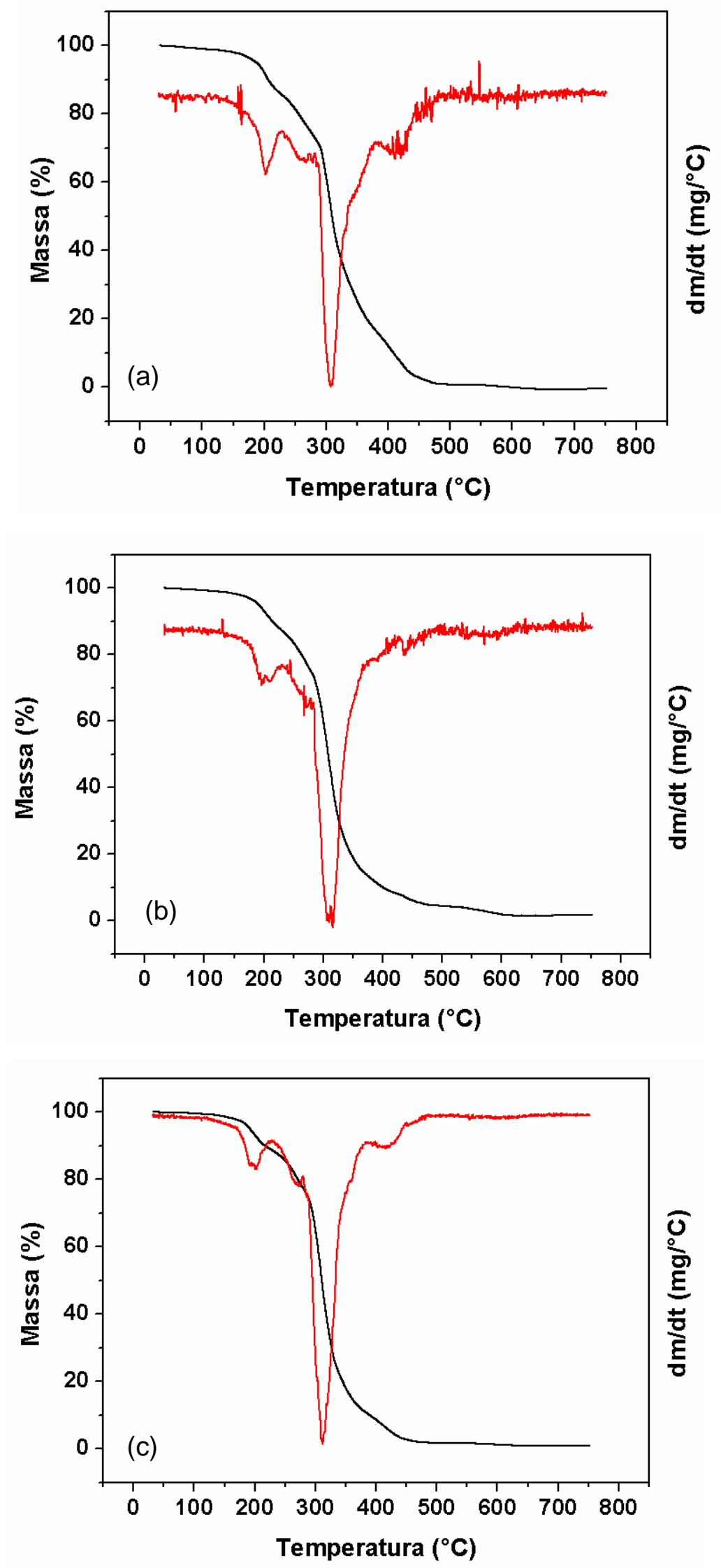

Figura 54. Curvas TG e DTG dos materiais: (a) PUOMa(1:3)/BF $/ 5 \mathrm{~min} / 24 \mathrm{~h}$, (b) PUOMa(1:3)/BF $/ 5 \mathrm{~min} / 48 \mathrm{~h}$. (c) PUOMa(1:3)/BF $/ 5 \mathrm{~min} / 72 \mathrm{~h}$. 

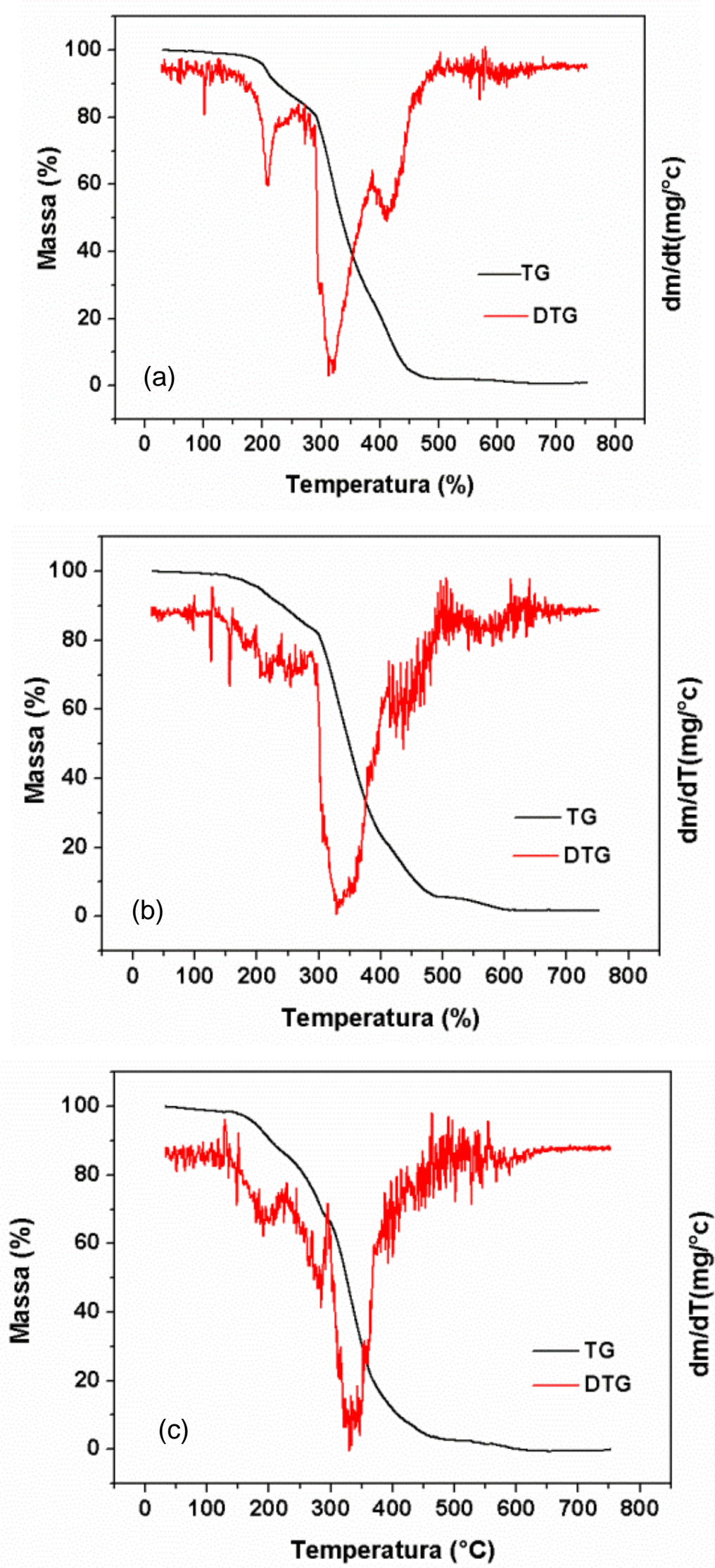

Figura 55. Curvas TG e DTG dos materiais: (a) PUOMa(1:4)/BF $/ 5 \mathrm{~min} / 24 \mathrm{~h}$, (b) $\mathrm{PUOMa}(1: 4) / \mathrm{BF}_{3} / 5 \mathrm{~min} / 48 \mathrm{~h}$. (c) $\mathrm{PUOMa}(1: 4) / \mathrm{BF}_{3} / 5 \mathrm{~min} / 72 \mathrm{~h}$. 
Usando uma maior quantidade de ureia, na proporção OMa:ureia de 1:8, foram obtidas curvas TG e DTG (Figura 56) bem distintas das curvas nas proporções anteriores, devido à nítida separação de fase entre o material polimérico formado e a ureia remanescente. Assim, para a análise, foi selecionada a porção de material que, aparentemente, tinha menor quantidade de ureia sem reagir. Então, pode-se observar que há pouca ureia se decompondo $\left(226^{\circ} \mathrm{C}\right)$ e uma etapa de decomposição térmica bem definida com $T_{d}$ em $350^{\circ} \mathrm{C}$, relacionada à decomposição das ligações uretanas, acil-uretanas e cadeias carbônicas. Os dados de $T_{d}$ e perda de massa para todas as amostras, usando o catalisador $\mathrm{BF}_{3}\left(\mathrm{Et}_{2} \mathrm{O}\right)$, estão apresentados na Tabela 9.

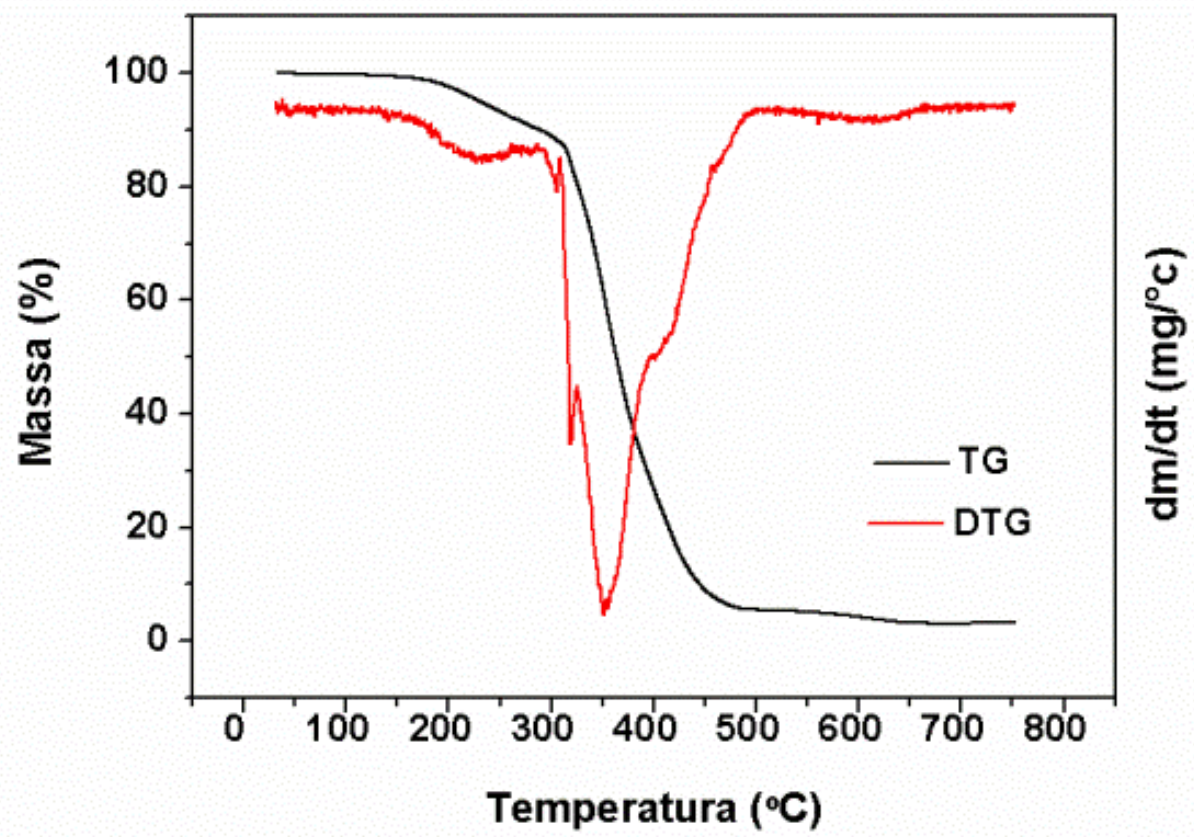

Figura 56. Curvas TG e DTG da amostra PUOMa(1:8)/BF $3 / 5 \mathrm{~min} / 24 \mathrm{~h}$.

Comparando os valores de $\mathrm{T}_{\text {onset }}$ de todos os materiais obtidos, usando 0 catalisador $\mathrm{BF}_{3}\left(\mathrm{Et}_{2} \mathrm{O}\right)$ (Figura 57) nas sínteses sem solvente, do OMa e da ureia, observa-se que foram obtidos polímeros com diferentes estabilidades térmicas, de acordo com a proporção OMa:ureia e tempo de cura utilizados. O gráfico mostra que quanto menor a quantidade de ureia na reação, exceto o $\mathrm{PUOMa}(1: 3) / \mathrm{BF}_{3} / 5 \mathrm{~min} / 48 \mathrm{~h}$, maior a estabilidade do material formado. Ou seja, todos os materiais com a proporção OMa:1:2 apresentaram estabilidade térmica entre a do OMa e da ureia, indicando, provavelmente, uma maior homogeneidade na estrutura desses materiais. No entanto, os outros materiais têm um comportamento térmico irregular, sendo possível que o aumento da quantidade de ureia promova alguma dificuldade na reação de formação do polímero, ou que dificulte uma melhor homogeneidade dos produtos formados. 


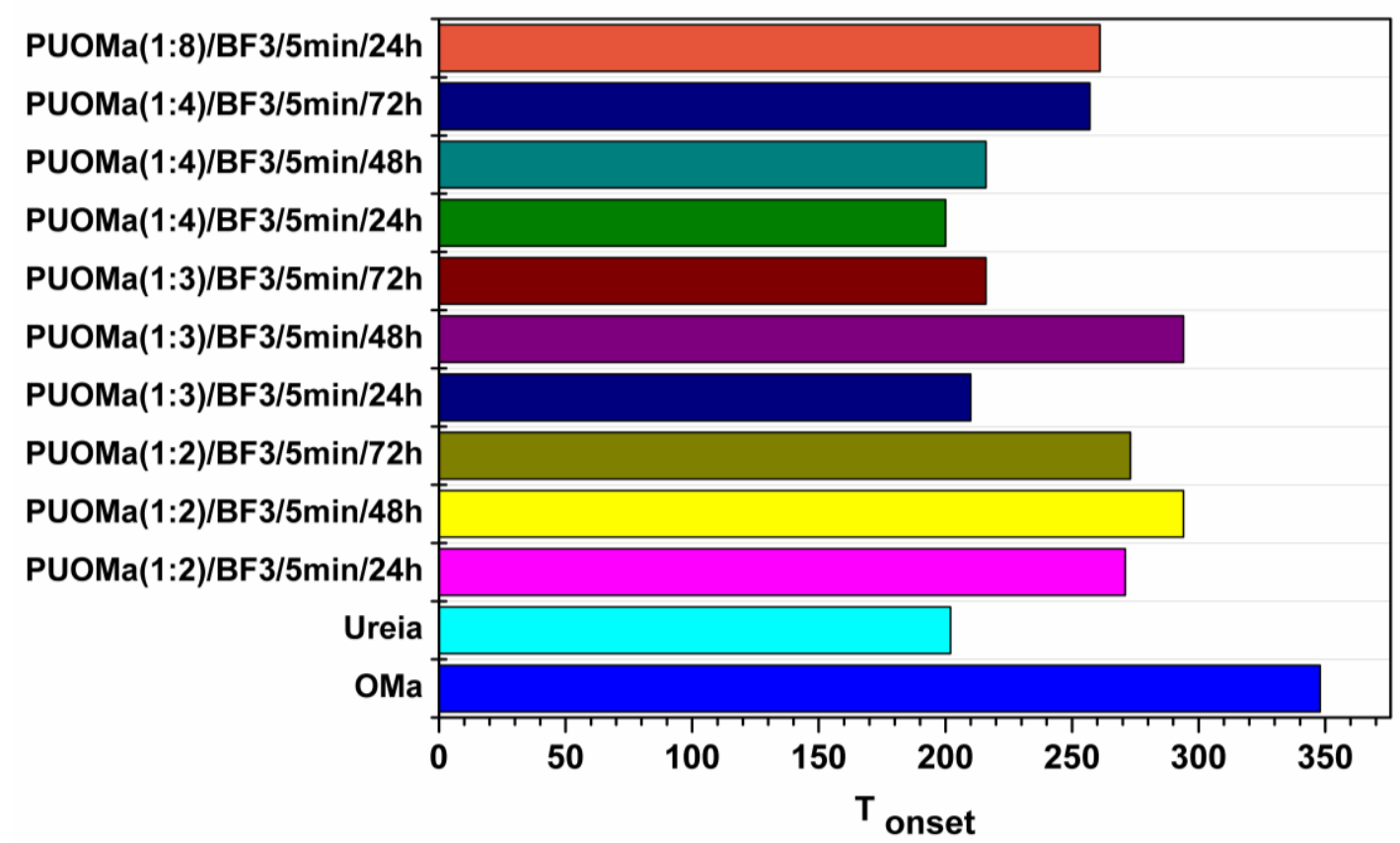

Figura 57. Comparação dos valores de $\mathrm{T}_{\text {onset }}$ do $\mathrm{OMa}$, da ureia e de todos os materiais obtidos usando o catalisador $\mathrm{BF}_{3}\left(\mathrm{Et}_{2} \mathrm{O}\right)$ nas sínteses sem solvente.

Tabela 11. Dados dos valores de $T_{d}$ e perda de massa dos materiais obtidos com diferentes proporções OMa:ureia e tempos de cura, usando o catalisador $\mathrm{BF}_{3}\left(\mathrm{Et}_{2} \mathrm{O}\right)$.

$\begin{array}{lllllll}\text { Amostra } & \mathrm{T}_{\mathrm{d}} 1 & \mathrm{~T}_{\mathrm{d}} \mathbf{2}\left({ }^{\circ} \mathrm{C}\right) & \mathrm{T}_{\mathrm{d}} 3 & \text { Perda de } & \text { Perda de } & \text { Perda de } \\ & \left({ }^{\circ} \mathrm{C}\right) & & \left({ }^{\circ} \mathrm{C}\right) & \text { massa } 1 & \text { massa } 2 & \text { massa } 3\end{array}$

\begin{tabular}{|c|c|c|c|c|c|c|}
\hline & & & & $(\%)$ & $(\%)$ & $(\%)$ \\
\hline $\mathrm{PUOMa}(1: 2) / \mathrm{BF}_{3} / 5 \mathrm{~min} / 24 \mathrm{~h}$ & 313 & 380 & 450 & 61,6 & 17,7 & 16,8 \\
\hline PUOMa(1:2)/BF $3 / 5 \mathrm{~min} / 48 \mathrm{~h}$ & 314 & 400 & 613 & 51,6 & 29,1 & 14,8 \\
\hline $\mathrm{PUOMa}(1: 2) / \mathrm{BF}_{3} / 5 \mathrm{~min} / 72 \mathrm{~h}$ & 300 & 376 & 497 & 59,8 & 24,6 & 12,9 \\
\hline $\mathrm{PUOMa}(1: 3) / \mathrm{BF}_{3} / 5 \mathrm{~min} / 24 \mathrm{~h}$ & 230 & 318 & - & 24,3 & 69,8 & - \\
\hline PUOMa(1:3)/BF $3 / 5 \mathrm{~min} / 48 \mathrm{~h}$ & 268 & 316 & - & 23,8 & 69,5 & - \\
\hline PUOMa(1:3)/BF $/ 5 \mathrm{~min} / 72 \mathrm{~h}$ & 273 & 314 & - & 24,7 & 70,5 & - \\
\hline $\operatorname{PUOMa}(1: 4) / \mathrm{BF}_{3} / 5 \mathrm{~min} / 24 \mathrm{~h}$ & 209 & 313 & - & 14,0 & 80,3 & - \\
\hline PUOMa(1:4)/BF $/ 5 \mathrm{~min} / 48 \mathrm{~h}$ & 254 & 329 & - & 13,3 & 78,8 & - \\
\hline $\operatorname{PUOMa}(1: 4) / \mathrm{BF}_{3} / 5 \mathrm{~min} / 72 \mathrm{~h}$ & 284 & 330 & - & 30,3 & 65,5 & - \\
\hline $\operatorname{PUOMa}(1: 8) / \mathrm{BF}_{3} / 5 \mathrm{~min} / 24 \mathrm{~h}$ & 226 & 351 & - & 10,3 & 83,5 & - \\
\hline
\end{tabular}


As curvas TG comparativas das proporções 1:2, 1:3 e 1:4 de OMa:ureia, nos diferentes tempos de cura, com o $\mathrm{BF}_{3}\left(\mathrm{Et}_{2} \mathrm{O}\right)$ estão apresentadas na Figura 58.
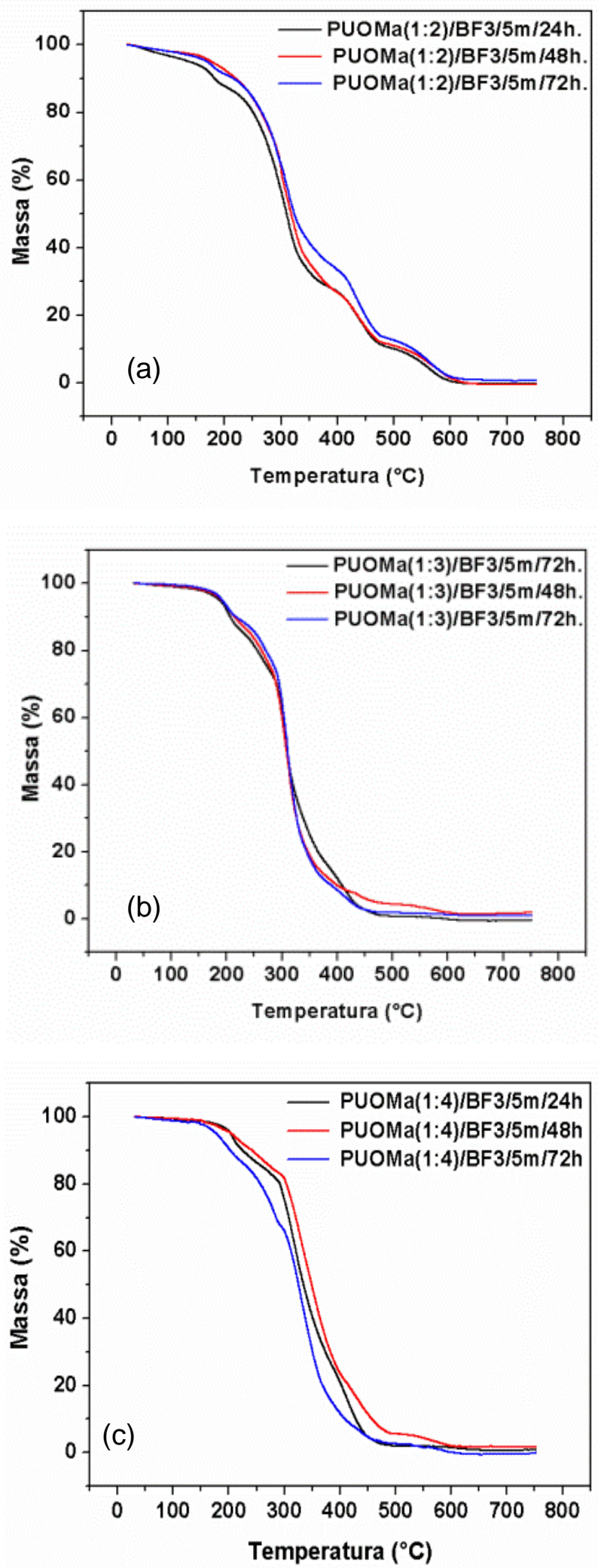

Figura 58. Curvas TG dos materiais em diferentes tempos de cura e proporção OMa:ureia: (a) $1: 2$; (b) $1: 3$ e (c) $1: 4$. 
As curvas TG comparativas permitem observar que, apesar dos materiais terem sido obtidos com tempos de cura diferentes, apresentam estabilidade térmica semelhante e perfis das curvas TG diferenciados para cada proporção OMa:ureia. No entanto, para a mesma proporção, os perfis das curvas TG são semelhantes.

É possível inferir que a proporção OMa:ureia interfere na formação das ligações cruzadas, como era previsto. Além disso, nota-se que $24 \mathrm{~h}$ de cura para esses materiais já são suficientes para a formação das ligações cruzadas, pois o comportamento das curvas TG depois desse tempo de cura não apresentam diferenças significativas. Esse resultado é importante, pois diminui o tempo de reação.

Uma vez verificado que todos os materiais obtidos na proporção OMa:ureia de 1:2, nos diferentes tempos de cura, com o catalisador $\mathrm{BF}_{3}\left(\mathrm{Et}_{2} \mathrm{O}\right)$, apresentaram melhores resultados nas técnicas utilizadas, até o momento, foram realizadas suas análises calorimétricas e as curvas DSC, que foram feitas no Laboratório de Cromatografia do Instituto de Geociências da UFPA e estão apresentadas na Figura 59. Observa-se que os três materiais apresentam transições termodinâmicas diferentes, podendo estar associados às diferentes quantidades de suas ligações cruzadas. O material com $24 \mathrm{~h}$ de cura apresenta uma discreta $T_{g}$ próxima a $-10{ }^{\circ} \mathrm{C}$, sugerindo que esse material apresenta apenas domínios amorfos. $A T_{g}$ do material curado durante 48 h é mais pronunciada e ocorre em uma faixa de temperatura maior $\left(25^{\circ} \mathrm{C}\right.$ a $\left.50{ }^{\circ} \mathrm{C}\right)$, enquanto na curva DSC do material com $72 \mathrm{~h}$ de cura nota-se, uma discreta $\mathrm{T}_{\mathrm{g}}$ e um pico endotérmico bastante largo, indicando a presença de domínios cristalinos com estruturas diferenciadas, que podem ser justificados pelo maior tempo de cura (72 h) suficiente para a formação de domínios cristalinos das cadeias da poli(acil-uretana).

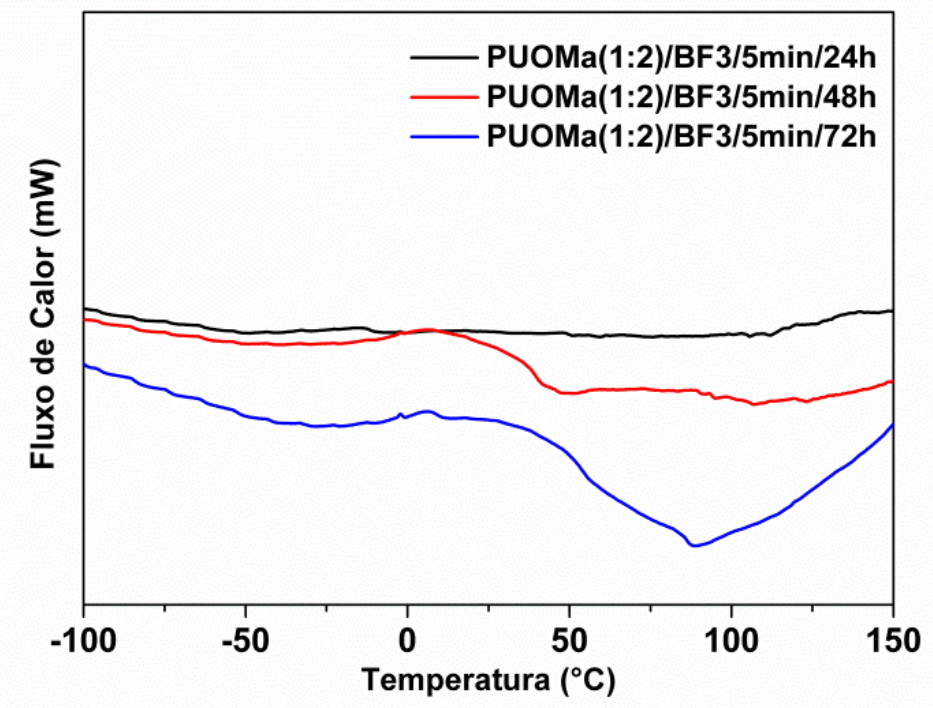

Figura 59. Curvas DSC dos materiais obtidos na proporção OMa:ureia de 1:2, nos diferentes tempos de cura, com o catalisador $\mathrm{BF}_{3}\left(\mathrm{Et}_{2} \mathrm{O}\right)$. 
Para a avaliação da absorção de água das PUs obtidas, foram realizadas medidas de absorção de umidade até $200 \mathrm{~h}$, com atmosfera controlada em umidade de $53 \%{ }^{59}$ Para esta análise, foram usados apenas os materiais na proporção 1:2 de OMa:ureia (Figura 60), tendo em vista que os materiais com proporção 1:3 e 1:4 desagregaram com cerca de $30 \mathrm{~h}$, indicando que o excesso de ureia presente na estrutura polimérica desestabiliza os materiais, por sua característica altamente higroscópica. Portanto, o material que apresentou melhores resultados para a absorção de umidade foi o com menor quantidade de ureia (1:2). Esses dados corroboram com os dados obtidos nas análises por TG e DSC.

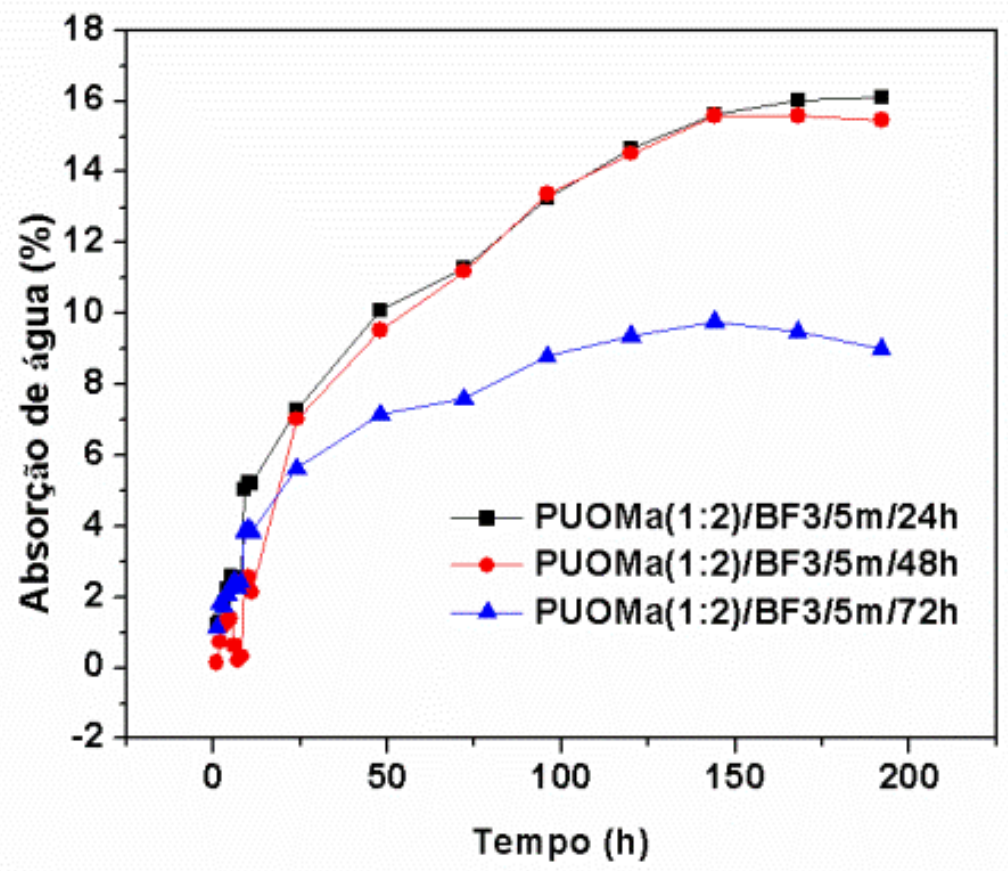

Figura 60. Curvas de absorção de umidade em função do tempo para os materiais obtidos na proporção OMa:ureia de 1:2, nos diferentes tempos de cura, com o catalisador $\mathrm{BF}_{3}\left(\mathrm{Et}_{2} \mathrm{O}\right)$.

$\mathrm{Na}$ Figura 60, observou-se que todos os materiais apresentam um ganho de massa com a absorção de água, em função do tempo. Além disso, a estabilização dos materiais se inicia após cerca de $140 \mathrm{~h}$ de exposição.

A cinética de absorção dos materiais é levemente diferente, visto que o PUOMa(1:2)/BF $/ 5 \mathrm{~min} / 72 \mathrm{~h}$, apresenta uma taxa de absorção muito menor que os demais, com absorção máxima de $8 \%$. Este fato sugere que neste material existe um maior empacotamento das cadeias poliméricas formadas, ou uma maior quantidade de ligações cruzadas. Os demais materiais, $\mathrm{PUOMa}(1: 2) / \mathrm{BF}_{3} / 5 \mathrm{~min} / 24 \mathrm{~h}$ e PUOMa(1:2)/BF $/ 5 \mathrm{~min} / 48 \mathrm{~h}$, absorveram cerca de $18 \%$ de água relativa à sua massa.

Pela diferença de tempo de cura entre os materiais, foi possível observar que a quantidade de ligações cruzadas entre as cadeias são semelhantes em 24 h e 48 h, 
tendo como base o ponto de estabilidade para a absorção de água. ${ }^{62}$ No entanto, o material com 72 h de cura, mostrou uma maior estabilidade, com menor absorção, portanto com mais ligações cruzadas, conforme já foi dito.

O mecanismo envolvido no processo de difusão com o tempo foi avaliado pela Equação 4, utilizando uma exponencial simples.

$$
\left(\frac{M_{t}-M_{0}}{M_{e q}}\right)=k t^{n}
$$

Em que,

$\mathbf{M}_{\mathbf{t}}$ é a massa da amostra, após um tempo " $\mathrm{t}$ " de exposição a um ambiente com umidade relativa controlada;

$\mathbf{M}_{0}$ é a massa da amostra antes da exposição ao referido ambiente;

$\mathbf{M}_{\mathrm{eq}}$ é a massa de água absorvida no equilíbrio;

n é o expoente de difusão

$\boldsymbol{k}$ é a constante de difusão, que caracteriza a matriz do polímero.

O expoente de difusão (n) pode ser comparado com o coeficiente angular da reta obtida, quando é traçado o gráfico In $\left(\mathrm{M}_{\mathrm{t}}-\mathrm{M}_{0} / \mathrm{M}_{\mathrm{eq}}\right)$ versus In $\mathrm{t}$. $\mathrm{E}$ a constante $\mathrm{k}$ pode ser obtida da interseção na ordenada. ${ }^{61}$ A Figura 61 mostra os dados linearizados da amostra PUOMa(1:2)/BF $/ 5 \mathrm{~min} / 24 \mathrm{~h}, \quad \mathrm{PUOMa}(1: 2) / \mathrm{BF}_{3} / 5 \mathrm{~min} / 48 \mathrm{~h} \quad \mathrm{e}$ $\mathrm{PUOMa}(1: 2) / \mathrm{BF}_{3} / 5 \mathrm{~min} / 72 \mathrm{~h}$.

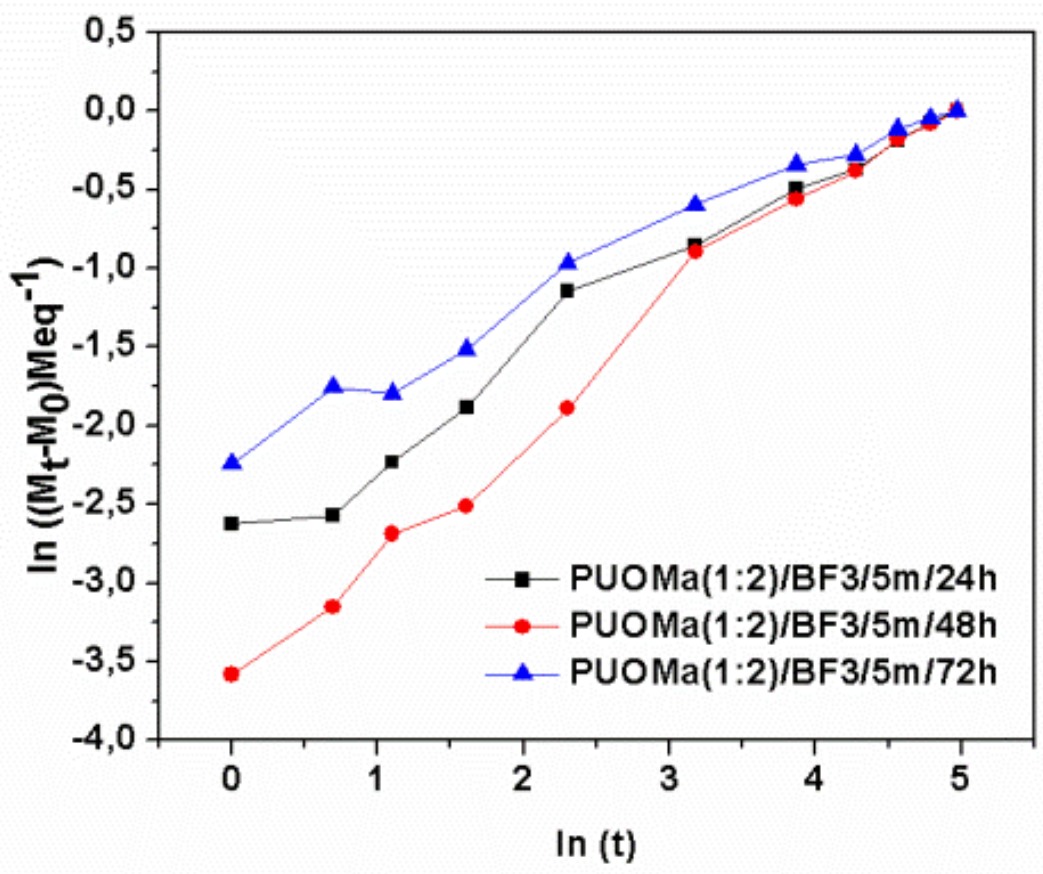

Figura 61. Linearização dos dados de absorção de água para os materiais obtidos na proporção OMa:ureia de 1:2, nos diferentes tempos de cura, com o catalisador $\mathrm{BF}_{3}\left(\mathrm{Et}_{2} \mathrm{O}\right)$. 
Na Tabela 12, estão descritos os dados de $n$ e os coeficientes de correlação $\left(R^{2}\right)$ obtidos para cada amostra.

Tabela 12. Valores do expoente de difusão para os materiais obtidos na proporção OMa:ureia de 1:2, nos diferentes tempos de cura, com o catalisador $\mathrm{BF}_{3}\left(\mathrm{Et}_{2} \mathrm{O}\right)$.

\begin{tabular}{cccc}
\hline Amostra & $\mathbf{n}$ & $\mathbf{R}^{2}$ & \\
\hline $\mathrm{PUOMa}(1: 2) / \mathrm{BF}_{3} / 5 \mathrm{~min} / 24 \mathrm{~h}$ & 0,56486 & 0,98051 & Não-fickiana \\
& & & Anômala \\
$\operatorname{PUOMa}(1: 2) / \mathrm{BF}_{3} / 5 \mathrm{~min} / 48 \mathrm{~h}$ & 0,74803 & 0,98969 & Não-fickiana \\
& & & Anômala \\
PUOMa(1:2)/BF $/ 5 \mathrm{~min} / 72 \mathrm{~h}$ & 0,45224 & 0,98396 & Fickiana \\
\hline
\end{tabular}

A difusão não-Fickiana do tipo Caso II ocorre quando $n$ é igual a 1 e a taxa de difusão é diretamente proporcional ao tempo. Para valores de $n$ entre 0,5 e 1 , a difusão é chamada de não-Fickiana do tipo anômala. Quando n é igual ou menor do que 0,5 , a difusão é conhecida como Fickiana, ou do tipo Caso I. ${ }^{63}$

A difusão de Fickiana é caracterizada por uma taxa de difusão do solvente mais lenta do que a taxa de relaxação do polímero. ${ }^{64}$ Os movimentos moleculares aleatórios são os principais responsáveis pela difusão e o movimento da matéria de uma parte para outra. ${ }^{64,66}$

A velocidade de difusão em um material depende da homogeneidade do material, da presença de grupos capazes de formar ligações de hidrogênio com a água, da polaridade de alguns grupos moleculares, da $T_{g}$ e da cristalinidade. ${ }^{60,65,66}$

O coeficiente de difusão (D) expressa a capacidade da água se difundir pelo material, que pode ser determinado pelo rearranjo da Equação 2 na forma de uma equação da reta, obtendo-se: ${ }^{64,66}$

$$
\left(\frac{M_{t}-M_{0}}{M_{e q}}\right)=\frac{4}{\pi^{1 / 2}} \times D^{1 / 2} \times \frac{t^{1 / 2}}{L}
$$

Onde, $L$ é a espessura do material e $D$ é o coeficiente de difusão.

A Figura 62 apresenta as curvas de sorção (Mt-M0)/Meq em função de $t^{1 / 2} / \mathrm{L}$ para os materiais $\mathrm{PUOMa}(1: 2) / \mathrm{BF}_{3} / 5 \mathrm{~min} / 24 \mathrm{~h}, \quad \mathrm{PUOMa}(1: 2) / \mathrm{BF}_{3} / 5 \mathrm{~min} / 48 \mathrm{~h} \quad \mathrm{e}$ $\operatorname{PUOMa}(1: 2) / \mathrm{BF}_{3} / 5 \mathrm{~min} / 72 \mathrm{~h}$. 


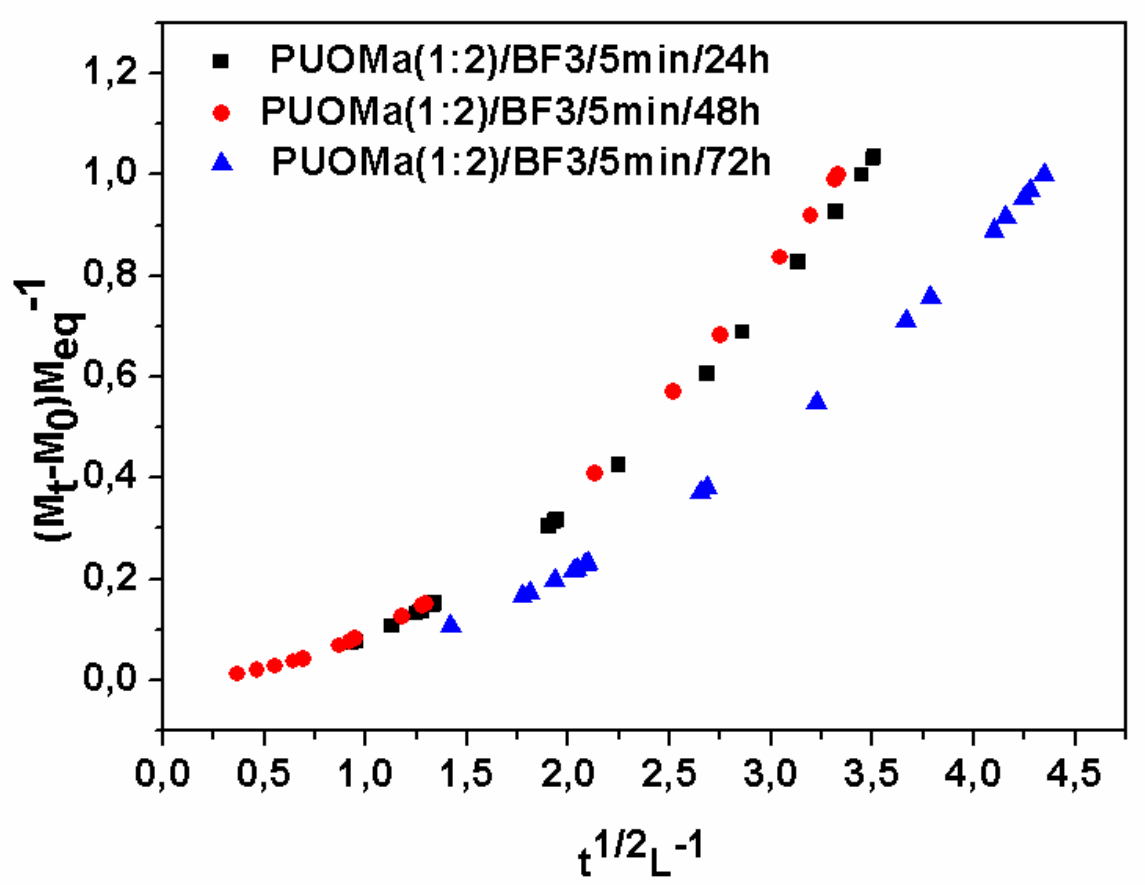

Figura 62. Curvas de cinética de sorção para os materiais obtidos na proporção OMa:ureia de 1:2, nos diferentes tempos de cura, com o catalisador $\mathrm{BF}_{3}\left(\mathrm{Et}_{2} \mathrm{O}\right)$.

O coeficiente de difusão da água é calculado a partir do coeficiente angular da reta do primeiro estágio das curvas mostradas na Figura 62 e expresso pela Equação 6, curva esta obtida pelos primeiros 9 pontos do primeiro estágio, em que "a" é o coeficiente angular da reta.

$$
D=a^{2} \times \frac{\pi}{16}
$$

A Tabela 13 apresenta os valores do coeficiente de difusão "D", referentes a cada amostra.

Tabela 13. Valores do coeficiente de difusão para os materiais obtidos na proporção OMa:ureia de 1:2, nos diferentes tempos de cura, com o catalisador $\mathrm{BF}_{3}\left(\mathrm{Et}_{2} \mathrm{O}\right)$.

\begin{tabular}{cccc}
\hline Amostra & $\mathbf{a}$ & $\mathbf{R}^{2}$ & $\mathbf{D}\left(\mathbf{m m}^{2} \mathbf{s}^{-1}\right)$ \\
\hline $\mathrm{PUOMa}(1: 2) / \mathrm{BF}_{3} / 5 \mathrm{~min} / 24 \mathrm{~h}$ & 0,13114 & 0,99789 & $3,37505 \times 10^{-3}$ \\
$\mathrm{PUOMa}(1: 2) / \mathrm{BF}_{3} / 5 \mathrm{~min} / 48 \mathrm{~h}$ & 0,12172 & 0,98391 & $2,90759 \times 10^{-3}$ \\
$\mathrm{PUOMa}(1: 2) / \mathrm{BF}_{3} / 5 \mathrm{~min} / 72 \mathrm{~h}$ & 0,18719 & 0,99591 & $6,87662 \times 10^{-3}$
\end{tabular}

É possível perceber que o tempo de cura dos materiais gerou influência nos valores do coeficiente de difusão, sendo mais pronunciada no tempo de cura de $72 \mathrm{~h}$, 
sugerindo que o coeficiente de difusão estaria mais relacionado com outros fatores, como o volume livre e a $\mathrm{T}_{\mathrm{g}}$.

Para confirmar se os materiais obtidos na proporção OMa:ureia de 1:2, nos diferentes tempos de cura, usando o catalisador $\mathrm{BF}_{3}\left(\mathrm{Et}_{2} \mathrm{O}\right)$ eram de fato polímeros, foram medidas as suas massa molares por GPC. A Figura 63 mostra as curvas de distribuição da massa molar para os três materiais em estudo. As massas molares médias e a polidispersividade, definidas no item 3.3.8 da Parte Experimental e obtidas pela análise de GPC estão apresentadas na Tabela 14.

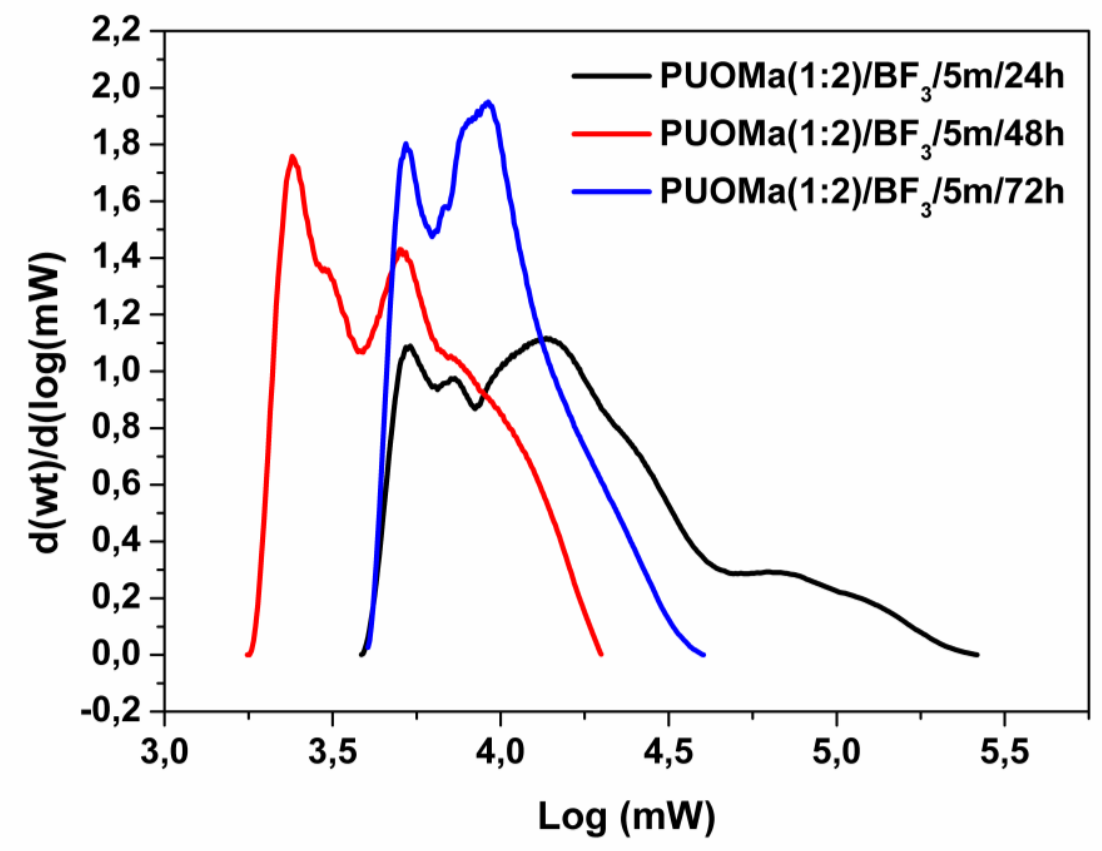

Figura 63. Curvas GPC para PUOMa(1:2)/BF $/ 5 \mathrm{~min} / 24 \mathrm{~h}, \quad \mathrm{PUOMa}(1: 2) / \mathrm{BF}_{3} / 5 \mathrm{~min} / 48 \mathrm{~h}$ e $\mathrm{PUOMa}(1: 2) / \mathrm{BF}_{3} / 5 \mathrm{~min} / 72 \mathrm{~h}$.

Tabela 14. Massas molares médias e polidispersividade, obtidas por GPC, dos materiais na proporção OMa:ureia de 1:2, nos diferentes tempos de cura, com o catalisador $\mathrm{BF}_{3}\left(\mathrm{Et}_{2} \mathrm{O}\right)$.

\begin{tabular}{ccccc}
\hline Amostra & $\begin{array}{c}\overline{M M}\left(\mathbf{g ~ m o l}^{-1}\right) \\
\text { Massa molar } \\
\text { média }\end{array}$ & $\begin{array}{c}\overline{M_{n}}\left(\mathbf{g ~ m o l}^{-1}\right) \\
\text { Massa numérica } \\
\text { média }\end{array}$ & $\begin{array}{c}\overline{M_{w}}\left(\mathbf{g ~ m o l}^{-1}\right) \\
\text { Massa ponderal } \\
\text { média }\end{array}$ & $\begin{array}{c}\text { Polidispersividade } \\
\left(\overline{M_{w}} / \overline{M_{n}}\right)\end{array}$ \\
\hline $\operatorname{PUOMa}(1: 2) / \mathrm{BF}_{3} / 5 \mathrm{~m} / 24 \mathrm{~h}$ & 64.6 & 11.8 & 25.6 & 2,2 \\
$\operatorname{PUOMa}(1: 2) / \mathrm{BF}_{3} / 5 \mathrm{~m} / 48 \mathrm{~h}$ & 8.0 & 4.2 & 5.8 & 1,4 \\
$\operatorname{PUOMa}(1: 2) / \mathrm{BF}_{3} / 5 \mathrm{~m} / 72 \mathrm{~h}$ & 13.5 & 8.45 & 10.5 & 1,2 \\
\hline
\end{tabular}

De acordo com a Figura 63 e os dados apresentados na Tabela 14, confirma-se que os materiais PUOMa(1:2)/BF $/ 5 \mathrm{~m} / 24 \mathrm{~h}$ e $\mathrm{PUOMa}(1: 2) / \mathrm{BF}_{3} / 5 \mathrm{~m} / 72 \mathrm{~h}$ são polímeros pelos valores das massas molares médias acima de $10.000 \mathrm{~g} \mathrm{~mol}^{-1}$, embora a $\overline{M_{n}}$ do 
material com $72 \mathrm{~h}$ de cura seja menor que $10.000 \mathrm{~g} \mathrm{~mol}^{-1}$. O material obtido com $48 \mathrm{~h}$ de cura é classificado como oligômero.

As curvas de distribuição de massa molar (Figura 63) mostram um comportamento polidisperso monomodal com ombros, sendo que o $\mathrm{PUOMa}(1: 2) / \mathrm{BF}_{3} / 5 \mathrm{~m} / 24 \mathrm{~h}$, embora apresente maior massa molar média, é o que apresenta maior polidispersividade $(2,2)$, ou seja, maior variação de tamanho das cadeias poliméricas. Já, o PUOMa(1:2)/BF $/ 5 \mathrm{~m} / 72 \mathrm{~h}$ é o material com menor polidispersividade, isto é, maior homogeneidade no tamanho das cadeias.Vale ressaltar que, o PUOMa(1:2)/BF $/ 5 \mathrm{~m} / 24 \mathrm{~h}$ foi totalmente solúvel em THF, para execução da análise, enquanto os outros dois materiais foram parcialmente solúveis em THF. Daí, um melhor resultado para o material com $24 \mathrm{~h}$ de cura. Acredita-se, então, que a parte insolúvel das poli(acil-uretanas) apresentam maiores massas molares que as detectadas. Portanto, não podemos descartar totalmente a hipótese de que as poli(acila-uretanas) PUOMa(1:2)/BF $/ 5 \mathrm{~m} / 48 \mathrm{~h}$ não são um material polimérico.

As Figuras 64 a 67 apresentam as imagens digitais das poli(acil-uretanas) obtidas, em diferentes ângulos. 

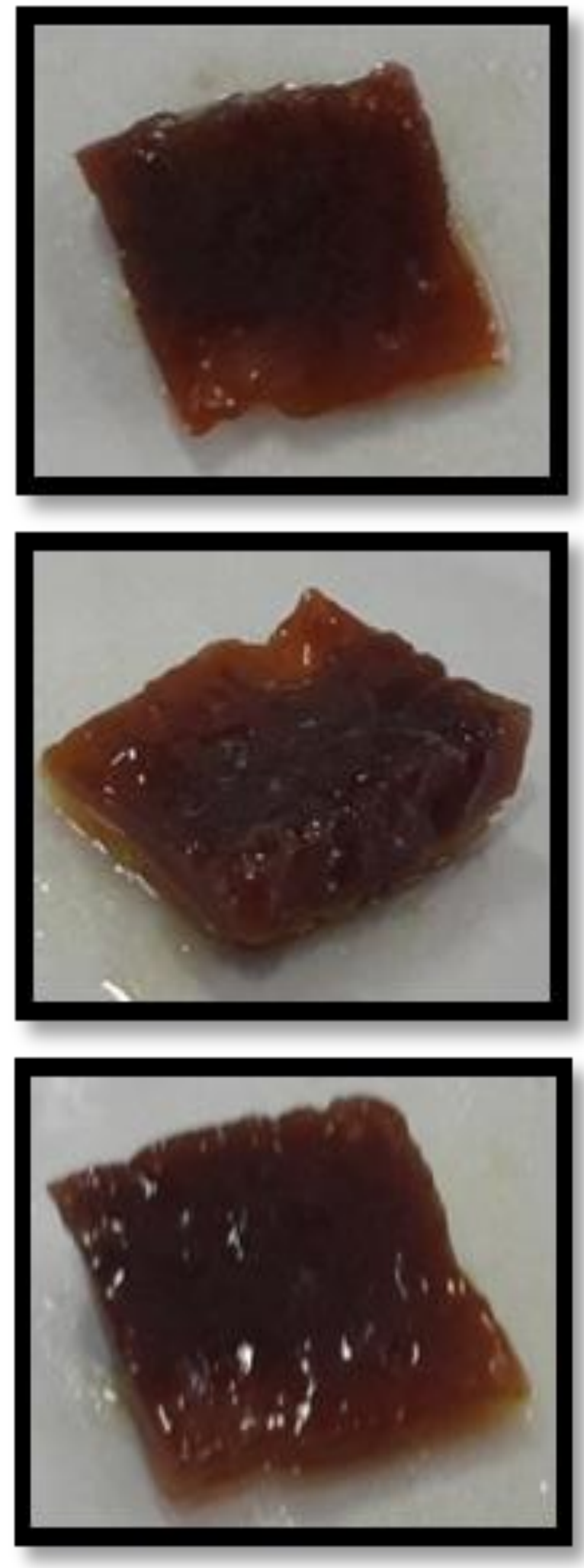

Figura 64. Imagens digitais da poli(acil-uretana) PUOMa(1:2)/BF $/ 3 / 5 m / 24 h$. 

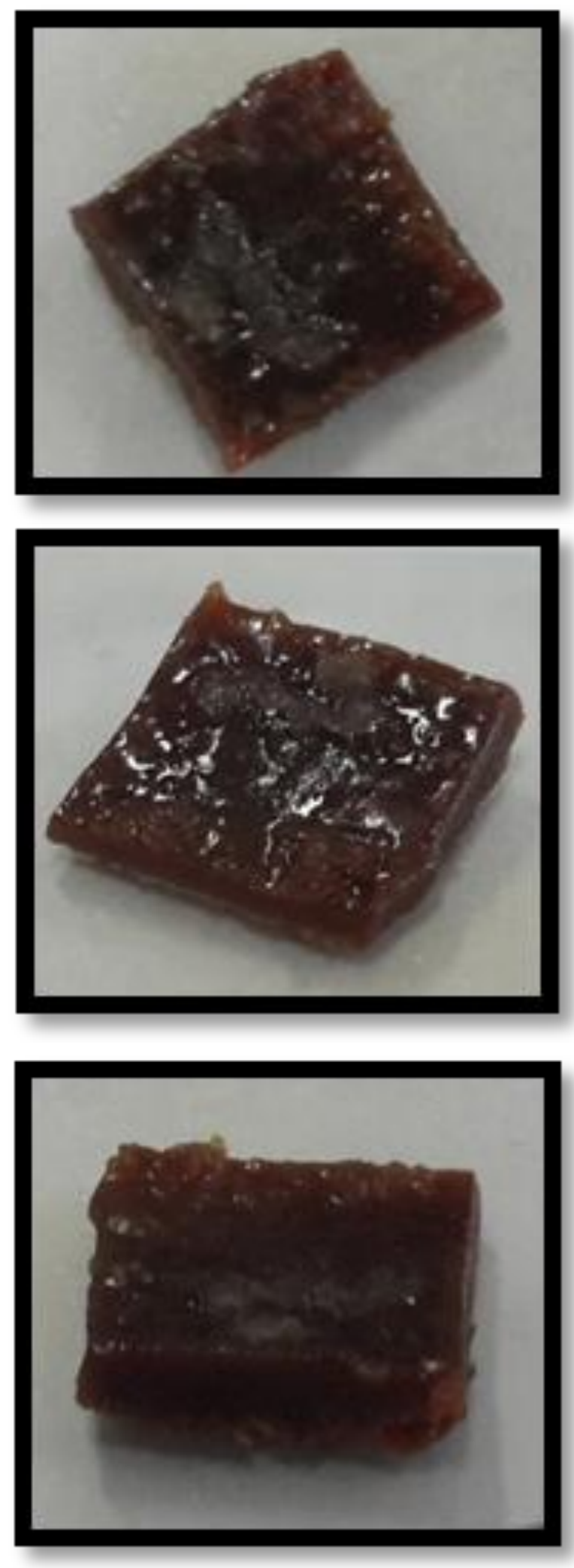

Figura 65. Imagens digitais da poli(acil-uretana) $\mathrm{PUOMa}(1: 2) / \mathrm{BF}_{3} / 5 \mathrm{~m} / 48 \mathrm{~h}$. 

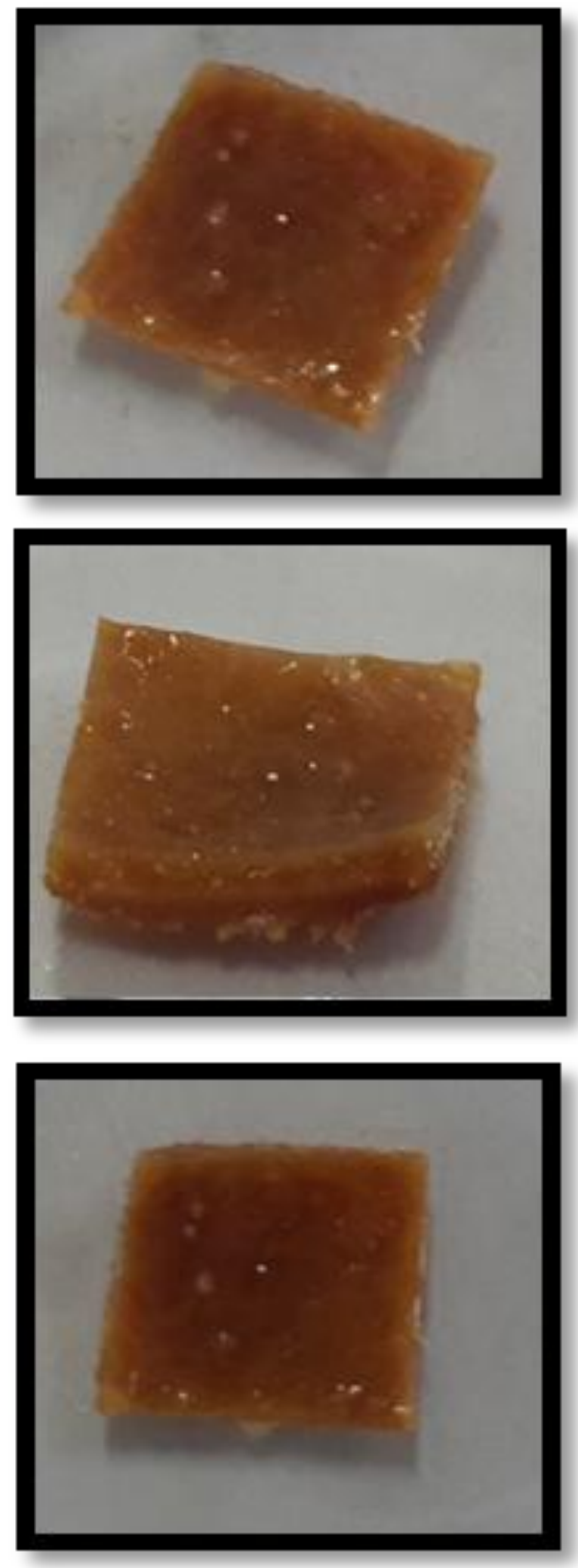

Figura 66. Imagens digitais da poli(acil-uretana) $\mathrm{PUOMa}(1: 2) / \mathrm{BF}_{3} / 5 \mathrm{~m} / 72 \mathrm{~h}$. 


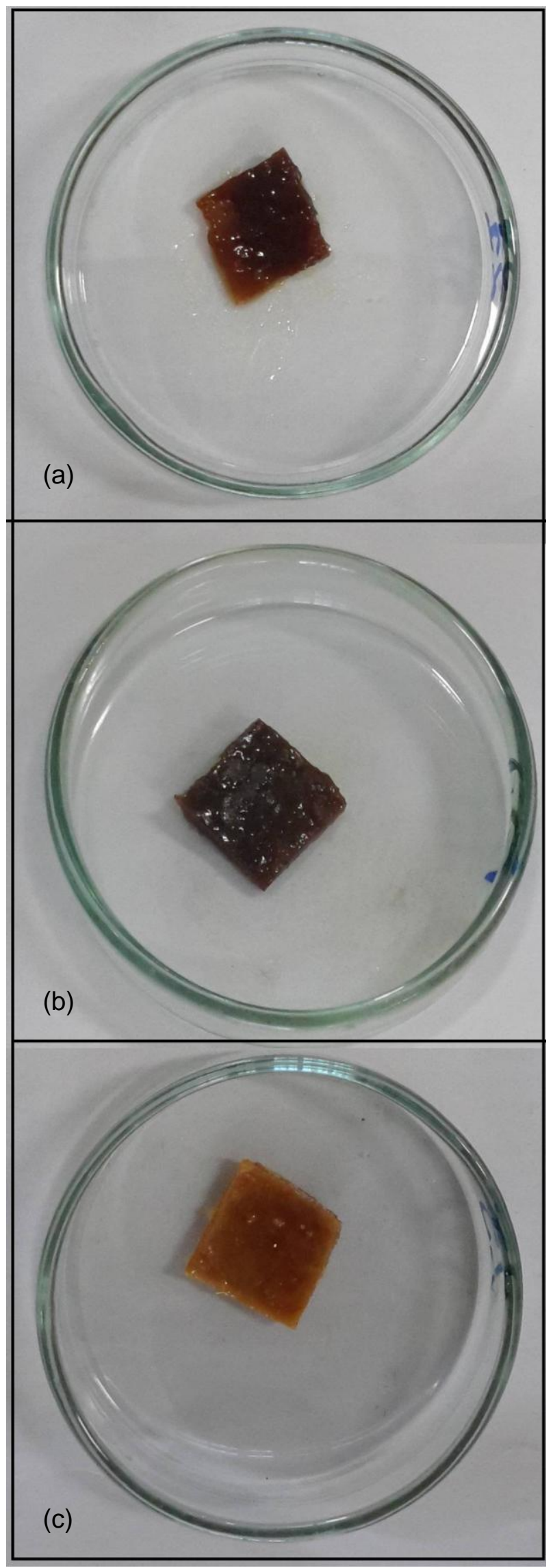

Figura 67. Imagens digitais das poli(acil-uretanas): (a) PUOMa(1:2)/BF $/ 5 \mathrm{~m} / 24 \mathrm{~h}$, (b) PUOMa(1:2)/BF $/ 5 \mathrm{~m} / 48 \mathrm{~h}$ e (c) PUOMa(1:2)/BF $/ 5 \mathrm{~m} / 72 \mathrm{~h}$. 


\subsection{PROPOSTA PRELIMINAR DO MECANISMO DE REAÇÃO COM CATÁLISE.}

Como proposta de polimerização o Esquema 1 demonstra o mecanismo de reação sugerido. $\mathrm{O} \mathrm{BF}_{3}\left(\mathrm{Et}_{2} \mathrm{O}\right)$ foi escolhido como catalisador para exemplificação do mecanismo, pelo fato de que dentre os materiais sintetizados, os que apresentaram os melhores resultados foram os sintetizados com o uso dele como catalisador.

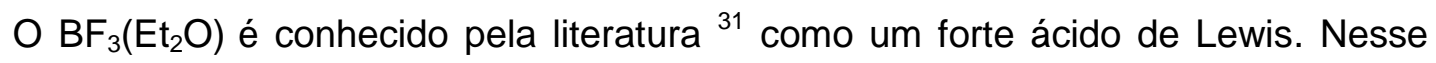
composto os átomos de flúor, por possuírem maior eletronegatividade, atraem os elétrons do átomo do boro formando uma carga parcial positiva no mesmo (Figura 68). Sendo assim, o boro que já possui um orbital $p$ livre, se torna altamente eletrofilico. ${ }^{31}$ Essa eletrofilicidade, em meio reacional, favorece a ligação com pares de elétrons livres de diversos átomos no sistema, incluindo os pares de elétrons livres dos oxigênio de carbonilas e carboxilas.

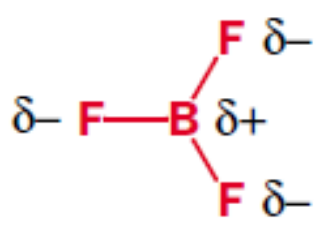

Figura 68. Representação das cargas parciais do composto $\mathrm{BF}_{3}\left(\mathrm{Et}_{2} \mathrm{O}\right) \cdot{ }^{31}$

No mecanismo proposto, na primeira etapa ocorre a formação da ligação do $\mathrm{BF}_{3}\left(\mathrm{Et}_{2} \mathrm{O}\right)$ com os pares de elétrons livres do oxigênio do da carboxila do éster na cadeia do ácido rícino do óleo de mamona. Esta ligação orienta o ataque à carboxila do éster, que se dá pelo ataque dos pares de elétrons livres do nitrogênio da ureia. Esse ataque só se torna possível por tal ação do catalisador.

Posteriormente ocorre uma transferência de um próton entre o nitrogênio originalmente da ureia, com o oxigênio originalmente do éster do óleo. Essa transferência se faz necessária para uma estabilização de cargas da estrutura.

Ocorre então, a restauração da carbonila com a eliminação do grupo $\mathrm{R}-\mathrm{OH}$, que possui um $\mathrm{pK}_{\mathrm{aH}}$ igual a -5 , sendo portanto este grupo o mais favorecido para tal eliminação.

Acredita-se na que há a formação de glicerol como subproduto da reação. Essa possibilidade é confirmada quando se analisa o espectro de $\mathrm{RMN}{ }^{1} \mathrm{H}$ da Figura 49. Os deslocamentos químicos em 3,4 ppm e 3,8 ppm característicos de hidrogênios metilenicos e metínicos do glicerol, além do deslocamento em 5,4 ppm característico de hidrogênios hidroxílicos. ${ }^{69}$ 
Com a formação da estrutura N-carbomilacetilamida, é sugerido que ocorra um ataque nucleofílico dos pares de elétrons livres do oxigênio da hidroxila do óleo na carbonila entre nitrogênios da estrutura.

Na sequência, acredita-se que ocorre a transferência de prótons entre o grupo R$\mathrm{OH}^{+}$e o grupo $\mathrm{NH}_{2}$ cujo nitrogênio possui um par de elétrons livres, ocorrendo, portanto, a formação do grupo $\mathrm{NH}_{3}$.

Em seguida, há a eliminação da amônia $\left(\mathrm{NH}_{3}\right)$ da estrutura, etapa justificada por várias razões, como: o $\mathrm{NH}_{3}$ possui um $\mathrm{PK}_{\mathrm{aH}}$ igual a 9, sendo um bom grupo de saída, além de um forte odor de amônia durante a reação.

Comparando a eletrofilicidade das carbonilas ${ }^{31}$, o mecanismo sugere que 0 ataque ocorra à carbonila menos eletrofilica, pela possibilidade da eliminação da amônia na etapa seguinte, que é um bom grupo de saída, como já citado. E caso o ataque ocorresse na carbonila do grupo acila, não haveria um bom grupo de saída. Além disso, a importância da hidroxila para tal etapa será mostrada no tópico 4.5.

Por fim, corroborando os dados de caracterização apresentados pelas análises de RMN ${ }^{1} \mathrm{H}$ e FT-IR, com o mecanismo de reação proposto (Esquema 1), acredita-se que há a formação do grupo $\mathrm{N}$-aciluretana ou $\mathrm{N}$-acilcarbamato.

Adicionalmente, com os dados das caracterizações químicas e físico-químicas apresentados ao longo da dissertação, infere-se que pode ter se formado uma nova classe de poliuretanas, as poli(acil-uretanas). 
<smiles>[R]C(=O)OCC(COC([R])=O)(CO[B-](F)(F)F)OC(=O)CCCC</smiles><smiles>[R]C(=O)OCC1COC([R])(O[B-](F)(F)F)COC(NC(N)=O)C1</smiles><smiles>[R]C(=O)OCC(COC([R])=O)OCC([R])(CO[P+](F)(F)F)OC(N)=O</smiles><smiles>[R]C(=O)NC(N)=O</smiles><smiles>[R]C(=O)NC(N)=O</smiles>

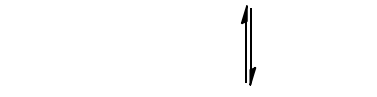

$$
\text { 列 }
$$<smiles>[R]C(=O)NC([NH-])([O-])COC(=O)CCCCCCC/C=C/CC(COC([R])=O)COC([R])=O</smiles><smiles>[R]C(=O)NC([O-])([O-])NC(C)=O</smiles><smiles>[R]C(=O)NC(=O)OC(C/C=C\CCCCCCC(=O)OCC(COC([R])=O)OC([R])=O)CCCCCC</smiles><smiles>[R]CCCCCCC(O)CC=CCCCCCCC(C)(C)C</smiles><smiles>CCCCCCCC(C/C=C/CCCCCCC(=O)NC(=O)CC)OCC</smiles>

Esquema 2. Proposta preliminar do mecanismo de reação para a síntese da poli(acil-uretana) livre de isocianato. 


\subsection{CONTRA PROVAS DA PROPOSTA PRELIMINAR DO MECANISMO DE REAÇÃO COM CATÁLISE.}

Com o intuito de comprovar o mecanismo de reação sugerido, foi realizada a mesma reação, mas utilizando o óleo de maracujá (OM). A escolha do óleo é justificada pelo mesmo possuir principalmente em sua composição o ácido linoléico que em sua estrutura não possui as hidroxilas características do ácido rícino, presente prioritariamente no óleo de mamona. A Tabela 15 mostra a composição OM, obtida em estudos realizados por Lopes et al. ${ }^{3}$

Tabela 15. Composição percentual (\%) dos principais ácidos graxos do OM. ${ }^{3}$

\begin{tabular}{cc}
\hline Ácidos graxos & Composição $(\%)$ \\
\hline Palmítico $\left(\mathrm{C}_{18: 0}\right)$ & 10,50 \\
Esteárico $\left(\mathrm{C}_{18: 0}\right)$ & 1,60 \\
Oléico $\left(\mathrm{C}_{18: 1}\right)$ & 13,90 \\
Linoléico $\left(\mathrm{C}_{18: 2}\right)$ & 72,80 \\
Linolênico $\left(\mathrm{C}_{18: 3}\right)$ & 0,50 \\
$\Sigma$ saturados & $\mathbf{1 2 , 1 0}$ \\
$\Sigma$ insaturados & $\mathbf{8 7 , 2 0}$
\end{tabular}

A Figura 68 apresenta o espectro no FT-IR do OM e do seu produto da reação com ureia (MatOmaracujá(1:2)/BF $/ 5 \mathrm{~m} / 24 \mathrm{~h}$ ). As bandas que se destacam são em: $3009 \mathrm{~cm}^{-}$ 1, que indica que o óleo é rico em ácidos poli-insaturados; $2900 \mathrm{~cm}^{-1}$ e $2850 \mathrm{~cm}^{-1}$, estiramento assimetrico referente ao carbono $\mathrm{sp}^{3}$ e $\mathrm{sp}^{2}$ das cadeias alifáticas e a banda de carbonila de éster próxima a $1740 \mathrm{~cm}^{-1}$. Sendo assim, é possível perceber que os dois possuem as mesmas faixas de absorção, indicando que não ocorreu reação do OM com a ureia. 


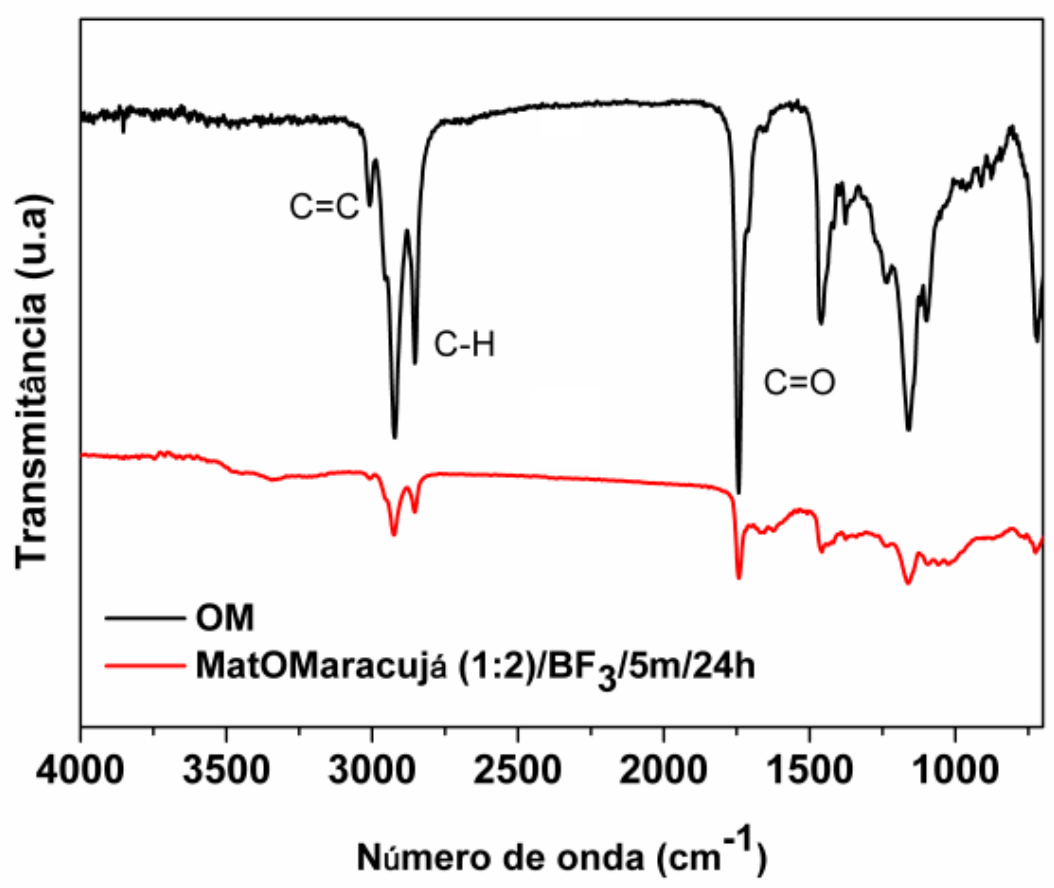

Figura 69. Espectro no FT-IR da amostra MatOmaracujá(1:2)/BF $3 / 5 \mathrm{~m} / 24 \mathrm{~h}$.

Corroborando com o resultado do FT-IR, a análise de RMN ${ }^{1} \mathrm{H}$ (Figura 70) mostra que os deslocamentos químicos do $\mathrm{OM}$ são os mesmos que o da amostra MatOmaracujá(1:2)/BF $3 / 5 \mathrm{~m} / 24 \mathrm{~h}$, confirmando que a reação do $\mathrm{OM}$ com a ureia não ocorre. Isso pode ser mais um indicativo de que a hidroxila é um importante grupo para a reação, participando em alguma etapa da mesma, podendo ser como o demonstrado no mecanismo de reação. Os sinais do espectro $R M N{ }^{1} \mathrm{H}$ são indicados na estrutura que representa o OM (Figura 71). 


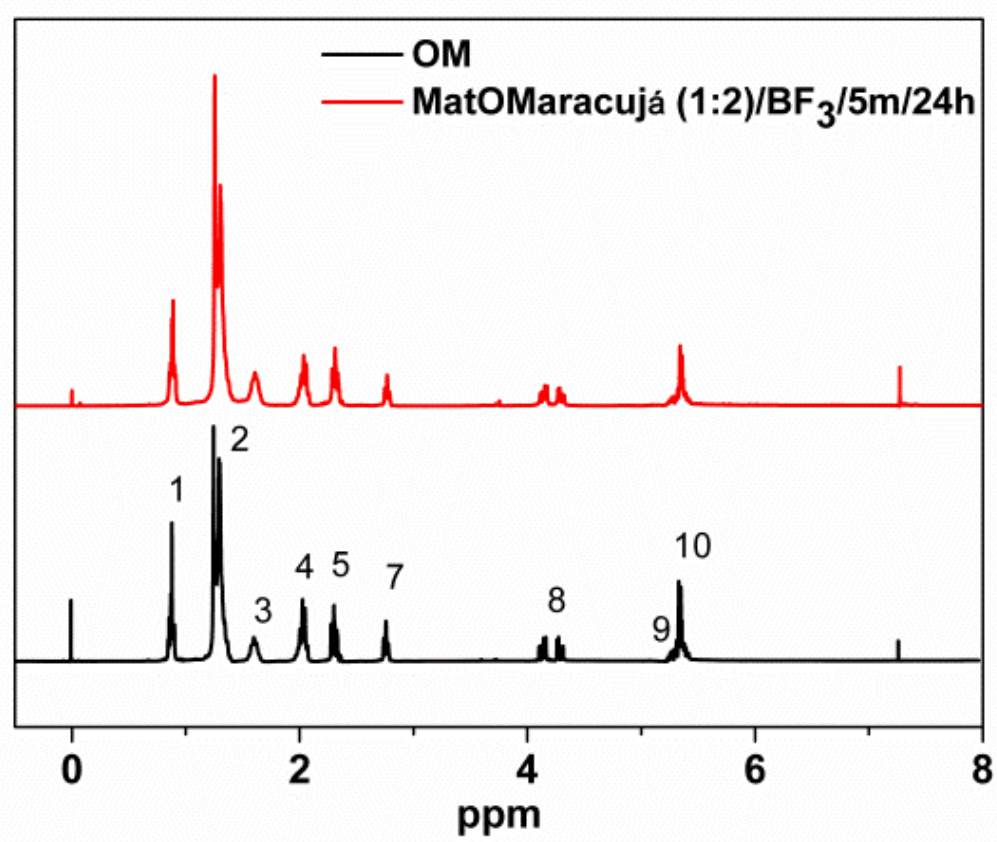

Figura 70. Espectros de $\mathrm{RMN}^{1} \mathrm{H}$ do $\mathrm{OM}$ e do material MatOmaracujá(1:2)/BF $/ 5 \mathrm{~m} / 24 \mathrm{~h}$.

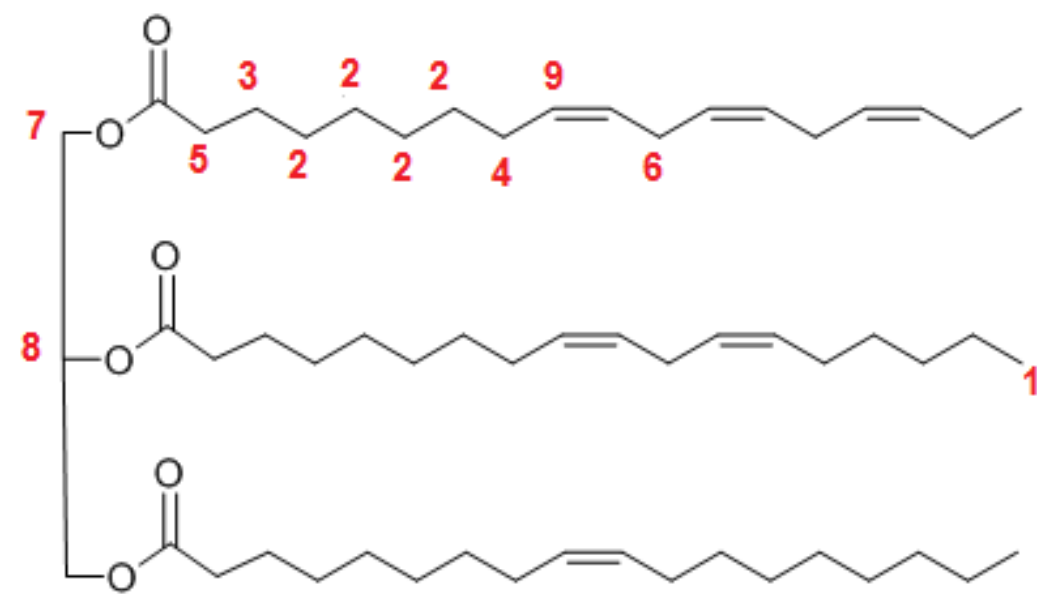

Figura 71. Estrutura representando o OM. 


\section{Capítulo 5}

CONCLUSÕES E TRABALHOS FUTUROS 


\subsection{CONCLUSÕES}

As sínteses com a utilização de etanol como solvente favoreceram, possivelmente, a formação apenas de oligômeros, que foram de extrema importância, pois indicaram que a reação era viável.

A síntese dos materiais sem a utilização de solvente se mostrou mais viável, considerando que ligações uretanas foram formadas e de fato uma estrutura polimérica.

A estabilidade dos materiais ainda é questionável, tendo em vista a grande absorção de umidade obtida pela maioria das proporções utilizadas nas sínteses.

A formação da poli(acil-uretana) foi confirmada e se mostrou estável, com síntese simples para reprodução, podendo ser otimizada para possíveis aplicações.

A poli(acil-uretana) com proporção 1:2 de OMa:ureia, menor quantidade de ureia utilizada, apresentou maior massa molar média, confirmando a formação de um polímero (massa molar média acima de 60.000). Esses dados favorecem ainda mais a síntese do material, tendo em vista, também, a redução do uso dos materiais de partida.

A tentativa infrutífera da reação do $\mathrm{OM}$ com a ureia confirmou o mecanismo proposto da formação das poli(acil-uretanas) a partir do OMa com a ureia.

$\mathrm{O}$ catalisador $\mathrm{BF}_{3}\left(\mathrm{Et}_{2} \mathrm{O}\right)$ foi o mais eficiente, mas ainda não é o ideal para a proposta geral do trabalho. 


\subsection{TRABALHOS FUTUROS}

Inicialmente, para futuros trabalhos, os autores pretendem realizar mais caracterizações químicas, físico-químicas como analises dinâmico-mecânico (DMA) e morfológicas das poli(acil-uretanas), com o intuito de propor possíveis aplicações para os materiais.

Aprimorar os parâmetros da reação, para aperfeiçoar o processo de produção das poli(acil-uretanas), envolvendo a utilização de outros catalisadores, que desempenhem a mesma função dos ácidos de Lewis, como algum sal de alumínio.

Como forma de prever uma possível aplicação, deseja-se realizar testes de biocompatibilidade do material in vitro.

Testar a síntese com outros precursores, como polióis de óleos vegetais, polióis dos seus respectivos biodieseis e com ácidos graxos relacionados aos óleos vegetais utilizados, com o intuito de melhorar as propriedades químicas e físico-químicas dos materiais. 


\section{REFERÊNCIAS}

1. Bain \& Company, Chamada publica BNDES/FEP 2014, 52, 1-42.

2. Gabriel, L. P; Zavaglia, C. A. C.; Jardini, A. L.; Carmen, G. B. T. Chem. Eng. Trans. 2014, 38, 253-258.

3. Lopes, R. de V. V. Tese de Doutorado, Universidade de Brasília, 2009, BrasíliaDF.

4. Drummond A. L. Dissertação de Mestrado, Universidade de Brasília, 2008, Brasília- DF.

5. Noreen, A.; Zia, K. M.; Zuber, M.; Tabasum, S. Prog. Org. Coat. 2016, 91, 2532.

6. Thébault, M.; Pizzi, A.; Essawy, H. A.; Barhoum, A. Assche, G. V. Europ. Pol. J. 2015, 67, 513-526.

7. Pathak, R.; Kathalewar, M.; Wazarkar, K.; Sabnis, A. Prog. Org. Coat. 2015, 89, 160-169.

8. Kathalewar, M. S.; Joshi, P. B.; Sabnis, A. S.; Malshe, V. C. RSC Adv. 2013, 3, 4110-4129.

9. Helou, M.; Guillaume, S. M. Green chem. 2011, 13, 266-271.

10.Javni, I.; Hong, D. P.; Petrovic, Z. S. J. Appl. Polym. Sci. 2012. 1-6.

11. Kreye, O.; Mutlu, H.; Meier, M. A. R. Green chem. 2013, 15, 1431-1455.

12. Deepa, P.; Jayakannan, M. J. Polym. Sci. 2007, 8, 2445-2458.

13. Ogunniyi, D S. Bioresource Technology. 2006, 97, 1086-1091.

14.Somani, K. P.; Kansara, S. S.; Patel, N. K.; Rakshit, A. K. Int. J. Adhes. Adhes. 2003, 23, 269-275.

15.Wang, C.; Zheng, Y.; Xie, Y.; Qiao, K.; Sun, Y.; Yue, L. J. Polym. Res. 2015, 22, 145.

16. Scarpa A.; Guerci, A. J. Ethnopharmacol. 1982, 5, 117-137.

17.Mutlu, H.; Meier, M. A. R. Europ. J. Lipid. Sci. Tech. 2010, 112, 10-30.

18. Gurunathan, T.; Mohanty, S.; Nayak, S. K. Prog. Org. Coat. 2015, 80, 39-48.

19.Li, K.; Shen, Y.; Fei, G.; Wang, H.; Li, J. Prog. Org. Coat. 2014, 118:12241-55.

20.Gooch, A.; Murphy, N. S.; Thomson, N. H.; Wilson, A. J. Macromol. 2013, 46, 9634-964.

21.Gooch, A.; Mcghee, A. M.; Renton, L. C.; Plante, J. P.; Lindsay, C. I.; Wilson, A. J. 2009, 21, 12-17.

22. O'Brien, R. D.; $2^{\text {nd }}$ edition, CRC Press: New York, 2009. 
23.Lehninger, A. L.; Nelson, D. L.; Cox, Michael M.; Princípios de Bioquímica, 4a edição, Sarvier: São Paulo, 2006.

24.Guan, J.; Song, Y.; Lin, Y.; Yin, X.; Zuo, M.; Zhao, Y.; Tao, X.; Zheng, Q. Ind. Eng. Chem. Res. 2011, 50, 6517-6527.

25. Rokicki, G.; Piotrowska, A. Polymer. 2002, 43, 2927-2935.

26. Bayer, O. E Angew .Chem., 59, 257, 1947.

27. Bayer, O.; Müller, E. Angew. Chem. 1960, 72, 934-939.

28. Taylor, P.; Petrovi, Z. S. Polymer Rev. 2008, 48,109-155.

29. Canevarolo J. R. S. V. 2ª edição. São Paulo. Editora Artliber, 2006.

30. Odian. G. 4ae edição. Principle of polymerization New York. John Wiley \& Sons, inc., 2004.

31. Clayden J.; Greeves, N. Organic chemistry $2^{\text {th }}$ edition, 2012.

32.http://soft-matter.seas.harvard.edu/index.php/Cross-linking. Acessado em 12/04/2016.

33.Zhang, C.; Xia, Y.; Chen, R.; Huh, S.; Johnston, P. A.; Kessler, M. R. Green Chem., 2013, 15 (6), 1477-1484.

34.Li, S.; Zhao, J.; Zhang, Z.; Zhang, J.; Yang, W. RSC Adv. 2014, 5, 6843-6852.

35.Rodrigues, J. D. O.; Silva, T. F.; Lopes, R. V. V.; Macedo J. L.; Quirino, R. L.; Beckler, B.; Sales, M. J. A. $20^{\circ}$ Congresso de Engenharia e Ciência dos Materiais - CBECimat, Joinvile, 2012.

36. Silva, T. F.; Rodrigues, J. D. O.; Lopes, R. V. V.; Macedo, J. L.; Paterno, L. G.; Sales, M. J. A. $21^{\circ}$ Congresso de Engenharia e Ciência dos Materiais CBECimat, Florianópolis, 2014.

37.Lopes, V. V.; Zamian, J. R. Z.; Resck, I. S.; Sales, M. J. A.; Santos, M. L.; Cunha, F. R. Eur. J. Lipid Sci. Technol. 2010, 112, 1252-1262.

38.Quirino, R. L.; Rodrigues, J. D. O.; Lopes, R.de V. V. Lopes, Macedo J. L., Ricardo, N. M. P. S.; Sales, M. J. A. $245^{\text {th }}$ ACS Meeting and Exposition. New Orleans, LA, 2013.

39.Barthus, R. C.; Poppi, R. J. Vib. Spectrosc. 2001, 26, 99-105.

40.Ubaghs, Luc. Tese. Universidade Técnica Rheinisch-Westphalian de Aachen, 2005.

41. Haemek, М. Инженерный вестник Дона (Engenheiros Don Gazette). 2014, 3, 2007.

42. Abbey, W.; En, E.; Klein, P. G. Polymer. 1981, 22, 1205-1210.

43. Houton, K. A.; Burslem, M. Wilson, A. J. Chem. Sci. 2015, 1-7.

44.Diakoumakos, C. D.; Koizev, D. L. Macromol. Symp. 2014, 216, 37-46. 
45. Pistor V. Trabalho de conclusão de curso. Caxias do sul. NTPol. 2010.

46.Tryznowski, M.; Swiderska, A.; Zo, Z.; Go, T.; Parzuchowski, G. Polymer. 2015, 80, 228-236.

47. Groszos, S. J.; Darien, Drechsel, E. K. United States Patent Office. 1957, 6, $(2,802,022)$,

48. Kreye, O.; Mutlu, H,; Meier, M. A. R. Green Chem. 2013.

49.Ammar, Y. A.; Cloutet, E.; Cramail, H.; Landais, Y. Macromol. 2012, 8, 22492256.

50. McLaughlin, M.; Garcia Rubio, S.; Muthyala, R.; Antunes, O. A. C.; Tilstam, U.; Zlota, A.; Yadav, G. D.; Laird, T. Org. Process. Res. Dev. 2006, 10, 853-865.

51. Silva, A. L.; Bordado, J. C. Catal. Rev. 2004, 46, 31-51.

52. Ionescu, M.; Chemistry and Technology of Polyols for Polyurethanes, First edition, Rapra Technology: United Kingdom, 2005.

53.71. Eaves, D.; Handbook of Polymers Foams. Rapra Technology: United Kingdom, 2004.

54. Silverstein, R. M; Webster, F. X.; Kiemle, D. J. 7º Edição, Editora LTC, 2005.

55.Kriz, G. S.; Pavia, D. L.; Lampman, G. M. $4^{\circ}$ edição, editora Cengage Learning, 2015.

56. Vasconcelos, A. F. F. Tese de Doutorado, Universidade da Paraiba, 2009, João pessoa - PB.

57.Orzechowski, K.; Słonka, T.; Głowinski, J. J. Phys. Chem. Solids. 2006, 67, 915-919.

58. Jones, J. M.; Rollinson, A. N. Thermochim. Acta. 2013, 565, 39-45.

59. Rafat, Fouzia. Arch. App Sci. Res, 2014, 6 (5), 75-78.

60. Gil, V. M. S.; Geraldes, C. F. G.; Fundação Caluste Gulbenkaian, 1987.

61. ASTM E-104-85. Standart pratice for maintaining constant humidity by means of aqueous solutions. Philadelphia, 1996.

62. Cyras, V. P.; Manfredi, L. B.; Ton-That, M.; Vásquez, A.; Carbohydr. Polymer. 2008, 73, 55.

63. Crank, J.; The mathematics of diffusion. Clarendon Press: Oxford, 1975.

64. Masaro, L.; Zhu, X. X.; Prog. Polym. Sci. 1999, 24, 731-775.

65. Teixeira, E. M.; Pasquini, D.; Curvelo, A. A. S.; Corradini, E.; Belgacem, M. N.; Dufresne, A.; Carbohydr. Polym. 2009, 78, 422.

66. Espert, A.; Vilaplana, F.; Karlsson, S.; Compos. A Part A: Appl. Sci. Manuf. 2004,35,1267. 
67.Nardi, S. Q. W. N. Dissertação de mestrado, Universidade tecnológica Federal do Paraná, Pato Branco, 2004.

68. Gardolinski, J. E.; Paiva, H.; Filho, M. Quim. Nov. 2003, 26, 30-35.

69. Lopes, R. de V. V. Tese de Doutorado, Universidade Federal do Rio de Janeiro, 2014, Rio de Janeiro-RJ. 


\section{ANEXOS}

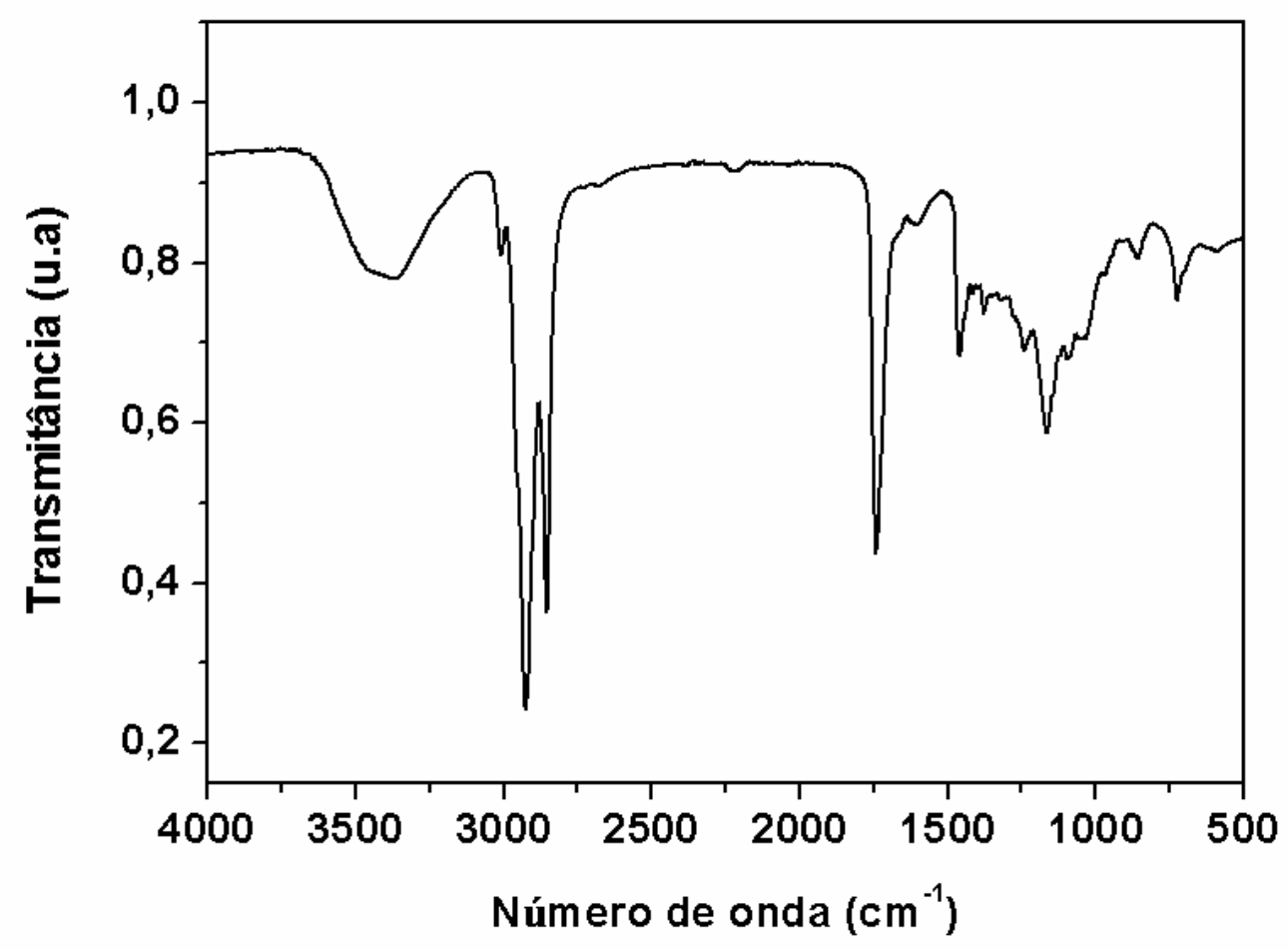

Espectro no FT-IR da parte líquida da amostra MatOMa(1:4)/Zn/Et/8h/24h.

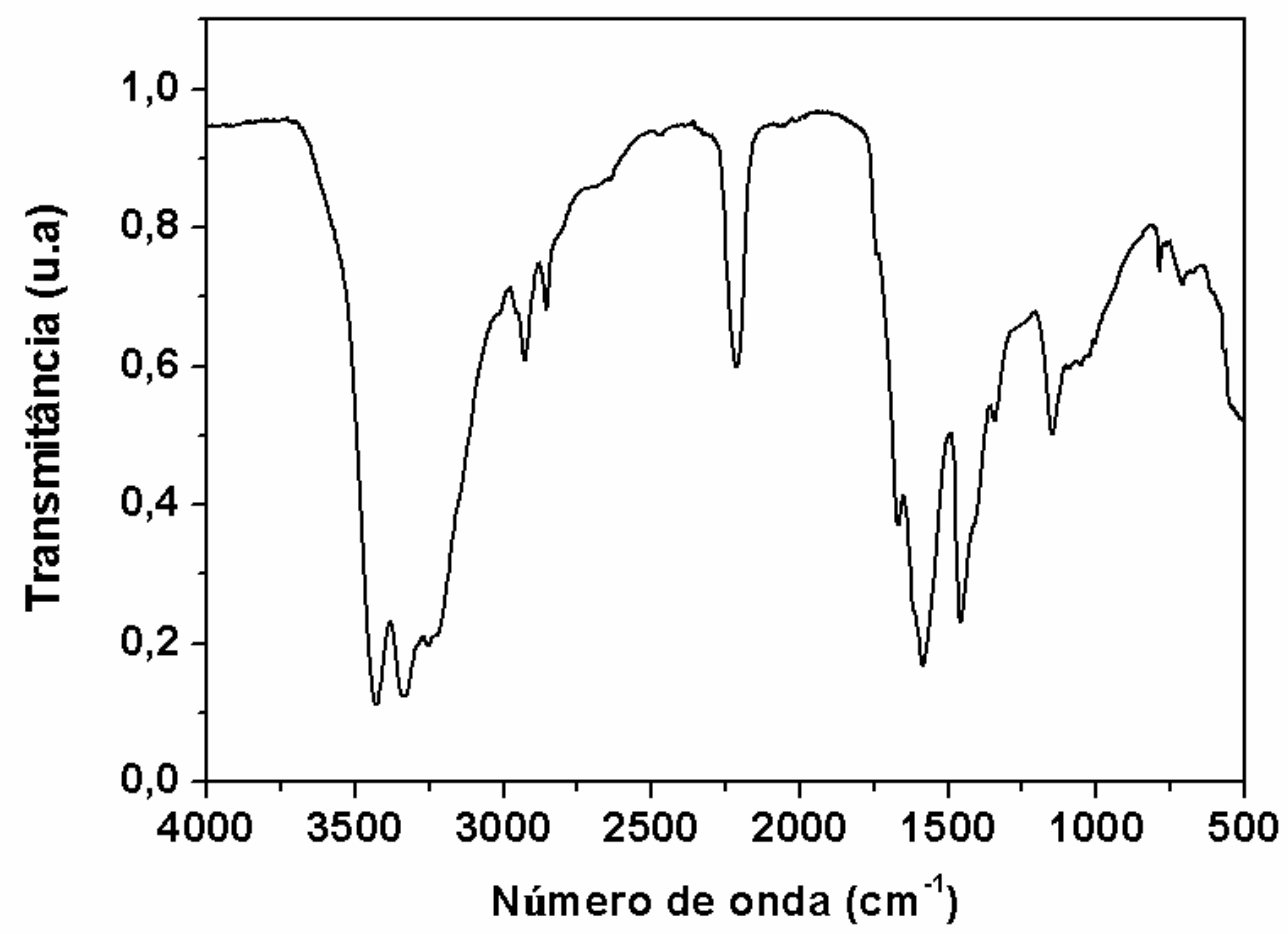

Espectro no FT-IR da parte sólida da amostra MatOMa(1:4)/Zn/Et/8h/24h. 


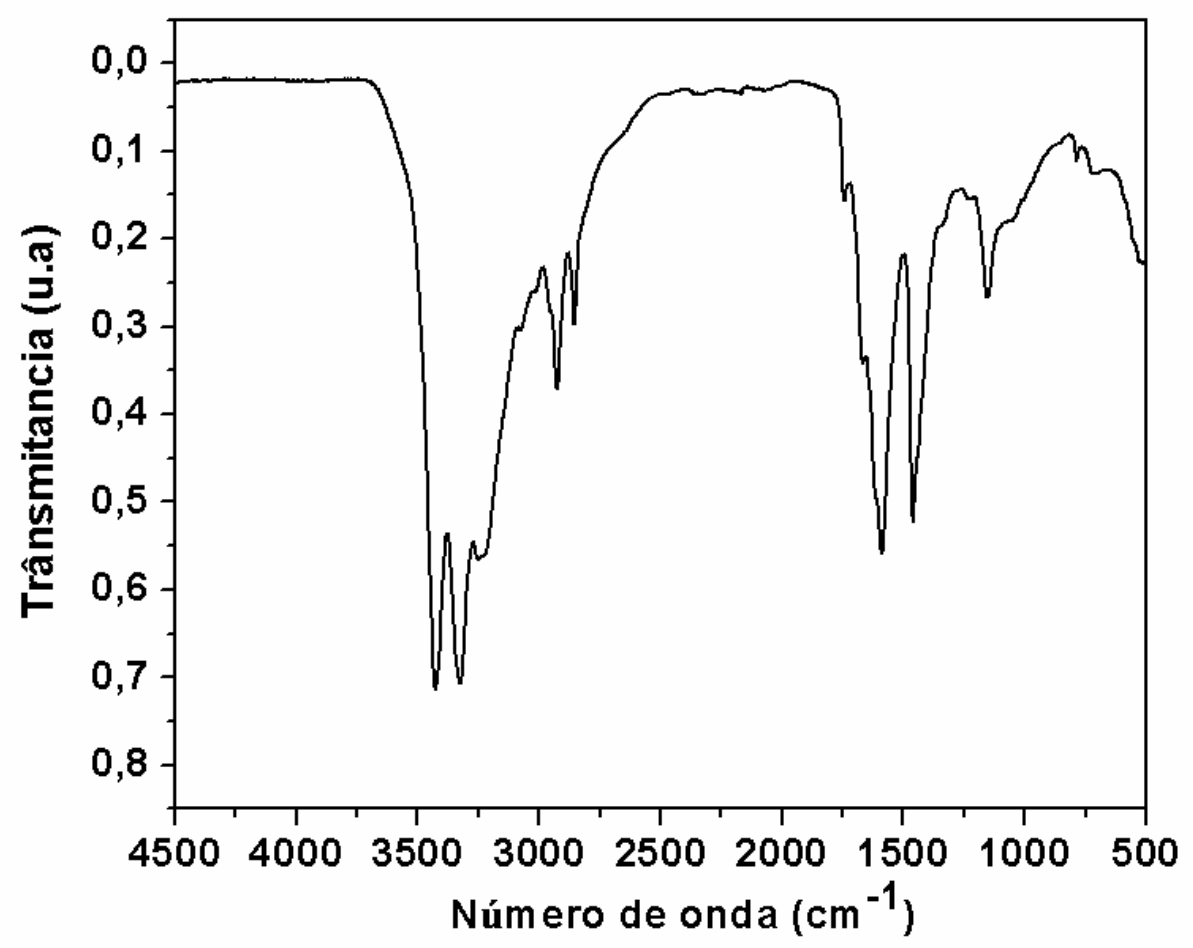

Espectro no FT-IR da parte sólida da amostra MatOMa(1:4)/Sn/Et/8h/24h.

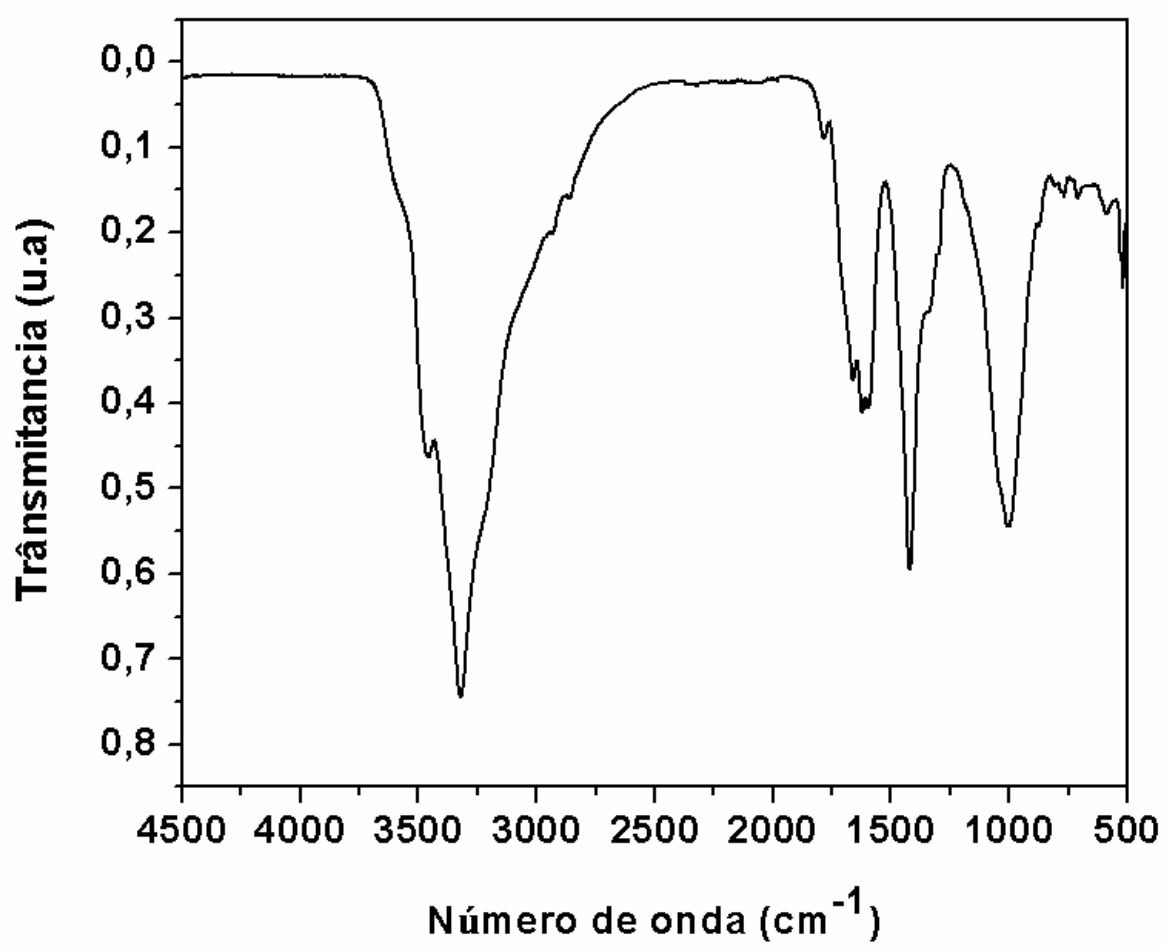

Espectro no FT-IR da parte sólida da amostra MatOMa(1:4)/BF/3/Et/8h/24h. 


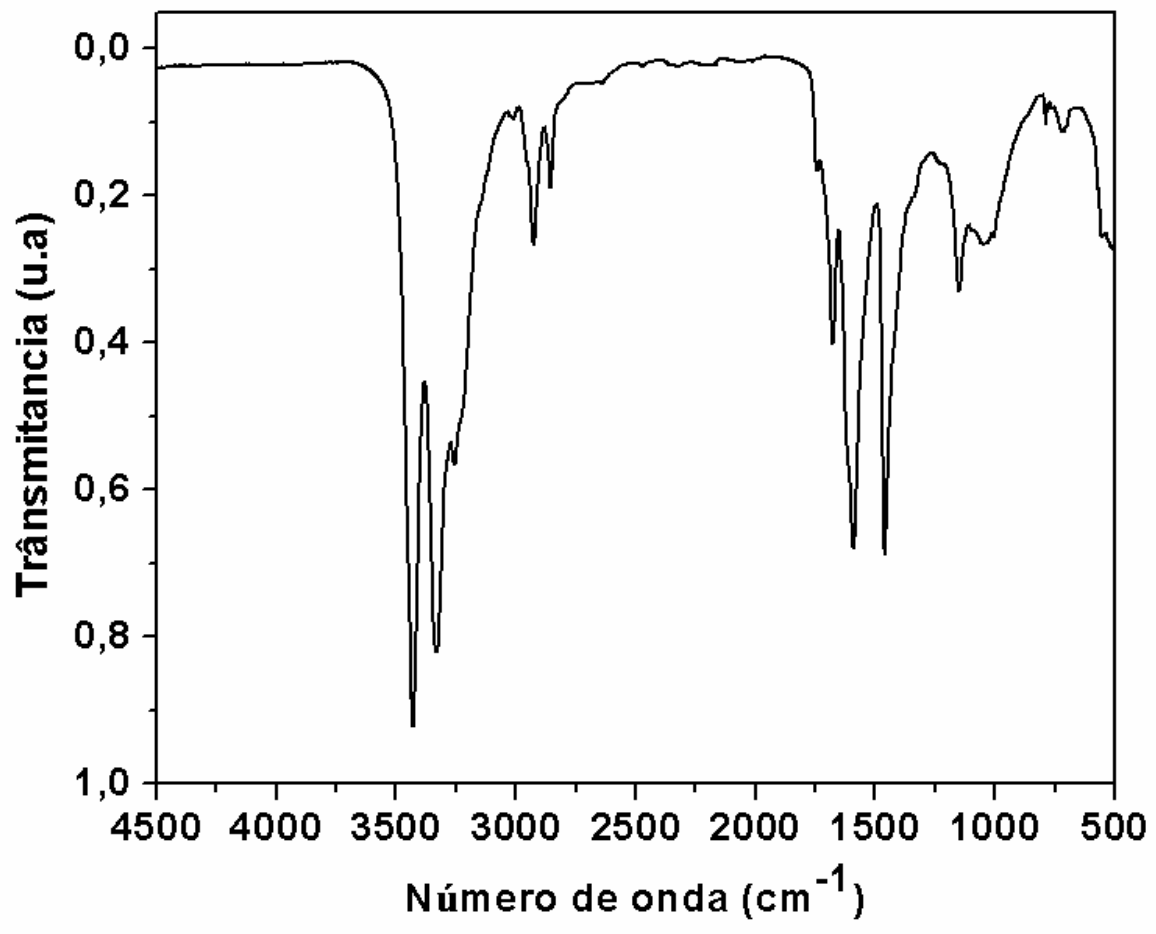

Espectro no FT-IR da parte sólida da amostra MatOMa(1:8)/BF $/ / \mathrm{Et} / 8 \mathrm{~h} / 24 \mathrm{~h}$.

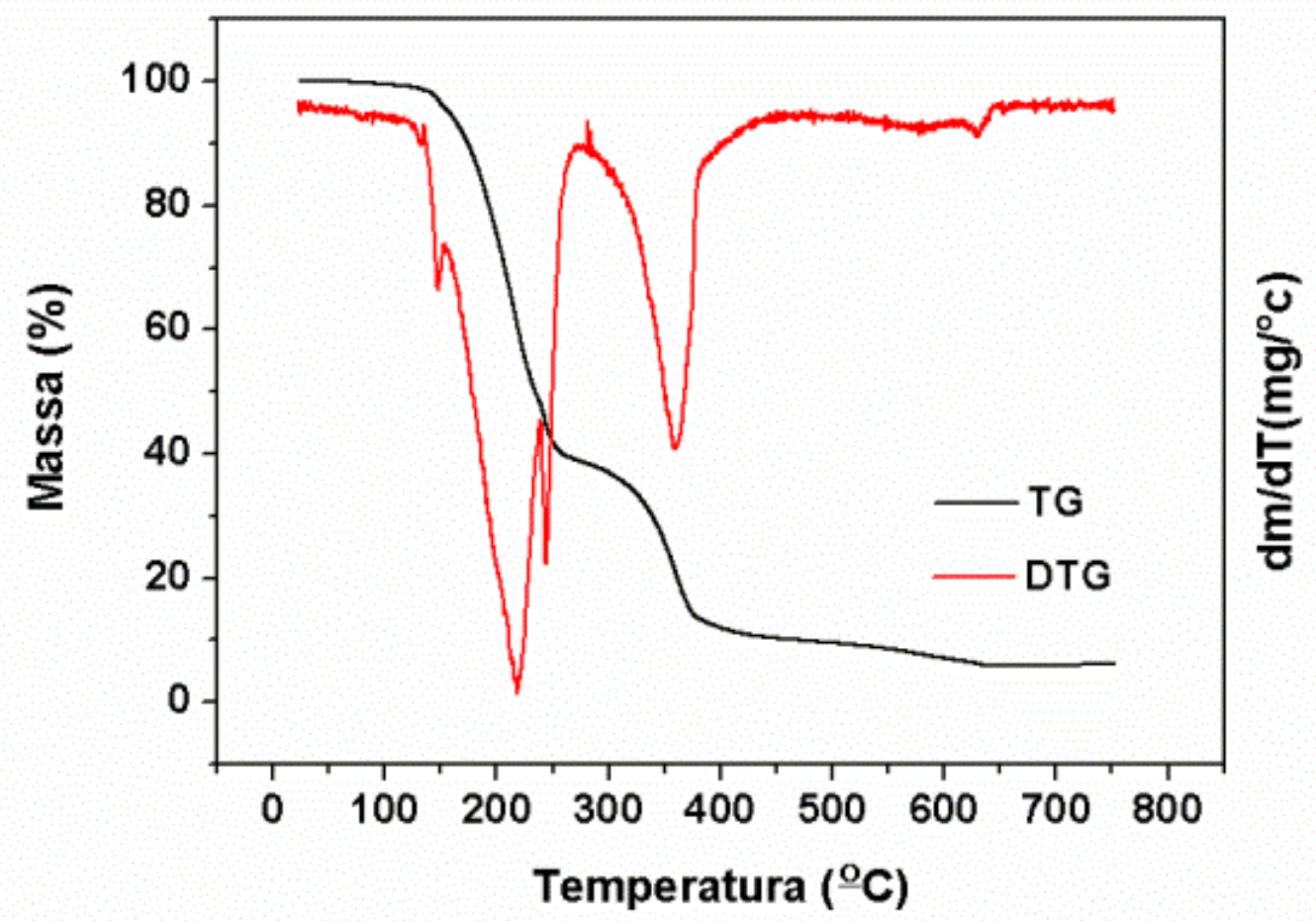

Curvas TG e DTG da parte sólida da amostra MatOMa(1:4)/Zn/Et/8h/24h. 


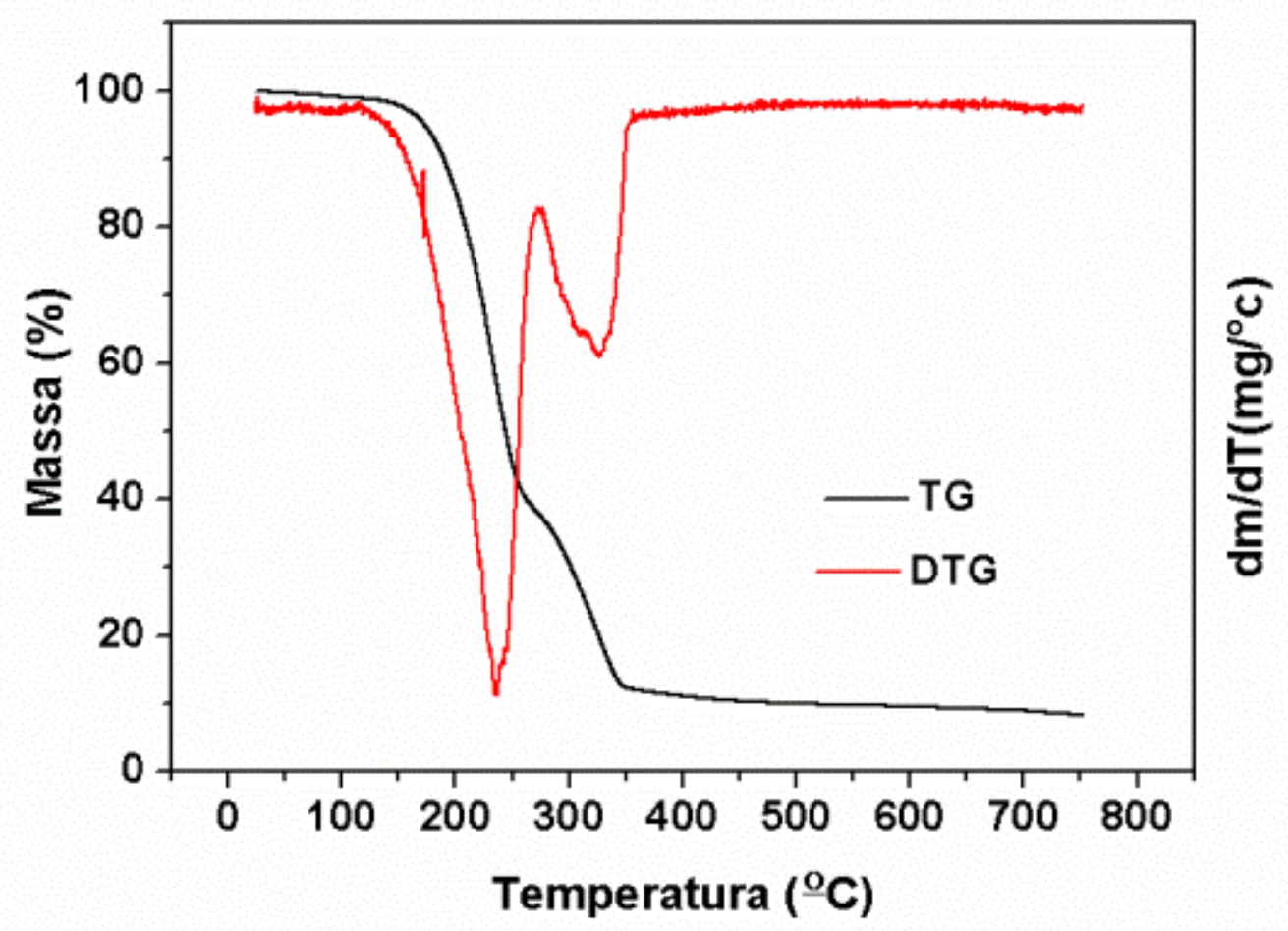

Curvas TG e DTG da parte sólida da amostra MatOMa(1:4)/Sn/Et/8h/24h.

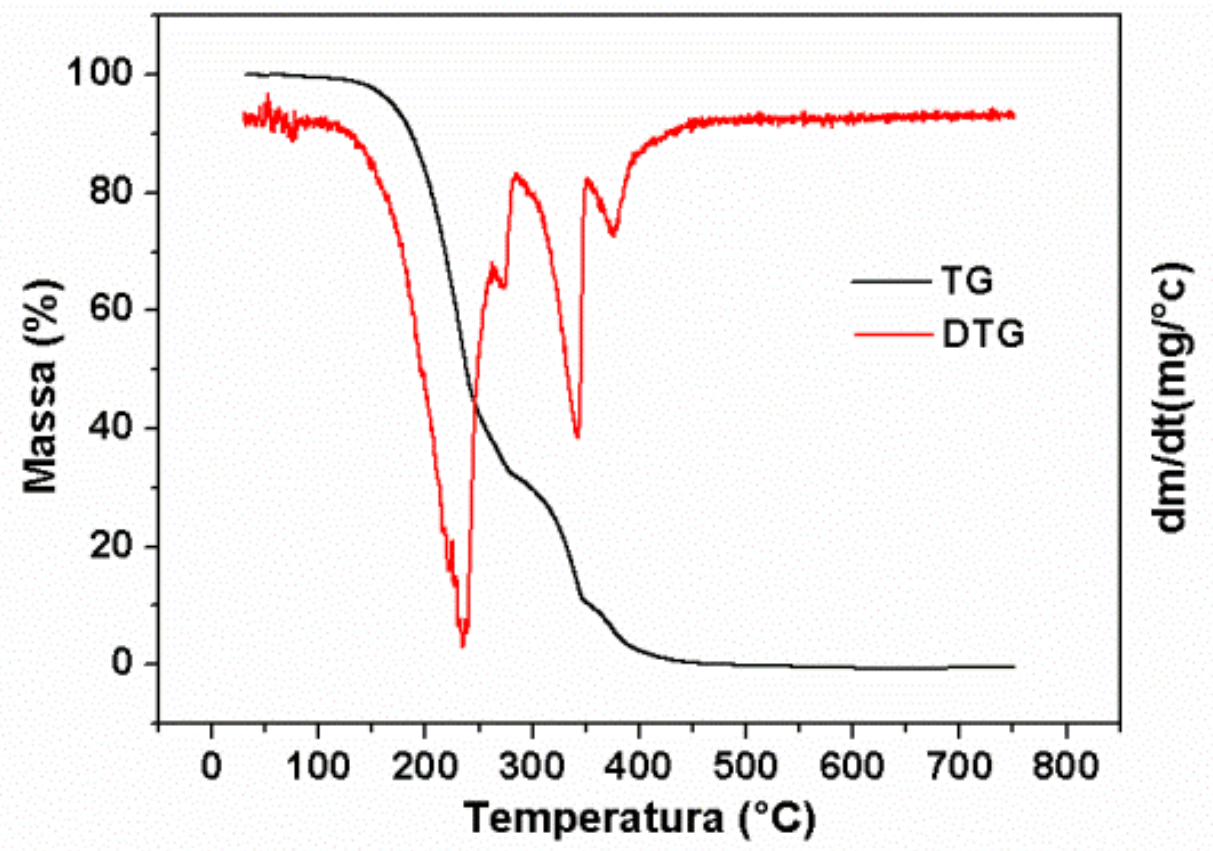

Curvas TG e DTG da parte sólida da amostra MatOMa(1:4)/BF $/ \mathrm{Et}_{3} / 8 \mathrm{~h} / 24 \mathrm{~h}$. 


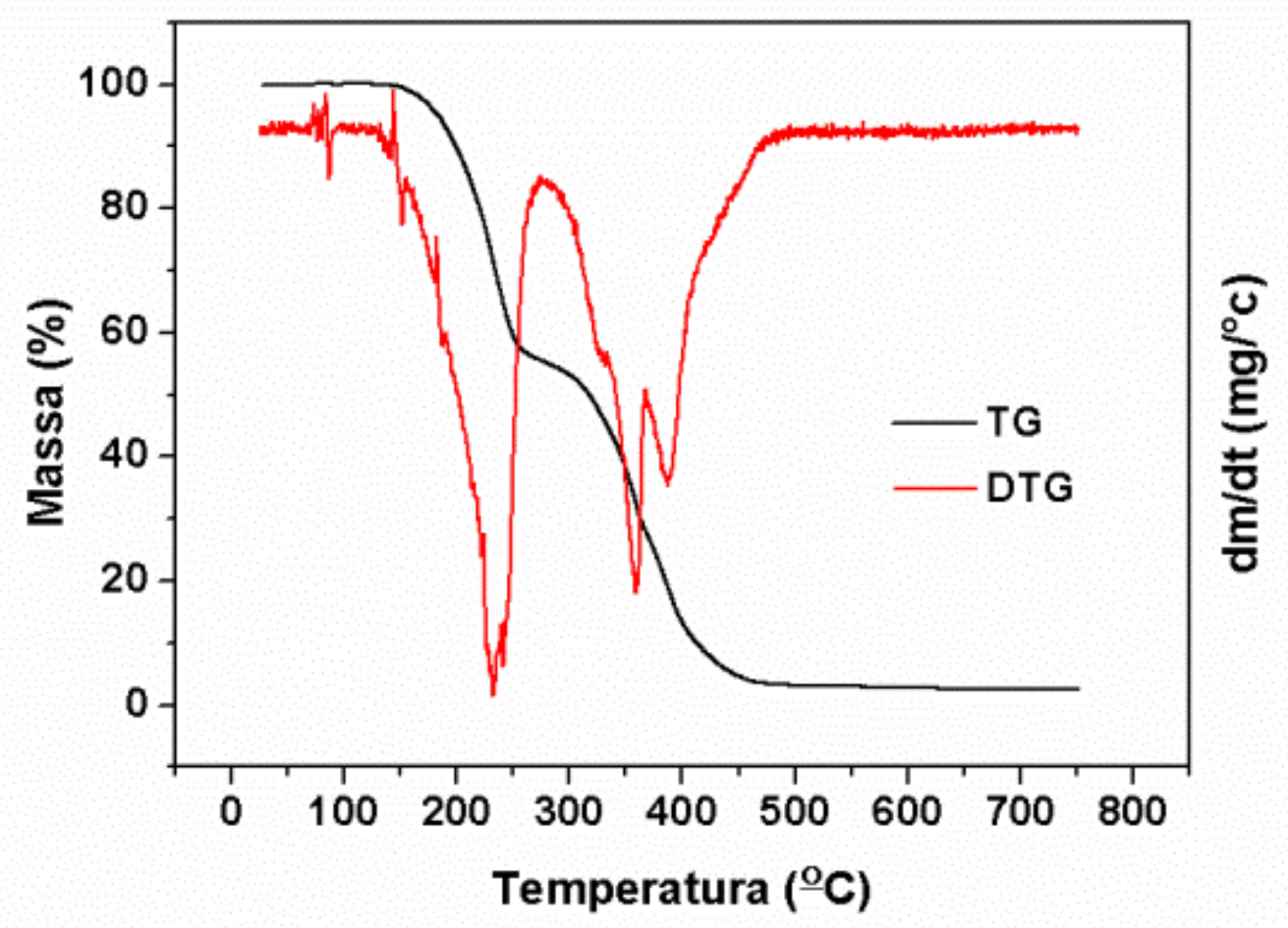

Curvas TG e DTG da parte sólida da amostra MatOMa(1:8)/BF $/ \mathrm{Et}_{3} / 8 \mathrm{~h} / 24 \mathrm{~h}$.

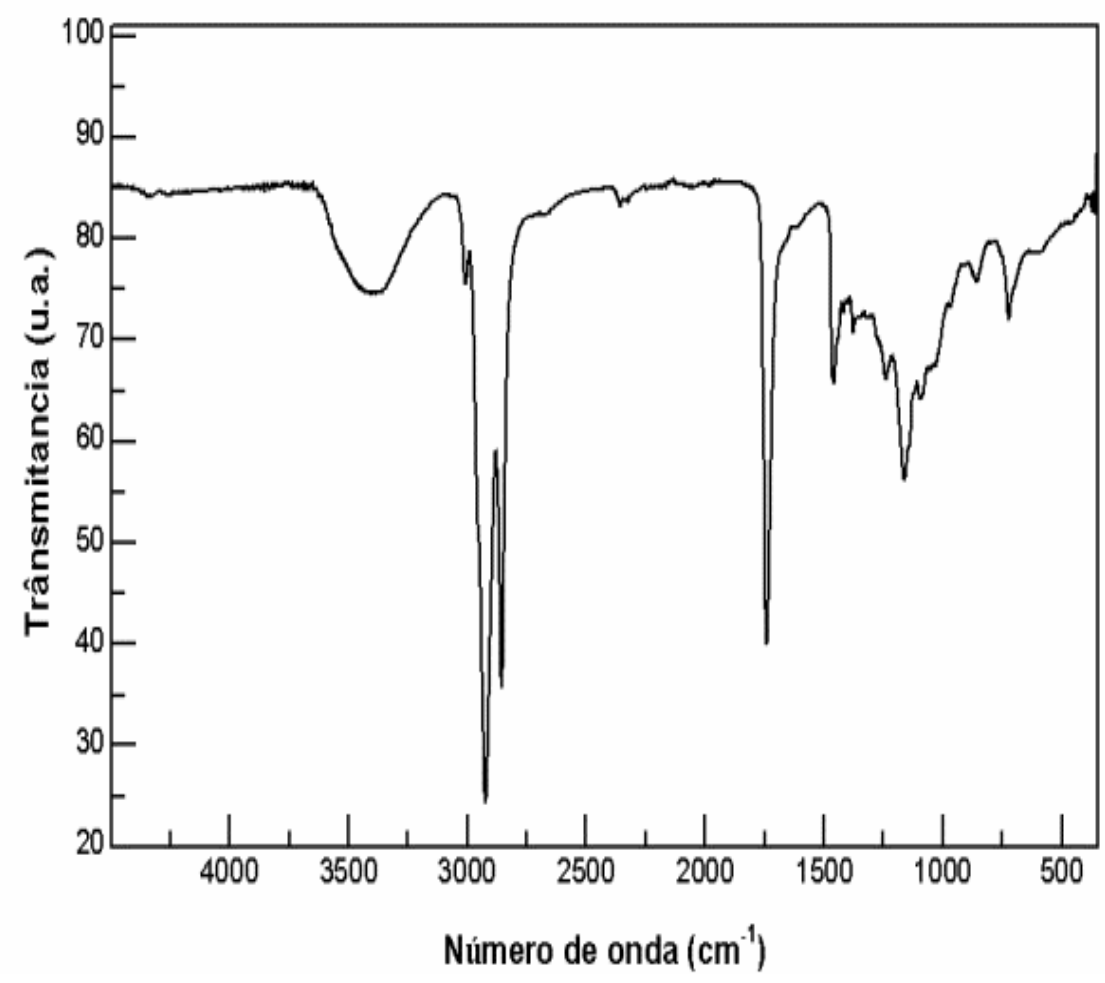

Espectro no FT-IR da parte líquida da amostra PUOMa(1:2)/Zn/1h/24h. 


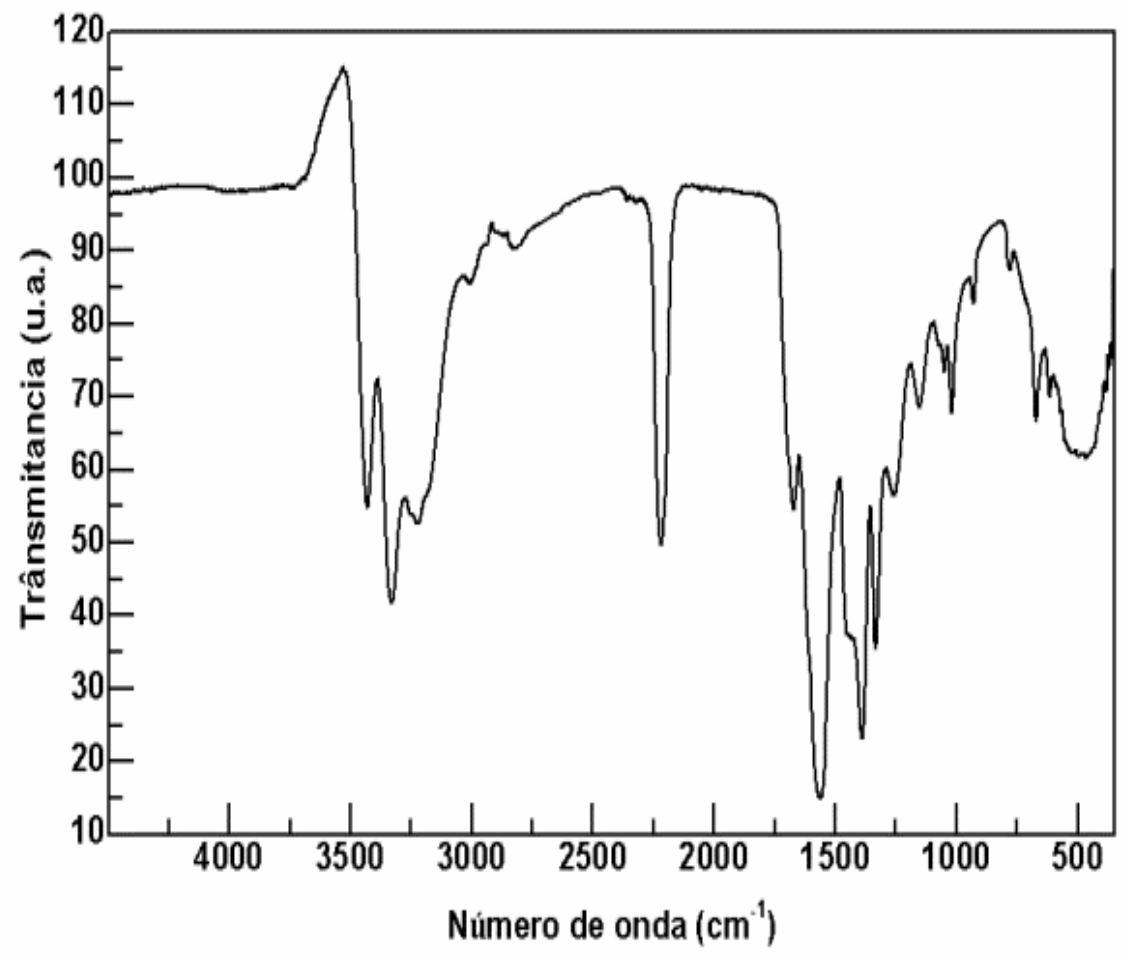

Espectro no FT-IR da parte sólida da amostra PUOMa(1:2)/Zn/1h/24h.

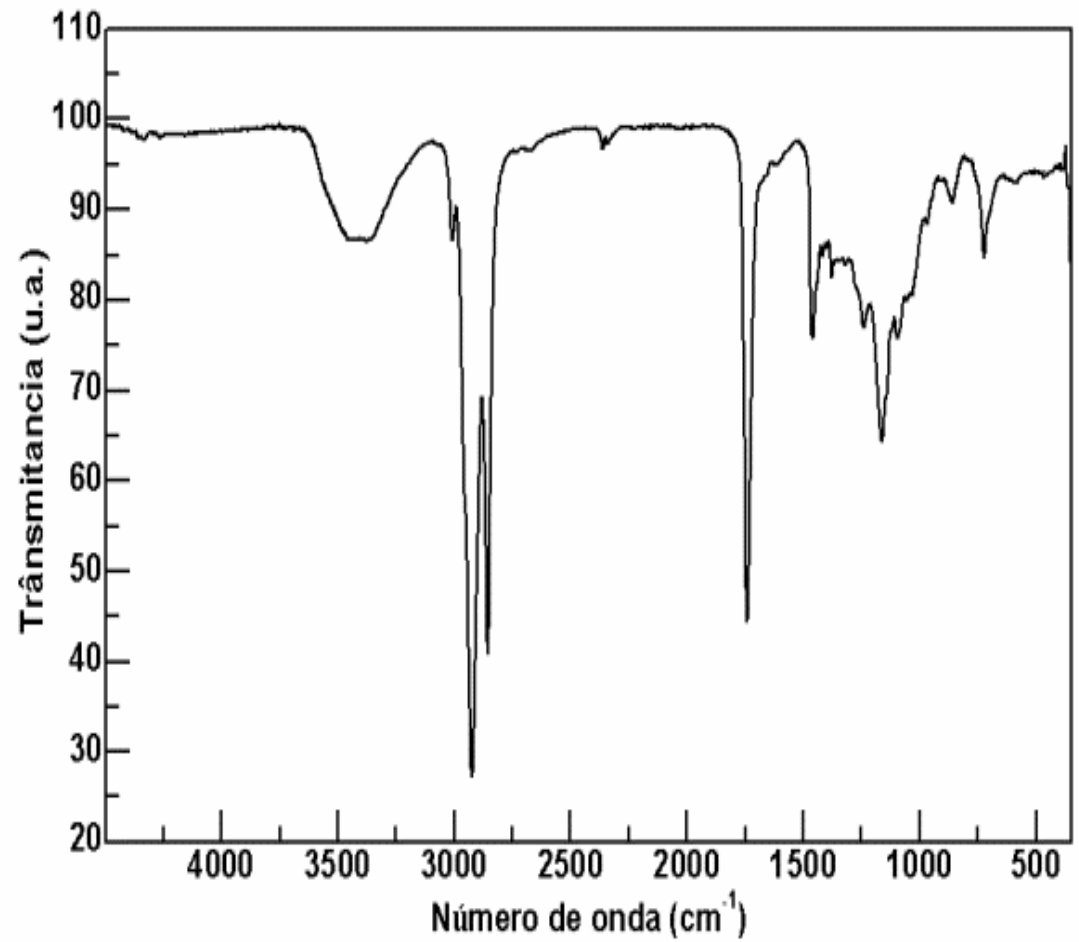

Espectro no FT-IR da parte líquida da amostra PUOMa(1:2)/Zn/4h/24h. 


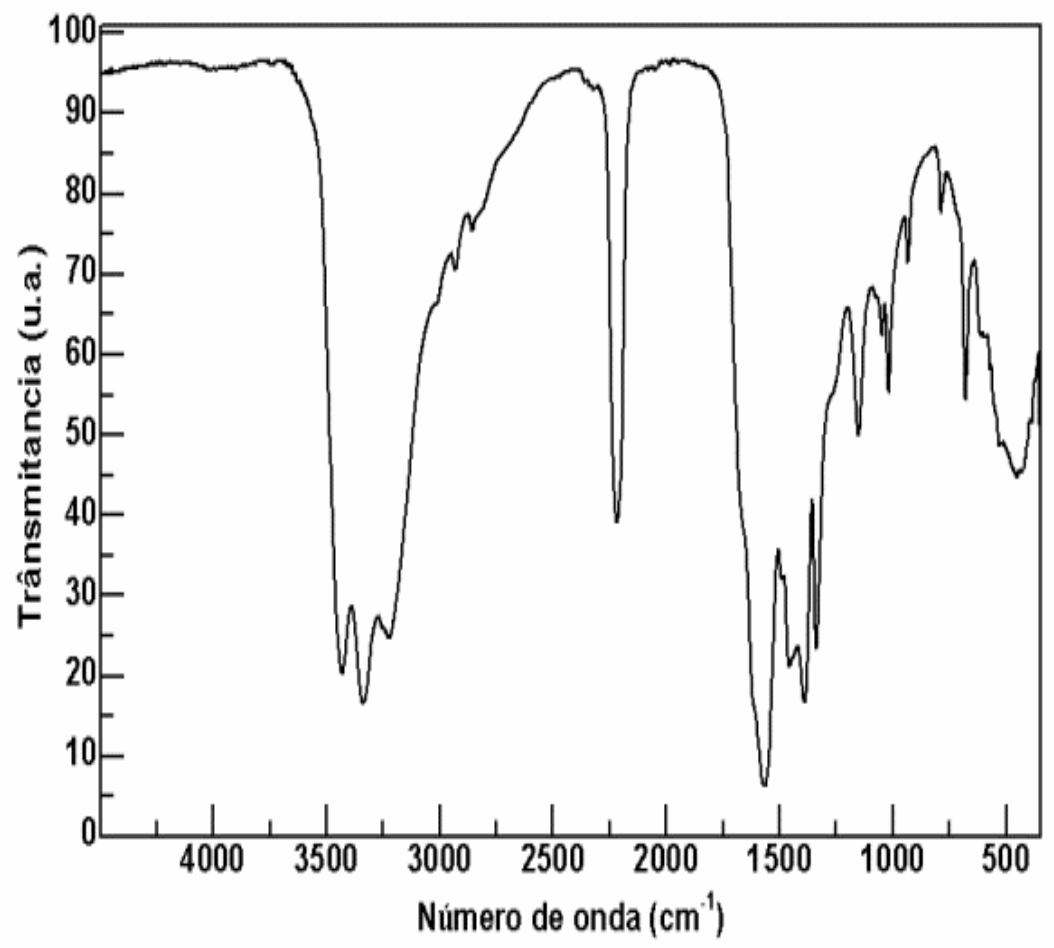

Espectro no FT-IR da parte sólida da amostra PUOMa(1:2)/Zn/4h/24h.

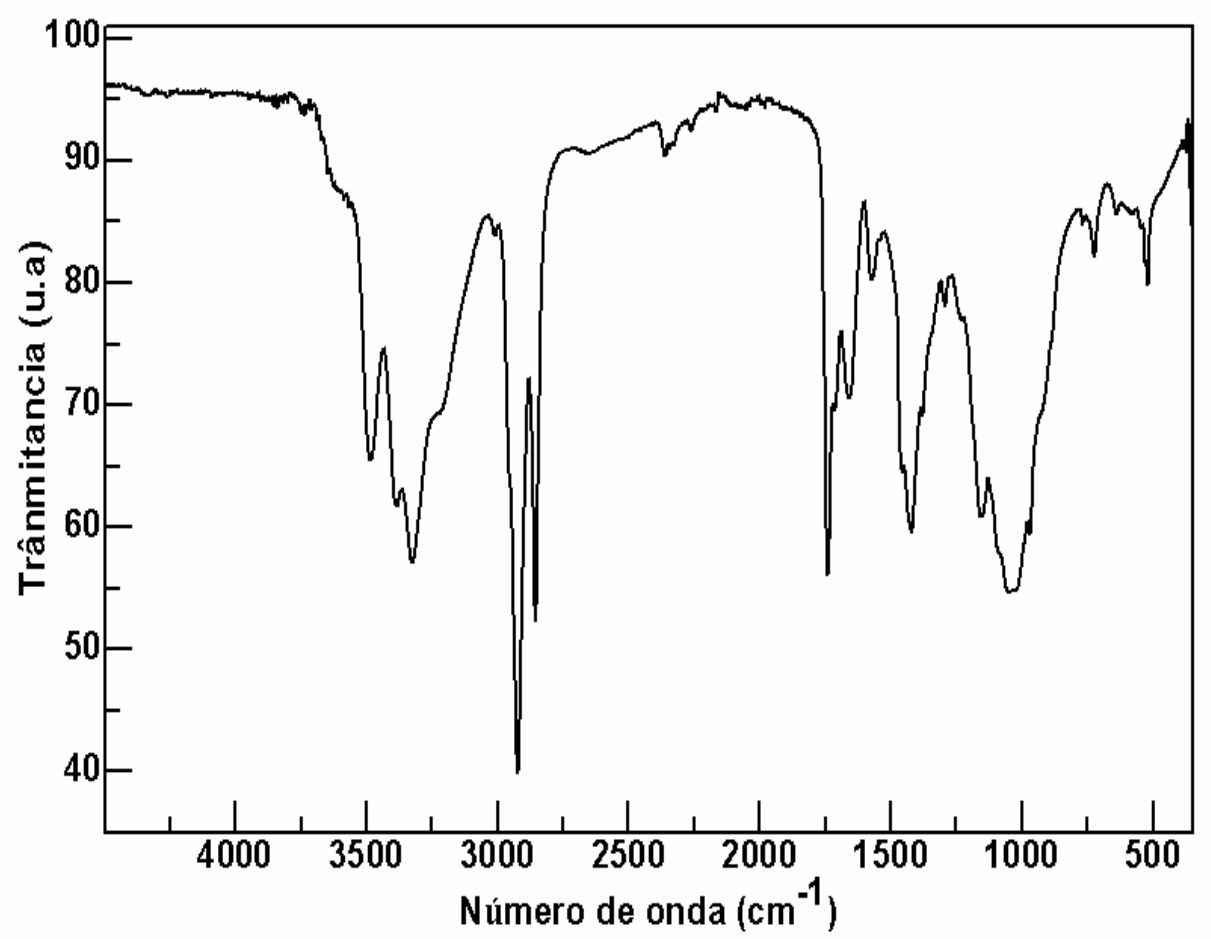

Espectro no FT-IR da amostra PUOMa(1:2)/BF $/ 5 \mathrm{~min} / 24 \mathrm{~h}$. 


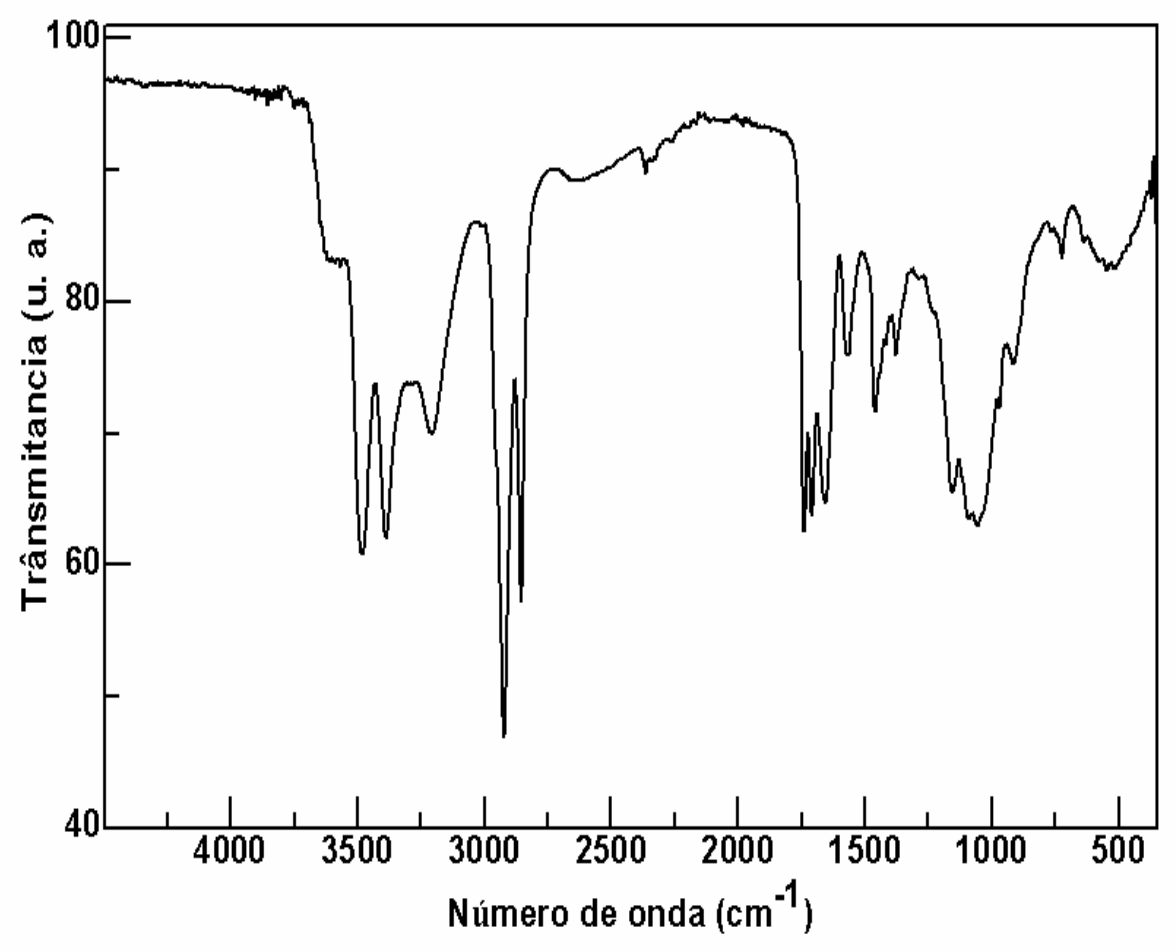

Espectro no FT-IR da amostra $\mathrm{PUOMa}(1: 2) / \mathrm{BF}_{3} / 5 \mathrm{~min} / 48 \mathrm{~h}$.

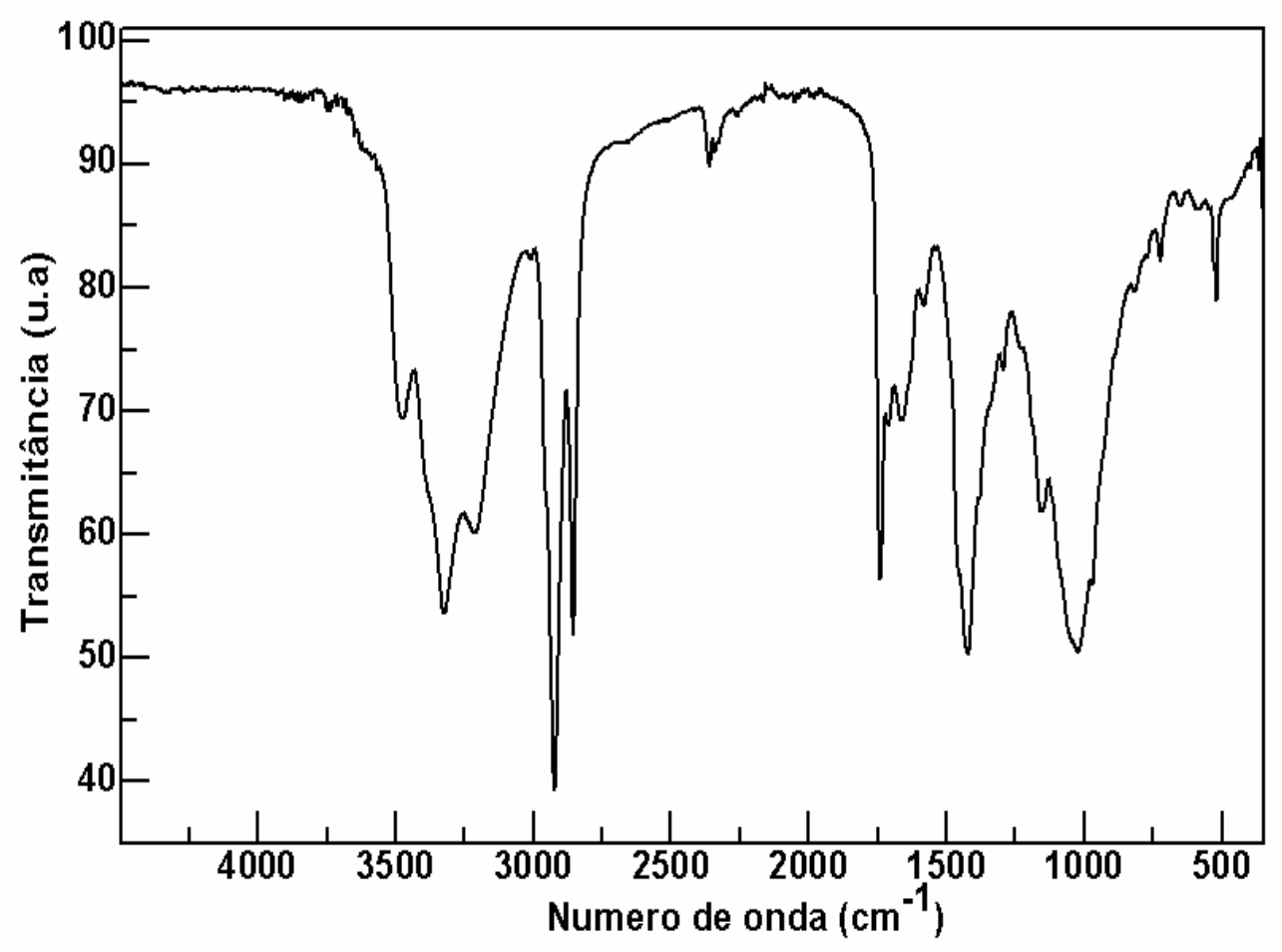

Espectro no FT-IR da amostra PUOMa(1:2)/BF $/ 3 / 5 \mathrm{~min} / 72 \mathrm{~h}$. 


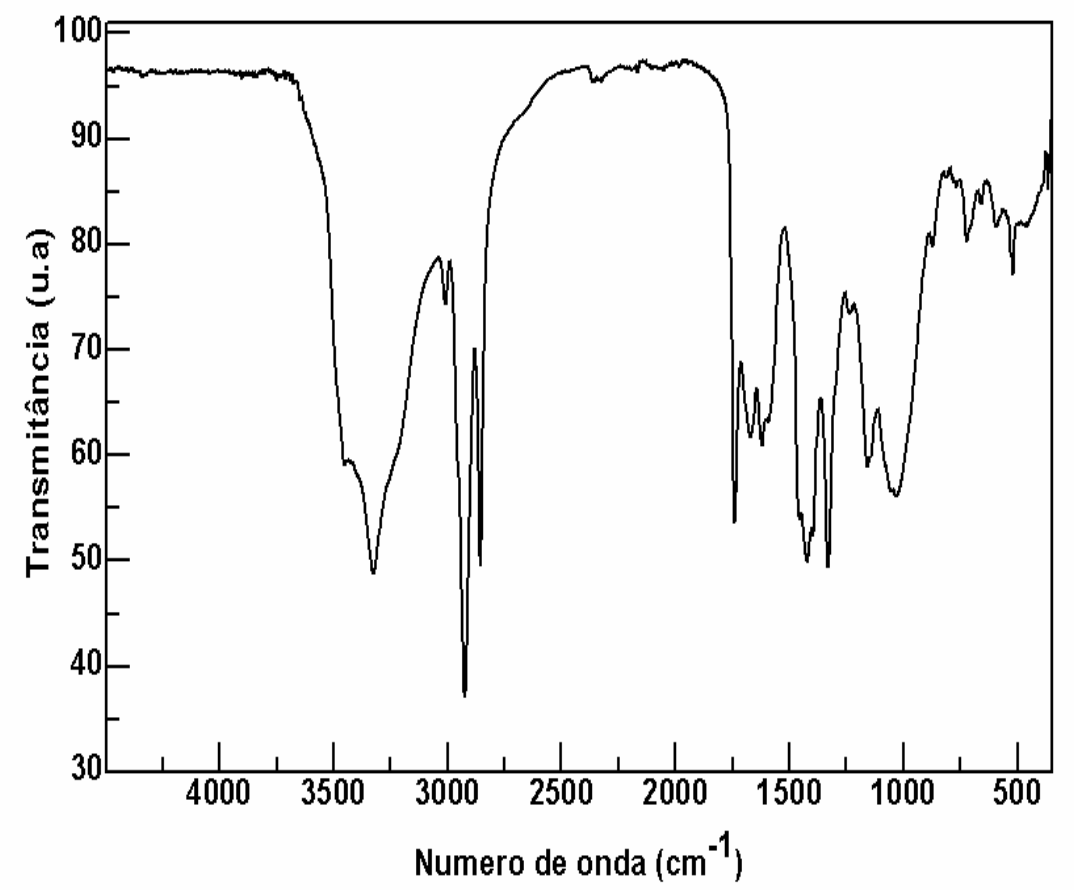

Espectro no FT-IR da amostra PUOMa(1:3)/BF $/ 5 \mathrm{~min} / 24 \mathrm{~h}$.

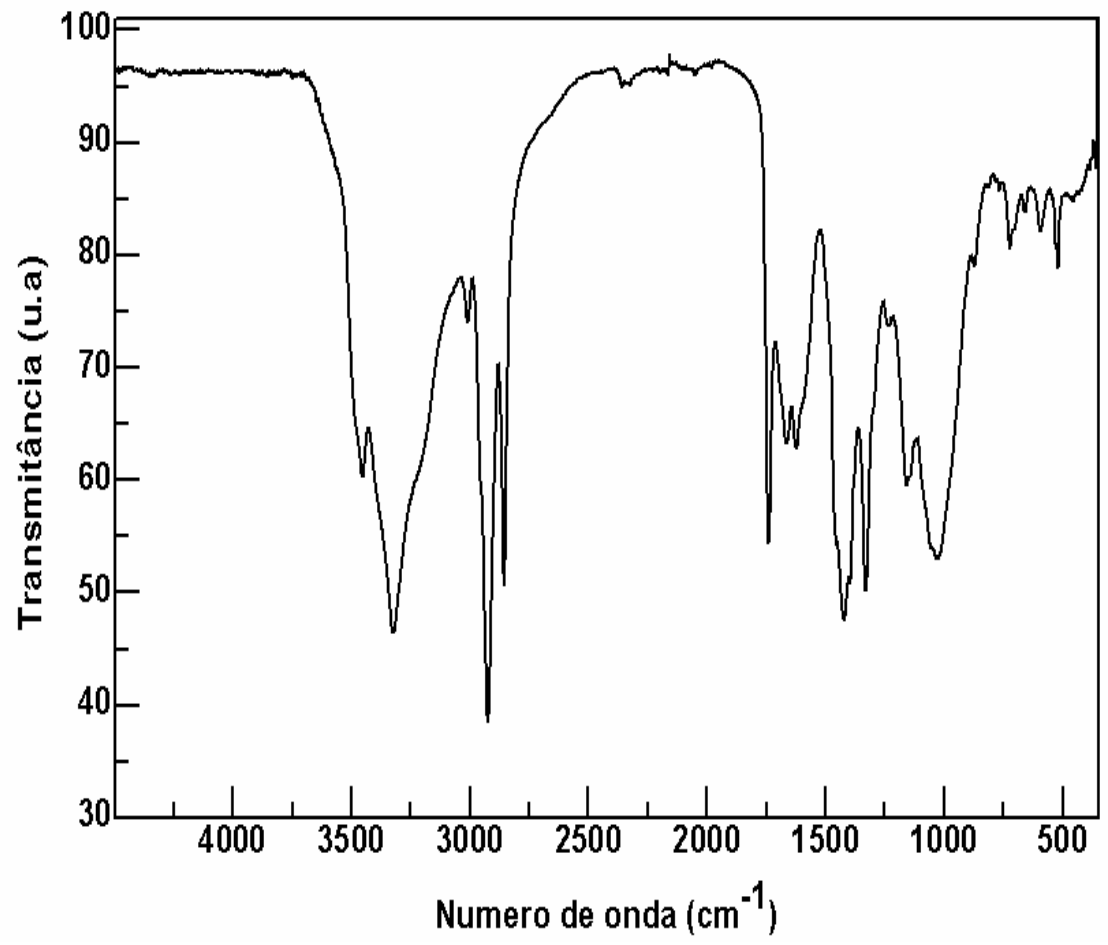

Espectro no FT-IR da amostra PUOMa(1:3)/BF $/ 5 \mathrm{~min} / 48 \mathrm{~h}$. 


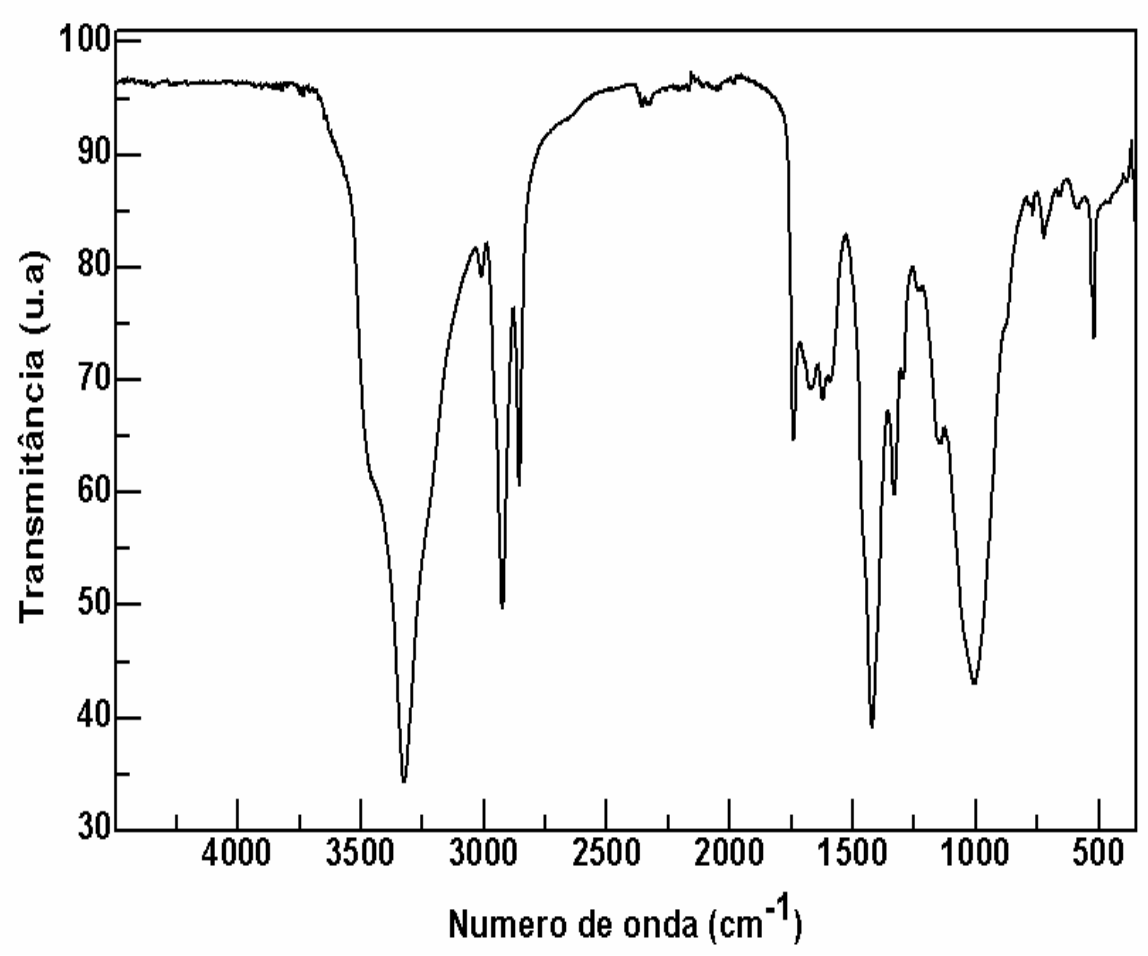

Espectro no FT-IR da amostra PUOMa(1:3)/BF $/ 5 \mathrm{~min} / 72 \mathrm{~h}$.

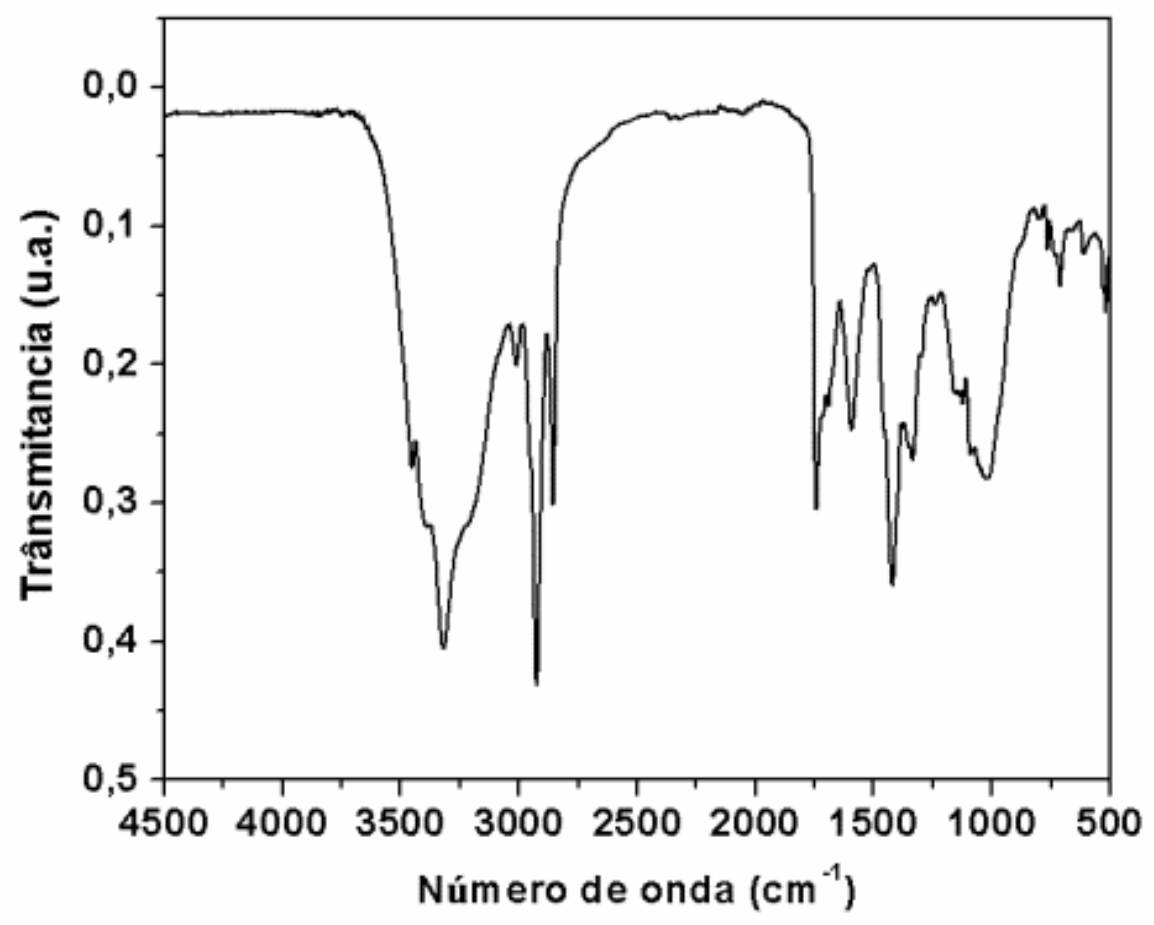

Espectro no FT-IR da amostra PUOMa(1:4)/BF $/ 5 \mathrm{~min} / 24 \mathrm{~h}$. 


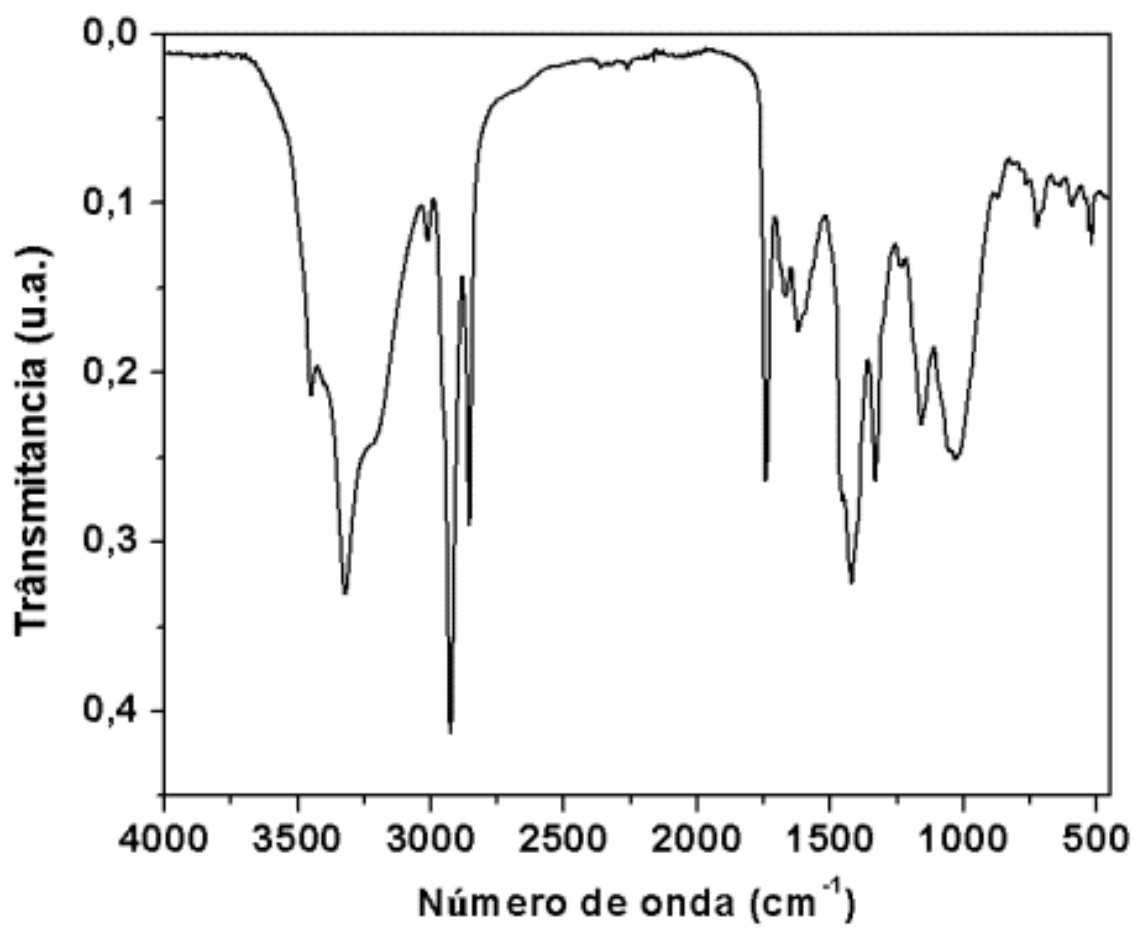

Espectro no FT-IR da amostra PUOMa(1:4)/BF $/ 5 \mathrm{~min} / 48 \mathrm{~h}$.

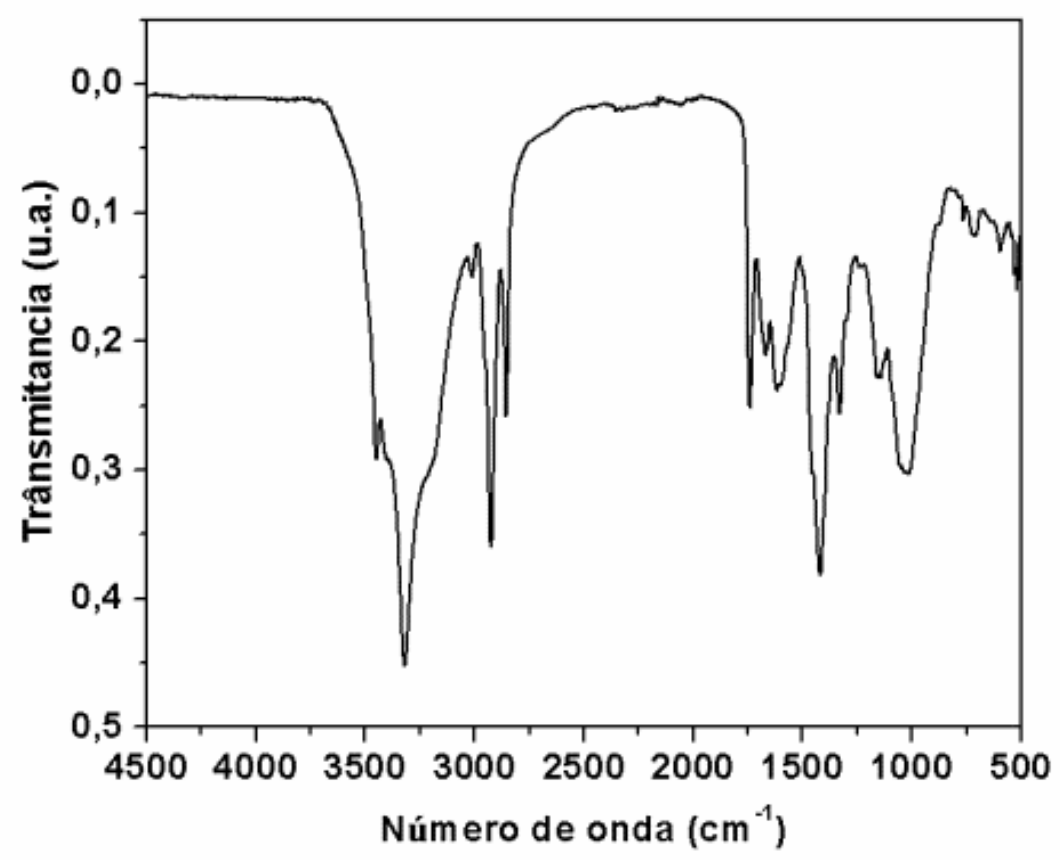

Espectro no FT-IR da amostra PUOMa(1:4)/BF $/ 5 \mathrm{~min} / 72 \mathrm{~h}$. 